FHWA/IN/JTRP-2008/5

Final Report

LIMIT STATES AND LOAD AND RESISTANCE DESIGN OF SLOPES AND RETAINING STRUCTURES

Dongwook Kim

Rodrigo Salgado

January 2009 


\section{TECHNICAL Summary}

INDOT Research

Technology Transfer and Project Implementation Information

TRB Subject Code: 62-1 Foundation Soils

Publication No. FHWA/IN/JTRP-2008/5, SPR-2634

January 2009

Final Report

\section{Limit States and Load Resistance Design of Slopes and Retaining Structures}

\section{Introduction}

The primary goal of this report was to develop Load and Resistance Factor Design (LRFD) methods for slopes and retaining structures. Even though there is past research on LRFD of shallow foundations and piles, there are very few publications available on LRFD of slopes and retaining structures. Most commonly, the design goal for slopes is to economically select (i) slope angle and (ii) slope protection measures that will not lead to any limit state. For retaining structures, the goal is the economical selection of the type and dimensions of the retaining structure, including of the reinforcement for MSE walls, again without violating limit state checks.

The design of slopes and retaining structures has traditionally been conducted using the Working Stress Design (WSD) approach. Even in recent years, WSD has remained the primary design approach in geotechnical engineering. Within this framework, for any design problem, capacity or resistance is compared with the loading. To account for the uncertainties associated with the calculation of resistance and loading, a single factor of safety is used to divide the capacity (or, from the opposite point of view, to multiply the loading) before the comparison is made. The factor of safety is the tool that the WSD approach uses to account for uncertainties. Thus, in designs following WSD, the uncertainties are expressed using a single number: the factor of safety. Therefore, the uncertainties related to load estimation cannot be separated from those related to resistance.

The LRFD method combines the limit states design concept with the probabilistic approach, accounting for the uncertainty of parameters related to both the loads and the resistance. In the present report, only Ultimate Limit States (ULSs) are considered. An ULS is a state for which the total load is equal to the maximum resistance of the system. When the total load is equal to or higher than the maximum resistance of the system, the system "fails" (that is, fails to perform according to pre-defined criteria). To prevent failure of the system, Limit State Design (LSD) requires the engineer to identify every possible ULS and to ensure that none of those are reached. However, in the case of LRFD, which combines the probabilistic approach with LSD, the probability of failure of the system is calculated from the probability density distributions of the total load and the maximum resistance. LRFD aims to keep this probability of failure from exceeding a certain level (the target probability of failure or target reliability index). LRFD uses an LSD framework, which checks for the ULS using partial factors on loads and on resistance. These partial factors, associated with the loads and the resistance, are calculated based on the uncertainties associated with the loads and the resistance.

\section{Findings}

We have developed LRFD methods for slopes and MSE walls using limit state design concepts and probability theory. Resistance Factor (RF) values that are compatible with the LFs of the AASHTO LRFD specifications (2007) are tentatively suggested in this report for LRFD of slopes and MSE walls from the result of reliability analyses on the basis of a rational assessment of the uncertainties of the parameters that are used in the analysis.

\section{LRFD of Slopes}

We have successfully employed Gaussian random field theory for the representation of spatial (inherent) soil variability. The reliability analysis 
program developed for LRFD of slopes using Monte Carlo simulations in conjunction with the soil parameters represented by Gaussian random fields works well and provides reliable results.

Even for the given target probability of failure, geometry of slope, and mean values of parameters and their uncertainties, there is no uniqueness of the RF value for slopes. In other words, the RF value resulting from Monte Carlo simulations varies from case to case. This is because the Gaussian random fields and also the slip surface at the ULS for each random realization of a slope defined by the mean and variance values of the strength parameters and unit weights of each layer and of the live load are different from simulation to simulation. We have proposed a way to deal with this nonuniqueness that provides an acceptable basis on which to make resistance factor recommendations.

\section{LRFD of MSE walls}

For each limit state, the First-Order Reliability Method (FORM) was successfully used to compute the values of loads and resistance at the ULS for the given target reliability index and the corresponding optimal load and resistance factors. A parametric study of the external stability (sliding and overturning) of MSE walls identified the unit weight of the retained soil as the parameter with the most impact on the RF value. This seems to be because the change of the unit weight of the retained soil results in a change of the composition of the uncertainty of the total lateral load acting on the reinforced soil. For example, if the unit weight of the retained soil increases, the ratio of the lateral load due to the live uniform surcharge load to the lateral load due to the self-weight of the retained soil decreases. Therefore, the uncertainty of the total load decreases because the lateral load due to the live uniform surcharge load has a much higher bias factor and COV compared to those of the lateral load due to the self-weight of the retained soil. Consequently, the RF values for sliding and overturning increase as the height of the MSE wall increases.

For pullout of the steel-strip reinforcement, the most important parameter on the RF value is the relative density of the reinforced soil because not only the relative density has the highest COV among all the parameters but also the mean value of the relative density has a significant influence on the pullout resistance factor. In addition, the level (or the vertical location) of the steel-strip reinforcement also has considerable impact on the RF value because the reinforcement level changes the uncertainty of total load significantly by changing the ratio of the load due to the self-weight of the reinforced soil to the load due to the live uniform surcharge load.

In this study, we found the worst cases, which have the lowest RF values, by varying the parameters within their possible ranges for different MSE wall heights and different target reliability indices. The "worst-case” RF values for sliding and overturning are given in the report. The "worst-case" RF values for pullout, which occur at the first reinforcement level from the top of the MSE wall, are suggested as RF values to use in pullout failure checks. Usually, the required reinforcement length $L$ at the first reinforcement level from the top of an MSE wall is used for all the other reinforcement levels when the vertical and horizontal spacing of the reinforcements are the same. Therefore, in general, this required reinforcement length $L$ can be calculated using the $\mathrm{RF}$ value for pullout at the first reinforcement depth $\mathrm{z}$.

\section{Implementation}

RF values for LRFD of slopes and MSE walls in this report are calculated based on analyses done for a limited number of conditions. The RF values for slopes and MSE wall designs given in this report are valid only when designers use (i) the equations for load and resistance and (ii) the test methods for design parameters given in this report. The RF values are computed for two different target probability of failure $\left(\mathrm{P}_{\mathrm{f}}=0.001\right.$ and 0.01$)$ for slopes and three different target reliability indices ( $\beta_{\mathrm{T}}=2.0,2.5$, and 3.0) for MSE walls. The higher values of target probability of failure (0.01) and the lower values of target reliability index (2.0 and 2.5) are provided for illustration purposes, as they would typically be excessively daring in most design problems. For slope stability, resistance factors for a probability of failure lower than 0.001 would require considerable time to calculate. In practice, the importance of the structure may vary; therefore, designers should select an appropriate target probability of failure (or target reliability index), which would produce an economical design without excessive risk to the stability of a structural and geotechnical system.

For development of complete and reliable sets of resistance factors for LRFD of slopes and MSE walls, we recommend the following:

(1) It is necessary to perform comprehensive research on the classification of the type of 
error associated with measurements, which is a process that requires extensive effort in testing and data collection. This effort would make it possible to assess the uncertainty of systematic errors more accurately. As uncertainties in parameters reflect directly on RF values, improved assessment of these uncertainties would be very beneficial.

(2) The load factors provided in the current AASHTO LRFD specifications (2007) are equal to one regardless of the load type. This means that RF values (0.75 when the geotechnical parameters are well defined and the slope does not support or contain a structural element, and 0.65 when the geotechnical parameters are based on limited information or the slope contains or supports a structural element) proposed in the specifications are the inverse values of the factors of safety (1.3 and 1.5) that were given in the old AASHTO specifications. Thus, LRFD of slopes as currently covered by the AASHTO specifications is in effect the same as Working Stress Design (WSD). Use of the algorithm provided in this report would produce appropriate load factors that reflect the uncertainty of the corresponding loadings and allow determination of suitable resistance factors. Then, the current load and resistance factor for LRFD of slopes in the AASHTO LRFD specifications could be updated to more closely reflect the principles of LRFD.
(3) More analyses are necessary for determining RF values for slope design. The following all should be explored: (i) different geometries; (ii) different external loading conditions (load type, location, and magnitude); (iii) different combinations of soil layers; (iv) different combinations of the values of soil properties (considering wide ranges of soil property values); (v) wider ranges of probability of failure (and, in particular, lower probabilities of failure); (vi) repeatability checks to further validate the method proposed to handle the nonuniqueness of resistance and load factors resulting from different simulations.

(4) Similarly to slopes, more analyses varying MSE wall geometry, loading condition and soil properties will be helpful to expand LRFD for MSE wall design for different site conditions.

(5) The RF value for general loss of stability of MSE walls could be examined using the appropriate load factors determined from extensive Monte Carlo simulations for LRFD of slopes.

(6) For certain geotechnical structures, such as levees, dams or abutments of large and massive bridges, lower target probabilities of failure (or higher target reliability index) should be considered. A more careful study of acceptable values of probability of failure should be conducted.

\section{Contacts}

For more information:

Prof. Rodrigo Salgado

Principal Investigator

School of Civil Engineering

Purdue University

West Lafayette IN 47907

Phone: (765) 494-5030

Fax: (765) 496-1364

E-mail: rodrigo@purdue.edu
Indiana Department of Transportation

Division of Research

1205 Montgomery Street

P.O. Box 2279

West Lafayette, IN 47906

Phone: (765) 463-1521

Fax: (765) 497-1665

\section{Purdue University}

Joint Transportation Research Program

School of Civil Engineering

West Lafayette, IN 47907-1284

Phone: (765) 494-9310

Fax: (765) 496-7996

E-mail: jtrp@ecn.purdue.edu

http://www.purdue.edu/jtrp 
Final Report

FHWA/IN/JTRP-2008/5

\title{
LIMIT STATES AND LOAD AND RESISTANCE DESIGN OF SLOPES AND RETAINING STRUCTURES
}

\author{
Dongwook Kim \\ Graduate Research Assistant \\ and \\ Rodrigo Salgado, P.E. \\ Professor \\ Geotechnical Engineering \\ School of Civil Engineering \\ Purdue University \\ Joint Transportation Research Program \\ Project No: C-36-36MM \\ File No: 06-14-39 \\ SPR-2634 \\ Prepared in Cooperation with the \\ Indiana Department of Transportation and \\ The U.S. Department of Transportation \\ Federal Highway Administration
}

The contents of this report reflect the views of the authors who are responsible for the facts and the accuracy of the data presented herein. The contents do not necessarily reflect the official views or policies of the Federal Highway Administration and the Indiana Department of Transportation. This report does not constitute a standard, specification or regulation.

\author{
Purdue University \\ West Lafayette, Indiana \\ April 2008
}




\begin{tabular}{|c|c|c|}
\hline $\begin{array}{l}\text { 1. Report No. } \\
\text { FHWA/IN/JTRP-2008/5 }\end{array}$ & 2. Government Accession No. & 3. Recipient's Catalog No. \\
\hline \multirow{2}{*}{\multicolumn{2}{|c|}{$\begin{array}{l}\text { 4. Title and Subtitle } \\
\text { Limit States and Load Resistance Design of Slopes and Retaining Structures }\end{array}$}} & $\begin{array}{l}\text { 5. } \quad \text { Report Date } \\
\text { January } 2009\end{array}$ \\
\hline & & 6. Performing Organization Code \\
\hline \multicolumn{2}{|l|}{$\begin{array}{l}\text { 7. Author(s) } \\
\text { Dongwook Kim and Rodrigo Salgado }\end{array}$} & $\begin{array}{l}\text { 8. Performing Organization Report No. } \\
\text { FHWA/IN/JTRP-2008/5 }\end{array}$ \\
\hline \multirow{2}{*}{\multicolumn{2}{|c|}{$\begin{array}{l}\text { 9. Performing Organization Name and Address } \\
\text { Joint Transportation Research Program } \\
550 \text { Stadium Mall Drive } \\
\text { Purdue University } \\
\text { West Lafayette, IN 47907-2051 }\end{array}$}} & 10. Work Unit No. \\
\hline & & $\begin{array}{l}\text { 11. Contract or Grant No. } \\
\text { SPR-2634 }\end{array}$ \\
\hline \multirow{2}{*}{\multicolumn{2}{|c|}{$\begin{array}{l}\text { 12. Sponsoring Agency Name and Address } \\
\text { Indiana Department of Transportation } \\
\text { State Office Building } \\
100 \text { North Senate Avenue } \\
\text { Indianapolis, IN } 46204\end{array}$}} & $\begin{array}{c}\text { 13. Type of Report and Period Covered } \\
\text { Final Report }\end{array}$ \\
\hline & & 14. Sponsoring Agency Code \\
\hline \multicolumn{3}{|l|}{ 15. Supplementary Notes } \\
\hline \multicolumn{3}{|c|}{ Prepared in cooperation with the Indiana Department of Transportation and Federal Highway Administration. } \\
\hline
\end{tabular}

Load and Resistance Factor Design (LRFD) methods for slopes and MSE walls were developed based on probability theory. The complexity in developing LRFD for slopes and MSE walls results from the fact that (1) the representation of spatial variability of soil parameters of slopes using Gaussian random field is computationally demanding and (2) LRFD of MSE walls requires examination of multiple ultimate limit states for both external and internal stability checks.

For each design case, a rational framework is developed accounting for different levels of target probability of failure (or target reliability index) based on the importance of the structure. The conventional equations for loads and resistance in the current MSE wall design guides are modified so that the equations more closely reproduce the ultimate limit states (ULSs) in the field with as little uncertainty as possible. The uncertainties of the parameters, the transformation and the models related to each ULS equation are assessed using data from an extensive literature review.

The framework used to develop LRFD methods for slopes and MSE walls was found to be effective. For LRFD of slopes, several slopes were considered. Each was defined by the mean value of the strength parameters and unit weight of each soil layer and of the live load. (1) Gaussian random field theory was used to generate random realizations of the slope (each realization had values of strength and unit weight that differed from the mean by a random amount), (2) a slope stability analysis was performed for each slope to find the most critical slip surface and the corresponding driving and resisting moments, (3) the probability of failure was calculated by counting the number of slope realizations for which the factor of safety did not exceed 1 and dividing that number by the total number of realizations, (4) the mean and variance of the soil parameters was adjusted and this process repeated until the calculated probability of failure was equal to the target probability of failure, and (5) optimum load and resistance factors were obtained using the ultimate limit state values and nominal values of driving and resisting moments. For LRFD of MSE walls, (1) the First-Order Reliability Method was successfully implemented for both external and internal limit states and (2) a reasonable RF value for each limit state was calculated for different levels of target reliability index.

17. Key Words

Load and Resistance Factor Design (LRFD); Slope;

Mechanically Stabilized Earth (MSE) wall; Reliability analysis; Gaussian random field; Monte Carlo simulation; First-Order Reliability Method (FORM).

\section{Distribution Statement}

No restrictions. This document is available to the public through the National Technical Information Service, Springfield, VA 22161
19. Security Classif. (of this report)

Unclassified
20. Security Classif. (of this page)

Unclassified
21. No. of Pages

233 


\section{TABLE OF CONTENTS}

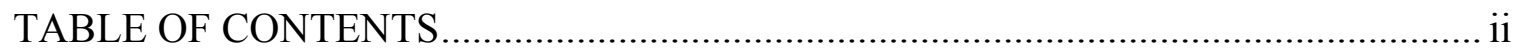

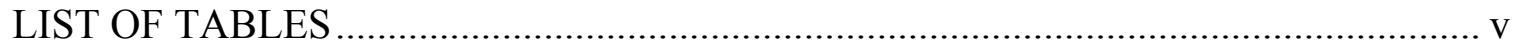

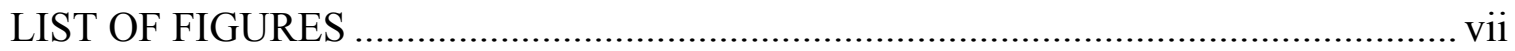

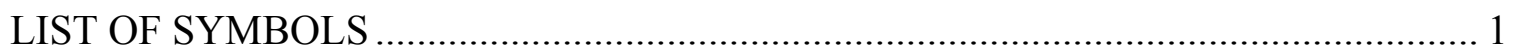

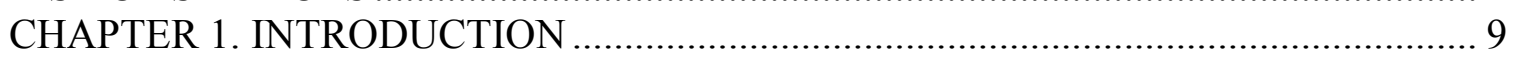

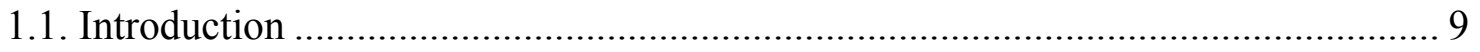

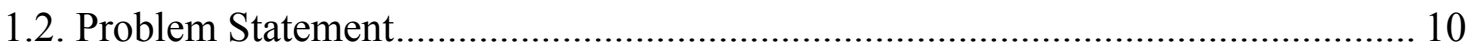

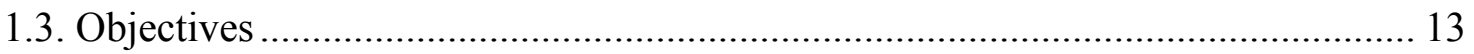

CHAPTER 2. LOAD AND RESISTANCE FACTOR DESIGN ................................... 14

2.1. Load and Resistance Factor Design Compared with Working Stress Design........ 14

2.2. Calculation of Resistance Factor RF ............................................................... 16

2.3. AASHTO Load Factors for LRFD .................................................................... 18

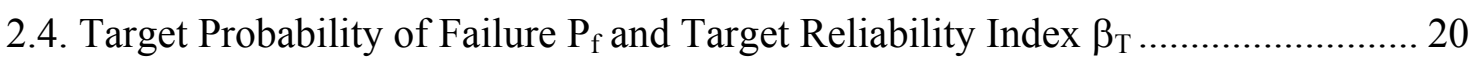

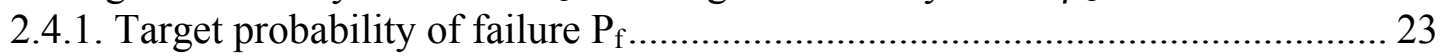

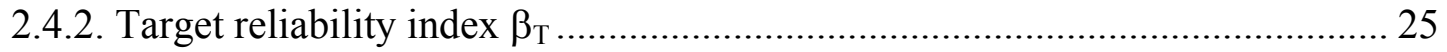

CHAPTER 3. APPLICATION OF LRFD TO SLOPE DESIGN..................................... 29

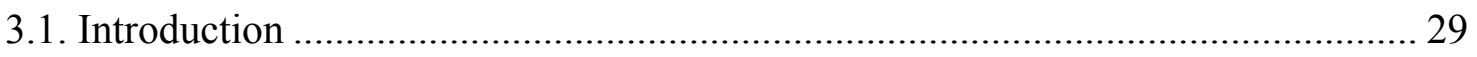

3.2. Bishop Simplified Method .................................................................................. 31

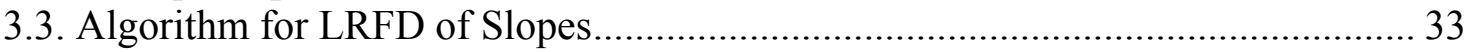

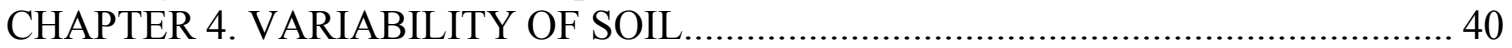

4.1. Uncertainty Associated with Soil Properties ............................................................. 40

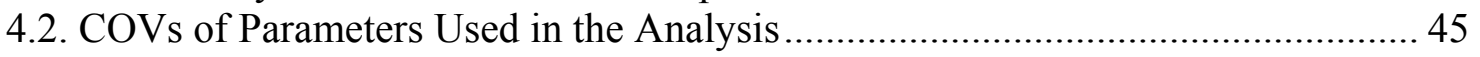

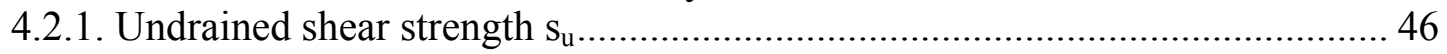

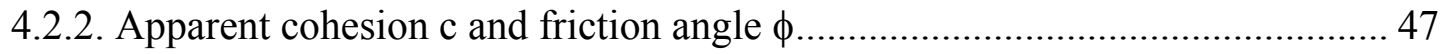

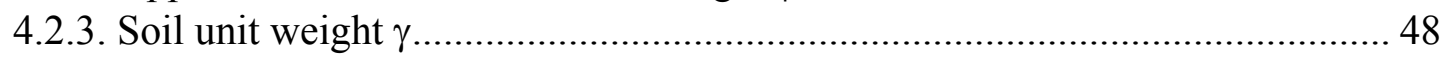

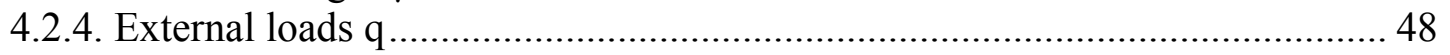

4.3. Spatial Variability of Soil Properties.................................................................. 50

4.3.1. Gaussian random field for spatial variability of soil properties ....................... 50

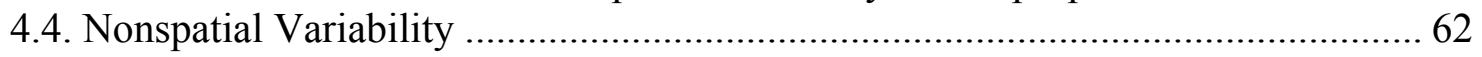

4.5. Use of Fourier Transforms to Generate Gaussian Random Fields ......................... 65

4.6. Procedure for Gaussian Random Field Generation ............................................... 70

CHAPTER 5. EXAMPLES OF RESISTANCE FACTOR CALCULATION................... 72

5.1. Effect of the Measurement Error on the Probability of Failure............................... 72 
5.2. Effect of the Isotropic Scale of Fluctuation of Soil Unit Weight on the Probability of Failure 74

5.3. Effect of the Isotropic Scales of Fluctuation of the Soil Properties on the

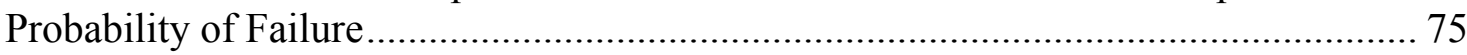

5.4. Examples for Slopes and Embankments .......................................................... 77

5.4.1. Slope example 1: $\mathrm{P}_{\mathrm{f}}=0.001$, no live uniform surcharge load on the crest of the slope 77

5.4.2. Slope example 2: $\mathrm{P}_{\mathrm{f}}=0.01$, no live uniform surcharge load on the crest of the slope 83

5.4.3. Slope example 3: $\mathrm{P}_{\mathrm{f}}=0.001$ with a live uniform surcharge load on the crest of the slope 87

5.4.4. Slope example 4: $\mathrm{P}_{\mathrm{f}}=0.01$ with a live uniform surcharge load on the crest of the slope .92

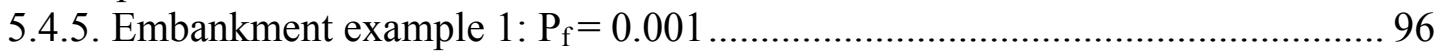

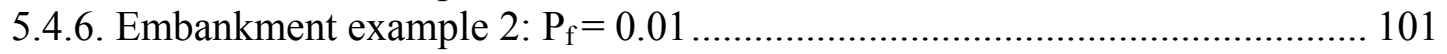

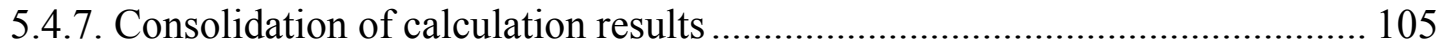

CHAPTER 6. EXTERNAL STABILITY OF MSE wALLS ....................................... 112

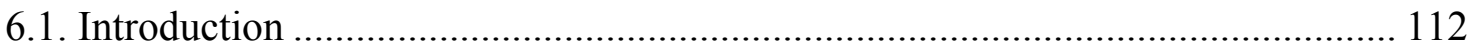

6.2. Ultimate Limit States Associated with External Stability .................................. 113

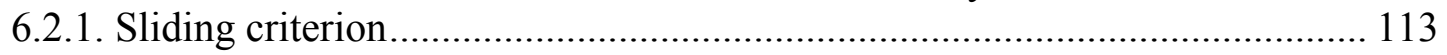

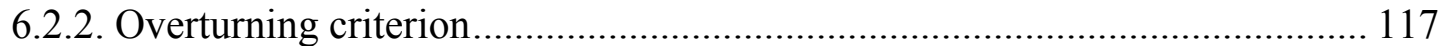

6.3. Determination of LFs for External Stability ..................................................... 118

6.4. Uncertainties of the Parameters That are Used in the Analysis ........................... 119

6.4.1. Uncertainty of dry unit weight $\gamma_{d}$ of the noncompacted retained soil ............ 119

6.4.2. Uncertainty of critical-state friction angle $\phi_{\mathrm{c}}$............................................... 120

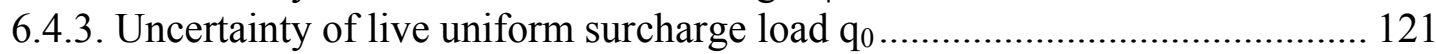

6.4.4. Uncertainty of interface friction angle $\delta\left(\delta^{*}\right)$ at the base of an MSE wall .... 123

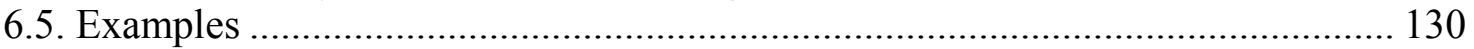

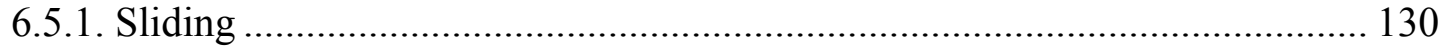

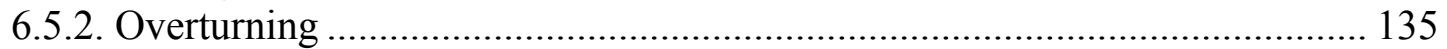

CHAPTER 7. INTERNAL STABILITY OF MSE WALLS.......................................... 141

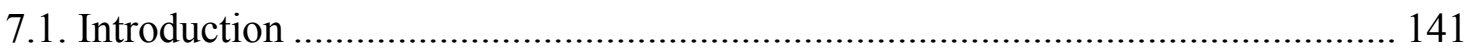

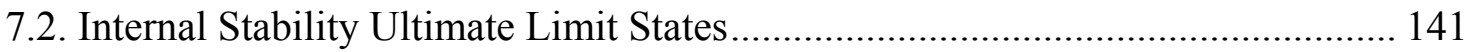

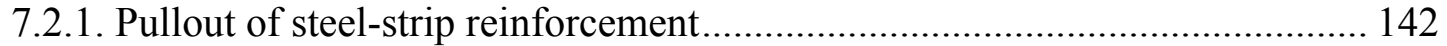

7.2.2. Structural failure of steel-strip reinforcement .............................................. 143

7.3. Determination of LFs for Internal Stability Calculations ..................................... 144

7.4. Uncertainty of Locus of Maximum Tensile Force along the Steel-Strip

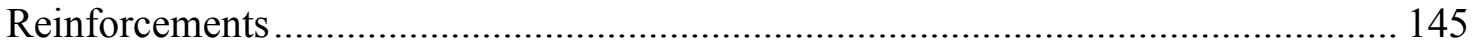

7.5. Uncertainties of the Parameters That are Used in the Analysis of the Internal

Stability of MSE Walls......................................................................................... 148

7.5.1. Uncertainty of dry unit weight of the compacted soil.................................. 149

7.5.2. Uncertainty of maximum dry unit weight and minimum dry unit weight for

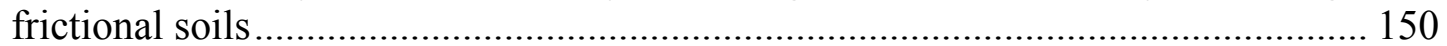

7.5.3. Uncertainty of relative density of backfill soil in the reinforced soil ............ 151

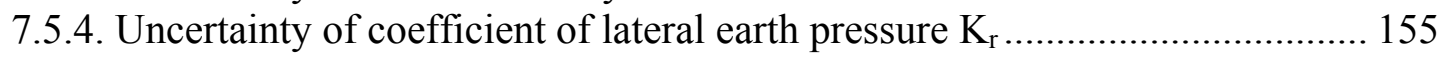




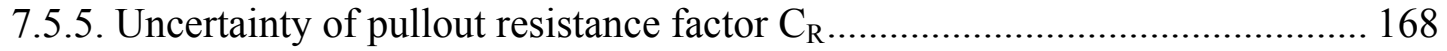

7.5.6. Uncertainty of yield strength of steel-strip reinforcement .............................. 170

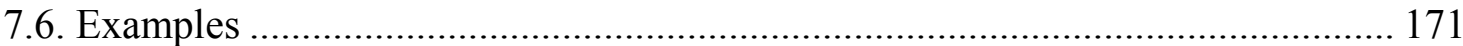

7.6.1. Pullout of steel-strip reinforcement............................................................ 172

7.6.2. Structural failure of steel-strip reinforcement .............................................. 185

CHAPTER 8. PARAMETRIC STUDY ……………......................................... 190

8.1. Effect of the Change in the Critical-State Friction Angle of Retained Soil on RF

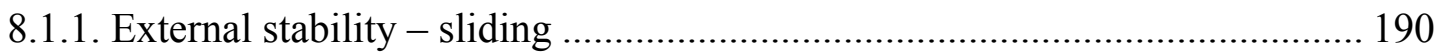

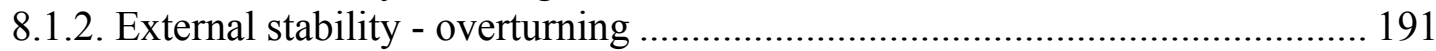

8.2. Effect of the Change in Relative Density of Reinforced Soil on RF................... 192

8.2.1. Internal stability - pullout of steel-strip reinforcement................................. 192

8.3. Effect of the Change in the Critical-State Interface Friction Angle of the Steel-Strip

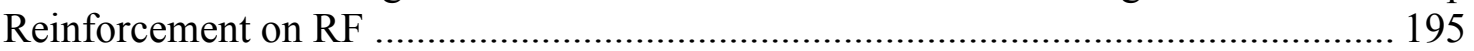

8.4. Effect of the Change in Unit Weight of Retained Soil on RF ............................. 197

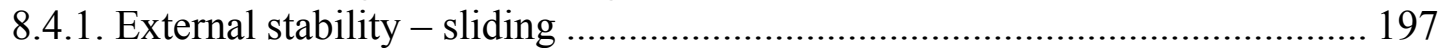

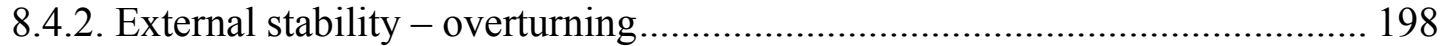

8.5. Effect of the Change in the Unit Weight of the Reinforced Soil on RF.............. 198

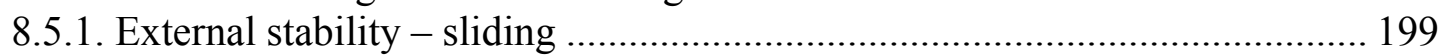

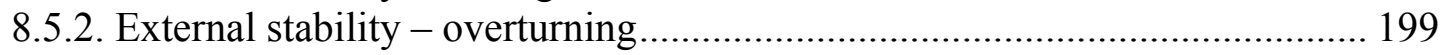

8.5.3. Internal stability - steel-strip reinforcement pullout..................................... 200

8.5.4. Internal stability - structural failure of steel-strip reinforcement .................. 202

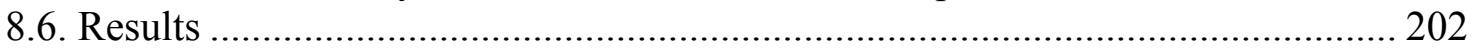

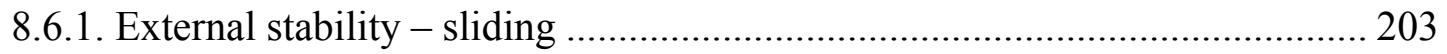

8.6.2. External stability - overturning ............................................................... 204

8.6.3. Internal stability - pullout of steel-strip reinforcement.................................. 204

8.7. Tentative RF Value Recommendations for Each Limit State ............................. 206

CHAPTER 9. CONCLUSIONS AND RECOMMENDATIONS ……......................... 210

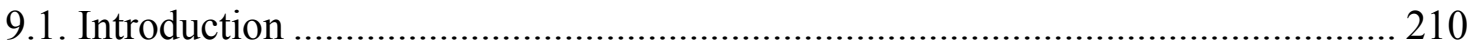

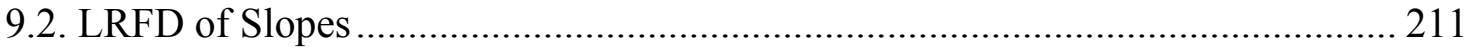

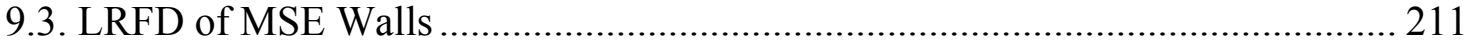

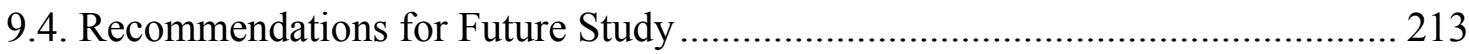




\section{LIST OF TABLES}

Table

Page

Table 2.1 AASHTO load factors and its combinations with different limit states

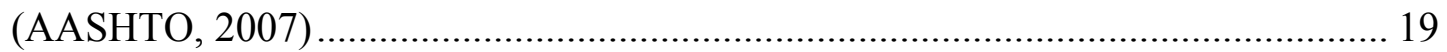

Table 2.2 Load factors $\lambda_{p}$ for different types of permanent loads (AASHTO, 2007) ...... 20

Table 2.3 Acceptable probability of failure for slopes (modified after Santamarina et al, 1992)

Table 2.4 The equivalent values of target probability of failure for a corresponding target reliability index

Table 3.1 Minimum factor of safety for slope designs (AASHTO, 2002) ...................... 29

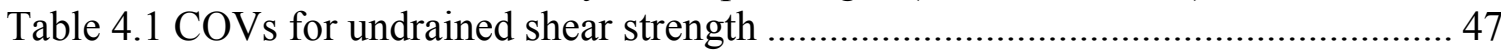

Table 4.2 COVs for soil unit weight ...................................................................... 48

Table 4.3 COVs and bias factors for dead load and live load...................................... 49

Table 4.4 Horizontal and vertical scales of fluctuation of undrained shear strength........ 57

Table 5.1 Optimum factors from the examples ( $\mathrm{LF}=1$ for all types of loads) ............. 105

Table 5.2 RF values for different LF values for dead and live load ............................. 106

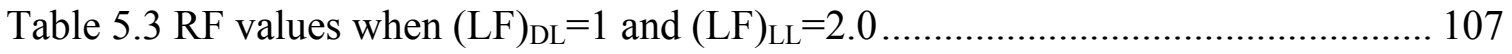

Table 6.1 COVs of $\phi_{c}$ of Ottawa sand from ring shear tests (after Negussey et al., 1987)

Table 6.2 Equivalent height of soil for vehicular loading on abutment perpendicular to traffic.

Table 6.3 Equivalent height of soil for vehicular loading on retaining walls parallel to traffic 121

Table 6.4 Bias factor and COV of the critical-state interface friction angle $\delta_{\mathrm{r}}^{*}\left(\alpha_{1}\right.$ is the major principal stress direction angle) ............................................................ 129

Table 6.5 Result of reliability analysis for sliding criterion (when $\mathrm{H}=10 \mathrm{~m}, \beta_{\mathrm{T}}=2.0$, and

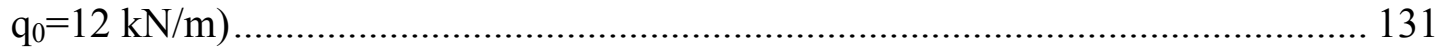

Table 6.6 ULS values of loads and resistance for sliding.......................................... 132

Table 6.7 Nominal values of loads and resistance and FS for sliding ......................... 132

Table 6.8 Calculation of optimum factors and RF using AASHTO LFs for sliding ...... 132

Table 6.9 Result of reliability analysis for overturning criterion (when the height of MSE wall $\mathrm{H}=10 \mathrm{~m}$, target reliability index $\beta_{\mathrm{T}}=2.0$ and nominal $\left.\mathrm{q}_{0}=12 \mathrm{kN} / \mathrm{m}\right) \ldots \ldots \ldots \ldots \ldots . . .136$

Table 6.10 Driving and resisting moments at the overturning ULS ........................... 136

Table 6.11 Nominal driving and resisting moments and FS for overturning ................ 137

Table 6.12 Calculation of optimum factors and RF using AASHTO LFs for overturning

Table 7.1 Particle size distribution for backfill soils of MSE walls (AASHTO T-27)... 149 


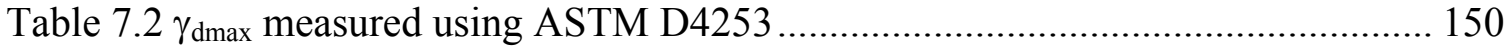

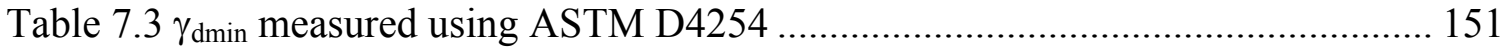

Table 7.4 COVs of relative density of compacted fine sand ...................................... 154

Table 7.5 COVs of relative density of compacted gravelly sand ................................. 154

Table 7.6 Result of reliability analysis for pullout of steel-strip reinforcement (when $\mathrm{s}_{\mathrm{v}}=0.6 \mathrm{~m}, \mathrm{~s}_{\mathrm{h}}=0.75 \mathrm{~m}, \mathrm{z}=0.60 \mathrm{~m}, \mathrm{H}=20 \mathrm{~m}, \beta_{\mathrm{T}}=3.0$, and the nominal $\left.\mathrm{q}_{0}=12 \mathrm{kN} / \mathrm{m}\right) \ldots \ldots .173$

Table 7.7 ULS values of loads and resistance for pullout of steel-strip reinforcement.. 174

Table 7.8 Nominal values of loads and resistance and FS value for pullout of steel-strip

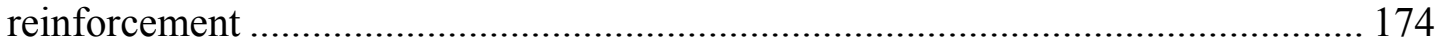

Table 7.9 Calculation of optimum factors and RF using AASHTO LFs for pullout of

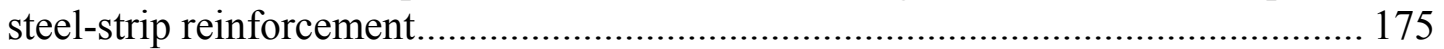

Table 7.10 Result of reliability analysis for structural failure of steel-strip reinforcement $\left(\mathrm{s}_{\mathrm{v}}=0.8 \mathrm{~m}, \mathrm{~s}_{\mathrm{h}}=0.75 \mathrm{~m}\right.$ and $\left.\beta_{\mathrm{T}}=3.5\right)$ 187

Table 7.11 ULS values of loads and resistance for structural failure of steel-strip reinforcement 187

Table 7.12 Nominal values of loads and resistance and FS value for structural failure of steel-strip reinforcement. 188

Table 7.13 Calculation of optimum factors and RF using AASHTO LFs for structural

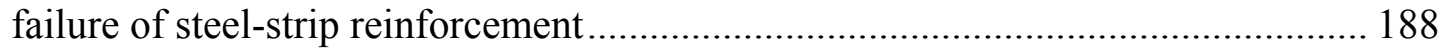

Table 7.14 RF and the corresponding reinforcement level for different target reliability indices $\left(\mathrm{s}_{\mathrm{h}}=0.75 \mathrm{~m}\right)$.

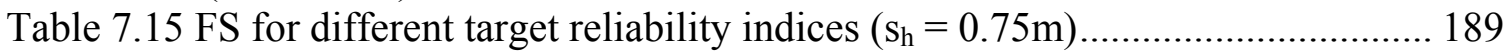

Table 8.1 RF value for structural failure of steel-strip reinforcement for $\gamma_{\mathrm{rf}}=20$ and 22

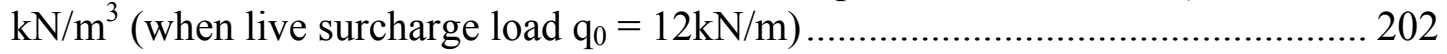

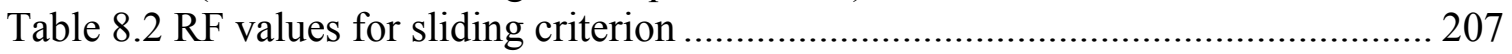

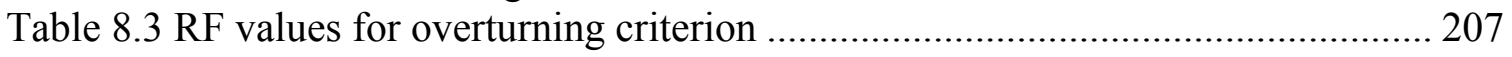

Table 8.4 Minimum RF value for pullout of steel-strip reinforcement for 5m-high MSE

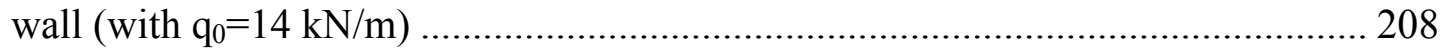

Table 8.5 Minimum RF value for pullout of steel-strip reinforcement for MSE walls more

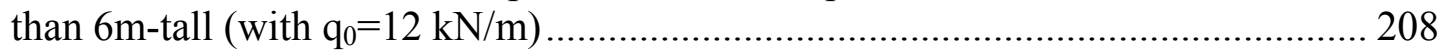

Table 8.6 RF value for structural failure of steel-strip reinforcement ......................... 208 


\section{LIST OF FIGURES}

Figure

Page

Figure 2.1 Distribution of total load Q and resistance $\mathrm{R}$ when two different cases have the same value of FS: (a) high load and resistance uncertainty and (b) low load and resistance uncertainty.... 15

Figure 2.2 Normal distribution of margin of safety $G\left(\mu_{G}\right.$ and $\sigma_{G}$ are the mean and standard deviation of margin of safety $\mathrm{G}$, and $\beta$ is reliability index) ....................... 22

Figure 3.1 Method of slices $\left(\ell_{i}\right.$ is the length of the bottom of $i^{\text {th }}$ slice; $\left.i=1, \cdots, n\right) \ldots \ldots \ldots \ldots . .31$

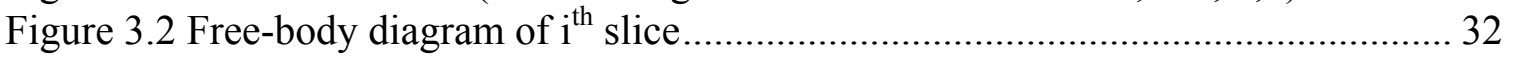

Figure 3.3 Algorithm for LRFD of slopes ........................................................... 35

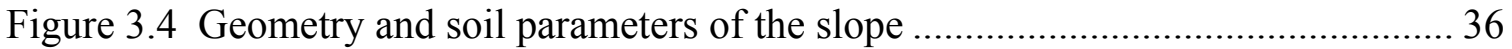

Figure 3.5 The array of data points generated by Gaussian random field theory ........... 37

Figure 3.6 Finding the most critical slip surface among a large number of trial slip

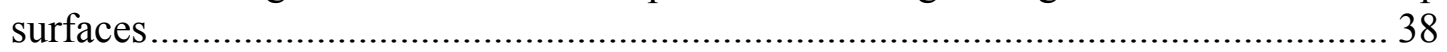

Figure 4.1 Four sources of uncertainty in soil property measurement (after Christian et

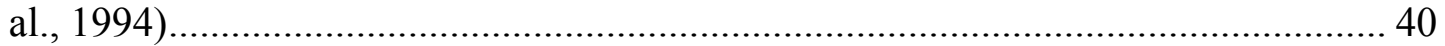

Figure 4.2 Scatter of the in situ values of a soil property. ........................................ 42

Figure 4.3 Bias due to statistical error in the mean................................................... 43

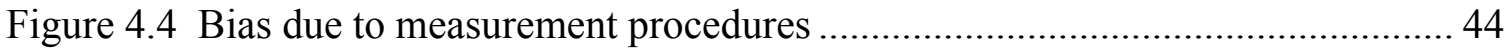

Figure 4.5 Measurement error................................................................................. 45

Figure 4.6 Live loads considered in slope design (consider destabilizing live surcharges

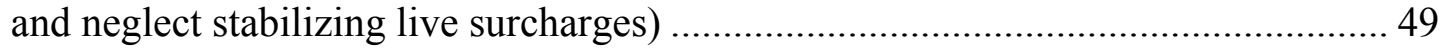

Figure 4.7 Exponential correlation coefficient functions for different isotropic scales of fluctuation (in one-direction) ( $\mathrm{s}_{\mathrm{f}}$ is the scale of fluctuation) ................................... 53

Figure 4.8 Surface maps of the exponential correlation coefficient functions in 2D space for different isotropic scales of fluctuation; (a) $\mathrm{s}_{\mathrm{f}}=1 \mathrm{~m}$, (b) $\mathrm{s}_{\mathrm{f}}=5 \mathrm{~m}$, (c) $\mathrm{s}_{\mathrm{f}}=10 \mathrm{~m}$, and

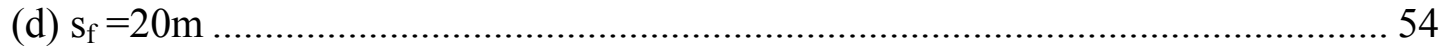

Figure 4.9 Meaning of scale of fluctuation $\mathrm{s}_{\mathrm{f}}$ for the exponential correlation coefficient

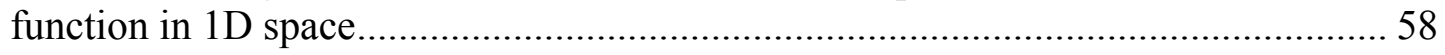

Figure 4.10 Estimation of the variance of measurement error of undrained shear strength $\mathrm{S}_{\mathrm{u}}$ by comparing the autocovariance function with the measured autocovariance values of undrained shear strength (after Christian et al., 1994) 64

Figure 4.11 Horizontal and tilted views of surface map of two-dimensional Gaussian random fields that has zero mean and unit standard deviation for different scales of

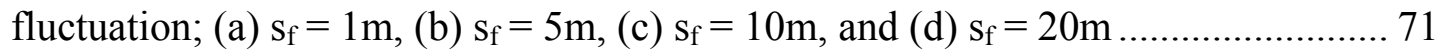

Figure 5.1 Geometry of a three-layer soil slope and its soil properties ......................... 73 
Figure 5.2 Effect of the COV of measurement on a probability of failure of the slope given in Figure 5.1 ........................................................................................ 74

Figure 5.3 Probability of failure of the slope shown in Figure 5.1 for different isotropic scale of fluctuation of soil unit weight .................................................................... 75

Figure 5.4 Effect of the isotropic scale of fluctuation on a probability of failure ............ 76

Figure 5.5 Geometry of a three-layer soil slope …………………............................ 78

Figure 5.6 Distribution of FS value and the ULS of the slope $\left(\mathrm{P}_{\mathrm{f}}=0.001\right.$ and without live

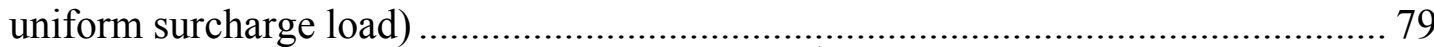

Figure 5.7 Distribution of optimum load factor (LF) ${ }^{*}$ DL for load due to self-weight of soil .

Figure 5.8 Distribution of optimum resistance factor $\mathrm{RF}^{*}$......................................... 82

Figure 5.9 Distribution of FS value and the ULS of the slope $\left(\mathrm{P}_{\mathrm{f}}=0.01\right.$, no live uniform

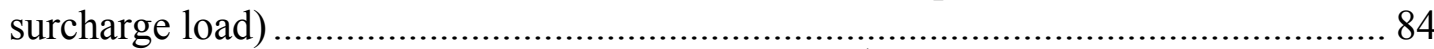

Figure 5.10 Distribution of optimum load factor $(\mathrm{LF})^{*} \mathrm{LD}$ for load due to self-weight of

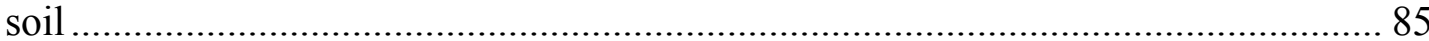

Figure 5.11 Distribution of optimum resistance factor $\mathrm{RF}^{*}$....................................... 86

Figure 5.12 Distribution of FS value and the ULS of the slope $\left(\mathrm{P}_{\mathrm{f}}=0.001\right.$ and live

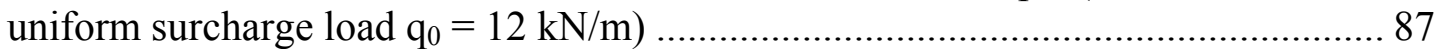

Figure 5.13 Distribution of optimum load factor $(\mathrm{LF})^{*}$ DL for load due to self-weight of soil

Figure 5.14 Distribution of optimum load factor $(\mathrm{LF})^{*}{ }_{\mathrm{LL}}$ for load due to live surcharge load.

Figure 5.15 Distribution of optimum resistance factor $\mathrm{RF}^{*}$........................................... 91

Figure 5.16 Distribution of FS value and the ULS of the slope $\left(\mathrm{P}_{\mathrm{f}}=0.01\right.$ and live uniform

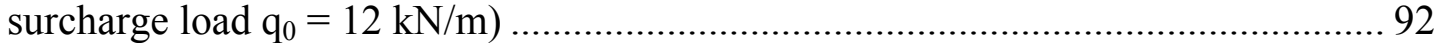

Figure 5.17 Distribution of optimum load factor (LF) ${ }^{*}$ DL for load due to self-weight of soil

Figure 5.18 Distribution of optimum load factor $(\mathrm{LF})_{\mathrm{LL}}^{*}$ for load due to live surcharge

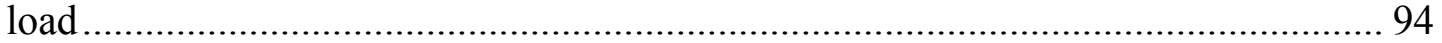

Figure 5.19 Distribution of optimum resistance factor $\mathrm{RF}^{*}$............................................ 95

Figure 5.20 Geometry of a road embankment (1:1 side slopes) .................................... 96

Figure 5.21 Distribution of FS value and the ULS of the slope $\left(\mathrm{P}_{\mathrm{f}}=0.001\right.$ and live

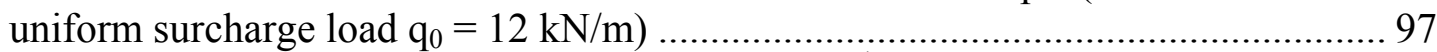

Figure 5.22 Distribution of optimum load factor (LF) ${ }^{*}$ DL for load due to self-weight of

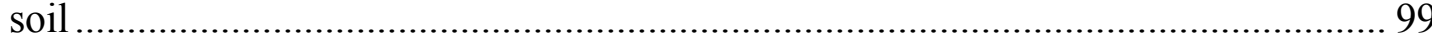

Figure 5.23 Distribution of optimum load factor $(\mathrm{LF})^{*} \mathrm{LL}$ for load due to live surcharge load 99

Figure 5.24 Distribution of optimum resistance factor $\mathrm{RF}^{*}$........................................... 100

Figure 5.25 Distribution of FS value and the ULS of the slope $\left(\mathrm{P}_{\mathrm{f}}=0.01\right.$ and live uniform

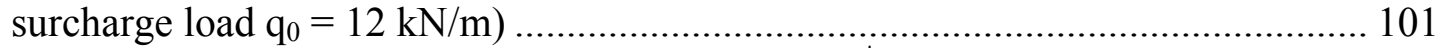

Figure 5.26 Distribution of optimum load factor (LF) ${ }^{*} \mathrm{DL}$ for load due to self-weight of soil..... 103

Figure 5.27 Distribution of optimum load factor $(\mathrm{LF})_{\mathrm{LL}}^{*}$ for load due to live surcharge load 103

Figure 5.28 Distribution of optimum resistance factor RF* 104 
Figure 6.1 Forces defining the sliding ULS equation $\left(\mathrm{E}_{\mathrm{A} 1}\right.$ and $\mathrm{E}_{\mathrm{A} 2}$ are the lateral forces due to the active earth pressures caused by the self-weight of the retained soil and the live uniform surcharge load $\mathrm{q}_{0, \mathrm{rt}} ; \mathrm{W}_{\mathrm{rf}}$ is the self-weight of the reinforced soil; $\mathrm{H}$ is the MSE wall height; $H$ is the reinforcement length; and $\delta$ is the interface friction angle at the bottom of the MSE wall) 114

Figure 6.2 Forces defining the overturning ULS equation $\left(\mathrm{E}_{\mathrm{A} 1}\right.$ and $\mathrm{E}_{\mathrm{A} 2}$ are the lateral forces due to the active earth pressures caused by the self-weight of the retained soil and the live uniform surcharge load $\mathrm{q}_{0, \mathrm{rt}} ; \mathrm{W}_{\mathrm{rf}}$ is the self-weight of the reinforced soil; $\mathrm{H}$ is the MSE wall height; and $\mathrm{H}$ is the reinforcement length) ............................. 117

Figure 6.3 Loads inducing sliding and overturning of an MSE wall ( $\mathrm{E}_{\mathrm{A} 1}$ and $\mathrm{E}_{\mathrm{A} 2}$ are the lateral forces due to the active earth pressures caused by the self-weight of the retained soil and the live uniform surcharge load $\mathrm{q}_{0, \mathrm{rt}}$ ).... 119

Figure 6.4 Torsional shearing under constant vertical stress $\sigma_{a}^{\prime}$ on the horizontal plane using the TSS apparatus $\left(\sigma^{\prime}{ }_{a}\right.$ : vertical effective stress; $\sigma_{t}^{\prime}$ : effective stress in torsional direction; $\sigma_{r}^{\prime}$ : effective stress in radial direction; $\alpha_{1}$ : major principal stress direction angle; and $\mathrm{K}_{0}$ : coefficient of lateral earth pressure at rest ).....

Figure 6.5 Estimation of $\phi_{\mathrm{c}}$ and $\delta_{\mathrm{r}}$ from the relationship between $\phi_{\mathrm{p}}$ and $\delta_{\mathrm{p}}$ with different initial void ratio when $\sigma_{\mathrm{a}}=98 \mathrm{kN} / \mathrm{m}^{2}\left(\phi_{\mathrm{p}}\right.$ and $\delta_{\mathrm{p}}$ of a purely contractive specimen are equal to $\phi_{\mathrm{c}}$ and $\delta_{\mathrm{r}}$, respectively) 125

Figure 6.6 Estimation of $\phi_{\mathrm{c}}$ and $\delta_{\mathrm{r}}$ from the relationship between $\phi_{\mathrm{p}}$ and $\delta_{\mathrm{p}}$ with different initial void ratio for different vertical stresses $\left(\sigma_{\mathrm{a}}=98-196.2 \mathrm{kN} / \mathrm{m}^{2}\right)$ on the horizontal plane ( $\phi_{\mathrm{p}}$ and $\delta_{\mathrm{p}}$ of a purely contractive specimen are equal to $\phi_{\mathrm{c}}$ and $\delta_{\mathrm{r}}$, respectively)

Figure 6.7 Relationship between critical-state friction angle $\phi_{\mathrm{c}}$ and critical-state interface friction angle $\delta_{\mathrm{r}}^{*}$ explained using the Mohr circle diagram $\left(\tau_{\mathrm{r}}\right.$ and $\sigma_{\mathrm{a}}$ are the criticalstate shear stress and the vertical stress on the sliding plane; $\sigma_{1}$ and $\sigma_{3}$ are the major and minor principal stresses; and $\alpha_{1}$ is the major principal stress direction angle) 127

Figure 6.8 Distribution of the critical-state interface friction angle $\delta_{\mathrm{r}}{ }_{\mathrm{r}}$ when $\phi_{\mathrm{c}}=30^{\circ}$ using Monte Carlo simulations 129

Figure 6.9 RF for different target reliability indices and different MSE wall heights for sliding. 133

Figure 6.10 Optimum factors for $\mathrm{E}_{\mathrm{A} 1}, \mathrm{E}_{\mathrm{A} 2}$ and the sliding resistance versus MSE wall height $\mathrm{H}$ (for $\beta_{\mathrm{T}}=2.0$ ) $\left[(\mathrm{LF})_{\mathrm{DL}}{ }^{*}\right.$ and $(\mathrm{LF})_{\mathrm{LL}}{ }^{*}$ are the optimum load factors for dead and live load, and $\mathrm{RF}^{*}$ is the optimum resistance factor] .................................... 134

Figure 6.11 FS as a function of target reliability index and MSE wall height for sliding 135

Figure 6.12 RF for different target reliability indices and different MSE wall heights for overturning 138

Figure 6.13 Optimum factors for $\mathrm{E}_{\mathrm{A} 1}, \mathrm{E}_{\mathrm{A} 2}$ and the overturning resistance versus $\mathrm{MSE}$ wall height (for $\left.\beta_{\mathrm{T}}=2.0\right)\left[(\mathrm{LF})_{\mathrm{DL}}{ }^{*}\right.$ and $(\mathrm{LF})_{\mathrm{LL}}{ }^{*}$ are the optimum load factors for dead and live load, and $\mathrm{RF}^{*}$ is the optimum resistance factor] 139

Figure 6.14 FS as a function of target reliability index and MSE wall height for overturning 140 
Figure 7.1 Loads for pullout and structural failure of the steel-strip reinforcement $\left(\mathrm{F}_{\mathrm{r}, \mathrm{DL}}\right.$ and $F_{r, L L}$ are the lateral loads acting on the reinforcement due to the self-weight of the reinforced soil and due to the live uniform surcharge load on the top of the reinforced soil $\left.\mathrm{q}_{0, \mathrm{rf}}\right)$. 145

Figure 7.2 Location of maximum tensile forces on the reinforcements and distribution of tensile force along the reinforcements 146

Figure 7.3 Location of the maximum tensile force normalized by the height of MSE walls 148

Figure 7.4 Relationship between relative density and relative compaction................... 152

Figure 7.5 Particle size distributions of fine sand and gravelly sand introduced in ASTM D2049-69. 153

Figure 7.6 Variation of $\mathrm{K}_{\mathrm{r}} / \mathrm{K}_{\mathrm{A}}$ for MSE walls with steel-strip reinforcements ( $\phi^{\prime}$ is peak

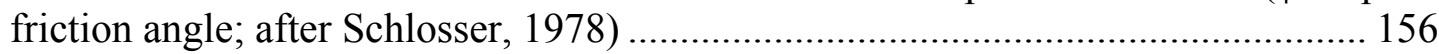

Figure 7.7 Relationship between $\mathrm{K}_{0}$ and $\mathrm{e}_{0}$ of Minnesota sand ................................. 158

Figure 7.8 Coefficient of lateral earth pressure at rest for normally consolidated Toyoura

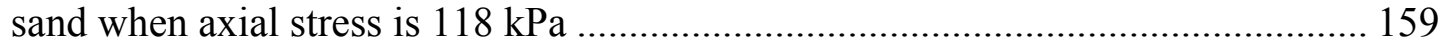

Figure 7.9 Coefficient of lateral earth pressure at rest for normally consolidated Toyoura sand when axial stress is $196 \mathrm{kPa}$................................................................... 159

Figure 7.10 Distribution of $\mathrm{K}_{\mathrm{r}}$ with depth $\mathrm{z}$ from the top of an MSE wall using the modified coherent gravity method ...................................................................... 161

Figure 7.11 Relationship between the measured and predicted maximum tensile forces based on the modified coherent gravity method .............................................. 163

Figure 7.12 Ratio of measured to predicted $\mathrm{T}_{\max }$ with depth from the top of MSE walls

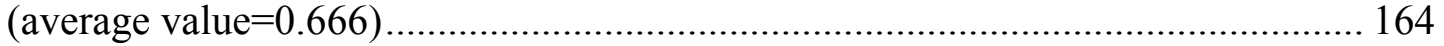

Figure 7.13 Relationship between predicted $T_{\max }$ multiplied by bias factor and measured $\mathrm{T}_{\max }$ based on the modified coherent gravity method ............................................ 165

Figure 7.14 Residuals of $\mathrm{K}_{\mathrm{r}}$ estimation with depth from the top of MSE walls ............. 165

Figure 7.15 Result of the regression analysis of $\mathrm{K}_{\mathrm{r}}$ on $\mathrm{z}$ with $\mathrm{z}_{\mathrm{cr}}=6 \mathrm{~m}$ and $\phi_{\mathrm{c}}=33^{\circ} \ldots \ldots 167$

Figure 7.16 Result of the regression analysis of $\mathrm{K}_{\mathrm{r}}$ on $\mathrm{z}_{\mathrm{cr}}=4.2 \mathrm{~m}, \phi_{\mathrm{c}}=35.7^{\circ}$ and $\mathrm{z} \ldots \ldots .167$

Figure 7.17 Comparison between $C_{R}$ suggested by AASHTO and FHWA specifications and $C_{R}$ data point from pullout tests (Data points from Commentary of the 1994 AASHTO Standard Specifications for Highway Bridges).

Figure 7.18 Distribution of yield strength of steel-strip reinforcements (data acquired from the Reinforced Earth Company) ............................................................... 171

Figure 7.19 RF for pullout of steel-strip reinforcement versus reinforcement depth $\mathrm{z}$ when

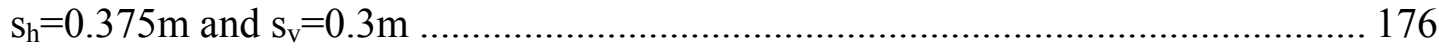

Figure 7.20 RF for pullout of steel-strip reinforcement versus reinforcement depth $\mathrm{z}$ when

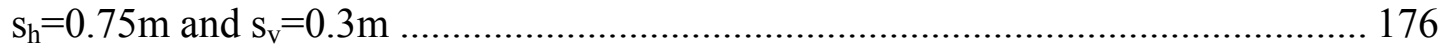

Figure 7.21 RF for pullout of steel-strip reinforcement versus reinforcement depth $\mathrm{z}$ when

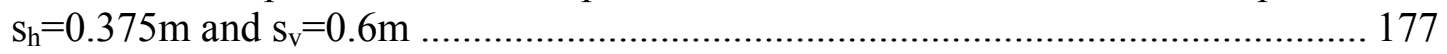

Figure 7.22 RF for pullout of steel-strip reinforcement versus reinforcement depth $\mathrm{z}$ when $\mathrm{s}_{\mathrm{h}}=0.75 \mathrm{~m}$ and $\mathrm{s}_{\mathrm{v}}=0.6 \mathrm{~m}$

Figure 7.23 RF for pullout of steel-strip reinforcement versus reinforcement depth $\mathrm{z}$ when $\mathrm{s}_{\mathrm{h}}=0.375 \mathrm{~m}$ and $\mathrm{s}_{\mathrm{v}}=0.8 \mathrm{~m}$ 
Figure 7.24 RF for pullout of steel-strip reinforcement versus reinforcement depth $\mathrm{z}$ when

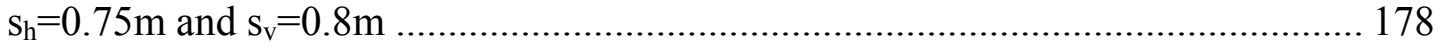

Figure 7.25 Changes of optimum factors (resistance factor, load factors for live load and dead load) with an increasing reinforcement depth from the top of MSE wall $\left(\mathrm{s}_{\mathrm{v}}=0.60 \mathrm{~m}, \mathrm{H}=20 \mathrm{~m}, \beta_{\mathrm{T}}=3.0\right.$, and $\left.\mathrm{q}_{0}=12 \mathrm{kN} / \mathrm{m}\right)\left[(\mathrm{LF})_{\mathrm{DL}}{ }^{*}\right.$ and $(\mathrm{LF})_{\mathrm{LL}}{ }^{*}$ are the optimum load factors for dead and live load, and $\mathrm{RF}^{*}$ is the optimum resistance factor]....... 179

Figure 7.26 Changes of $\mathrm{RF}^{*}$, $(\mathrm{LF})_{\mathrm{DL}}{ }^{*} /(\mathrm{LF})_{\mathrm{DL}}$, and $(\mathrm{LF})_{\mathrm{LL}}{ }^{*} /(\mathrm{LF})_{\mathrm{LL}}$ with increasing reinforcement depth $\mathrm{z}\left(\mathrm{s}_{\mathrm{v}}=0.60 \mathrm{~m}, \mathrm{H}=20 \mathrm{~m}, \beta_{\mathrm{T}}=3.0\right.$, and $\left.\mathrm{q}_{0}=12 \mathrm{kN} / \mathrm{m}\right)\left[(\mathrm{LF})_{\mathrm{DL}}{ }^{*}\right.$ and $(\mathrm{LF})_{\mathrm{LL}}{ }^{*}$ are the optimum load factors for dead and live load, $\mathrm{RF}^{*}$ is the optimum resistance factor, and $(\mathrm{LF})_{\mathrm{DL}}$ and $(\mathrm{LF})_{\mathrm{LL}}$ are the AASHTO load factors]. 181

Figure 7.27 FS for pullout of steel-strip reinforcement versus reinforcement depth $\mathrm{z}$ when

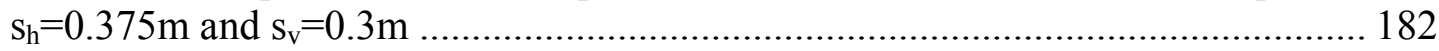

Figure 7.28 FS for pullout of steel-strip reinforcement versus reinforcement depth $\mathrm{z}$ when $\mathrm{s}_{\mathrm{h}}=0.75 \mathrm{~m}$ and $\mathrm{s}_{\mathrm{v}}=0.3 \mathrm{~m}$ 182

Figure 7.29 FS for pullout of steel-strip reinforcement versus reinforcement depth $\mathrm{z}$ when $\mathrm{s}_{\mathrm{h}}=0.375 \mathrm{~m}$ and $\mathrm{s}_{\mathrm{v}}=0.6 \mathrm{~m}$ 183

Figure 7.30 FS for pullout of steel-strip reinforcement versus reinforcement depth $\mathrm{z}$ when $\mathrm{s}_{\mathrm{h}}=0.75 \mathrm{~m}$ and $\mathrm{s}_{\mathrm{v}}=0.6 \mathrm{~m}$

Figure 7.31 FS for pullout of steel-strip reinforcement versus reinforcement depth $\mathrm{z}$ when

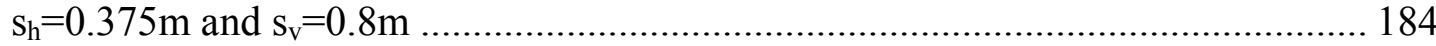

Figure 7.32 FS for pullout of steel-strip reinforcement versus reinforcement depth $\mathrm{z}$ when $\mathrm{s}_{\mathrm{h}}=0.75 \mathrm{~m}$ and $\mathrm{s}_{\mathrm{v}}=0.8 \mathrm{~m}$ 184

Figure 7.33 Reliability index $\beta$ for structural failure of steel-strip reinforcement versus reinforcement depth $\mathrm{z}$ (horizontal reinforcement spacing $\mathrm{s}_{\mathrm{h}}=0.75 \mathrm{~m}$ and vertical reinforcement spacing $\mathrm{s}_{\mathrm{v}}=0.4,0.5,0.6,0.7$, and $0.8 \mathrm{~m}$ ). 186

Figure 8.1 RF for sliding for different MSE wall heights when $\phi_{\mathrm{c}, \mathrm{rt}}$ is equal to $30^{\circ}$ and $33^{\circ}$ ( $\mathrm{q}_{0}$ is the live surcharge load)

Figure 8.2 RF for overturning for different MSE wall heights when $\phi_{\mathrm{c}, \mathrm{rt}}$ is equal to $30^{\circ}$ and $33^{\circ}\left(\mathrm{q}_{0}\right.$ is the live surcharge load)

Figure 8.3 Minimum RF for pullout of steel-strip reinforcement for different values of $\mathrm{D}_{\mathrm{R}, \mathrm{rf}}$ when $\mathrm{s}_{\mathrm{v}}=0.3 \mathrm{~m}$ ( $\mathrm{q}_{0}$ is the live surcharge load) 193

Figure 8.4 Minimum RF for pullout of steel-strip reinforcement for different values of $\mathrm{D}_{\mathrm{R}, \mathrm{rf}}$ when $\mathrm{s}_{\mathrm{v}}=0.6 \mathrm{~m}\left(\mathrm{q}_{0}\right.$ is the live surcharge load).... 194

Figure 8.5 Minimum RF for pullout of steel-strip reinforcement for different values of $\mathrm{D}_{\mathrm{R}, \mathrm{rf}}$ when $\mathrm{s}_{\mathrm{v}}=0.8 \mathrm{~m}\left(\mathrm{q}_{0}\right.$ is the live surcharge load). 194

Figure 8.6 Minimum RF for pullout of steel-strip reinforcement for different values of $\delta_{\mathrm{cv}}$ when $\mathrm{s}_{\mathrm{v}}=0.3 \mathrm{~m}$ ( $\mathrm{q}_{0}$ is the live surcharge load). 195

Figure 8.7 Minimum RF for pullout of steel-strip reinforcement for different values of $\delta_{\mathrm{cv}}$ when $\mathrm{s}_{\mathrm{v}}=0.6 \mathrm{~m}\left(\mathrm{q}_{0}\right.$ is the live surcharge load $)$ 196

Figure 8.8 Minimum RF for pullout of steel-strip reinforcement for different values of $\delta_{\mathrm{cv}}$ when $\mathrm{s}_{\mathrm{v}}=0.8 \mathrm{~m}$ ( $\mathrm{q}_{0}$ is the live surcharge load) 196

Figure 8.9 RF for sliding for different MSE wall heights when $\gamma_{\mathrm{rt}}=18$ and $20 \mathrm{kN} / \mathrm{m}^{3}\left(\mathrm{q}_{0}\right.$ is the live surcharge load) 197 
Figure 8.10 RF for overturning for different MSE wall heights when $\gamma_{\mathrm{rt}}=18$ and

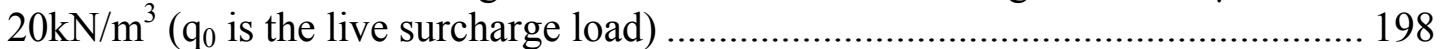

Figure 8.11 RF for sliding for different MSE wall heights when $\gamma_{\mathrm{rf}}=20$ and $22 \mathrm{kN} / \mathrm{m}^{3}\left(\mathrm{q}_{0}\right.$ is the live surcharge load) 199

Figure 8.12 RF for overturning for different MSE wall heights when $\gamma_{\mathrm{rf}}=20$ and 22

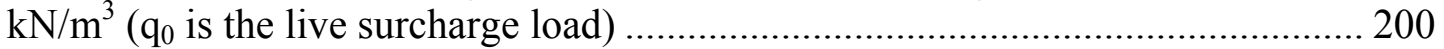

Figure 8.13 Minimum RF for pullout of steel-strip reinforcement for different vertical spacings of reinforcement for $\gamma_{\mathrm{rf}}=20$ and $22 \mathrm{kN} / \mathrm{m}^{3}(\mathrm{H}=5 \mathrm{~m}) \ldots \ldots \ldots \ldots \ldots \ldots \ldots \ldots \ldots . . . . . . . . . . . . . .201$

Figure 8.14 Minimum RF for pullout of steel-strip reinforcement for different vertical spacings of reinforcement for $\gamma_{\mathrm{rf}}=20$ and $22 \mathrm{kN} / \mathrm{m}^{3}(\mathrm{H} \geq 6 \mathrm{~m}) \ldots \ldots \ldots \ldots \ldots \ldots \ldots \ldots \ldots . . . . . . . . . . . . .201$

Figure 8.15 Comparison between the RF values of the worst case scenario (producing the lowest RF value) and those calculated in the examples in chapters 6 for sliding ( $\mathrm{q}_{0}$ is

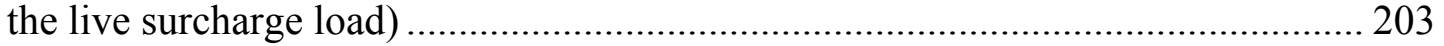

Figure 8.16 Comparison between the RF values of the worst-case scenario (producing the lowest RF value) and those calculated in the examples in chapters 6 for overturning ( $\mathrm{q}_{0}$ is the live surcharge load) 204

Figure 8.17 Comparison between the minimum RF values of the worst-case scenario (producing the lowest RF value) and those calculated in the examples in chapter 7 for

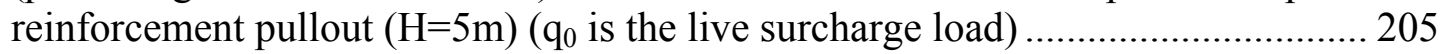

Figure 8.18 Comparison between the minimum RF values of the worst-case scenario (producing the lowest RF value) and those calculated in the examples in chapter 7 for

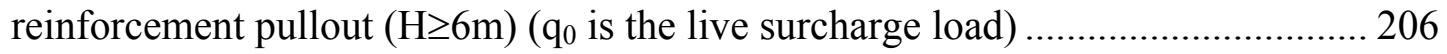

Figure D.1 Plot of $\mathrm{N}_{\sigma}$ value versus number of data.............................................. 245 


\section{LIST OF SYMBOLS}

$\mathrm{A}_{\mathrm{c}} \quad$ Cross-sectional area of steel-strip reinforcement

$\mathrm{A}_{\mathrm{mn}} \quad$ Fourier coefficient

b Width of steel-strip reinforcements or slices of slopes

$\mathrm{B}_{\mathrm{mn}} \quad$ Fourier coefficient

BSM Bishop simplified method

BST Borehole shear test

c Apparent cohesion

COV Coefficient of variation

Cov Covariance

$\mathrm{C}_{\mathrm{R}} \quad$ Pullout resistance factor

$\mathrm{D}_{10} \quad$ Diameter corresponding to weight-percent of soil finer than $10 \%$

$\mathrm{D}_{50} \quad$ Diameter corresponding to weight-percent of soil finer than $50 \%$

$\mathrm{D}_{60} \quad$ Diameter corresponding to weight-percent of soil finer than $60 \%$

$\mathrm{D}_{\mathrm{R}} \quad$ Relative density

DST Direct shear test

$\mathrm{E}_{\mathrm{A} 1} \quad$ Lateral forces due to the active earth pressures by the self-weight of the retained soil $\begin{array}{ll}\mathrm{E}_{\mathrm{A} 2} & \text { Lateral forces due to the active earth pressures by live uniform surcharge } \\ \text { load }\end{array}$ 


\begin{tabular}{|c|c|}
\hline $\mathrm{e}$ & Measurement error \\
\hline $\mathrm{e}_{\max }$ & Maximum void ratio \\
\hline $\mathrm{e}_{\min }$ & Minimum void ratio \\
\hline FORM & First-Order Reliability Method \\
\hline FS & Factor of safety \\
\hline $\mathrm{f}_{\mathrm{y}}$ & Yield strength of steel-strip reinforcement \\
\hline $\mathrm{F}_{\mathrm{r}, \mathrm{DL}}$ & $\begin{array}{l}\text { Lateral load acting on the reinforcement due to self-weight of reinforced } \\
\text { soil }\end{array}$ \\
\hline $\mathrm{F}_{\mathrm{r}, \mathrm{LL}}$ & $\begin{array}{l}\text { Lateral load acting on the reinforcement due to live uniform surcharge } \\
\text { load on the top of reinforced soil }\end{array}$ \\
\hline $\mathrm{G}$ & Margin of safety \\
\hline $\mathrm{G}(\mathbf{)}$ & Spectral density function \\
\hline $\mathrm{G}_{\mathrm{s}}$ & Specific gravity of soil \\
\hline $\mathrm{H}$ & Height of an MSE wall \\
\hline $\mathrm{h}_{\mathrm{eq}}$ & Equivalent height of soil for vehicular loading \\
\hline $\mathrm{K}_{1}$ & Finite number of discretization in $\mathrm{x}$ uni-direction \\
\hline $\mathrm{K}_{2}$ & Finite number of discretization in y uni-direction \\
\hline $\mathrm{K}_{\mathrm{A}}$ & Active earth pressure coefficient \\
\hline $\mathrm{K}_{\mathrm{r}}$ & Coefficient of lateral earth pressure \\
\hline $\mathrm{L}$ & Total length of steel-strip reinforcement \\
\hline $\mathrm{L}_{1}$ & Length of Gaussian random field in horizontal direction \\
\hline $\mathrm{L}_{2}$ & Length of Gaussian random field in vertical direction \\
\hline $\mathrm{L}_{\mathrm{a}}$ & Steel-strip reinforcement length inside active zone in reinforced soil \\
\hline
\end{tabular}


$\mathrm{L}_{\mathrm{e}} \quad$ Effective length of steel-strip reinforcement

LF Load factor

$(\mathrm{LF})^{*} \quad$ Optimum load factor

$\mathrm{M}_{\mathrm{d}} \quad$ Driving moment inducing instability of slopes

$\mathrm{M}_{\mathrm{r}} \quad$ Resisting moment against slope failure

$\mathrm{m}_{\alpha, \mathrm{i}} \quad$ Term used in Bishop simplified method

$\mathrm{N} \quad$ Normal force on slice base of slopes

$\mathrm{p}($ ) Probability density function

P Probability of failure

$\mathrm{P}_{\mathrm{f}} \quad$ Target probability of failure

PS Plane strain

q Uniform surcharge load

$\mathrm{q}_{0} \quad$ Nominal uniform live surcharge load

Q Nominal load

Q $\quad$ Allowable load

Q $\quad$ Design load

QLS Load at ultimate limit state

Qult Load at ultimate limit state

$\mathrm{r}_{\text {slip }} \quad$ Radius of circular slip surface

R Resistance

$\mathrm{R}_{\mathrm{PO}} \quad$ Pullout resistance of the steel-strip reinforcement 


\begin{tabular}{|c|c|}
\hline RF & Resistance factor \\
\hline$(\mathrm{RF})^{*}$ & Optimum resistance factor \\
\hline $\mathrm{R}_{\mathrm{LS}}$ & Resistance at ultimate limit state \\
\hline $\mathrm{R}_{\mathrm{n}}$ & Nominal resistance \\
\hline $\mathrm{s}$ & Separation distance \\
\hline$S_{f}$ & Scale of fluctuation \\
\hline $\mathrm{S}_{\mathrm{f}, \text { iso }}$ & Isotropic scale of fluctuation \\
\hline $\mathrm{s}_{\mathrm{f}, \mathrm{x}}$ & Scale of fluctuation in the horizontal direction \\
\hline $\mathrm{s}_{\mathrm{f}, \mathrm{y}}$ & Scale of fluctuation in the vertical direction \\
\hline $\mathrm{S}_{\mathrm{h}}$ & Horizontal spacing of steel-strip reinforcement \\
\hline $\mathrm{S}_{\mathrm{V}}$ & Vertical spacing of steel-strip reinforcement \\
\hline $\mathrm{S}_{\mathrm{u}}$ & Undrained shear strength \\
\hline $\mathrm{T}$ & Tangential force on slice base \\
\hline $\mathrm{T}_{\max }$ & Maximum tensile force on steel-strip reinforcement \\
\hline $\mathrm{U}$ & Water force on slice base \\
\hline VST & Vane shear test \\
\hline $\mathrm{W}$ & Weight of soil (slice) \\
\hline WSD & Working Stress Design \\
\hline $\mathrm{X}$ & Horizontal component of inter-slice forces of a slice \\
\hline $\mathrm{Y}$ & Vertical component of inter-slice forces of a slice \\
\hline Z & Standard normal random variable \\
\hline
\end{tabular}


$\mathrm{z}_{\mathrm{cr}} \quad$ Depth from the top of an MSE wall where active condition prevails

$\mathrm{z}_{\mathrm{m}} \quad$ Measurement of soil property

$\mathrm{Z}_{\mathrm{spat}} \quad$ Soil property value reflecting spatial variability

$\Phi($ ) Standard normal cumulative distribution function

$\alpha \quad$ Inclination angle to the horizontal plane of slice base

$\alpha_{\delta_{p}} \quad$ Bias factor of interface friction angle between backfill material in reinforced soil and steel-strip reinforcement

$\alpha_{1} \quad$ Major principal stress direction angle

$\beta \quad$ Reliability index

$\beta_{\mathrm{T}} \quad$ Target reliability index

$\delta_{\mathrm{cv}} \quad$ Critical-state interface friction angle

$\delta_{\mathrm{p}} \quad$ Interface friction angle between backfill material in reinforced soil and steel-strip reinforcement

$\delta^{*} \quad$ Interface friction angle at the bottom of an MSE wall

$\delta_{\mathrm{p}}^{*} \quad$ Peak interface friction angle at the bottom of an MSE wall

$\delta_{\mathrm{r}}^{*} \quad$ Critical-state interface friction angle at the bottom of an MSE wall

$\phi \quad$ Friction angle

$\phi_{\mathrm{c}} \quad$ Critical-state friction angle

$\phi_{\mathrm{p}} \quad$ Peak friction angle

$\gamma \quad$ Shear strain (or unit weight of soil)

$\gamma_{d} \quad$ Dry unit weight of soil

$\gamma_{\mathrm{dmax}} \quad$ Maximum dry unit weight of soil

$\gamma_{\mathrm{dmin}} \quad$ Minimum dry unit weight of soil 


\begin{tabular}{|c|c|}
\hline$\eta_{\delta_{\mathrm{p}}}$ & $\begin{array}{l}\text { Distributor parameter for interface friction angle between backfill material } \\
\text { in reinforced soil and steel-strip reinforcement }\end{array}$ \\
\hline$\lambda$ & Mean of the lognormal distribution \\
\hline$\lambda_{\mathrm{p}}$ & Load factors for different type of permanent loads \\
\hline$\mu$ & Mean \\
\hline$\mu_{\text {bias }}$ & Mean accounting bias due to measurement procedure \\
\hline$\mu_{\mathrm{G}}$ & Mean of margin of safety \\
\hline$\mu_{\text {meas }}$ & Mean accounting measurement error \\
\hline$\mu_{\mathrm{R}}$ & Mean of resistance \\
\hline$\mu_{\text {real }}$ & Mean of real in-situ values \\
\hline$\mu_{\mathrm{Q}}$ & Mean of load \\
\hline$\mu_{\text {stat }}$ & Mean accounting statistical error \\
\hline$\rho()$ & Correlation coefficient function \\
\hline$\sigma_{\mathrm{G}}$ & Standard deviation of margin of safety \\
\hline$\sigma$ & Standard deviation \\
\hline$\sigma_{1}$ & Major principal stress \\
\hline$\sigma_{3}$ & Minor principal stress \\
\hline$\sigma_{\mathrm{a}}$ & Constant vertical stress \\
\hline$\sigma_{\mathrm{R}}$ & Standard deviation of resistance \\
\hline$\sigma_{\mathrm{Q}}$ & Standard deviation of load \\
\hline$\sigma_{\mathrm{v}}$ & Vertical stress \\
\hline$\sigma_{h}^{\prime}$ & Horizontal effective stress \\
\hline
\end{tabular}




$\begin{array}{ll}\sigma^{\prime}{ }_{\mathrm{v}} & \text { Vertical effective stress } \\ \tau & \text { Shear stress } \\ \tau_{\mathrm{r}} & \text { Residual shear stress } \\ \omega_{\mathrm{x}} & \text { Angular frequency for } \mathrm{x} \text { direction } \\ \omega_{\mathrm{y}} & \text { Angular frequency for } \mathrm{y} \text { direction } \\ \zeta & \text { Standard deviation of the lognormal distribution }\end{array}$


PART I - INTRODUCTORY CONCEPTS 


\section{CHAPTER 1. INTRODUCTION}

\subsection{Introduction}

The primary goal of this report was to develop Load and Resistance Factor Design (LRFD) methods for slope and retaining structure design. Even though there is past research on LRFD of shallow foundations and piles, there are few publications available on LRFD of slopes and retaining structures (notable among these being Chen, 1999; Chen, 2000; Simpson, 1992; Loehr et al, 2005). The design goals for slopes and retaining structures are the economical selection of the slope angle and slope protection measures (in the case of slopes) and the type and appropriate dimensions (in the case of retaining walls) in order to avoid "failure."

The design of slopes and retaining structures has traditionally been conducted using the Working Stress Design (WSD) approach. Even in recent years, it remains the primary design approach in geotechnical engineering. Within this framework, every design problem becomes one of comparing a capacity or resistance with a loading. To account for the uncertainties, a single factor of safety is used to divide the capacity (or, from the opposite point of view, to multiply the loading) before the comparison is made. The factor of safety is the tool that the WSD approach uses to account for uncertainties. The uncertainties are expressed in a single number, the factor of safety, so there is no way in WSD to separate the uncertainties related to load estimation, for example, from those related to soil variability.

The LRFD method combines the Limit States Design (LSD) concept with the

probabilistic approach that accounts for the uncertainty of parameters that are related to both the loads and the resistance. There are two types of limit states (Salgado 2008): (1) Ultimate Limit States (ULS) and (2) Serviceability Limit States (SLS). An ULS is related to lack of safety of structures, such as structural failure or collapse, and serviceability 
limit state is associated with malfunctioning of structures, such as excessive uniform or differential settlement of structures. In this report, only ULSs are considered.

An ULS is a state for which the total load is equal to the maximum resistance of the system. When the total load matches the maximum resistance of the system, the system fails. To prevent failure of the system, LSD requires the engineer to identify every possible ULS during design in order to make sure that it is not reached. However, in the case of LRFD, which combines the probabilistic approach with LSD, the probability of failure of the system is calculated from the probability density distributions of the total load and the maximum resistance. Probability of failure for a given ULS is the probability of attainment of that ULS. LRFD aims to keep this probability of failure from exceeding a certain level (the target probability of failure or target reliability index). Finally, LRFD is explained using an LSD framework, which checks for the ULS using partial factors on loads and on resistance. These partial factors associated with the loads and the resistance are calculated based on their uncertainties.

\subsection{Problem Statement}

There are issues that geotechnical engineers face when using LRFD in geotechnical designs. Some of the main issues are:

1) As opposed to concrete or steel, which are manufactured materials and thus have properties that assume values within a relatively narrow spread, soils are materials deposited in nature in ways that lead them to have properties that show striking spatial variability. In addition, soil exhibits anisotropic properties. The result of this is that soil properties assume values that are widely dispersed around an average; therefore, the assessment of the uncertainties of soil parameters is very important for economical design.

2) It is usually true in structural design, and to a large extent in foundation design, that load and resistance effects are reasonably independent; this is not true for 
slopes and retaining structures, for which soil weight is both a significant source of the loading and a significant source of the resistance to sliding. This has created problems for engineers attempting to design such structures using LRFD, leading to doubts about the approach.

3) Because of the wide variability in the shear strength of soils, the loosely defined values of resistance factors in the codes and the lack of familiarity by engineers with the LRFD approach, engineers have often been conservative when using the LRFD approach in design (Becker, 1996). In this report, the equations for loads and resistance reflect well established concepts, and the process of calculating load factors and resistance factor is well explained for easy understanding.

4) Different organizations in Europe, Canada, and the U.S. have proposed different types of ULS factored design. In Europe it is customary to factor soil shear strength (that is, $\mathrm{c}$ and $\phi$ ) directly (Eurocode 7, 1994), while in North America the codes and recommendations (e.g., AASHTO, 2007) propose to factor the final soil resistance or shear strength (which creates certain difficulties). The load factors vary widely across codes; in the U.S., for example, the load factors recommended in the American Association of State Highway and Transportation (AASHTO) LRFD bridge design specifications (2007) are not the same as those recommended in the ACI reinforced concrete code. The resistance factors have typically been defined through rough calibrations with the WSD approach. This myriad of methods, recommendations, and values has led to considerable confusion and has not made it easier for the practicing engineer to use the approach. We intend to clarify such issues.

The LRFD approach in the case of slopes and retaining structures poses a different but interesting challenge to geotechnical engineers. Unlike structural or conventional geotechnical designs, both the load and resistance contain soil parameters 
(Goble 1999). The weight of the soil is a source of both the demand (load) and the capacity (resistance) in the case of slopes and retaining structures. This makes the problem complicated since the load and resistance factors have to be extracted from the same parameters.

The calculation of loads in the case of foundation problems is straightforward. However, in the case of retaining structures, the loads come partly from dead load (earth pressures due to self-weight of soil) and partly from live load (e.g., vehicular load on the top of the retaining structures). It is important to determine which factors must be used for each load source when calculating the factored load. This situation greatly magnifies the advantage of LRFD over WSD. In WSD, a single factor (factor of safety) would be used to account for the uncertainties, possibly leading to unnecessarily conservative designs.

The interest in LRFD comes, ultimately, from the expectation that LRFD designs are more economical than WSD designs for the same level of safety (in terms of probability of failure of the structures). This economy would be a consequence of a number of possibilities offered by the LRFD approach, but not by WSD, namely:

(1) To account for load uncertainties and resistance uncertainties separately, and consequently, more realistically;

(2) To more precisely define a characteristic shear strength or characteristic soil resistance;

(3) To allow separate consideration of permanent versus temporary or accidental loads;

(4) To design following the same general approach followed by structural engineers, eliminating the design interface currently in place and encouraging better interaction between the geotechnical and the structural engineers;

(5) To allow future improvements in the design of geotechnical structures;

(6) To allow each type of analysis or design method to have its own resistance factors. 


\subsection{Objectives}

In order to realize the potential benefits (1) through (6) outlines in the previous section of the LRFD approach, a credible set of load and resistance factors and a compatible way of defining characteristic soil resistance that can be consistently used by geotechnical engineers needs to be determined. This system must be based on more than rough calibrations of LRFD with WSD, which is the basic procedure followed in the current AASHTO LRFD bridge design specifications (2007). Load and resistance factors must also be based on scientifically defensible methods. They must be based on analysis that considers the underlying probabilistic nature of loads and resistances, on a reasonable proposal of how to define characteristic shear strength and characteristic soil resistance, and on the models and analyses that will be used to analyze the various slope and retaining structure design problems.

This study focuses on the general analysis and design methods of both slopes and MSE walls and provides examples of them. In order to accomplish these tasks, a number of intermediate objectives need to be achieved:

(1) Determination of load factors from AASHTO LRFD specifications (2007) for permanent and temporary loads of different types and under various combinations;

(2) Determination of the best equation for each ULS to be checked;

(3) Development of recommendations on how to assess the uncertainty of soil parameters;

(4) Development of resistance factors compatible with the load factors. 


\section{CHAPTER 2. LOAD AND RESISTANCE FACTOR DESIGN}

\subsection{Load and Resistance Factor Design Compared with Working Stress Design}

As mentioned in the previous chapter, the concept of Working Stress Design (WSD) has been commonly used in geotechnical analyses and designs for many decades. Appropriate values of Factor of Safety (FS) were suggested for most of the geotechnical structures, such as shallow foundations, piles, slopes, embankments, and retaining structures, and those values have been determined based on accumulated experience from case histories and failure data. However, using a single FS in design is not the best choice in the sense that the method does not consider the uncertainty of the loads applied on the structure and the resistance of the structure separately. In Figure 2.1, due to higher uncertainties of both the load and the resistance, the probability of failure of case (a) is much higher than that of case (b) although the values of FS in both cases are the same. 


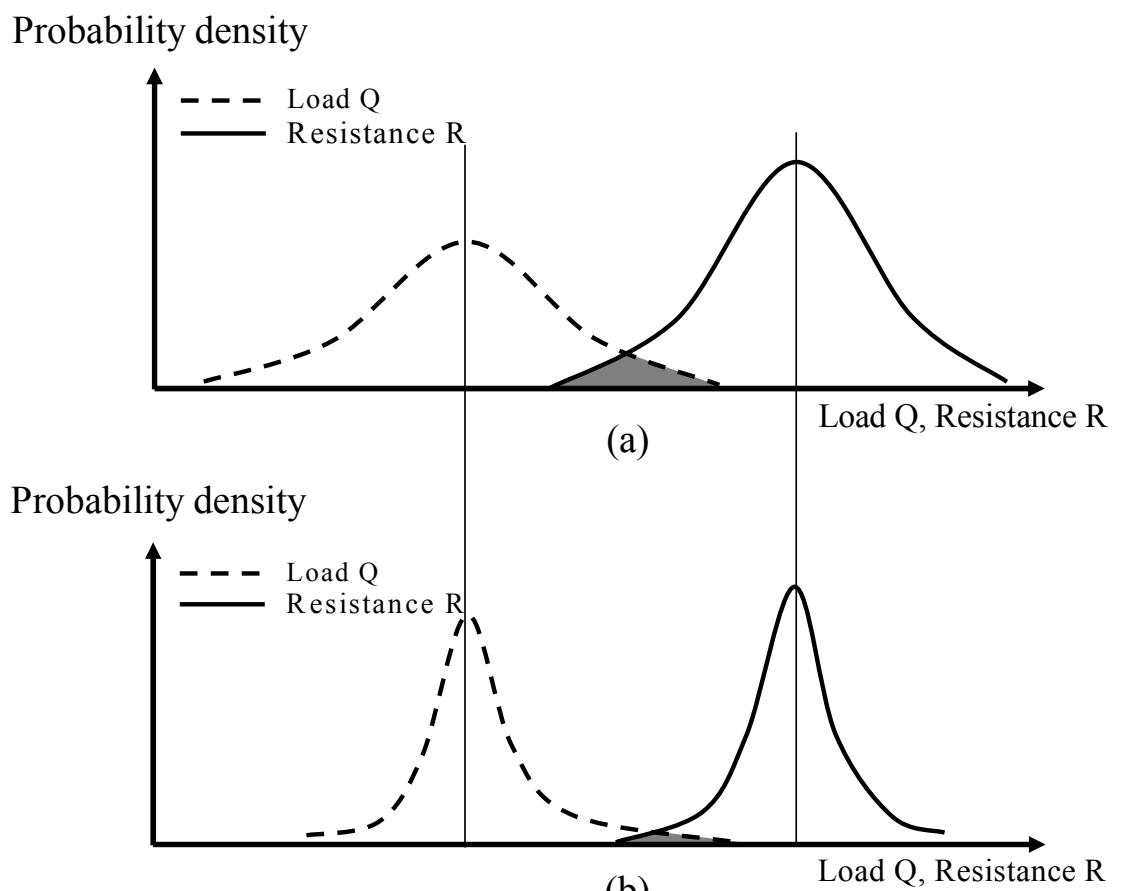

(b)

Figure 2.1 Distribution of total load $\mathrm{Q}$ and resistance $\mathrm{R}$ when two different cases have the same value of FS: (a) high load and resistance uncertainty and (b) low load and resistance uncertainty

LRFD is a more sophisticated design method that considers the uncertainties of load and resistance separately. LRFD in structural engineering has been successfully adopted in practice. The design method has reduced costs for many types of steel and concrete structures. The recent interest in the implementation of LRFD in geotechnical engineering is due to the possibilities that it offers for a more rational and economical design of foundations and geotechnical structures.

The FS is defined as the ratio of the ultimate resistance of an element to the total load applied to the element. WSD imposes an extra margin of safety to the structure so that it can withstand more load than the design (nominal) load. In WSD, the design load is equal to or less than the allowable load, which is the load at ultimate limit state (ULS) divided by FS: 


$$
\mathrm{Q}_{\mathrm{d}} \leq \mathrm{Q}_{\mathrm{a}}=\frac{\mathrm{Q}_{\mathrm{ult}}}{\mathrm{FS}}
$$

where $\mathrm{Q}_{\mathrm{d}}$ is the design load, $\mathrm{Q}_{\mathrm{a}}$ is the allowable load, and $\mathrm{Qult}_{\mathrm{u}}$ is the load at ULS.

As mentioned in the previous chapter, LRFD is based on the limit state design framework, which compares the factored resistance to the sum of the factored loads. The factors that are multiplied to the resistance and loads are determined based on the results of reliability analyses and load factors (LFs) from design specifications, such as AASHTO (2007), AISC (2005), and others. The method to determine these factors is explained in the next section. According to LRFD, the following criterion needs to be satisfied:

$$
(\mathrm{RF}) \mathrm{R}_{\mathrm{n}} \geq \sum(\mathrm{LF})_{\mathrm{i}} \mathrm{Q}_{\mathrm{i}}
$$

where $R F$ is the resistance factor, $R_{n}$ is the nominal resistance, $(L F)_{i}$ are the load factors that have different values for different types of loads and their combinations, and $\mathrm{Q}_{i}$ are the loads of various types, such as dead load, live load, earthquake load, and other loading types.

\subsection{Calculation of Resistance Factor RF}

Calculation of the Resistance Factor (RF) in the inequality (2.2) is our final goal in this study. The process of determining RF starts from the ULS equation. The ULS is

defined as the state at which the value of the total load is equal to that of the resistance:

$$
\mathrm{R}_{\mathrm{LS}}=\sum \mathrm{Q}_{\mathrm{i}, \mathrm{LS}}
$$


We can rewrite Eq. (2.3) as

$$
\left(\frac{\mathrm{R}_{\mathrm{LS}}}{\mathrm{R}_{\mathrm{n}}}\right) \mathrm{R}_{\mathrm{n}}=\sum\left(\frac{\mathrm{Q}_{\mathrm{i}, \mathrm{LS}}}{\mathrm{Q}_{\mathrm{i}}}\right) \mathrm{Q}_{\mathrm{i}}
$$

We can define the optimum resistance factor $(\mathrm{RF})^{*}$ and the optimum load factors $(\mathrm{LF})_{\mathrm{i}}^{*}$ as:

$$
\begin{aligned}
& (\mathrm{RF})^{*}=\frac{\mathrm{R}_{\mathrm{LS}}}{\mathrm{R}_{\mathrm{n}}} \\
& (\mathrm{LF})_{\mathrm{i}}^{*}=\frac{\mathrm{Q}_{\mathrm{i}, \mathrm{LS}}}{\mathrm{Q}_{\mathrm{i}}}
\end{aligned}
$$

$(\mathrm{RF})^{*}$ and $(\mathrm{LF})_{\mathrm{i}}{ }^{*}$ can be considered as the ideal resistance factor and load factors that optimally satisfy inequality (2.2), but these optimum factors are problem-specific (i.e., their values vary with input loads, geometry, and material parameters). For practical purposes, design specifications provide fixed sets of load factors. Further modification of Eq. (2.4) is necessary for calculating an RF value corresponding to predefined (virtually always not optimal) load factors (LF) .

Inequality (2.2) can be written as a design requirement as

$$
(\mathrm{RF})^{*} \mathrm{R}_{\mathrm{n}} \geq \sum(\mathrm{LF})_{\mathrm{i}}^{*} \mathrm{Q}_{\mathrm{i}}
$$

and modified using a code-specified $(\mathrm{LF})_{\mathrm{i}}$ :

$$
(\mathrm{RF})^{*} \mathrm{R}_{\mathrm{n}} \geq \sum(\mathrm{LF})_{\mathrm{i}}\left(\frac{(\mathrm{LF})_{\mathrm{i}}^{*}}{(\mathrm{LF})_{\mathrm{i}}}\right) \mathrm{Q}_{\mathrm{i}}
$$




$$
\begin{aligned}
& \text { Because max }\left(\frac{(\mathrm{LF})_{\mathrm{i}}^{*}}{(\mathrm{LF})_{\mathrm{i}}}\right) \sum(\mathrm{LF})_{\mathrm{i}} \mathrm{Q}_{\mathrm{i}} \geq \sum(\mathrm{LF})_{\mathrm{i}}\left(\frac{(\mathrm{LF})_{\mathrm{i}}^{*}}{(\mathrm{LF})_{\mathrm{i}}}\right) \mathrm{Q}_{\mathrm{i}} \text {, the inequality } \\
& (\mathrm{RF})^{*} \mathrm{R}_{\mathrm{n}} \geq\left(\text { maximum over all values of } \frac{(\mathrm{LF})_{\mathrm{i}}^{*}}{(\mathrm{LF})_{\mathrm{i}}}\right) \sum(\mathrm{LF})_{\mathrm{i}} \mathrm{Q}_{\mathrm{i}}
\end{aligned}
$$

implies Inequality (2.8). Inequality (2.9) can be modified as follows:

$$
\min \left(\frac{(\mathrm{LF})_{\mathrm{i}}}{(\mathrm{LF})_{\mathrm{i}}^{*}}\right)(\mathrm{RF})^{*} \mathrm{R}_{\mathrm{n}} \geq \sum(\mathrm{LF})_{\mathrm{i}} \mathrm{Q}_{\mathrm{i}}
$$

Since the minimum value of $(\mathrm{LF})_{\mathrm{i}} /(\mathrm{LF})_{\mathrm{i}}{ }^{*} \mathrm{~S}$ is the same as the inverse value of the maximum value among $(\mathrm{LF})_{\mathrm{i}}{ }^{*} /(\mathrm{LF})_{\mathrm{i}}$, by comparing Inequality (2.2) and Inequality (2.10), a new RF can be defined as

$$
\mathrm{RF}=\min \left(\frac{(\mathrm{LF})_{\mathrm{i}}}{(\mathrm{LF})_{\mathrm{i}}^{*}}\right)(\mathrm{RF})^{*}
$$

The RF value determined by this procedure produces slightly conservative results, but it enables us to use the load factors from design specifications without violating the design criterion (Inequality (2.2)).

\subsection{AASHTO Load Factors for LRFD}

The AASHTO LRFD bridge design specifications (2007) provide load factor values for different types of loads and their combinations. These are listed in Table 2.1. The notations in Table 2.1 are explained in Appendix A. Strength $I$ is defined as the basic load combination for general vehicular uses of the bridge without wind consideration. 
Table 2.1 AASHTO load factors and its combinations with different limit states (AASHTO, 2007)

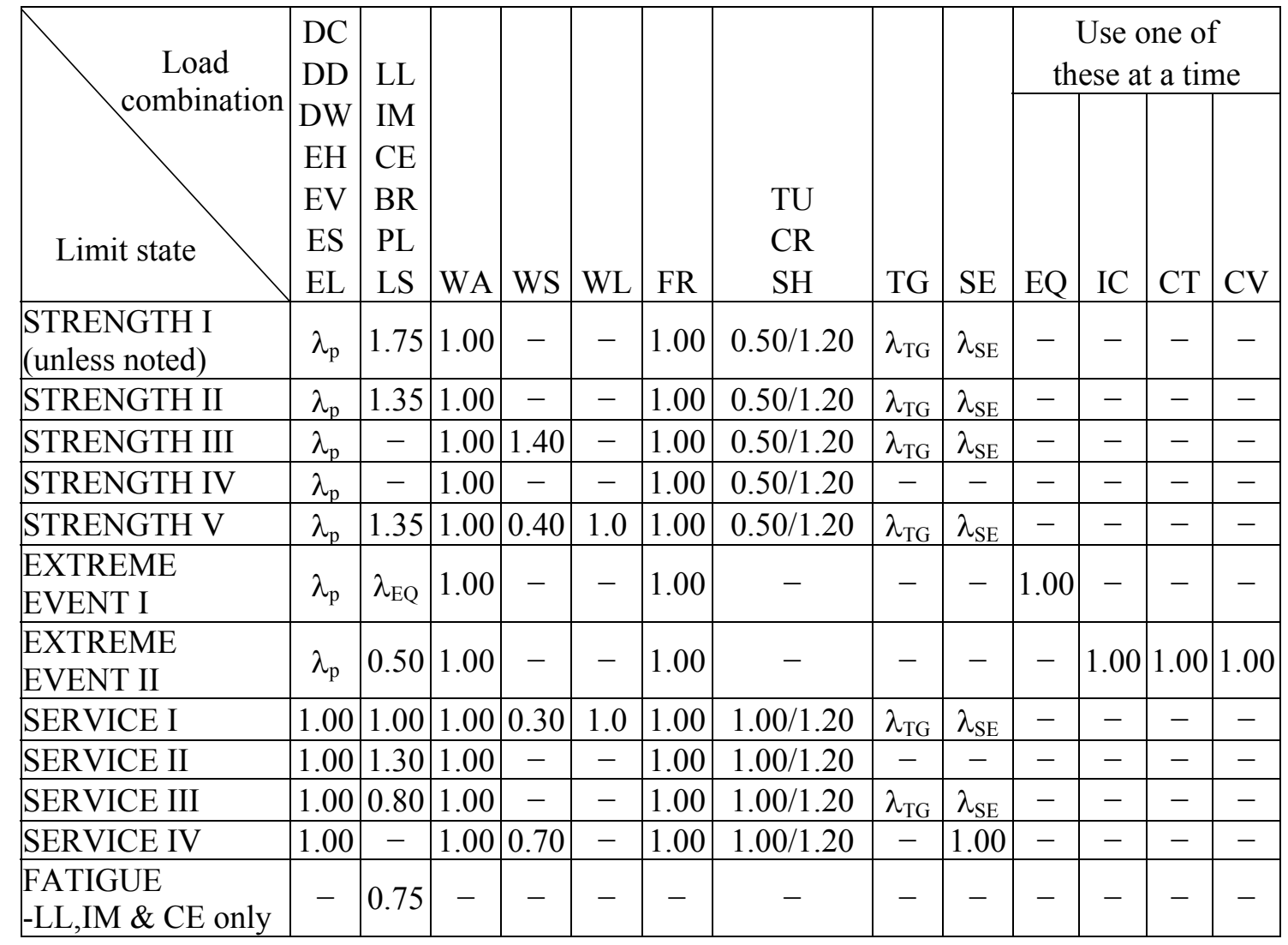

( $\lambda_{\mathrm{p}}$ : load factors for different types of permanent loads, DC: dead load of structural components and nonstructural attachment, EH: horizontal earth pressure load, EV: vertical pressure from dead load of earth fill, ES: earth surcharge load, LL: vehicular live load, LS: live load surcharge.)

In Table 2.2, the load factors $\left(\lambda_{\mathrm{p}}\right)$ for permanent loads in Table 2.1 are given as a range (AASHTO LRFD specifications propose minimum and maximum values of load factors). 
Table 2.2 Load factors $\lambda_{\mathrm{p}}$ for different types of permanent loads (AASHTO, 2007)

\begin{tabular}{|c|c|c|c|}
\hline \multirow{2}{*}{\multicolumn{2}{|c|}{$\begin{array}{l}\text { Type of load, foundation type, and } \\
\text { method used to calculate downdrag }\end{array}$}} & \multicolumn{2}{|c|}{ Load Factor } \\
\hline & & Maximum & Minimum \\
\hline \multirow{2}{*}{\multicolumn{2}{|c|}{$\begin{array}{l}\text { DC: Component and attachments } \\
\text { DC: Strength IV only }\end{array}$}} & 1.25 & 0.90 \\
\hline & & 1.50 & 0.90 \\
\hline \multirow{3}{*}{ DD: Downdrag } & Piles, $\alpha$ Tomlinson method & 1.40 & 0.25 \\
\hline & Piles, $\lambda$ method & 1.05 & 0.30 \\
\hline & Drilled shafts, O'Neill and Reese (1999) method & 1.25 & 0.35 \\
\hline \multicolumn{2}{|c|}{ DW: Wearing Surfaces and Utilities } & 1.50 & 0.65 \\
\hline \multicolumn{2}{|c|}{ EH: Horizontal earth pressure } & & \\
\hline \multicolumn{2}{|c|}{ - Active } & 1.50 & 0.90 \\
\hline \multicolumn{2}{|l|}{ - At-rest } & 1.35 & 0.90 \\
\hline \multicolumn{2}{|c|}{ EL: Locked-in erection stresses } & 1.00 & 1.00 \\
\hline \multicolumn{2}{|c|}{ EV: Vertical earth pressure } & & \\
\hline \multicolumn{2}{|c|}{ • Overall Stability } & 1.00 & N/A \\
\hline \multicolumn{2}{|c|}{ - Retaining walls and abutments } & 1.35 & 1.00 \\
\hline \multicolumn{2}{|c|}{ - Rigid buried structure } & 1.30 & 0.90 \\
\hline \multicolumn{2}{|c|}{ • Rigid frames } & 1.35 & 0.90 \\
\hline \multicolumn{2}{|c|}{ - Flexible buried structures other than metal box culverts } & 1.95 & 0.90 \\
\hline \multicolumn{2}{|c|}{ • Flexible metal box culverts } & 1.50 & 0.90 \\
\hline \multicolumn{2}{|c|}{ ES: Earth surcharge } & 1.50 & 0.75 \\
\hline
\end{tabular}

From the LF range given in Table 2.2, the load factors are determined in such a way that a combination of factored loads (loads multiplied by their LFs) lead to the worst-case scenario in terms of the stability of the structural system. By assuming that the system is exposed to the worst-case scenario (maximizing the loads that decrease the stability to the system and minimizing the loads that increase its stability), the design using the single RF values proposed in design specifications can be very conservative for structures that are exposed to small loads.

\subsection{Target Probability of Failure $\mathrm{P}_{f}$ and Target Reliability Index $\beta_{\mathrm{T}}$}

LRFD can be developed using reliability theory with either a consistent probability of failure or a consistent target reliability index $\beta$. These target values vary according to 
how important the structure is and how serious the consequences will be after the potential failure of the structure. A one-to-one relationship exists between the target probability of failure and the target reliability index if the distributions of the total load Q and resistance $\mathrm{R}$ follow a normal distribution or can be converted to an equivalent normal distribution. By defining margin of safety $G$ as

$$
\mathrm{G}=\mathrm{R}-\mathrm{Q}
$$

Then the mean $\mu_{\mathrm{G}}$ of $\mathrm{G}$ is

$$
\mu_{\mathrm{G}}=\mu_{\mathrm{R}}-\mu_{\mathrm{Q}}
$$

where $\mu_{\mathrm{R}}$ and $\mu_{\mathrm{Q}}$ are the means of $\mathrm{R}$ and $\mathrm{Q}$, respectively.

If $\mathrm{R}$ and $\mathrm{Q}$ are uncorrelated, the standard deviation $\sigma_{\mathrm{G}}$ of $\mathrm{G}$ is

$$
\sigma_{\mathrm{G}}=\sqrt{\sigma_{\mathrm{R}}^{2}+\sigma_{\mathrm{Q}}^{2}}
$$

where $\sigma_{\mathrm{R}}$ and $\sigma_{\mathrm{Q}}$ are the standard deviations of R and $\mathrm{Q}$, respectively.

The distribution of margin of safety $\mathrm{G}$ follows a normal distribution when $\mathrm{R}$ and Q are normally distributed and uncorrelated. Figure 2.2 shows the distribution of margin of safety $\mathrm{G}$. The probability of failure for the distribution of $\mathrm{G}$ is equal to the shaded area in Figure 2.2. The horizontal distance between the mean $\mu_{\mathrm{G}}$ of $\mathrm{G}$ and the $\mathrm{y}$-axis can be represented as a multiple $\beta$ of the standard deviation $\sigma_{G}$ of $G$. This number $\beta$ is known as the reliability index. 


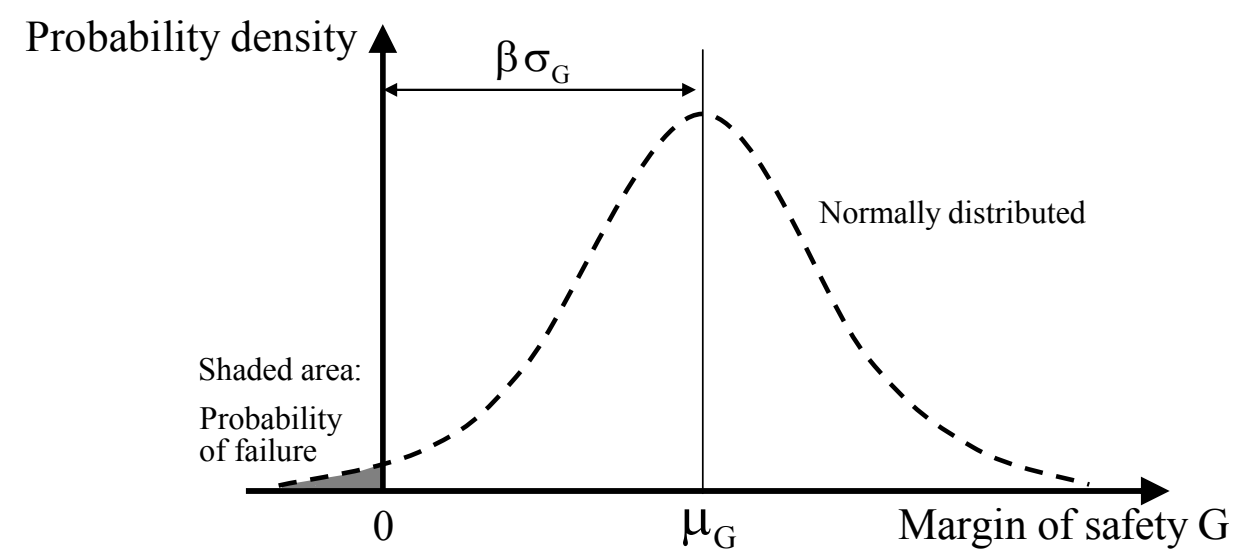

Figure 2.2 Normal distribution of margin of safety $G\left(\mu_{\mathrm{G}}\right.$ and $\sigma_{\mathrm{G}}$ are the mean and standard deviation of margin of safety $\mathrm{G}$, and $\beta$ is reliability index)

The normal distribution of the margin of safety $G$ can be converted into the standard normal distribution that has zero mean and unit standard deviation. A random variable that follows the standard normal distribution is named a standard normal random variable $\mathrm{Z}$ and is represented as

$$
\mathrm{Z}=\frac{\mathrm{G}-\mu_{\mathrm{G}}}{\sigma_{\mathrm{G}}}
$$

where $\mathrm{G}$ is normally distributed.

The cumulative distribution function $\Phi(Z)$ for a standard normal random variable $\mathrm{Z}$ denotes the area under a probability density function from $-\infty$ to $\mathrm{Z}$. Therefore, the probability of failure in Figure 2.2 can be calculated as

$$
\text { Probability of failure }=\Phi\left(\frac{0-\mu_{\mathrm{G}}}{\sigma_{\mathrm{G}}}\right)=\Phi(-\beta)
$$

where $\Phi()$ is the standard normal cumulative distribution function. 
Eq. (2.16) is the mathematical expression of the one-to-one relationship between the target probability of failure and the target reliability index when $\mathrm{Q}$ and $\mathrm{R}$ are uncorrelated and normally distributed. If the distribution of total load and resistance are unpredictable or indefinable, it is impossible to correlate the target probability of failure with a corresponding reliability index. In this case, we can only use a target probability of failure criterion for LRFD.

A target probability of failure is used in LRFD of slopes because its analysis is very complicated and the distributions of the total load (driving moment) and resistance (resisting moment) are irregular or arbitrary. For the method of estimating a probability of failure of slopes, Monte Carlo simulations are used. Monte Carlo simulation is the repetitive process of generating very large numbers of values that can reproduce the probability distributions of the parameters and models. The advantage of this method is its simplicity, but the method requires a large number of simulations and thus is computationally costly.

A target reliability index criterion is employed in LRFD of MSE walls because the distributions of the total load and resistance, as well as the parameters that are used in the analysis, are either normally distributed or can be approximated to be normally distributed. The First-Order Reliability Method (FORM) is used for LRFD of MSE walls to calculate a reliability index. FORM is the method that computes a reliability index $\beta$ using a geometric interpretation of the minimum distance between the point corresponding to the mean values of the parameters used in the analysis (the peak point of the probability distribution function of the parameters) and an ultimate limit state surface. The basic concepts of probability theory, Monte Carlo simulation and FORM are introduced in Appendix B.

\subsubsection{Target probability of failure $P_{f}$}

Chowdhury and Flentje (2002) suggested values of target probability of failure for a natural slope for different slope types and locations (urban versus nonurban areas). A lower value of target probability of failure is suggested for slopes whose failure will have 
minor consequences. They concluded that the target probability of failure could vary from 0.001 to 0.15 . This is consistent with traditional WSD practice, according to which different factors of safety are used depending on the importance of the structure or the quantity and quality of the data used in the design.

Christian et al. (1994) proposed that an acceptable target probability of failure for slope design purposes is 0.001 ; however, for slopes of less importance, a greater target probability of failure $\left(\mathrm{P}_{\mathrm{f}}=0.01\right)$ may be used. Loehr et al. (2005) set the range of target probability of failure from 0.001 to 0.01 for slopes: 0.01 for relatively low potential risk and 0.001 for high potential risk.

An effort was made to determine an acceptable probability of failure for slopes by Santamarina et al (1992). The authors did a survey to engineers involved in slope stability analysis. The results are summarized in Table 2.3

Table 2.3 Acceptable probability of failure for slopes (modified after Santamarina et al, 1992)

\begin{tabular}{|l|c|}
\hline \multicolumn{1}{|c|}{ Conditions } & $\begin{array}{c}\text { Acceptable } \\
\text { probability of failure }\end{array}$ \\
\hline Temporary structures: no potential life loss, low repair cost & 0.1 \\
\hline $\begin{array}{l}\text { Minimal consequences of failure: high cost to reduce the } \\
\text { probability of failure (bench slope or open pit mine) }\end{array}$ & $0.1-0.2$ \\
\hline $\begin{array}{l}\text { Minimal consequences of failure: repairs can be done when time } \\
\text { permits (repair cost is less than cost of reducing probability of } \\
\text { failure) }\end{array}$ & 0.01 \\
\hline Existing large cut on interstate highway & $0.01-0.02$ \\
\hline Large cut on interstate highway to be constructed & $<0.01$ \\
\hline Lives may be lost when slopes fail & 0.001 \\
\hline Acceptable for all slopes & 0.0001 \\
\hline Unnecessarily low & $<0.00001$ \\
\hline
\end{tabular}

In our study, two levels of target probability of failure will be considered $(0.001$ and 0.01 ) to establish bounds on the resistance factors for use in design. However, target probabilities of failure that are lower than 0.001 should be also considered for many cases 
of interest in practice including important structures like dams or large levees, whose failure may cause loss of many lives. Definitive values of LFs and RFs for slopes therefore will require additional analysis.

\subsubsection{Target reliability index $\beta_{\mathrm{T}}$}

The target reliability index $\beta_{\mathrm{T}}$ for LRFD of MSE walls may vary with the importance of the wall. In this study, different values of target reliability indices $\left(\beta_{\mathrm{T}}=2.0,2.5,3.0\right.$, and 3.5) are used for LRFD of MSE walls. A target reliability index of 3.0 is widely used in probabilistic stability analysis of geotechnical structures (Foye, 2004; Ellingwood et al., 1980; and Palkowsky et al., 2004). Foye (2004) also stated that $\beta_{\mathrm{T}}$ of 3.0 is widely used in structural practice; therefore, the substructures that are supporting superstructures should have a consistent $\beta_{\mathrm{T}}$. In general, AASHTO LRFD bridge design specification (2007) uses a target reliability index of 3.5 for main elements and components whose failure may cause bridge failure. For elements or components that are not failure-critical, lower values of target reliability index (target reliability index less than 3.5) may be considered. The lower values of $\beta_{\mathrm{T}}$ (2.0 and 2.5) may be used by designers who want to have less conservatism in MSE wall design.

When FORM is used in analysis, a target reliability index can be converted into a target probability of failure using Eq. (2.16) because of their unique relationship under the assumption that both total load and resistance follow a normal distribution. Table 2.4 shows the values of target probability of failure corresponding to various values of reliability index. If the variable is not normally distributed but follows a certain type of distribution, the changing of a nonnormally distributed variable into a normally distributed variable is possible using the concept of an equivalent mean and standard deviation. 
Table 2.4 The equivalent values of target probability of failure for a corresponding target reliability index

\begin{tabular}{|c|c|}
\hline Target reliability index $\beta_{\mathrm{T}}$ & Target probability of failure $\mathrm{P}_{\mathrm{f}}$ \\
\hline 1 & 0.16 \\
\hline 1.5 & 0.067 \\
\hline 2 & 0.023 \\
\hline 2.5 & 0.0062 \\
\hline 3 & 0.0013 \\
\hline 3.5 & 0.00023 \\
\hline 4 & 0.000032 \\
\hline 4.5 & 0.0000034 \\
\hline 5 & 0.00000029 \\
\hline
\end{tabular}

The conversion of a target probability of failure into an equivalent target reliability index is conducted typically using the chart for standard normal curve area. This chart is provided in most books on statistics. For example, $\beta_{\mathrm{T}}=3$ corresponds to $Z=$ -3 in Eq. (2.16); therefore, the probability that corresponds to $Z=-3$ is found to be 0.013 from the chart. 


\section{PART II - LRFD OF SLOPES}

The primary goal of a slope design is the economical selection of slope angle or height while achieving a satisfying level of safety for the slope. To evaluate the stability of slopes, it is important to understand the topography, geological condition, the seasonal variation of groundwater, and the external load characteristics of the slopes. The examination of whether the slope stability under short-term condition or that under longterm condition is the worst case is also required. After examining these factors, a slope stability analysis is conducted using the slope geometry, soil strength parameters, soil unit weights, and external loads reflecting these factors.

Slope stability has been traditionally evaluated using WSD and a factor of safety. For slope design purposes, design specifications provide a minimum factor of safety that must be exceeded. However, the proposed minimum factor of safety is employed for all types of slopes regardless of (1) the degrees of uncertainty associated with loads inducing instability of the slope and the resistance against the loads and (2) the geometry of the slope. LRFD of slopes accounts for these two conditions in slope design so that LRFD more effectively pursues the primary goal for slope design, which is an economical and safe design.

The slope part of this report (chapter 3 through chapter 5) introduces (1) an algorithm for LRFD development for slopes, (2) an assessment of uncertainty associated with soil parameter measurements, (3) a representation of spatial soil variability using Gaussian random field theory, and (4) a calculation of optimum factors for LRFD of slopes. 


\section{CHAPTER 3. APPLICATION OF LRFD TO SLOPE DESIGN}

\subsection{Introduction}

Working Stress Design (WSD) of slopes is a design method that considers the design parameters as deterministic values. WSD has worked reasonably well for slope design. The factor of safety (FS) for slope stability is the ratio of the sum of the resisting forces (or moments) to the sum of the driving forces (or moments). The equation for the FS is as follows:

$$
\mathrm{FS}=\frac{\text { Sum of resisting forces (moments) }}{\text { Sum of driving forces (moments) }}
$$

Table 3.1 presents the minimum factor of safety values for different conditions that are recommended in the old AASHTO bridge design specifications (AASHTO, 2002). These minimum FS values are determined based on the past experience of engineers or case histories.

Table 3.1 Minimum factor of safety for slope designs (AASHTO, 2002)

\begin{tabular}{|c|c|}
\hline Conditions & Factor of safety \\
\hline $\begin{array}{c}\text { Soil and rock parameters and groundwater levels are } \\
\text { determined based on in situ or laboratory tests }\end{array}$ & 1.3 \\
\hline Abutments are supported above a retaining wall & 1.8 \\
\hline Otherwise & 1.5 \\
\hline
\end{tabular}


These minimum factors of safety values do not vary with the slope geometry or the levels of uncertainties of loads and soil strength parameters. Therefore, the current WSD proposes a single value of factor of safety that may be extremely conservative for some slopes with small slope angle and a lesser amount of load and strength parameter uncertainty. LRFD of slopes guarantees that a probability of failure of a slope does not exceed the target probability of failure if the development of the LRFD method for slopes is done in a rational way.

To develop LRFD for slopes, the assessment of the uncertainties of the parameters must be done with great care. For example, the assessment of the uncertainties of soil parameters is likely to be erroneous if limited data are obtained for natural slopes or slopes with large dimensions. In addition, development of LRFD for slopes is very expensive in terms of computation time and effort. However, once a wellestablished LRFD method for slopes is developed, it will produce more consistent and reliable results for slope design than WSD.

In this study, Gaussian random field theory is used to reproduce the uncertainty of the strength parameters and the unit weight of the soil slopes. In addition, the ULS for slope stability is defined using the Bishop simplified method with a factor of safety equal to unity.

The current AASHTO LRFD design specifications (2007) use a resistance factor that is equal to the inverse of the factor of safety because it assumes all the load factors for different types of loads associated with slope designs to be equal to one $\left(\mathrm{LF}_{\mathrm{i}}=1\right)$. Although the use of LF equal to one for all types of loads is not reasonable, this study will not address specifically what those values should be. This may be possible to do after a substantial number of reliability analyses, covering various geometries of slopes and site conditions (location of soil layers, values of soil parameters, and so on), is done. However, the six examples given in chapter 5 provide elements upon which recommendation of suitable LF values may be possible. 


\subsection{Bishop Simplified Method}

Bishop (1955) proposed the Bishop Simplified Method (BSM), which is applicable to circular slip surfaces. BSM is a method of slices that divides the sliding mass vertically into many slices, as shown in Figure 3.1. There are other types of methods of slices, such as Fellenius' method, Janbu's method, Spencer's method and others. The methods differ in the assumption about inter-slice forces and the shape of the slip surface. Despite the difference in the assumption about inter-slice forces, the calculated FS using BSM is comparable to those using more rigorous methods, such as Spencer's method for a given circular slip surface (the FS from BSM is slightly less than those from the other two). In general, the selection of the method for slope stability analysis is less important than the determination of the strength parameters and the geometry of the slopes. Additionally, any resistance factors found to be appropriate for BSM would be slightly conservative for a more rigorous method, such as Spencer's method.

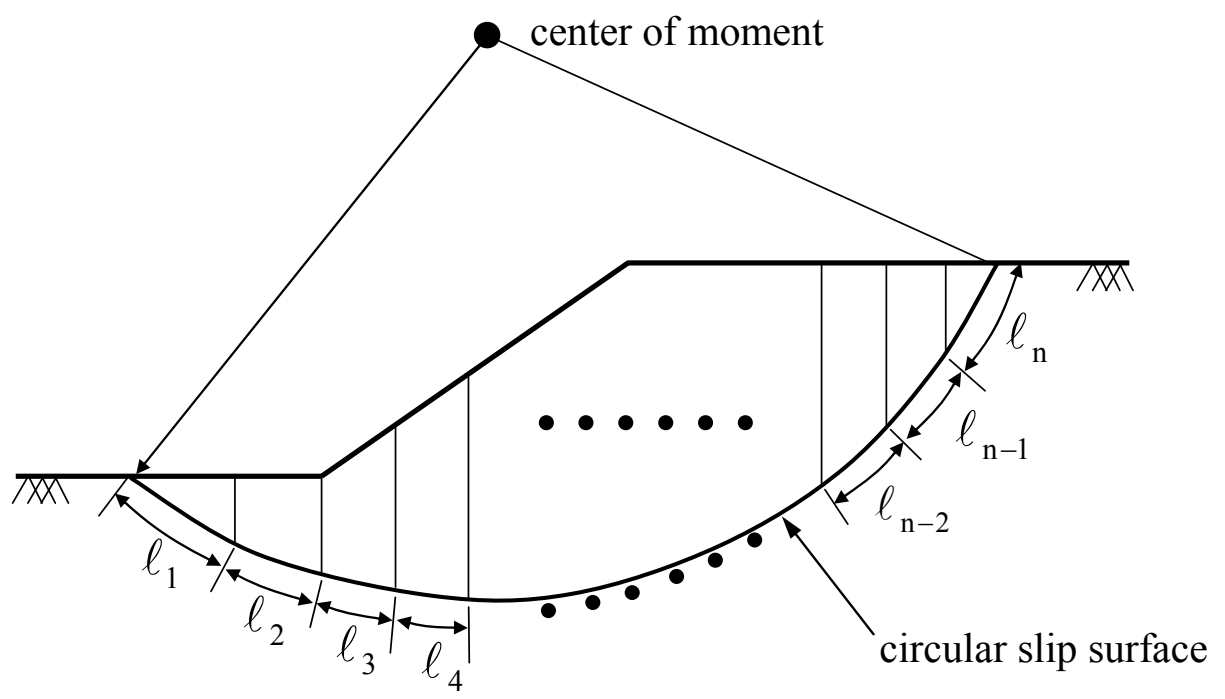

Figure 3.1 Method of slices $\left(\ell_{i}\right.$ is the length of the bottom of $i^{\text {th }}$ slice; $\left.i=1, \cdots, n\right)$

Figure 3.2 represents the forces acting on an arbitrary slice of the soil mass above the potential slip surface. For the inter-slice forces of each slice (X and $\mathrm{Y}$ in Figure 3.2), 
BSM ignores the vertical components $\mathrm{Y}$ of the inter-slice forces on each side of the slice and only considers the horizontal components $\mathrm{X}$ in the calculation of driving and resisting moments. BSM satisfies the overall moment equilibrium and vertical force equilibrium, while it does not satisfy the individual slice moment equilibrium and horizontal force equilibrium.

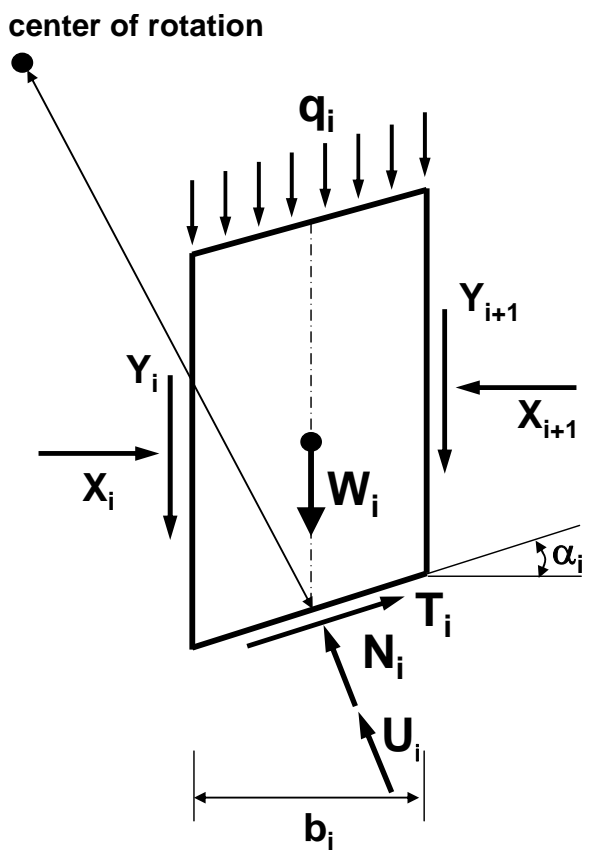

$$
\begin{aligned}
& q \text { : uniform surcharge acting on the } \\
& \text { top of the slice } \\
& Y \text { : vertical component of inter-slice } \\
& \text { forces of the slice } \\
& X \text { : horizontal component of inter- } \\
& \text { slice forces of the slice } \\
& W \text { : weight of the slice } \\
& \alpha \text { : inclination angle to the horizontal } \\
& \text { plane of the base of each slice } \\
& T \text { : tangential force on the base of } \\
& \text { the slice } \\
& \mathrm{N}: \text { normal force on the base of the } \\
& \text { slice } \\
& U \text { : water force on the base of the } \\
& \text { slice } \\
& \text { b : width of the slice }
\end{aligned}
$$

Figure 3.2 Free-body diagram of $i^{\text {th }}$ slice

The factor of safety for BSM is

$$
(F S)_{B S M}=\frac{\sum_{i=1}^{n} \frac{c_{i} b_{i}+\left(W_{i}+q_{i}-u_{i}\right) \tan \phi_{i}}{m_{\alpha, i}}}{\sum_{i=1}^{n}\left(W_{i}+q_{i}\right) \sin \alpha_{i}} \quad(i=1,2, \cdots, n)
$$

where $\mathrm{n}$ is the total number of slices, $\mathrm{c}$ is the apparent cohesion of soil (or the undrained shear strength $s_{u}$ when friction angle $\phi=0$ ) on the base of each slice, $b$ is the width of each 
slice, $\mathrm{W}$ is the soil weight of each slice, $\mathrm{q}$ is the uniform surcharge acting on the top of each slice, $\mathrm{u}$ is the water force acting on the base of each slice, $\phi$ is the friction angle on the base of each slice, and $\alpha$ is the angle with the horizontal of the base of each slice. The term $\mathrm{m}_{\alpha, \mathrm{i}}$ is defined as follows:

$$
\mathrm{m}_{\alpha, \mathrm{i}}=\cos \alpha_{\mathrm{i}}\left(1+\frac{\tan \alpha_{\mathrm{i}} \tan \phi_{\mathrm{i}}}{\mathrm{FS}}\right) \quad(\mathrm{i}=1,2, \cdots, \mathrm{n})
$$

When all the parameters that are used in the analysis are deterministic, a single value of FS is calculated for a trial slip surface. The generation of a large number of trial slip surfaces is required to find the most critical slip surface for the given slope. The most critical slip surface corresponds to the slip surface that has the lowest FS among the FS values for all trial slip surfaces. However, for LRFD of slopes, the limit-state equation for $\mathrm{BSM}$ is defined for $\mathrm{FS}=1$. Therefore, to represent this limit-state equation, Eq. (3.2) can be revised as

$$
\begin{gathered}
\sum_{i=1}^{n} \frac{c_{i} b_{i}+\left(W_{i}+q_{i}-u_{i}\right) \tan \phi_{i}}{\cos \alpha_{i}\left(1+\tan \alpha_{i} \tan \phi_{i}\right)}-\sum_{i=1}^{n}\left(W_{i}+q_{i}\right) \sin \alpha_{i}=0 \\
(i=1,2, \cdots, n)
\end{gathered}
$$

\subsection{Algorithm for LRFD of Slopes}

In our analysis, we only consider the following parameters to have uncertainty: (1) soil unit weight $\gamma,(2)$ undrained shear strength $s_{u}$, (3) apparent cohesion c, and (4) friction angle $\phi$. The uncertainty in the slope geometry is neglected. We also do not consider pore pressure or other water conditions because these are highly time-dependent. Instead, designers should work with worst-case groundwater assumptions. 
The optimum resistance factor and load factors are calculated using the algorithm shown in Figure 3.3. There are two loops in this algorithm: (1) the iterative process to find the most critical slip surface for a given geometry and a given set of parameters (undrained shear strength $\mathrm{s}_{\mathrm{u}}$, apparent cohesion $\mathrm{c}$, friction angle $\phi$, and soil unit weight $\gamma$ ); and (2) the iteration to find the mean values of the parameters $\left(s_{u}, c, \phi\right.$, and $\left.\gamma\right)$ for which the calculated probability of failure is equal to the target probability of failure $\mathrm{P}_{\mathrm{f}}$. 
Step 1. Select (Guess) expected values (means) and coefficient of variations (COVs) of $c_{i}\left(s_{u i}\right), \phi_{i}, \gamma_{i}$, and $q$ (external loads) for each layer. (i=layer number)

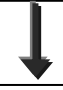

Step 2. Generate Gaussian random fields for each parameter $\left(\mathrm{c}_{\mathrm{i}}\left(\mathrm{s}_{\mathrm{ui}}\right), \phi_{\mathrm{i}}\right.$, and $\left.\gamma_{\mathrm{i}}\right)$ and superpose these fields.

Step 3. Generate a large number of trial slip surfaces and find the most critical slip surface. For the most critical slip surface, save the corresponding driving moments $M_{d}$ (both $M_{d}$ due to the self-weight of the soil and $M_{d}$ due to the external loads separately) and the resisting moment $\mathrm{M}_{\mathrm{r}}$.

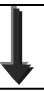

Step 4. Repeat "Step 2" and "Step 3" N times.

Step 5. For the $\mathrm{N}$ most critical slip surfaces (corresponding to the $\mathrm{N}$ iterations), count the cases $(n)$ for which total $M_{d}$ (a sum of $M_{d}$ due to self-weight of the soil and $M_{d}$ due to the external loads) is equal to or greater than $M_{r}$. Probability of failure $=n / N$.

No

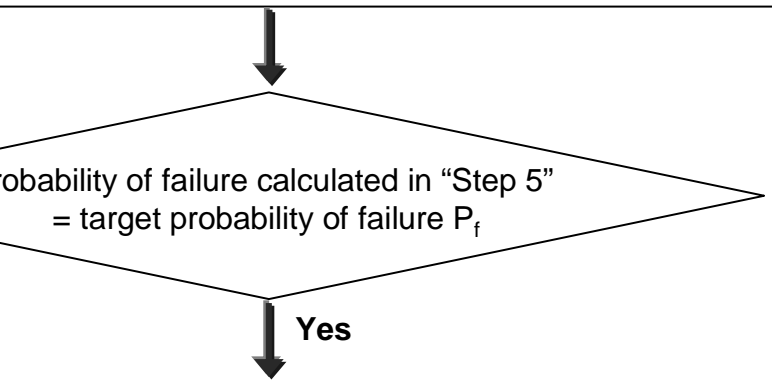

Step 6. Single out the limit state that corresponds to $M_{d} / M_{r}=1$. Save the limit-state values of $M_{d}$ (both $M_{d}$ due to the self-weight of the soil and $M_{d}$ due to the external loads) and $\mathrm{M}_{\mathrm{r}}$.

Step 7. Calculate nominal values of $c_{i}\left(s_{u i}\right), \phi_{i}, \gamma_{i}$, and $q$ by multiplying the bias factors of the parameters by their mean values for which the calculated probability of failure is equal to the target probability of failure.

Step 8. Run deterministic limit equilibrium analysis using these nominal values, find the most critical slip surface, and calculate the nominal $M_{d}\left(M_{d}\right.$ due to the self-weight and $M_{d}$ due to the external loads) and the nominal $M_{r}$ for the most critical slip surface.

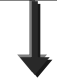

Step 9. Calculate optimum values of RF, LFs, and RF which will be denoted by RF*, $\mathrm{LF}^{\star} \mathrm{S}$, and RF, respectively.

Figure 3.3 Algorithm for LRFD of slopes 
A large computational effort is required to find the combination of expected values and the corresponding COVs of $\mathrm{c}_{\mathrm{i}}\left(\mathrm{s}_{\mathrm{ui}}\right), \phi_{\mathrm{i}}, \gamma_{\mathrm{i}}$, and $\mathrm{q}$ that correspond to the target probability of failure. The algorithm is coded using FORTRAN. Finding one set of appropriate $\mathrm{c}_{\mathrm{i}}\left(\mathrm{s}_{\mathrm{ui}}\right), \phi_{\mathrm{i}}, \gamma_{\mathrm{i}}$, and $\mathrm{q}$ values that satisfy the target probability of failure for a three-layer soil slope has taken at least a week even though we have used a highperformance computer (Intel Core 2 CPU 6400@2.13Ghz with 2GB of RAM) for the analysis.

In Step 1, we select the initial expected values and the corresponding COVs of $\mathrm{c}_{\mathrm{i}}$ $\left(\mathrm{s}_{\mathrm{ui}}\right), \phi_{\mathrm{i}}, \gamma_{\mathrm{i}}$, and $\mathrm{q}$ (Figure 3.4). Ideally, we would guess perfectly, and these values would produce the target probability of failure $\mathrm{P}_{\mathrm{f}}$. In reality, we will need to adjust these values based on how far the calculated probability of failure is from the target probability of failure. A good guess of the values of these parameters will naturally save time and effort.

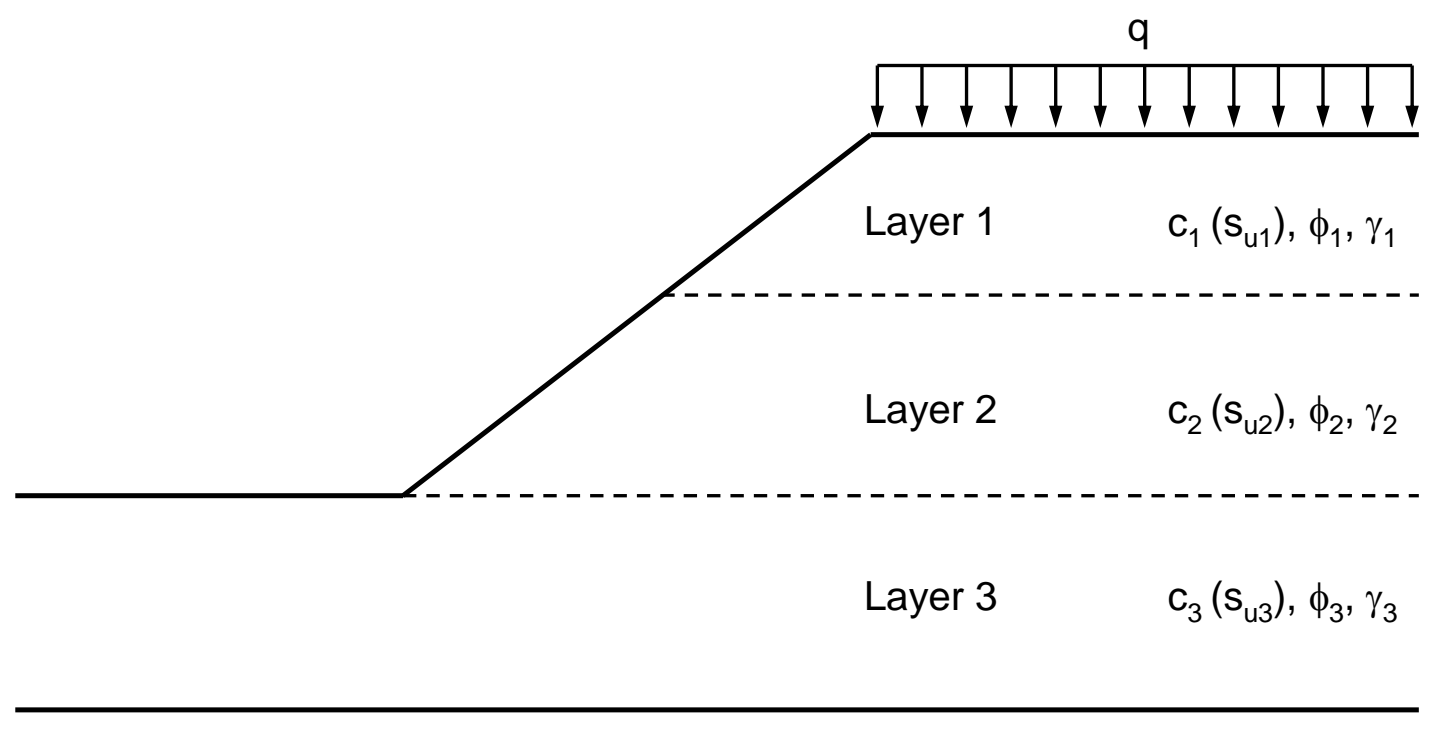

Figure 3.4 Geometry and soil parameters of the slope

Next, in Step 2, we generate a Gaussian random field for each parameter for each layer. For example, if the slope consists of three layers each with its own $\mathrm{c}\left(\mathrm{s}_{\mathrm{u}}\right), \phi$, and $\gamma$, the total number of Gaussian random fields that are required in this step will be nine. A Gaussian random field of each parameter will be shown as an array of values that have constant spacing as shown in Figure 3.5. The values at every point are different from 
point to point as dictated by the Gaussian random field; however, the expected value and the standard deviation of the parameter $\left(\mathrm{c}_{\mathrm{i}},\left(\mathrm{s}_{\mathrm{ui}}\right), \phi_{\mathrm{i}}\right.$, and $\left.\gamma_{\mathrm{i}}\right)$ are the same at each point. The generation of Gaussian random fields will be discussed in detail in the next chapter.

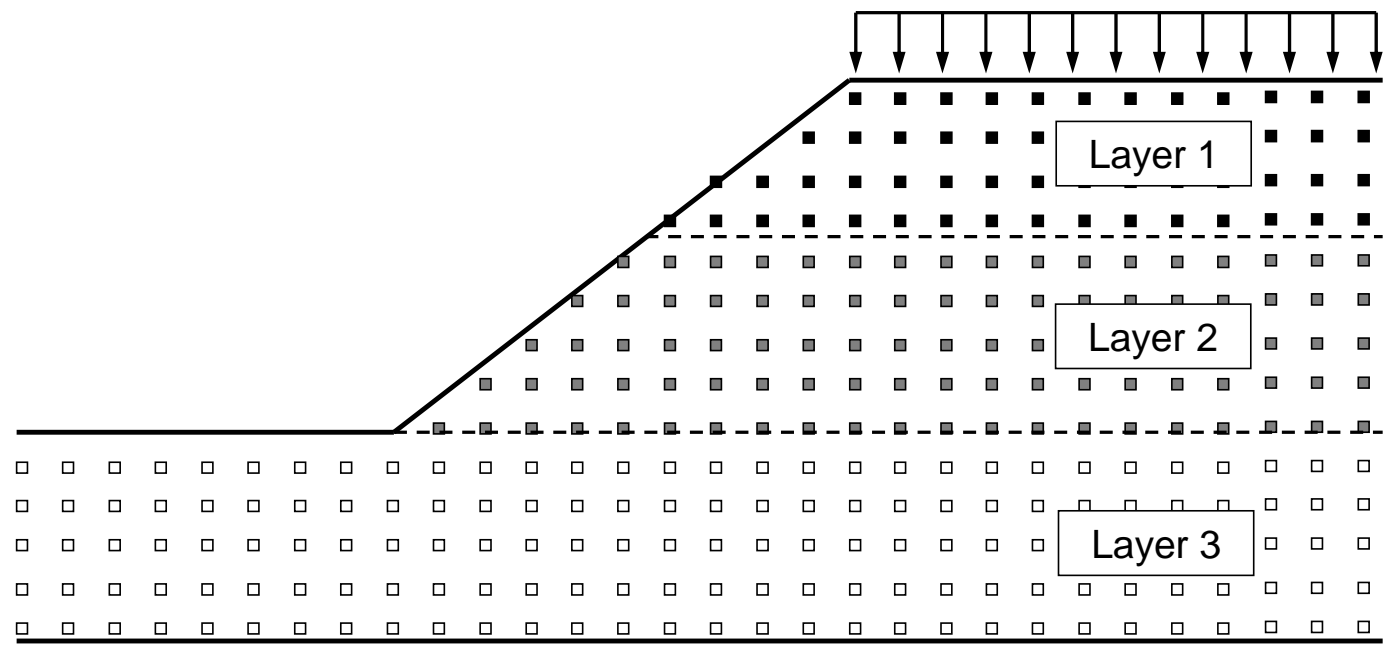

Figure 3.5 The array of data points generated by Gaussian random field theory

Nonspatial variability, such as a measurement error, can be represented by a purely random field such that each value within the random field is independent of all other values, has zero mean and has the variance of the nonspatial variability. This can then be added to the Gaussian random field generated earlier.

Step 3 consists of finding the most critical slip surface and the corresponding values of the driving moments and the resisting moment from a large number of trial slip surfaces (Figure 3.6). The factor of safety (FS) is the lowest for the most critical slip surface. The procedure of finding the most critical slip surface is the same as that of conventional slope stability analysis. 


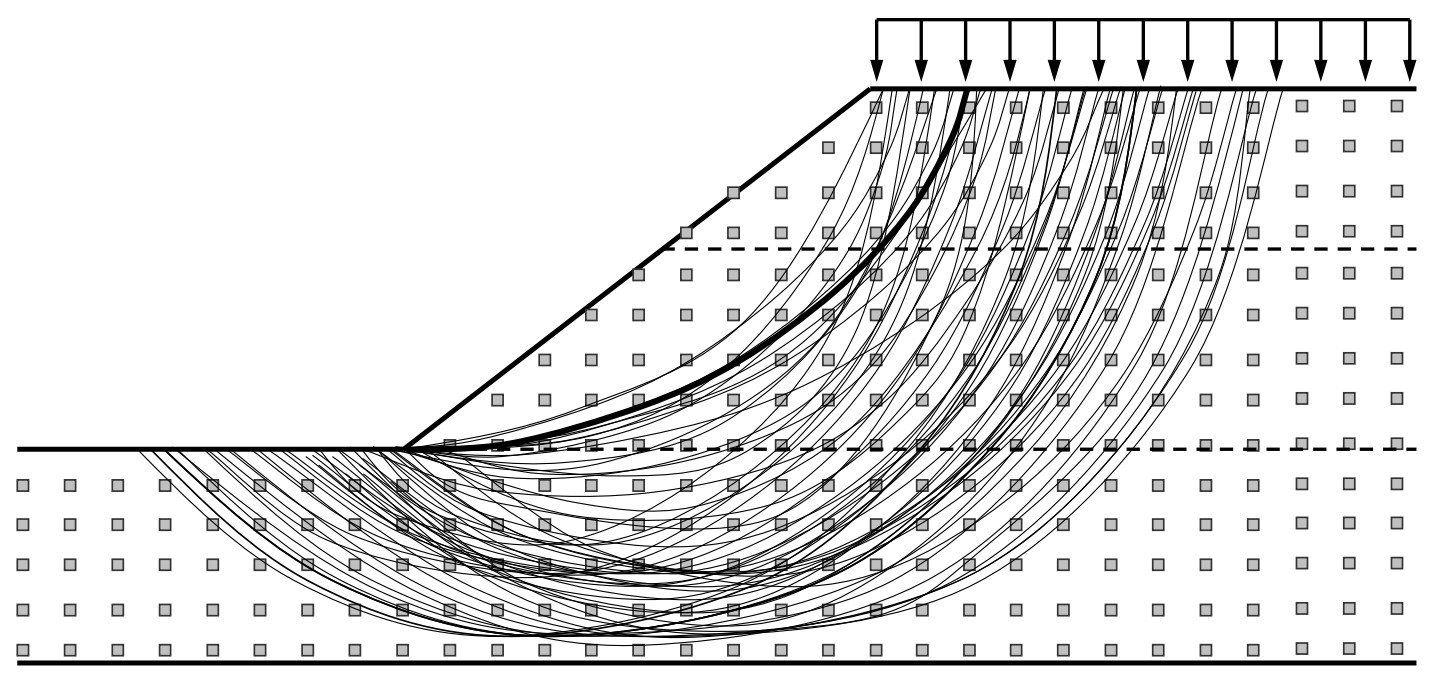

Figure 3.6 Finding the most critical slip surface among a large number of trial slip surfaces

Up to this point, we have found the most critical slip surface for a slope with soil properties $\left(\mathrm{c}_{\mathrm{i}}\left(\mathrm{s}_{\mathrm{ui}}\right), \phi_{\mathrm{i}}\right.$, and $\left.\gamma_{\mathrm{i}}\right)$ defined by one specific combination of random fields. For the most critical slip surface determined in Step 3, the calculated values of the driving moments (the driving moment due to the self-weight of the soil and that due to the external loads, separately) and the resisting moment must be saved for the calculation of the optimum load and resistance factors in Step 9. If the external loads are classified into different categories (such as dead load, live load, or wind load), we need to separate the calculation of the moments for each external load category.

We repeat the process (Step 2 and Step 3) of finding the most critical slip surfaces for $\mathrm{N}$ different combinations of random-field realizations of the soil properties $\left(\mathrm{c}_{\mathrm{i}}\left(\mathrm{s}_{\mathrm{ui}}\right), \phi_{\mathrm{i}}\right.$, and $\gamma_{i}$ ) until we have a sufficient number of critical slip surfaces to perform a probability of failure calculation.

In Step 4, we collect the most critical slip surfaces and corresponding FS values from the multiple iterations of Steps 2 and 3. Suppose that we did N iterations of Steps 2 and 3, this means that we have $\mathrm{N}$ values of FS. From these $\mathrm{N}$ values of FS, we count the cases for which FS is less than or equal to one. FS less than or equal to one corresponds to "failure" of the slope. Suppose there are n cases of failure; the probability of failure of 
the slope will then be $\mathrm{n}$ divided by N. If the probability of failure calculated in Step 5 is not equal to or is not very close to the target probability of failure $\mathrm{P}_{\mathrm{f}}$ (in our analysis, $\mathrm{P}_{\mathrm{f}}=$ 0.001 or 0.01 ), we go back to Step 1 and change the initial expected values (mean values) of the soil parameters, repeat the steps and keep adjusting these mean values until the target probability of failure is met.

Once the target probability of failure is met, we single out the case where FS is equal to or is very close to one out of $\mathrm{N}$ cases. This case, with FS $=1$, corresponds to the ULS for the target probability of failure. For the calculation of the optimum factors, we must save the limit-state values of driving moments (the driving moment due to the selfweight of the soil and that due to the external loads) and the resisting moment.

A conventional deterministic slope stability analysis is performed using the nominal values of the soil parameters and external loads. Nominal values of the soil properties are obtained by multiplying the bias factors of the parameters by their mean values (for which the calculated probability of failure is equal to the target probability of failure). From this deterministic analysis, we find the most critical slip surface and the corresponding nominal values of the driving moments and the resisting moment.

In the final step (Step 9), the optimum resistance factor and load factors are determined using the pre-calculated limit-state moments and nominal moments in Steps 5 and 6. Eq. (2.5) and Eq. (2.6) are used to calculate the optimum factors. In Eq. (2.5) and Eq. (2.6), the driving moments $M_{d}$ and the resisting moment $M_{r}$ will replace loads $Q$ and resistance $\mathrm{R}$, respectively. 


\section{CHAPTER 4. VARIABILITY OF SOIL}

\subsection{Uncertainty Associated with Soil Properties}

Christian et al. (1994) classified the uncertainty associated with soil properties into four categories: (1) spatial soil variability (inherent soil variability); (2) measurement error; (3) statistical error in the mean; and (4) bias in measurement procedures (Figure 4.1).

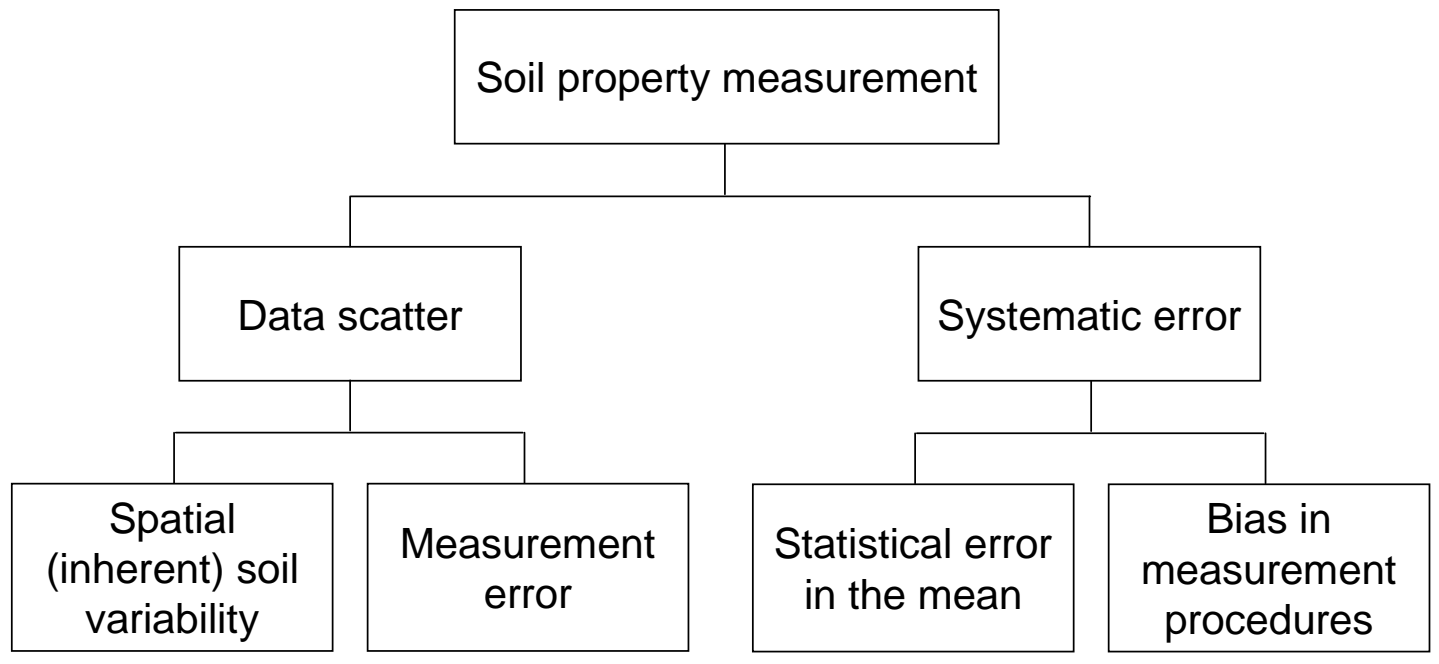

Figure 4.1 Four sources of uncertainty in soil property measurement (after Christian et al., 1994)

For deterministic slope stability analysis, the slopes are traditionally divided into soil layers in a way that each layer could be considered as a homogeneous layer. For a homogenous soil layer, a soil property is the same at every point inside the layer.

In the context of this report, we divide the slopes into layers which soil properties are uniform with respect to mean and standard deviation. Additionally, soil parameters 
are governed by isotropic correlation coefficient functions. These soil layers may be referred to as "statistically homogeneous."

If the uncertainty associated with soil property measurement does not exist, the mean and standard deviation of a soil parameter of a statistically homogeneous soil layer are the mean and the standard deviation of the real in situ soil property. The variability of the real in situ soil property corresponds to that of spatial soil variability. However, the direct assessment of spatial soil variability is impossible because the exact real in situ soil property is unattainable in reality. Therefore, to simulate spatial soil variability, we must separate spatial soil variability from uncertainties associated with soil property measurement.

In reality, the four sources of uncertainty in soil property measurement (Figure 4.1) are grouped together so that it is hard to differentiate between them. However, an effort has been made to separate these four sources step by step. Figure 4.2 illustrates the spatial variability of a soil property. For the purpose of slope stability analysis, we assume that there is no directional trend of the mean of soil parameters within a statistically homogeneous layer, as shown in Figure 4.2.

Due to spatial soil variability, the soil properties in a statistically homogeneous layer change with the location. The scatter of real in situ values around their mean, as shown in Figure 4.2, is due to spatial soil variability. 


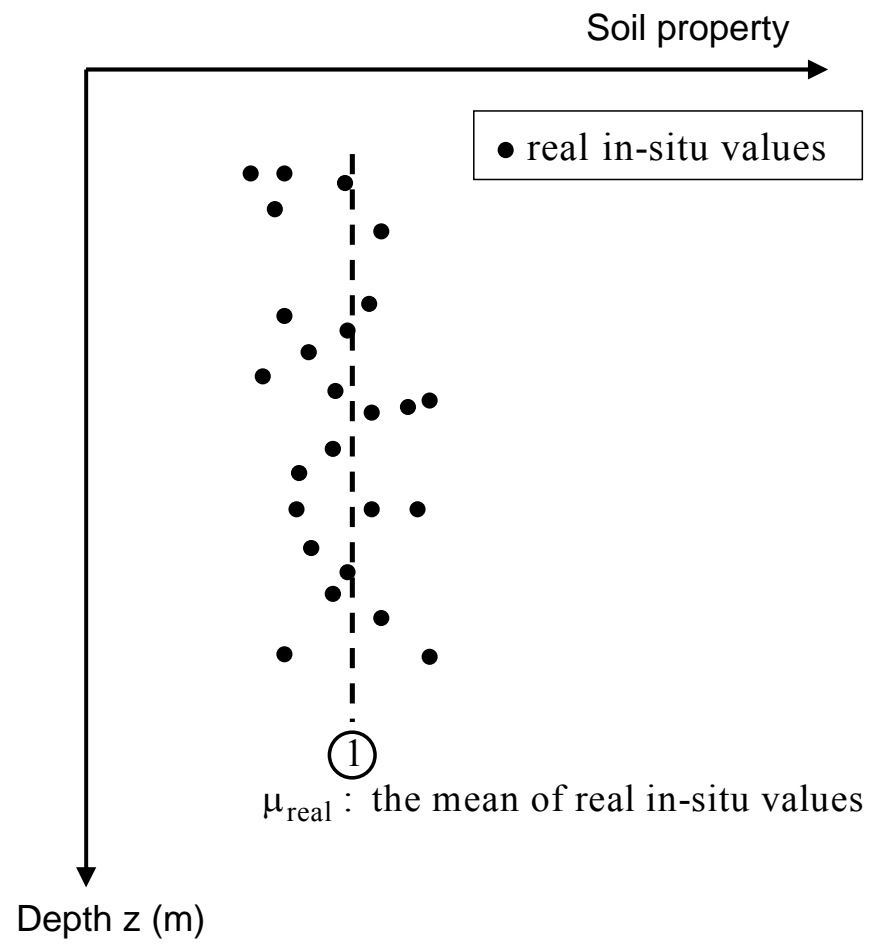

Figure 4.2 Scatter of the in situ values of a soil property.

If the representative (mean) value is obtained from limited data, there is a high probability that this representative value is biased compared to the real in situ mean. The bias resulting from the limited data is called statistical error in the mean and can be reduced by acquiring more data. Figure 4.3 shows that the mean of the values of four locations is much less than the real in situ mean. 


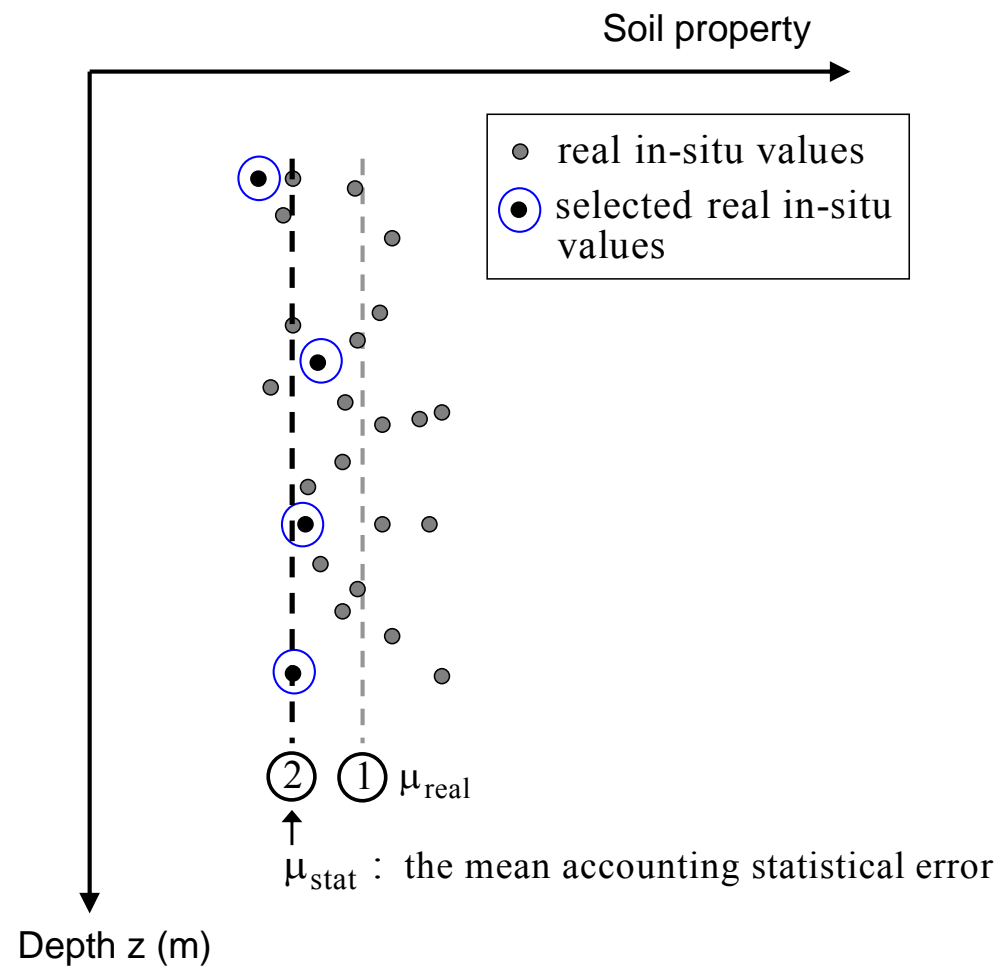

Figure 4.3 Bias due to statistical error in the mean

There is another error that is caused by the bias from measurement procedures. This bias results from disturbance of the samples or the type of test that is used to evaluate the soil property. If the samples are disturbed during sampling or testing, the soil property, such as the strength parameters, will be less than the real in situ values. Also, a different test method will give different results even though the samples are identical. 


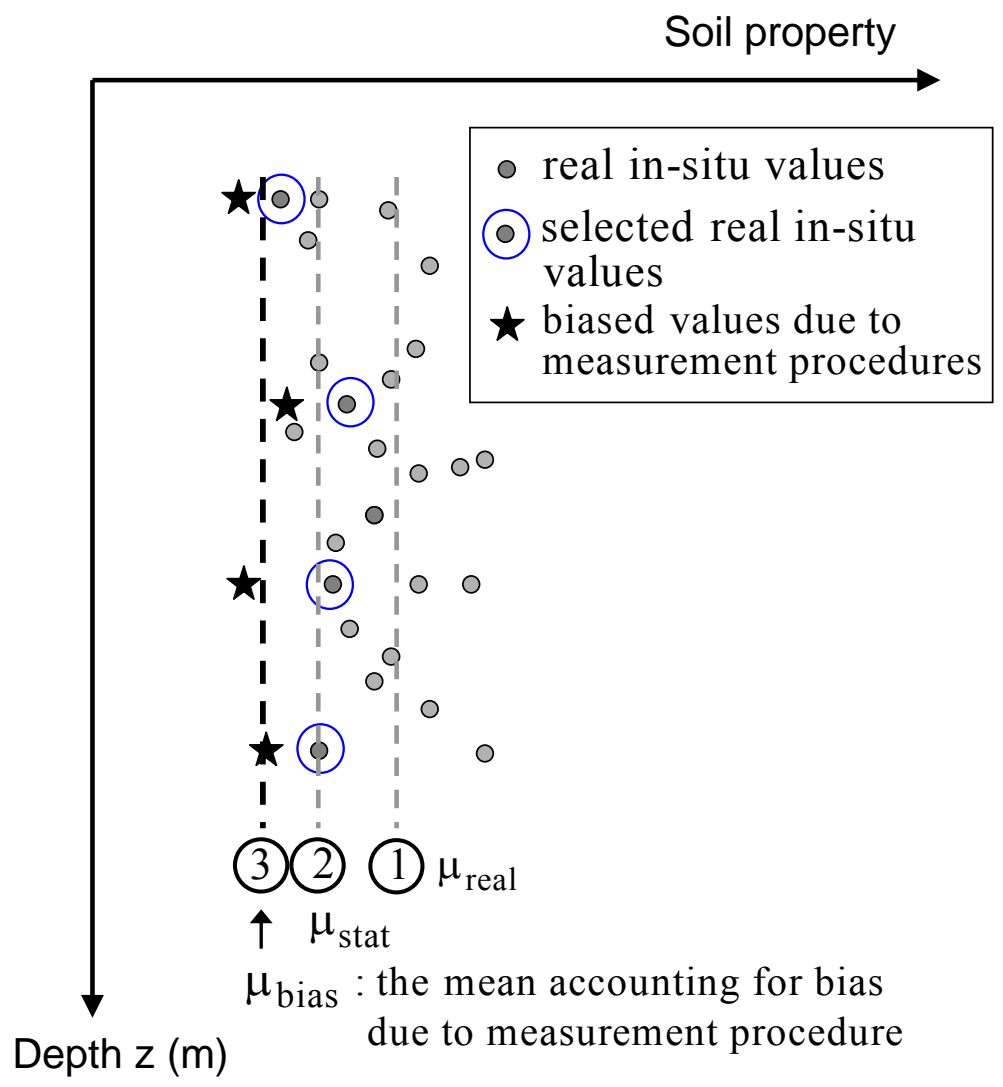

Figure 4.4 Bias due to measurement procedures

Measurement error results from one of two sources: (a) random experimental error (random testing error) or (b) noise. Random testing error can be assessed by analyzing many replicate tests assuming that the equipment, testing procedure, and operator are identical in every test. In reality, it is impossible for all conditions to be strictly identical every time. However, Orchant et al. (1988) claim that a considerable portion of the total uncertainty of soil property measurement is due to random experimental (or testing) errors that are not directly assessable. Christian et al. (1994) proposed an indirect method to assess the measurement error. The details of this method will be given in a later section (section 4.4). In general, it is acceptable to assume that measurement error has a zero mean and its residuals satisfy homogeneity and normality. Homogeneity of the residual implies that the variance of the residual is independent of 
location, while normality of the residual means that the distribution of the residual is normal.

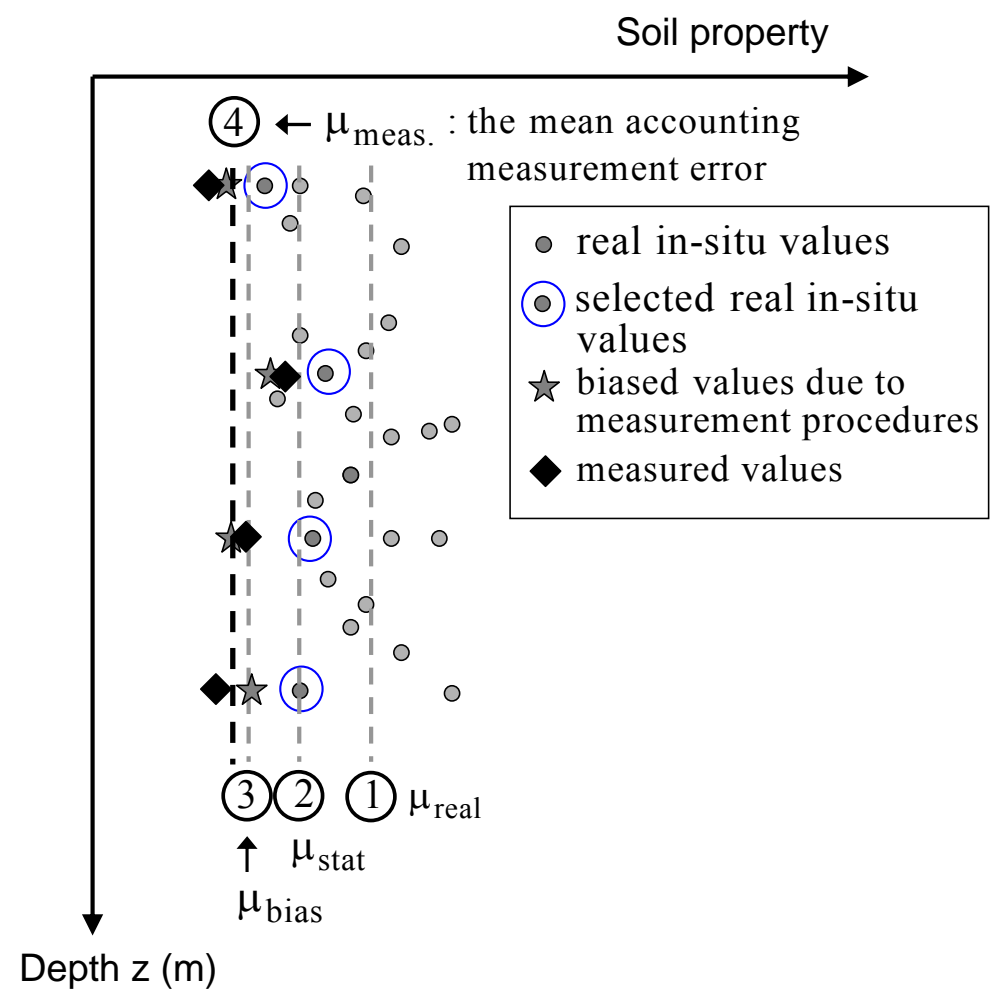

Figure 4.5 Measurement error

\subsection{COVs of Parameters Used in the Analysis}

The division of a slope into multiple statistically homogeneous layers must be done very carefully because the sizes and locations of the soil layers will change the means and COVs of soil properties of the layers considerably. The division of the slope in layers is subjective because designers make decisions based on their engineering judgment and in situ or laboratory test results. Also, both the location and the spacing of the sample collection or in situ testing play a large role in the location of boundaries and the determination of the uncertainty of soil parameters (DeGroot and Baecher, 1993). 
Yang et al. (2005) examined fourteen cases of slope failures with an evident slip surface. The failed slopes mainly consisted of either clay shale or glacial till. The slope angles were between 11 and 13 degrees, and the heights were between 6 and 23 meters. The authors attempted to locate the failure surface of the slopes and back-calculated the strength parameters. They also estimated the in situ strength parameters (both effective cohesion and friction angle) corresponding to peak strength parameters using the borehole shear test and the residual strength parameter using the ring shear test on undisturbed samples. The back-calculated shear strength resulted between the peak shear strength and the residual strength. Even considering the uncertainties related to the backanalysis process, when the mean and the COV of strength parameters associated with residual, critical or any other strength state are assessed using either in situ tests or laboratory tests, designers need to keep in mind that the calculated mean and COV may be quite different from the mean and COV of the actual strength parameters along the slip surface at potential failure. In fact, different strengths are most likely mobilized at different locations along the slip surface.

\subsubsection{Undrained shear strength $\mathrm{s}_{\mathrm{u}}$}

Spry et al. (1988) collected a large amount of test data on undrained shear strength. The undrained shear strengths of clay and clayey silt from various sites were examined. The COVs of the undrained shear strength varied from 0.18 to 1.45 ; and most of the COVs were between 0.2 and 0.4 . The COVs of the soil parameters could possibly have been reduced further if the site were divided into multiple "statistically homogeneous" soil regions (or layers). The COV values of undrained shear strength that were reported or used in several papers are listed in Table 4.1. In developing LRFD for slopes, based on the COV values in Table 4.1, we assume that the COV of undrained shear strength is 0.4 (the maximum COV value in Table 4.1) allowing a certain degree of conservatism for the cases that $\mathrm{COV}$ of undrained shear strength is less than 0.4 . 
Table 4.1 COVs for undrained shear strength

\begin{tabular}{|c|c|c|c|}
\hline Soil property & COV & Soil type & Reference \\
\hline \multirow{4}{*}{$\begin{array}{c}\text { undrained } \\
\text { shear } \\
\text { strength, } \\
\mathrm{s}_{\mathrm{u}}\end{array}$} & $0.1-0.4$ & clay & Phoon and Kulhawy (1999) \\
\cline { 2 - 4 } & $0.1-0.4$ & clay & Popescu et al. (2005) \\
\cline { 2 - 4 } & $0.1-0.4$ & clay & Cherubini (2000) \\
\cline { 2 - 4 } & $0.1-0.4$ & - & Auvinet and Gonzalez (2000) \\
\cline { 2 - 4 } & $0.4-0.4$ & - & $\begin{array}{c}\text { Fredlund and Dahlman (1972) } \\
\text { cited by Harr (1987) }\end{array}$ \\
\cline { 2 - 4 } & $0-0.33$ & - & $\begin{array}{c}\text { Assumed by Shannon and Wilson, } \\
\text { Inc., and Wolff (1994) }\end{array}$ \\
\hline
\end{tabular}

\subsubsection{Apparent cohesion $\mathrm{c}$ and friction angle $\phi$}

For the purpose of representation of soil strength, many engineers express the soil strength in terms of the apparent cohesion $\mathrm{c}$ and friction angle $\phi$. The "apparent" term is used because apparent cohesion is not a true cohesion such as observed for cemented (aged) soils. It should be noted that these strength parameters do not have physical meaning. They are just fitting parameters for a line that is drawn approximately tangentially to the Mohr-circles from several strength tests with different initial stresses. Therefore, it is not advisable to speak of COV of either $\mathrm{c}$ or $\phi$. However, for the purpose of developing LRFD for slopes, we assume that the COVs of apparent cohesion and friction angle are 0.4 and 0.2 , respectively. In the previous section, we found that the maximum COV for undrained shear strength $\mathrm{s}_{\mathrm{u}}$ is 0.4 for a statistically homogeneous soil region. It is likely conservative to assume that the COV of apparent cohesion is comparable to that of undrained shear strength. Foye (2006) concluded the uncertainty of peak friction angle of sandy soil is close to 0.07 for a known CPT tip resistance. For the values of $\mathrm{COV}$ (up to 0.08 ) of tip resistance found in the literature, it is acceptable to assume that the maximum $\mathrm{COV}$ for friction angle is 0.2 . 


\subsubsection{Soil unit weight $\gamma$}

The uncertainty of soil unit weight is the least among the parameters. Luckman (1987) mentioned that slope stability analysis results are insensitive to the soil unit weight variation. Table 4.2 shows that the COV of the soil unit weight varies from 0.01 to 0.1 . Therefore, the recommended values for the COV of the soil unit weight would be 0.1 for a highly variable site and 0.05 for a less variable site.

Table 4.2 COVs for soil unit weight

\begin{tabular}{|c|c|c|c|}
\hline Soil property & $\mathrm{COV}$ & Soil type & Reference \\
\hline \multirow{9}{*}{$\begin{array}{c}\text { Soil unit } \\
\text { weight, } \\
\gamma\end{array}$} & $0.01 \sim 0.12$ & dry unit weight & Phoon and Kulhawy (1999) \\
\hline & $0.03 \sim 0.2$ & unit weight & $"$ \\
\hline & 0.08 & Compacted fill & $\begin{array}{c}\text { White et al. (2005) } \\
\text { - Sugar Creek embankment } \\
\end{array}$ \\
\hline & 0.11 & Alluvium & $"$ \\
\hline & 0.1 & $\begin{array}{l}\text { High weathered } \\
\text { shale }\end{array}$ & $"$ \\
\hline & 0.1 & $\begin{array}{c}\text { Moderately } \\
\text { weathered shale }\end{array}$ & $"$ \\
\hline & 0.1 & $\begin{array}{c}\text { Slightly } \\
\text { weathered shale }\end{array}$ & $"$ \\
\hline & 0.03 & - & $\begin{array}{c}\text { Hammitt (1966), } \\
\text { cited by Harr (1987) }\end{array}$ \\
\hline & $0.04 \sim 0.08$ & - & $\begin{array}{c}\text { Assumed by Shannon and } \\
\text { Wilson, Inc., and Wolff (1994) }\end{array}$ \\
\hline
\end{tabular}

\subsubsection{External loads q}

The bias factor and the COV of $\mathrm{q}_{0}$ are suggested in Table 4.3 by Ellingwood (1999) and Nowak (1994) (Foye, 2004). These bias factor and COVs for dead and live load are obtained for bridge load components. Dead loads are normally distributed with a bias 
factor of 1.05 and a COV of 0.15 , while the live load exhibits lognormal distribution with a bias factor of 1.15 and a COV of 0.25 .

Table 4.3 COVs and bias factors for dead load and live load

\begin{tabular}{|c|c|c|c|}
\hline Variable & Bias factor & COV & Distribution type \\
\hline Dead load & 1.05 & 0.15 & Normal \\
\hline Live load & 1.15 & 0.25 & Lognormal \\
\hline
\end{tabular}

(After Ellingwood, 1999 and Nowak,1994)

When we define the ULS of slope stability analysis for LRFD purposes, we neglect the live loads that help stabilize a slope while we do consider the live loads that are destabilizing the slope (Figure 4.6).

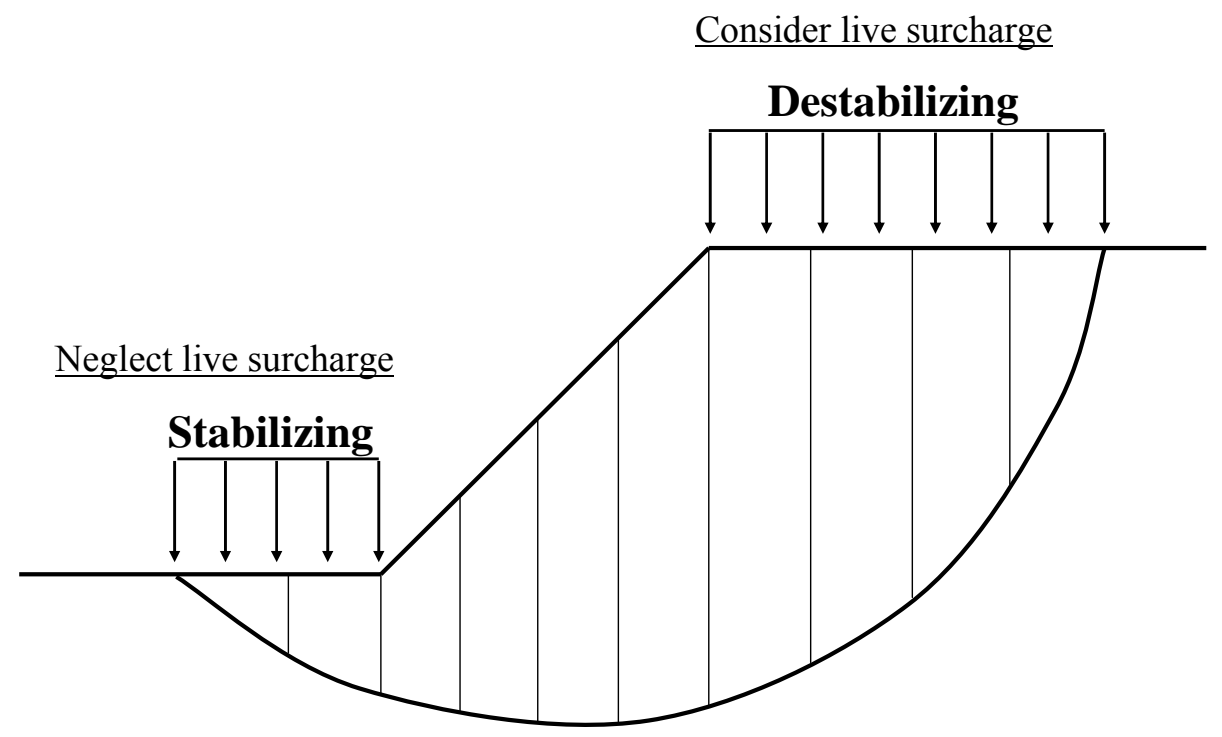

Figure 4.6 Live loads considered in slope design (consider destabilizing live surcharges and neglect stabilizing live surcharges) 


\subsection{Spatial Variability of Soil Properties}

The spatial variability of a soil property indicates the variation (or distribution) of the scatter of the soil property values within a certain region. The spatial variability of a soil property results mainly from soil deposition or weathering processes. Typically, the degree of spatial soil variability in the vertical direction is higher than in the horizontal direction because a deposition process occurs layer by layer.

Obtaining the true, exact value of a soil property at a point in a soil layer is impossible. Strictly speaking, the soil properties of a statistically homogeneous soil layer, which is divided based on engineering judgment and field test results, exhibit heterogeneity at small scales. The soil properties within a statistically homogeneous soil layer are considered as random variables following the theory for weakly stationary Gaussian random field. A weakly stationary Gaussian random field model is used for the representation of spatial soil variability. A random field is called "weakly stationary" if the following conditions are met: (1) the expected value (mean) and variance are the same at every point within the region of definition of the random field and (2) the correlation coefficient function governs the random field by setting the degree of correlation between the residuals of any two points. The correlation coefficient function is a function of the separation distance between any two points within the random field. The "Gaussian" term means that the random variable for which the field is defined follows a Gaussian (normal) distribution function. From here forward, we will refer to weakly stationary Gaussian random fields as simply Gaussian random fields.

\subsubsection{Gaussian random field for spatial variability of soil properties}

For our slope stability analysis, Gaussian random fields are generated using the Fourier transform technique that Fenton (1990) proposed. Only an isotropic Gaussian random field is considered. For an isotropic Gaussian random field, the correlation coefficient function is a function of the distance of two points but it is independent of their direction. 


\subsubsection{Correlation coefficient function}

Covariance (Cov) is the measure of how strong the correlation between two random variables is. When two random variables are positively correlated (if one variable increases, then the other variable also increases and vice versa), the Cov of these two variables is a positive value. On the other hand, if two random variables are negatively correlated (if one variable increases, the other variable decreases and vice versa), the covariance has a negative sign. If two random variables are independent of each other, then the covariance is equal to zero. The Covariance of two random variables $\left(z_{1}\right.$ and $\left.z_{2}\right)$ is

$$
\operatorname{Cov}\left(z_{1}, z_{2}\right)=E\left[\left(z_{1}-\mu_{z 1}\right)\left(z_{2}-\mu_{z 2}\right)\right]
$$

where $\mu_{\mathrm{z} 1}$ and $\mu_{\mathrm{z} 2}$ are the mean of $\mathrm{z}_{1}$ and $\mathrm{z}_{2}$, respectively.

The correlation coefficient of $z_{1}$ and $z_{2}$ is defined as the covariance of $z_{1}$ and $z_{2}$ divided by the product of their standard deviations $\left(\sigma_{z 1}\right.$ and $\left.\sigma_{z 2}\right)$. The correlation coefficient changes from -1 to 1 depending on the degree of correlation between the two variables. The correlation coefficient $\rho\left(z_{1}, z_{2}\right)$ of $z_{1}$ and $z_{2}$ is

$$
\rho\left(z_{1}, z_{2}\right)=\frac{\operatorname{Cov}\left(z_{1}, z_{2}\right)}{\sigma_{z 1} \sigma_{z 2}}=\frac{E\left[\left(z_{1}-\mu_{z 1}\right)\left(z_{2}-\mu_{z 2}\right)\right]}{\sigma_{z 1} \sigma_{z 2}}
$$

where $\sigma_{\mathrm{z} 1}$ and $\sigma_{\mathrm{z} 2}$ are the standard deviations of $\mathrm{z}_{1}$ and $\mathrm{z}_{2}$, respectively.

The correlation coefficient could be defined for a single random variable $\mathrm{z}$ depending on two different independent variables $\mathrm{x}$ and $\mathrm{y}$. Suppose that we are calculating the correlation coefficient of $\mathrm{z}$ between two points that are $\Delta \mathrm{x}$ apart in the horizontal direction and $\Delta y$ apart in the vertical direction. The covariance and correlation coefficient in this case are 


$$
\begin{aligned}
& \operatorname{Cov}[z(x, y), z(x+\Delta x, y+\Delta y)]=E\left\{\left[z(x, y)-\mu_{z}\right]\left[z(x+\Delta x, y+\Delta y)-\mu_{z}\right]\right\} \\
& \rho[z(x, y), z(x+\Delta x, y+\Delta y)]=\frac{E\left\{\left[z(x, y)-\mu_{z}\right]\left[z(x+\Delta x, y+\Delta y)-\mu_{z}\right]\right\}}{\sigma_{z}^{2}}
\end{aligned}
$$

where $\mathrm{x}$ and $\mathrm{y}$ are the random variables that define the location of the value $\mathrm{z}$, and $\mu_{\mathrm{z}}$ is the mean of the random variable $\mathrm{z}$ in the space containing $\mathrm{x}, \mathrm{y}, \mathrm{x}+\Delta \mathrm{x}$, and $\mathrm{y}+\Delta \mathrm{y}$.

In the field, the values of a soil property at two close points are more likely to be similar than those of two points that are far away from each other. An appropriate correlation coefficient function should be selected so that it produces a reasonable representation of the spatial soil variability observed in the domain within which the field is defined. There are different types of correlation coefficient functions. Rackwitz (2000) introduced six popular functions. However, Suzuki and Takara (1998) claim that the correlation distance (which is directly related to scale of fluctuation), rather than the type of correlation coefficient function, controls the representation of spatial variability. Therefore, the selection of a correlation coefficient function does not have much influence on the representation of spatial soil variability. An exponential correlation coefficient function is commonly used in Gaussian random field generation. The expression for this function for an isotropic random field is

$$
\rho(s)=\exp \left(-\frac{2 s}{s_{f}}\right)
$$

where $\mathrm{s}$ is separation distance and $\mathrm{s}_{\mathrm{f}}$ is an isotropic scale of fluctuation. 
The value " 2 " inside the exponential correlation coefficient function Eq. (4.5) is placed according to the definition of $\mathrm{s}_{\mathrm{f}}$ (the isotropic scale of fluctuation is equal to the integral from negative infinity to infinity of the correlation coefficient function).

$$
s_{\mathrm{f}}=\int_{-\infty}^{\infty} \rho(s) d s
$$

This scale of fluctuation $\mathrm{s}_{\mathrm{f}}$ is the parameter in the correlation coefficient function that controls the degree of reduction in the correlation coefficient between any two points that are s apart when s increases. Figure 4.7 shows how the exponential correlation coefficient function varies with separation distance for different isotropic scales of fluctuation $\left(\mathrm{s}_{\mathrm{f}}=1,5,10\right.$, and $\left.20 \mathrm{~m}\right)$.

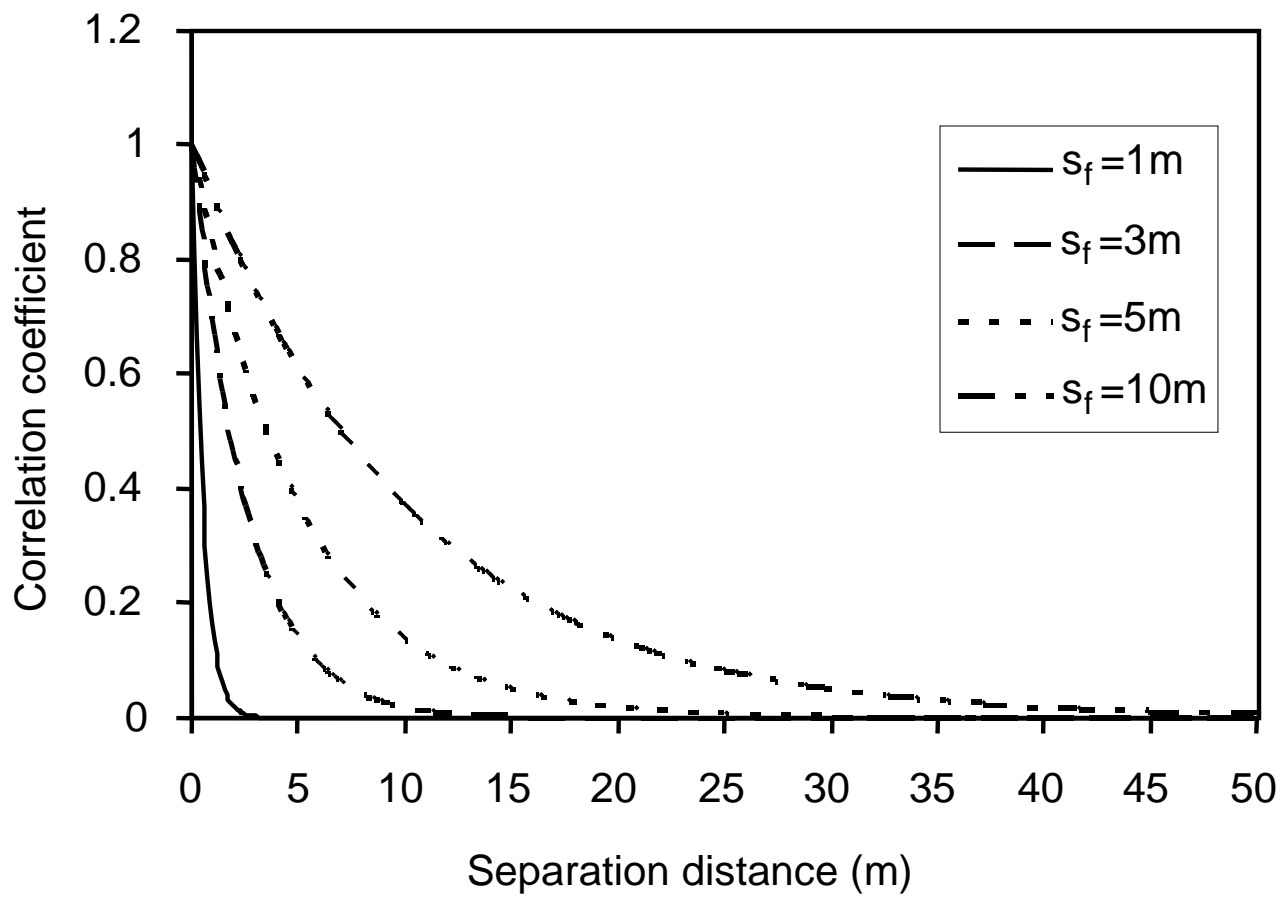

Figure 4.7 Exponential correlation coefficient functions for different isotropic scales of fluctuation (in one-direction) ( $\mathrm{s}_{\mathrm{f}}$ is the scale of fluctuation) 
For a two-dimensional isotropic random field, the exponential correlation coefficient function of a variable between two points that are $\Delta \mathrm{x}$ apart in the horizontal direction and $\Delta y$ apart in the vertical direction can be written as:

$$
\rho(\Delta x, \Delta y)=\exp \left(-\frac{2}{s_{f}} \sqrt{\Delta x^{2}+\Delta y^{2}}\right)
$$

Figure 4.8 shows a visual depiction of the surfaces created by Eq. (4.7) for different isotropic scales of fluctuation $\left(\mathrm{s}_{\mathrm{f}}=1,5,10\right.$, and $\left.20 \mathrm{~m}\right)$.

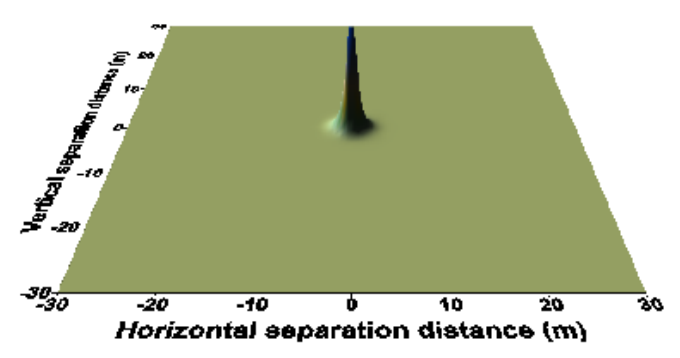

(a)

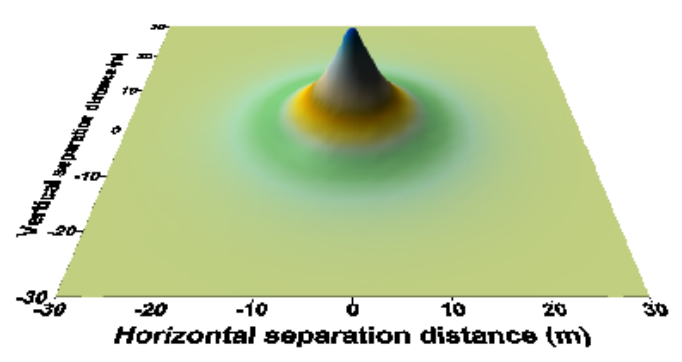

(c)

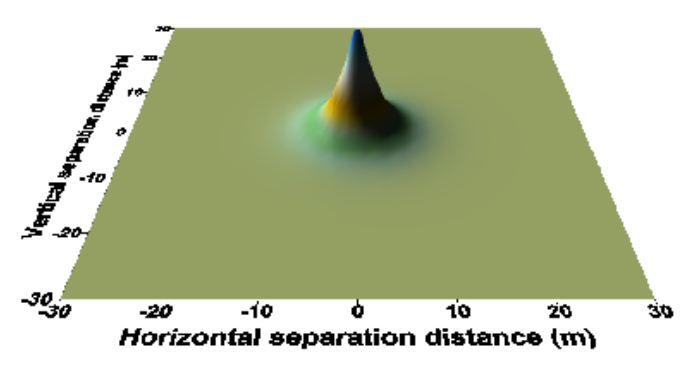

(b)

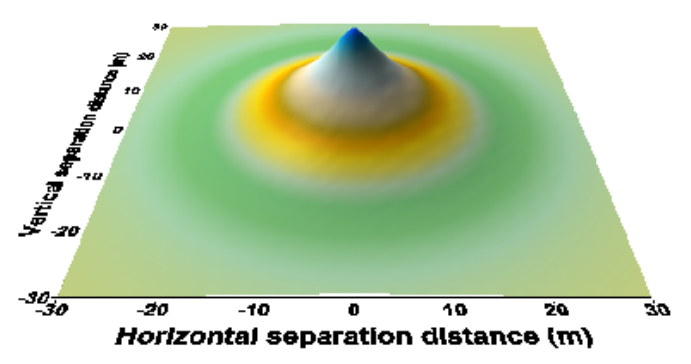

(d)

Figure 4.8 Surface maps of the exponential correlation coefficient functions in 2D space for different isotropic scales of fluctuation; (a) $\mathrm{s}_{\mathrm{f}}=1 \mathrm{~m}$, (b) $\mathrm{s}_{\mathrm{f}}=5 \mathrm{~m}$, (c) $\mathrm{s}_{\mathrm{f}}=10 \mathrm{~m}$, and (d) $\mathrm{s}_{\mathrm{f}}$ $=20 \mathrm{~m}$ 
Fenton (1990) derived the exponential correlation coefficient function in 2D space for an anisotropic random field:

$$
\rho(\Delta x, \Delta y)=\exp \left(-2 \sqrt{\left(\frac{\Delta x}{s_{f, x}}\right)^{2}+\left(\frac{\Delta y}{s_{f, y}}\right)^{2}}\right)
$$

where $s_{f, x}$ and $s_{f, y}$ are the scales of fluctuation for the two reference directions $x$ and $y$, respectively.

\subsubsection{Scale of fluctuation $\mathrm{s}_{f}$}

Determination of a reliable scale of fluctuation $s_{f}$ is not easy because large amounts of test data are required at narrow spacings. The smaller the value of $\mathrm{s}_{\mathrm{f}}$ is, the less correlation exists between two nearby values of a variable. If the $s_{f}$ is an infinite value, all the values of a random variable in a Gaussian random field are perfectly correlated; therefore, the values are the same over the whole Gaussian random field, and the layer is uniform. On the other hand, when $\mathrm{s}_{\mathrm{f}}$ is equal to zero, the values of the random variable at all locations are independent of each other. 
Table 4.4 shows the values of $\mathrm{s}_{\mathrm{f}}$ for the undrained shear strength that are reported or used in analyses in the literature. The scale of fluctuation in the horizontal direction is much larger than the one in the vertical direction. 
Table 4.4 Horizontal and vertical scales of fluctuation of undrained shear strength

\begin{tabular}{|c|c|c|c|c|c|}
\hline \multicolumn{2}{|c|}{$\begin{array}{c}\text { Soil } \\
\text { property }\end{array}$} & $\begin{array}{l}\text { Scale of } \\
\text { fluctuation }\end{array}$ & Soil type & Reference & Note \\
\hline \multirow{16}{*}{$\mathrm{s}_{\mathrm{u}}$} & \multirow{11}{*}{$\mathrm{V}$} & $0.8 \sim 6.1$ & clay & Phoon and Kulhawy (1999) & \\
\hline & & $5 \sim 12$ & - & Asaoka et al. (1982) & \\
\hline & & 8.6 & Chicago clay & Wu (1974) & \\
\hline & & $2.0 \sim 6.2$ & clay & Phoon and Kulhawy (1999) & VST \\
\hline & & $2 \sim 6$ & clay & Asaoka and A-Grivas (1982) & VST \\
\hline & & 2 & sensitive clay & Baecher (1982) & VST \\
\hline & & 4 & sensitive clay & Chaisson et al. (1995) & VST \\
\hline & & 4 & - & Soulie et al. (1990) & VST \\
\hline & & 5 & $\begin{array}{c}\text { New Liskeard } \\
\text { Varved clay }\end{array}$ & $\begin{array}{l}\text { Vanmarcke (1977) and Lacasse and } \\
\text { Ladd (1973) }\end{array}$ & VST \\
\hline & & 2.4 & $\begin{array}{l}\text { soft clay, } \\
\text { New York }\end{array}$ & Asaoka and A-Grivas (1982) & VST \\
\hline & & 6.2 & $\begin{array}{l}\text { soft clay, } \\
\text { New York }\end{array}$ & Asaoka and A-Grivas (1982) & VST \\
\hline & \multirow{4}{*}{$\mathrm{H}$} & 46 & sensitive clay & DeGroot and Baecher (1993) & VST \\
\hline & & 40 & - & Soulie et al. (1990) & VST \\
\hline & & 46 & $\begin{array}{c}\text { New Liskeard } \\
\text { varved clay }\end{array}$ & $\begin{array}{l}\text { Vanmarcke (1977) and Lacasse and } \\
\text { Ladd (1973) }\end{array}$ & VST \\
\hline & & $2 \sim 10$ & - & Al-Homoud and Tanash (2001) & \\
\hline & I & $\begin{array}{l}\text { Less than } 0.5 \\
\text { rarely more } \\
\text { than } 10\end{array}$ & - & Rackwitz (2000) & \\
\hline
\end{tabular}

(V: vertical, H: horizontal, I: isotropic, and VST: vane shear test)

The scale of fluctuation is determined by fitting measured data to the correlation coefficient function using regression techniques. Theoretically, the scale of fluctuation in 1D space is described as the area under the given exponential correlation coefficient function (Rackwitz, 2000; and Vanmarcke, 1983). Figure 4.9 shows the graphical expression of the relationship between the scale of fluctuation and the area under the correlation coefficient function (which takes the form of Eq. (4.5) in this case). Instead of using separation distance s given in Eq. (4.5), the correlation coefficient function is 
expressed using relative distance $\mathrm{x}$ in $1 \mathrm{D}$ space. A sign of $\mathrm{x}$ will be positive (negative) if a point is located on the right (left) side of a reference point.

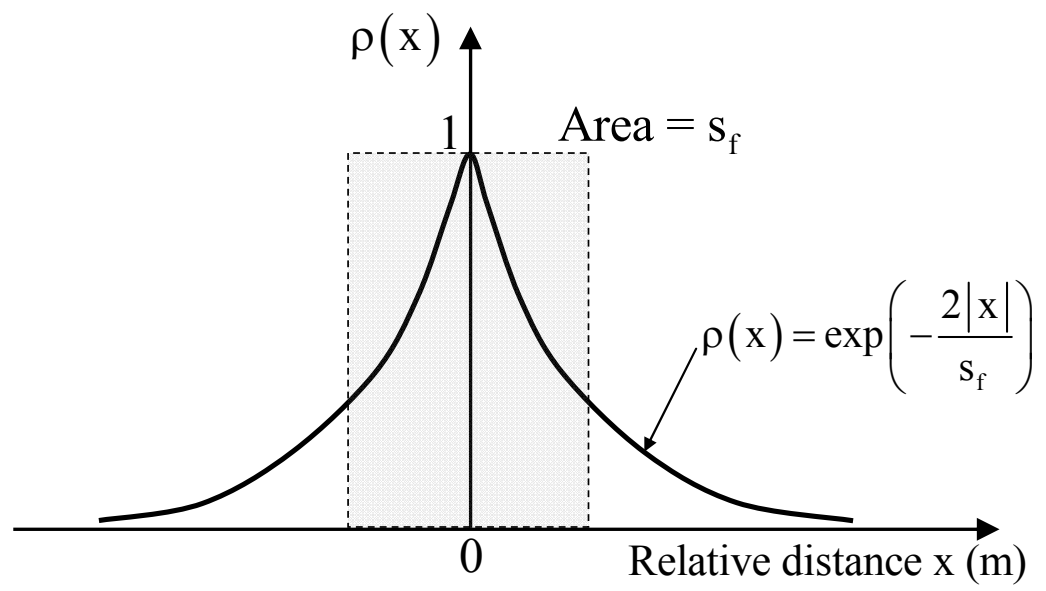

Figure 4.9 Meaning of scale of fluctuation $\mathrm{s}_{\mathrm{f}}$ for the exponential correlation coefficient function in $1 \mathrm{D}$ space

The area under the exponential correlation coefficient function in 1D space is

$$
\int_{-\infty}^{\infty} \rho(x) d x=\int_{-\infty}^{\infty} \exp \left(-\frac{2|x|}{s_{f}}\right) d x
$$

Because the correlation coefficient function is symmetrical about the y axis, Eq. (4.9) can be modified as

$$
\int_{-\infty}^{\infty} \exp \left(-\frac{2|x|}{s_{f}}\right) d x=2 \int_{0}^{\infty} \exp \left(-\frac{2 x}{s_{f}}\right) d x
$$

Evaluation of the integral proves that the area under the correlation coefficient function is equal to the isotropic scale of fluctuation. 


$$
2 \int_{0}^{\infty} \exp \left(-\frac{2 \mathrm{x}}{\mathrm{s}_{\mathrm{f}}}\right) \mathrm{dx}=\left.2\left(-\frac{2}{\mathrm{~s}_{\mathrm{f}}}\right)^{-1} \exp \left(-\frac{2 \mathrm{x}}{\mathrm{s}_{\mathrm{f}}}\right)\right|_{0} ^{\infty}=-\mathrm{s}_{\mathrm{f}}(0-1)=\mathrm{s}_{\mathrm{f}}
$$

For the exponential correlation coefficient function in 2D space, the value of the integral of the correlation coefficient function corresponds to the volume under the given correlation coefficient function. The larger volume under the given correlation coefficient function implies a stronger correlation between the soil property values. Despite the fact that scale of fluctuation of a soil property in the field is truly anisotropic, we are assuming isotropy in scale of fluctuation in our analysis. Therefore, we need to find an equivalent isotropic scale of fluctuation $\mathrm{s}_{\mathrm{f} \text {,eq }}$ that could replicate this anisotropy (represented by horizontal and vertical scales of fluctuation $\mathrm{s}_{\mathrm{f}, \mathrm{x}}$ and $\mathrm{s}_{\mathrm{f}, \mathrm{y}}$, respectively). Because the volume under the exponential correlation coefficient function implies the overall intensity of correlation between soil property values, we can find the $\mathrm{s}_{\mathrm{f}, \mathrm{eq}}$ by assuming that the volume under the correlation coefficient functions for isotropic scale of fluctuation (Eq. (4.7)) is the same as that for anisotropic scale of fluctuation (Eq.(4.8)).

The volume under the exponential correlation coefficient function for isotropic scale of fluctuation $\mathrm{V}_{\text {iso }}$ is

$$
\mathrm{V}_{\text {iso }}=\int_{-\infty}^{\infty} \int_{-\infty}^{\infty} \exp \left(-\frac{2}{\mathrm{~s}_{\mathrm{f}, \mathrm{eq}}} \sqrt{\mathrm{x}^{2}+\mathrm{y}^{2}}\right) \mathrm{dxdy}
$$

where $\mathrm{x}$ and $\mathrm{y}$ are the relative distances (or lagging distances) in the horizontal and vertical directions, respectively.

To get rid of the square root in Eq. (4.12), we can make the following substitution:

$$
\mathrm{x}=\mathrm{r} \cos \alpha \text { and } \mathrm{y}=\mathrm{r} \sin \alpha
$$

where $\mathrm{r}$ and $\alpha$ are nonnegative real variables $(0 \leq \mathrm{r} \leq \infty$ and $0 \leq \alpha \leq 2 \pi)$ 
$\mathrm{V}_{\text {iso }}$ becomes:

$$
\begin{aligned}
\mathrm{V}_{\text {iso }} & =\int_{0}^{\infty} \int_{0}^{2 \pi} \exp \left(-\frac{2}{\mathrm{~s}_{\mathrm{f}, \mathrm{eq}}} \sqrt{(\mathrm{r} \cos \alpha)^{2}+(\mathrm{r} \sin \alpha)^{2}}\right) \mathrm{rdr} \alpha \\
& =\int_{0}^{\infty} \int_{0}^{2 \pi} \mathrm{r} \exp \left(-\frac{2}{\mathrm{~s}_{\mathrm{f}, \mathrm{eq}}} \mathrm{r}\right) \mathrm{drd} \alpha=\frac{\pi}{2} \mathrm{~s}_{\mathrm{f}, \mathrm{eq}}^{2}
\end{aligned}
$$

The volume under the correlation coefficient functions for anisotropic scales of fluctuation $\left(\mathrm{s}_{\mathrm{f}, \mathrm{x}}\right.$ and $\left.\mathrm{s}_{\mathrm{f}, \mathrm{y}}\right)$ is

$$
\mathrm{V}_{\text {aniso }}=\int_{-\infty}^{\infty} \int_{-\infty}^{\infty} \exp \left(-2 \sqrt{\left(\frac{\mathrm{x}}{\mathrm{s}_{\mathrm{f}, \mathrm{x}}}\right)^{2}+\left(\frac{\mathrm{y}}{\mathrm{s}_{\mathrm{f}, \mathrm{y}}}\right)^{2}}\right) d x d y
$$

By representing $\mathrm{x} / \mathrm{s}_{\mathrm{f}, \mathrm{x}}=\mathrm{x}^{\prime}$ and $\mathrm{y} / \mathrm{s}_{\mathrm{f}, \mathrm{y}}=\mathrm{y}^{\prime}$, Eq. (4.15) can be modified as

$$
\begin{aligned}
\mathrm{V}_{\text {aniso }} & =\int_{-\infty}^{\infty} \int_{-\infty}^{\infty} \exp \left(-2 \sqrt{\mathrm{x}^{\prime 2}+\mathrm{y}^{\prime 2}}\right) \mathrm{s}_{\mathrm{f}, \mathrm{x}} \mathrm{s}_{\mathrm{f}, \mathrm{y}} \mathrm{dx} \mathrm{x}^{\prime} \mathrm{dy} \\
& =\mathrm{s}_{\mathrm{f}, \mathrm{x}} \mathrm{s}_{\mathrm{f}, \mathrm{y}} \int_{-\infty}^{\infty} \int_{-\infty}^{\infty} \exp \left(-2 \sqrt{\mathrm{x}^{\prime 2}+\mathrm{y}^{\prime 2}}\right) \mathrm{dx} \mathrm{x}^{\prime} \mathrm{dy} \mathrm{y}^{\prime}
\end{aligned}
$$

To remove the square root in Eq. (4.16), the substitution used earlier is made:

$$
x^{\prime}=r \cos \alpha \quad \text { and } \quad y^{\prime}=r \sin \alpha
$$


where $r$ and $\alpha$ are nonnegative real variables $(0 \leq r \leq \infty$ and $0 \leq \alpha \leq 2 \pi)$

From the evaluation of the integration, the volume under that correlation coefficient function for anisotropic scale of fluctuation is

$$
\begin{aligned}
\mathrm{V}_{\text {aniso }} & =\mathrm{s}_{\mathrm{f}, \mathrm{x}} \mathrm{s}_{\mathrm{f}, \mathrm{y}} \int_{0}^{\infty} \int_{0}^{2 \pi} \exp \left(-2 \sqrt{(\mathrm{r} \cos \alpha)^{2}+(\mathrm{r} \sin \alpha)^{2}}\right) \mathrm{rdr} \mathrm{d} \alpha \\
& =\frac{\pi}{2} \mathrm{~s}_{\mathrm{f}, \mathrm{x}} \mathrm{s}_{\mathrm{f}, \mathrm{y}}
\end{aligned}
$$

Given that the two volumes calculated in Eq. (4.14) and Eq. (4.18) must be the same, the equivalent isotropic scale of fluctuation $\mathrm{s}_{\mathrm{f}, \mathrm{eq}}$ can be expressed in terms of the two anisotropic scales of fluctuation $\left(\mathrm{s}_{\mathrm{f}, \mathrm{x}}\right.$ and $\left.\mathrm{s}_{\mathrm{f}, \mathrm{y}}\right)$ as:

$$
s_{f, e q}=\sqrt{s_{f, x} s_{f, y}}
$$

Scale of fluctuation of one direction can be interpreted as a factor that stretches the correlation coefficient function in the same direction. Suppose that we have a twodimensional correlation coefficient function that has an isotropic scale of fluctuation. Given that we have two axes ( $\mathrm{x}$ and $\mathrm{y}$ axes) that are perpendicular to each other, if we want to stretch the correlation coefficient in one direction by a factor $\mathrm{n}$ without changing the volume under the correlation coefficient function, the correlation coefficient function should shrink in the other direction by the same factor $n$.

Referring to the values of the vertical and horizontal scales of fluctuation in 
Table 4.4, it is acceptable to consider the possible maximum value for the equivalent isotropic scale of fluctuation for the undrained shear strength to be less than $20 \mathrm{~m}$. It is not proper to recommend isotropic scales of fluctuations of apparent cohesion and friction angle because they are just fitting parameters and negatively correlated to each other. However, for the development of LRFD for slopes, the equivalent isotropic scales of fluctuation of these two strength parameters (apparent cohesion and friction angle) are conservatively set to be $20 \mathrm{~m}$ based on considerations made earlier.

There is limited published study on the isotropic scale of fluctuation $\mathrm{s}_{\mathrm{f}}$ of soil unit weight. We assumed that the value of the isotropic scale of fluctuation of soil unit weight has a minor effect on the probability of failure of a slope because the COV of soil unit weight is very small compared to that of strength. In the next chapter, for a given slope, the sensitivity of probability of failure is tested by varying $\mathrm{s}_{\mathrm{f}}$ of the soil unit weight.

\subsection{Nonspatial Variability}

The assessment and implementation of the systematic error in Figure 4.1 is impractical because the errors are grouped together and it is impossible to assess the uncertainty of the systematic error separately from data scatter (spatial soil variability and measurement error). We will group sources of soil variability that are not related to spatial soil variability as nonspatial soil variability. The systematic error can be substantially reduced by increasing the number of measurements. In this study, we will consider that nonspatial variability results only from measurement error.

The assessment of the uncertainty of a measurement error is important because we need to separate spatial soil variability from nonspatial soil variability. The variance due to spatial soil variability is independent of that due to a measurement error (nonspatial soil variability). Therefore, the variance of measurements of the soil property is equal to the sum of the variance due to the spatial soil variability and that due to the measurement error. 


$$
\mathrm{V}\left[\mathrm{z}_{\mathrm{m}}\right]=\mathrm{V}\left[\mathrm{z}_{\text {spat }}\right]+\mathrm{V}[\mathrm{e}]
$$

where $z_{m}$ is the measurement of soil property, $z_{\text {spat }}$ is the soil property value reflecting spatial variability, and e is the measurement error.

There are two ways to separate the measurement error from the spatial soil variability when the variance (or the COV) of the measurement error is (1) known and (2) unknown (Kulhawy et al. 1992). For the known variance of measurement error, the calculation of the variance of spatial soil variability is straightforward from Eq. (4.20):

$$
\mathrm{V}\left[\mathrm{z}_{\text {spat }}\right]=\mathrm{V}\left[\mathrm{z}_{\mathrm{m}}\right]-\mathrm{V}[\mathrm{e}]
$$

When the variance of measurement error is unknown, the method of Christian et al. (1994) and Kulhawy et al. (1992) can be used. A figure in Christian et al. (1994) showing how the autocovariance of the measured undrained shear strength changes with the separation distance in the vertical direction is reproduced in Figure 4.10. 


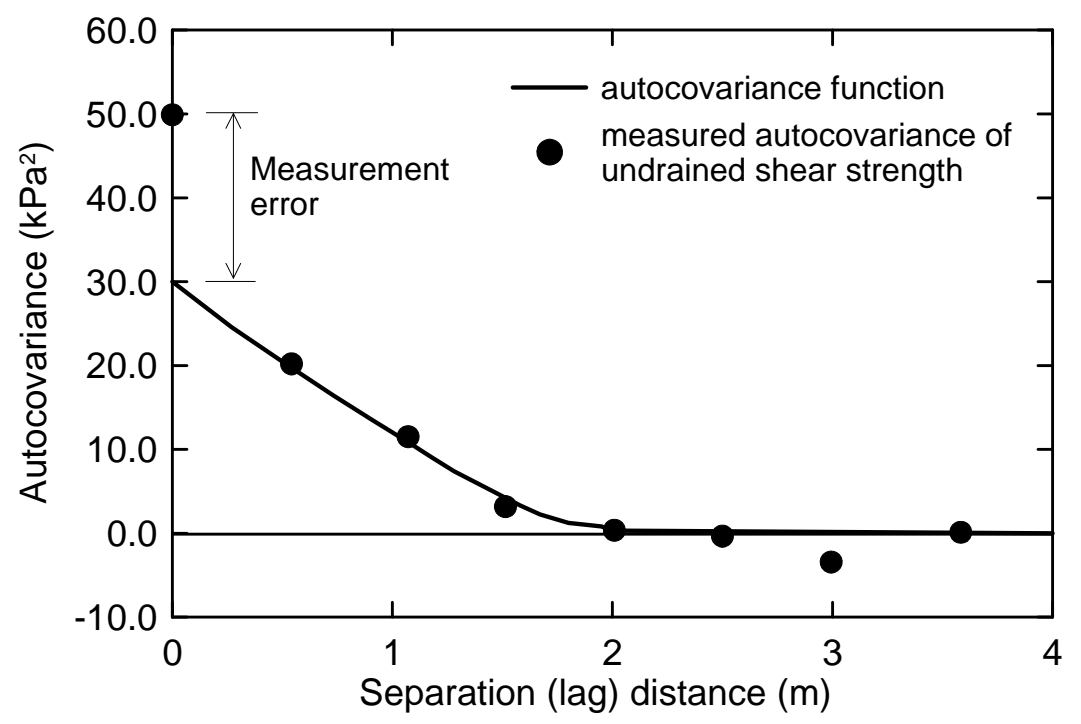

Figure 4.10 Estimation of the variance of measurement error of undrained shear strength $\mathrm{s}_{\mathrm{u}}$ by comparing the autocovariance function with the measured autocovariance values of undrained shear strength (after Christian et al., 1994)

Theoretically, the correlation coefficient value at zero separation distance should be equal to one; accordingly, the corresponding autocovariance value is equal to the variance of the undrained shear strength. However, in Figure 4.10, the autocovariance (covariance between two points) value from the measurement at the separation distance very close to zero is higher than its theoretical value (the variance of the undrained shear strength). Christian et al. (1994) and Kulhawy et al. (1992) explain that the difference between these two autocovariance values is the variance of measurement error.

There is only limited study on the evaluation of the total variation of measurements, spatial variability, and measurement error. Research on evaluation of these three types of uncertainty was conducted using limited data that are not sufficient to guarantee the accuracy of the proposed method. Orchant et al. (1988) observed that the typical range for the COV of measurement error for vane shear test is between 0.1 and 0.2 . For this reason, in our slope stability analysis, we consider a wider range (zero to 0.3 ) for the $\mathrm{COV}$ of measurement error. 


\subsection{Use of Fourier Transforms to Generate Gaussian Random Fields}

A Gaussian random field of a soil property for a statistically homogeneous soil layer is fully defined by the following components: (1) mean; (2) variation (or COV); (3) correlation coefficient function; and (4) scale of fluctuation.

Generation of a Gaussian random field that reflects the mean and standard deviation of the soil property could be done as follows: (1) select appropriate correlation coefficient function and scale of fluctuation that reproduces the spatial soil variability of the field; (2) generate a Gaussian random field that has zero mean and a standard deviation of one using the correlation coefficient function and scale of fluctuation; (3) multiply the standard deviation of the soil property by every value in the Gaussian random field that is generated in the previous step; (4) add the mean value of the soil property to each value of the Gaussian random field.

Fenton (1990) proposed a method for the generation of a Gaussian random field using Fourier transforms. The two-dimensional discrete Fourier transform of the real process written in terms of angular frequency is

$$
\begin{aligned}
\mathrm{z}_{\mathrm{ij}} & =\mathrm{z}\left(\mathrm{x}_{\mathrm{i}}, \mathrm{y}_{\mathrm{j}}\right)=\mathrm{z}(\mathrm{i} \Delta \mathrm{x}, \mathrm{j} \Delta \mathrm{y}) \\
& =\lim _{\mathrm{K}_{1} \rightarrow \infty} \lim _{\mathrm{K}_{2} \rightarrow \infty} \sum_{\mathrm{m}=0}^{\mathrm{K}_{1}-1} \sum_{\mathrm{n}=0}^{\mathrm{K}_{2}-1}\left[\mathrm{~A}_{\mathrm{mn}} \cos \left(\mathrm{i} \Delta \mathrm{x} \omega_{\mathrm{x}, \mathrm{m}}+\mathrm{j} \Delta \mathrm{y} \omega_{\mathrm{y}, \mathrm{n}}\right)+\mathrm{B}_{\mathrm{mn}} \sin \left(\mathrm{i} \Delta \mathrm{x} \omega_{\mathrm{x}, \mathrm{m}}+\mathrm{j} \Delta \mathrm{y} \omega_{\mathrm{y}, \mathrm{n}}\right)\right. \\
& =\lim _{\mathrm{K}_{1} \rightarrow \infty} \lim _{\mathrm{K}_{2} \rightarrow \infty} \sum_{\mathrm{m}=0}^{\mathrm{K}_{\mathrm{K}}-1} \sum_{\mathrm{n}=0}^{\mathrm{K}_{2}-1}\left[\mathrm{~A}_{\mathrm{mn}} \cos \left(\frac{2 \pi \mathrm{im}}{\mathrm{K}_{1}}+\frac{2 \pi \mathrm{jn}}{\mathrm{K}_{2}}\right)+\mathrm{B}_{\mathrm{mn}} \sin \left(\frac{2 \pi \mathrm{im}}{\mathrm{K}_{1}}+\frac{2 \pi \mathrm{jn}}{\mathrm{K}_{2}}\right)\right]
\end{aligned}
$$

where $\Delta \mathrm{x}$ and $\Delta \mathrm{y}$ are the discretization intervals in the $\mathrm{x}$ and $\mathrm{y}$ directions, $\mathrm{K}_{1}$ and $\mathrm{K}_{2}$ are the discretization elements in the $\mathrm{x}$ and $\mathrm{y}$ direction, $\mathrm{A}_{\mathrm{mn}}$ and $\mathrm{B}_{\mathrm{mn}}$ are the independent Fourier coefficients that follow a normal distribution with zero mean, $x_{i}$ and $y_{j}$ are the physical lengths from zero to the end of the $\mathrm{i}^{\text {th }}$ and $\mathrm{j}^{\text {th }}$ interval in the $\mathrm{x}$ and $\mathrm{y}$ directions, and $\omega_{\mathrm{x}, \mathrm{m}}\left(=2 \mathrm{~m} \pi / \mathrm{K}_{1} \Delta \mathrm{x}\right)$ and $\omega_{\mathrm{y}, \mathrm{n}}\left(=2 \mathrm{n} \pi / \mathrm{K}_{2} \Delta \mathrm{y}\right)$ are the angular frequencies of the Fourier series in the $\mathrm{x}$ and $\mathrm{y}$ directions. 
Because Gaussian random fields used in slope stability analysis have a finite number of discretization elements in the $\mathrm{x}$ and $\mathrm{y}$ direction, $\mathrm{z}_{\mathrm{ij}}$ can be represented as:

$$
\mathrm{z}_{\mathrm{ij}}=\sum_{\mathrm{m}=0}^{\mathrm{K}_{1}-1} \sum_{\mathrm{n}=0}^{\mathrm{K}_{2}-1}\left[\mathrm{~A}_{\mathrm{mn}} \cos \left(\frac{2 \pi \mathrm{im}}{\mathrm{K}_{1}}+\frac{2 \pi \mathrm{jn}}{\mathrm{K}_{2}}\right)+\mathrm{B}_{\mathrm{mn}} \sin \left(\frac{2 \pi \mathrm{im}}{\mathrm{K}_{1}}+\frac{2 \pi \mathrm{jn}}{\mathrm{K}_{2}}\right)\right]
$$

Then, the Fourier coefficients $A_{m n}$ and $B_{m n}$ (derivation of the Fourier coefficients is provided in Appendix C) in Eq. (4.23) are

$$
\begin{aligned}
& A_{m n}=\frac{1}{K_{1} K_{2}} \sum_{i=0}^{K_{1}-1} \sum_{j=0}^{K_{2}-1} z_{i j} \cos \left(\frac{2 \pi i m}{K_{1}}+\frac{2 \pi j n}{K_{2}}\right) \\
& B_{m n}=\frac{1}{K_{1} K_{2}} \sum_{i=0}^{K_{1}-1} \sum_{j=0}^{K_{2}-1} z_{i j} \sin \left(\frac{2 \pi i m}{K_{1}}+\frac{2 \pi j n}{K_{2}}\right)
\end{aligned}
$$

Because the expected value of $\mathrm{z}_{\mathrm{ij}}$ is zero for any points $\left(\mathrm{x}_{\mathrm{i}}, \mathrm{y}_{\mathrm{j}}\right)$ in the random field, the expected values of $A_{m n}$ and $B_{m n}$ must be zero; therefore, the variances of $A_{m n}$ and $B_{m n}$ are equal to the expected values of the squares of $A_{m n}$ and $B_{m n}$, respectively:

$$
\begin{aligned}
& \mathrm{V}\left[\mathrm{A}_{\mathrm{mn}}\right]=\mathrm{E}\left[\mathrm{A}_{\mathrm{mn}}^{2}\right] \\
&=\frac{1}{\left(\mathrm{~K}_{1} \mathrm{~K}_{2}\right)^{2}} \sum_{\mathrm{i}=0}^{\mathrm{K}_{1}-1} \sum_{\mathrm{j}=0}^{\mathrm{K}_{2}-1} \sum_{\mathrm{k}=0}^{\mathrm{K}_{1}-1} \sum_{\mathrm{l}=0}^{\mathrm{K}_{2}-1}\left\{\operatorname{E}\left[\mathrm{z}_{\mathrm{ij}} \mathrm{z}_{\mathrm{kl}}\right] \times\right. \\
& \mathrm{V}\left[\mathrm{B}_{\mathrm{mn}}\right]=\mathrm{E}\left[\mathrm{B}_{\mathrm{mn}}^{2}\right] \\
&=\frac{1}{\left(\mathrm{~K}_{1} \mathrm{~K}_{2}\right)^{2}} \sum_{\mathrm{i}=0}^{\mathrm{K}_{1}-1} \sum_{\mathrm{j}=0}^{\mathrm{K}_{2}-1} \sum_{\mathrm{k}=0}^{\mathrm{K}_{1}-1} \sum_{\mathrm{l}=0}^{\mathrm{K}_{2}-1}\left\{\cos \left(\frac{2 \pi \mathrm{km}}{\mathrm{K}_{1}}+\frac{2 \pi \mathrm{ln}}{\mathrm{K}_{2}}\right)\right\} \\
&\left.\sin \left(\frac{2 \pi \mathrm{im}}{\mathrm{K}_{1}}+\frac{2 \pi \mathrm{jn}}{\mathrm{K}_{2}}\right) \sin \left(\frac{2 \pi \mathrm{km}}{\mathrm{K}_{1}}+\frac{2 \pi \mathrm{ln}}{\mathrm{K}_{2}}\right)\right\}
\end{aligned}
$$


The calculation of the variances of $A_{m n}$ and $B_{m n}$ can be approximated using the spectral density function $\mathrm{S}$ of the process $\mathrm{z}_{\mathrm{ij}}$. The spectral density function represents the strength of the variations in terms of frequency. For example, when the spectral density function has a high value at a certain frequency, it means the variation at that frequency is strong. The integration of the spectral density function within a specific frequency range renders the strength of variation within that frequency range. From Wiener-Chintchin relationship, the relationship between spectral density function $\mathrm{S}$ and the correlation coefficient function $\rho$ for the Gaussian random field is

$$
\rho(x, y)=\int_{-\infty}^{\infty} \int_{-\infty}^{\infty} S\left(\omega_{x}, \omega_{y}\right) \cos \left(\omega_{x} x+\omega_{y} y\right) d \omega_{x} d \omega_{y}
$$

where $\mathrm{x}$ and $\mathrm{y}$ are the separation distances in the horizontal and vertical directions, respectively.

Using the relationship that $\cos (\alpha+\beta)=\cos (\alpha) \cos (\beta)-\sin (\alpha) \sin (\beta)$, Eq. (4.28) can be modified as

$$
\rho(\mathrm{x}, \mathrm{y})=\int_{-\infty}^{\infty} \int_{-\infty}^{\infty}\left\{\begin{array}{l}
\mathrm{S}\left(\omega_{\mathrm{x}}, \omega_{\mathrm{y}}\right) \\
\times\left[\cos \left(\omega_{\mathrm{x}} \mathrm{x}\right) \cos \left(\omega_{\mathrm{y}} \mathrm{y}\right)-\sin \left(\omega_{\mathrm{x}} \mathrm{x}\right) \sin \left(\omega_{\mathrm{y}} \mathrm{y}\right)\right]
\end{array}\right\} \mathrm{d} \omega_{\mathrm{x}} \mathrm{d} \omega_{\mathrm{y}}
$$

Because the spectral density function $\mathrm{S}$ is even function with respect to each direction $\mathrm{x}$ and $\mathrm{y}$, Eq. (4.29) can be revised as

$$
\rho(x, y)=2^{2} \int_{0}^{\infty} \int_{0}^{\infty} S\left(\omega_{x}, \omega_{y}\right) \cos \left(\omega_{x} x\right) \cos \left(\omega_{y} y\right) d \omega_{x} d \omega_{y}
$$

By defining the one-sided spectral density function $G$ as 


$$
\mathrm{G}\left(\omega_{\mathrm{x}}, \omega_{\mathrm{y}}\right)=2^{2} \mathrm{~S}\left(\omega_{\mathrm{x}}, \omega_{\mathrm{y}}\right)
$$

Eq. (4.30) can be revised as

$$
\rho(x, y)=\int_{0}^{\infty} \int_{0}^{\infty} G\left(\omega_{x}, \omega_{y}\right) \cos \left(\omega_{x} x\right) \cos \left(\omega_{y} y\right) d \omega_{x} d \omega_{y}
$$

For the Gaussian random field that has zero mean and standard deviation of one, the correlation coefficient function of the process $\mathrm{z}_{\mathrm{ij}}$ can be represented as

$$
\rho_{z}(x, y)=E\left[z\left(\xi_{x}, \xi_{y}\right) z\left(\xi_{x}+x, \xi_{y}+y\right)\right]
$$

where $\xi_{\mathrm{x}}$ and $\xi_{\mathrm{y}}$ are the random variables in $\mathrm{x}$ and $\mathrm{y}$ directions.

Suppose that the separation distances in the horizontal and vertical directions are $\mathrm{x}=|\mathrm{i}-\mathrm{k}| \Delta \mathrm{x}$ and $\mathrm{y}=|\mathrm{j}-1| \Delta \mathrm{y}$, respectively. From Eq. (4.30) and Eq. (4.33), the correlation coefficient function $\rho_{z}$ of the process $z_{i j}$ can be written in terms of the spectral density function $\mathrm{G}_{\mathrm{z}}$ :

$$
\begin{aligned}
& \rho_{\mathrm{z}}(\mathrm{x}, \mathrm{y})=\rho_{\mathrm{z}}(|\mathrm{i}-\mathrm{k}| \Delta \mathrm{x},|\mathrm{j}-\mathrm{k}| \Delta \mathrm{y})= \\
& \mathrm{E}\left[\mathrm{z}_{\mathrm{ij}} \mathrm{z}_{\mathrm{k} l}\right] \approx \Delta \omega_{\mathrm{x}} \Delta \omega_{\mathrm{y}} \sum_{\mathrm{m}=0}^{\mathrm{K}_{1}-1} \sum_{\mathrm{n}=0}^{\mathrm{K}_{2}-1} \mathrm{G}_{\mathrm{z}}\left(\omega_{\mathrm{x}, \mathrm{m}}, \omega_{\mathrm{y}, \mathrm{n}}\right) \cos \left(\frac{2 \pi \mathrm{m}(\mathrm{i}-\mathrm{k})}{\mathrm{K}_{1}}\right) \cos \left(\frac{2 \pi \mathrm{n}(\mathrm{j}-1)}{\mathrm{K}_{1}}\right)
\end{aligned}
$$

From the Wiener-Khinchin relationship, the spectral density function $G_{z}$ for the correlation coefficient function $\rho_{z}(\mathrm{x}, \mathrm{y})($ Eq. (4.7)) is

$$
\mathrm{G}_{\mathrm{z}}\left(\omega_{\mathrm{x}, \mathrm{m}}, \omega_{\mathrm{y}, \mathrm{n}}\right)=\left(\frac{1}{\pi}\right)^{2} \int_{0}^{\infty} \int_{0}^{\infty} \rho_{\mathrm{z}}(\mathrm{x}, \mathrm{y}) \cos \left(\omega_{\mathrm{x}, \mathrm{m}} \mathrm{x}+\omega_{\mathrm{y}, \mathrm{n}} \mathrm{y}\right) \mathrm{dx} d \mathrm{y}
$$


The integration of Eq. (4.35) reveals (Fenton, 1990)

$$
\mathrm{G}_{\mathrm{z}}\left(\omega_{\mathrm{x}, \mathrm{m}}, \omega_{\mathrm{y}, \mathrm{n}}\right)=\frac{4 \mathrm{~s}_{\mathrm{f}}^{2}}{\pi\left(4+\mathrm{s}_{\mathrm{f}}^{2}\left(\omega_{\mathrm{x}, \mathrm{m}}{ }^{2}+\omega_{\mathrm{y}, \mathrm{n}}{ }^{2}\right)\right)^{1.5}}
$$

By inserting Eq. (4.34) into Eq. (4.26) and Eq. (4.27), the variances of $A_{m n}$ and $B_{m n}$ are summarized as follows (Fenton, 1990):

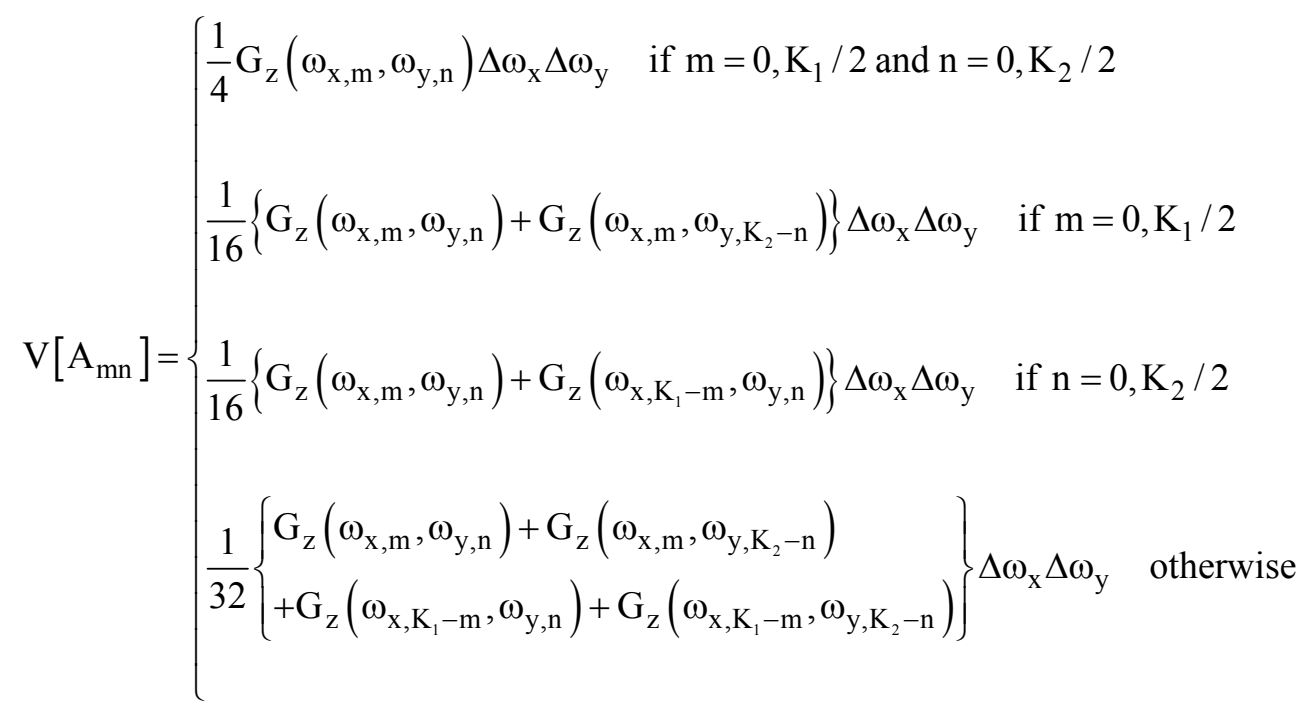

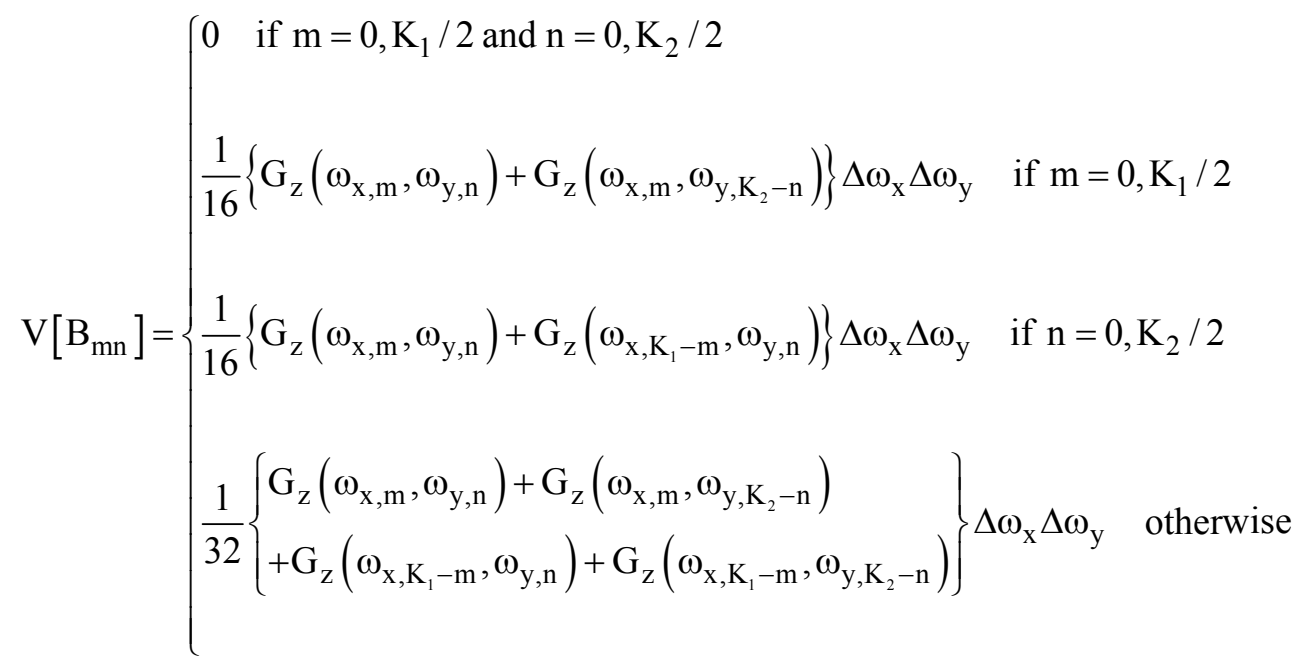




\subsection{Procedure for Gaussian Random Field Generation}

The following are the steps for the generation of a two-dimensional Gaussian random field using Fourier transforms (Fenton, 1990):

1. Suppose the area for which we will use a Gaussian random field theory to represent a specific soil property has dimensions $\mathrm{L}_{1} \times \mathrm{L}_{2}\left(\mathrm{~L}_{1}\right.$ and $\mathrm{L}_{2}$ are the lengths in the horizontal and vertical directions, respectively). In this case, we need to generate a Gaussian random field for which the lengths in each direction ( $\mathrm{D}_{1}$ and $\mathrm{D}_{2}$ for the horizontal and vertical directions respectively) are twice the required lengths $\left(D_{1}=2 L_{1}\right.$ and $\left.D_{2}=2 L_{2}\right)$. The excess lengths will be disregard in the final step (Fenton, 1994);

2. Divide the lengths of the horizontal and vertical directions $\left(\mathrm{D}_{1}\right.$ and $\left.\mathrm{D}_{2}\right)$ into small intervals;

3. Calculate the variances of $A_{m n}$ and $B_{m n}$ for $m=0,1, \cdots, K_{1}-1$ and $n=0,1, \cdots, K_{2}-1$ using Eq. (4.37) and Eq. (4.38);

4. Generate random numbers for $A_{m n}$ and $B_{m n}$ (for $m=0,1, \cdots, K_{1}-1$ and $n=0,1, \cdots$ , $\mathrm{K}_{2}-1$ ) based on the assumptions that $\mathrm{A}_{\mathrm{mn}}$ and $\mathrm{B}_{\mathrm{mn}}$ follow normal distributions with zero mean and the variance determined in the previous step (step 3);

5. Generate the values of the random variable $\mathrm{z}\left(\mathrm{x}_{\mathrm{i}}, \mathrm{x}_{\mathrm{j}}\right)_{\text {real }}$ for all the discretization points for the required domain $\left(\mathrm{L}_{1} \times \mathrm{L}_{2}\right)$ by inputting $\mathrm{A}_{\mathrm{mn}}$ and $\mathrm{B}_{\mathrm{mn}}$ values into Eq. (4.23);

6. Multiply the $\mathrm{z}\left(\mathrm{x}_{\mathrm{i}}, \mathrm{x}_{\mathrm{j}}\right)$ real values by the standard deviation of the soil property and add its mean value to them for the representation of the soil property.

Using this procedure, we generated two-dimensional Gaussian random fields that have zero mean and unit standard deviation for different scales of fluctuation $\left(\mathrm{s}_{\mathrm{f}}=1,5,10\right.$, and 20), as shown in Figure 4.11. For each scale of fluctuation, Figure 4.11 shows the horizontal and tilted (15 degrees from the horizontal) views of the surface map of the Gaussian random field. 


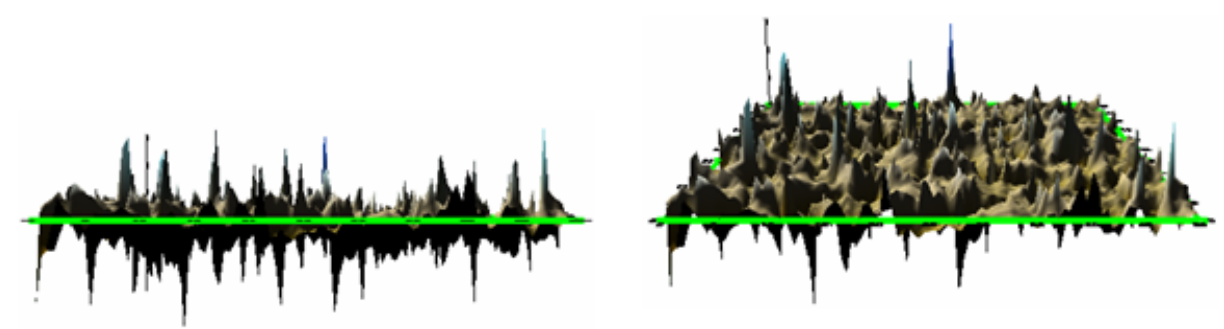

(a) $\mathrm{s}_{\mathrm{f}}=1 \mathrm{~m}$
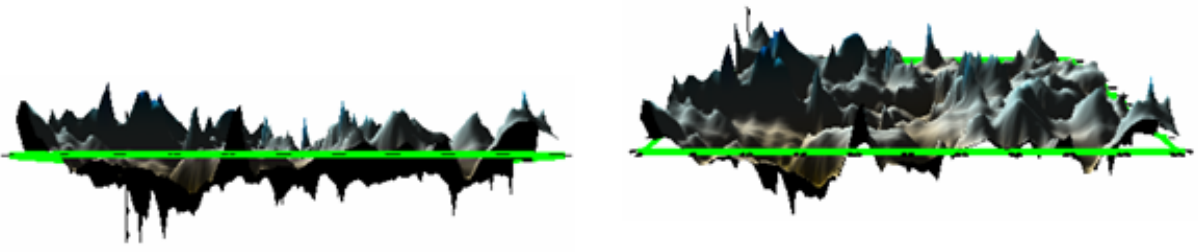

(b) $\mathrm{s}_{\mathrm{f}}=5 \mathrm{~m}$
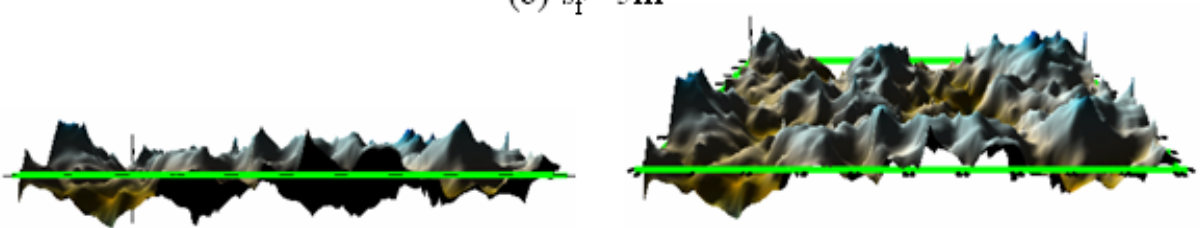

(c) $\mathrm{s}_{\mathrm{f}}=10 \mathrm{~m}$
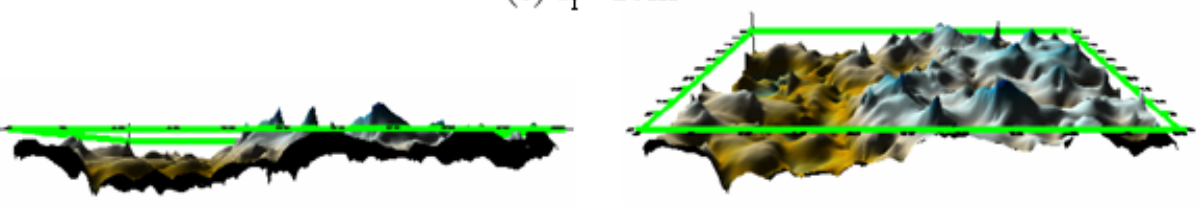

(d) $\mathrm{s}_{\mathrm{f}}=20 \mathrm{~m}$

Figure 4.11 Horizontal and tilted views of surface map of two-dimensional Gaussian random fields that has zero mean and unit standard deviation for different scales of fluctuation; (a) $\mathrm{s}_{\mathrm{f}}=1 \mathrm{~m}$, (b) $\mathrm{s}_{\mathrm{f}}=5 \mathrm{~m}$, (c) $\mathrm{s}_{\mathrm{f}}=10 \mathrm{~m}$, and (d) $\mathrm{s}_{\mathrm{f}}=20 \mathrm{~m}$ 


\section{CHAPTER 5. EXAMPLES OF RESISTANCE FACTOR CALCULATION}

In this chapter, a series of slope stability analyses were performed using Monte Carlo simulations to examine the effect of the scale of fluctuation and the uncertainty level of measurement error on the probability of failure of the slope. In addition, examples are given to show how to determine optimum factors (both optimum load and resistance factors) for LRFD of slopes.

\subsection{Effect of the Measurement Error on the Probability of Failure}

To examine the effect of the measurement error on the probability of failure of slopes, sets of reliability analyses were performed for the slope given in Figure 5.1, varying the $\mathrm{COV}$ of measurement error. We assumed that the mean values for apparent cohesion c, friction angle $\phi$ and soil unit weight $\gamma$ of each soil layer are the values shown in Figure 5.1. The COVs for the spatial variabilities of $\mathrm{c}, \phi$, and $\gamma$ that are used for this analysis are taken as $0.2,0.2$, and 0.05 , respectively. The scales of fluctuation for the parameters $\mathrm{c}, \phi$, and $\gamma$ are assumed as $10 \mathrm{~m}$. The $\mathrm{COV}$ and scale of fluctuation values for these soil parameters are selected for the purpose of examining the effect of the measurement error on the probability of failure. These values are different from the values that we are using for the development of LRFD for slopes. 


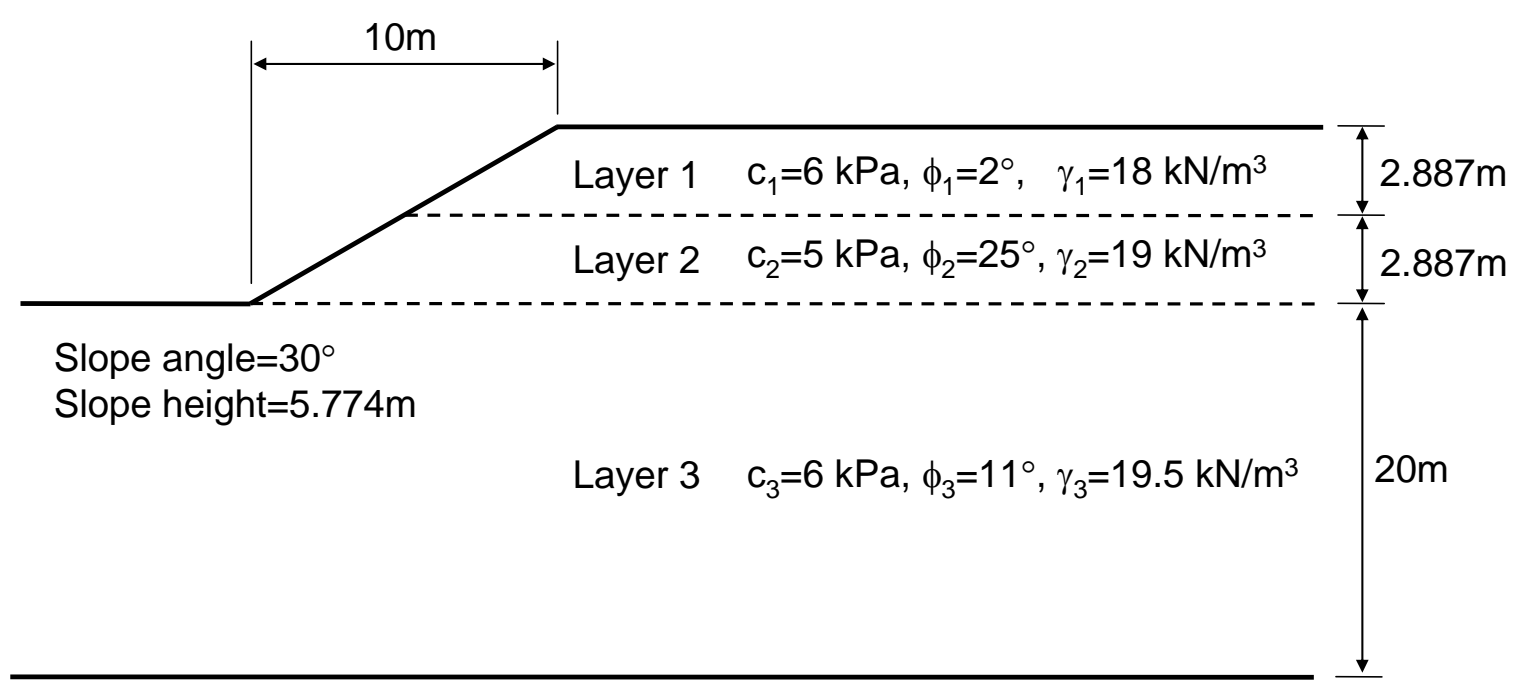

Figure 5.1 Geometry of a three-layer soil slope and its soil properties

Different levels of the COV of measurement error are selected $(0,0.1,0.2$, and 0.3 ) to assess its effect on the probability of failure of the given slope. For each level of the COV of measurement, the computed probability of failure using Monte Carlo simulation with 10,000 realizations (or FS calculations) varied from simulation to simulation within a narrow range. To overcome this convergence issue, a large number of realizations are required. We tried to determine the minimum number of realizations that would produce a converging (or consistent) probability of failure. From Figure 5.2, we had a fairly consistent probability of failure after 30,000 realizations. Accordingly, we conducted more than 30,000 realizations in Monte Carlo simulation for every probability of failure calculation.

As shown in Figure 5.2, we found that an increase in the COV of the measurement error does not have a significant effect on probability of failure. If the method of slices is used for slope stability analysis, distribution of the measurement error at each slice has zero mean following a normal distribution; therefore, the probability that the measurement error of soil property will increase the stability of a slope is equal to the probability that it will decrease the stability of the slope. For a large number of slices this means that the change in probability of failure due to the measurement error is not significant. 


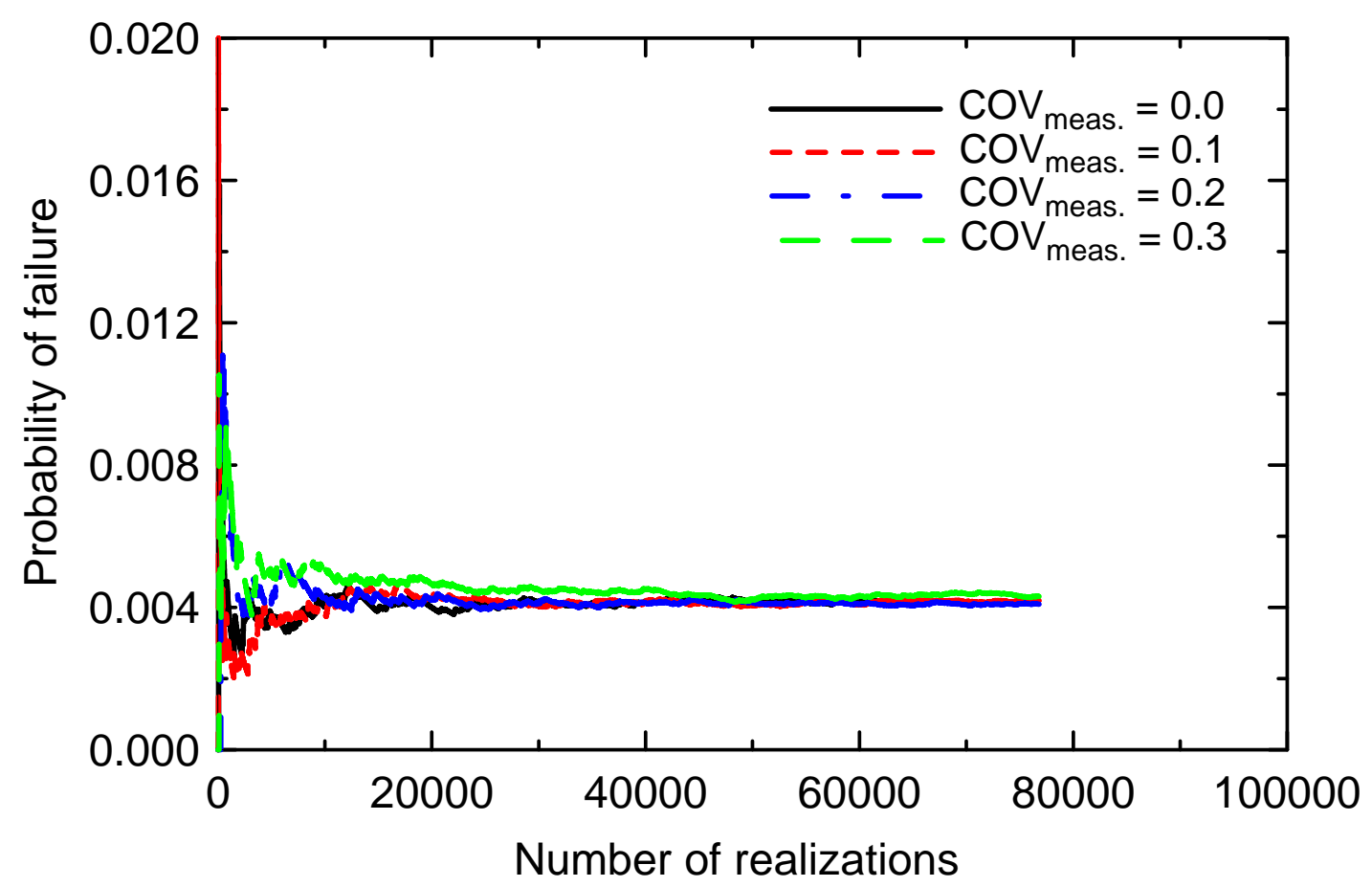

Figure 5.2 Effect of the COV of measurement on a probability of failure of the slope given in Figure 5.1

\subsection{Effect of the Isotropic Scale of Fluctuation of Soil Unit Weight on the Probability of} $\underline{\text { Failure }}$

As mentioned in chapter 4 , due to the scarcity of published research performed on the isotropic scale of fluctuation $s_{f}$ of soil unit weight, we conducted sets of reliability analyses for the slope given in Figure 5.1 to examine the effect of the isotropic scale of fluctuation of soil unit weight on the probability of failure of the slope, fixing the $\mathrm{s}_{\mathrm{f}}$ values of strength parameters equal to $10 \mathrm{~m}$ and varying the $\mathrm{s}_{\mathrm{f}}$ of soil unit weight $\left(\mathrm{s}_{\mathrm{f}}=1,5\right.$, 10 , and $20 \mathrm{~m}$ ). We assumed that the mean values and COVs for spatial variabilities of the parameters (c, $\phi$, and $\gamma$ ) used for this analysis are the same as those used in the example in the previous section (section 5.1).

The probabilities of failure calculated for the slope in Figure 5.1 for different values of $\mathrm{s}_{\mathrm{f}}\left(\mathrm{s}_{\mathrm{f}}=1,5,10\right.$, and $\left.20 \mathrm{~m}\right)$ of soil unit weight are represented in Figure 5.3. The probability of failure ranged from 0.0042 to 0.0049 with an average of 0.0046 . Even though we observe some difference in probability of failure with respect to the value of 
isotropic scale of fluctuation of soil unit weight, its effect on the probability of failure is minor. Therefore, for the development of LRFD for slopes, it is acceptable that we assume the equivalent isotropic scale of fluctuation for the soil unit weight is $20 \mathrm{~m}$.

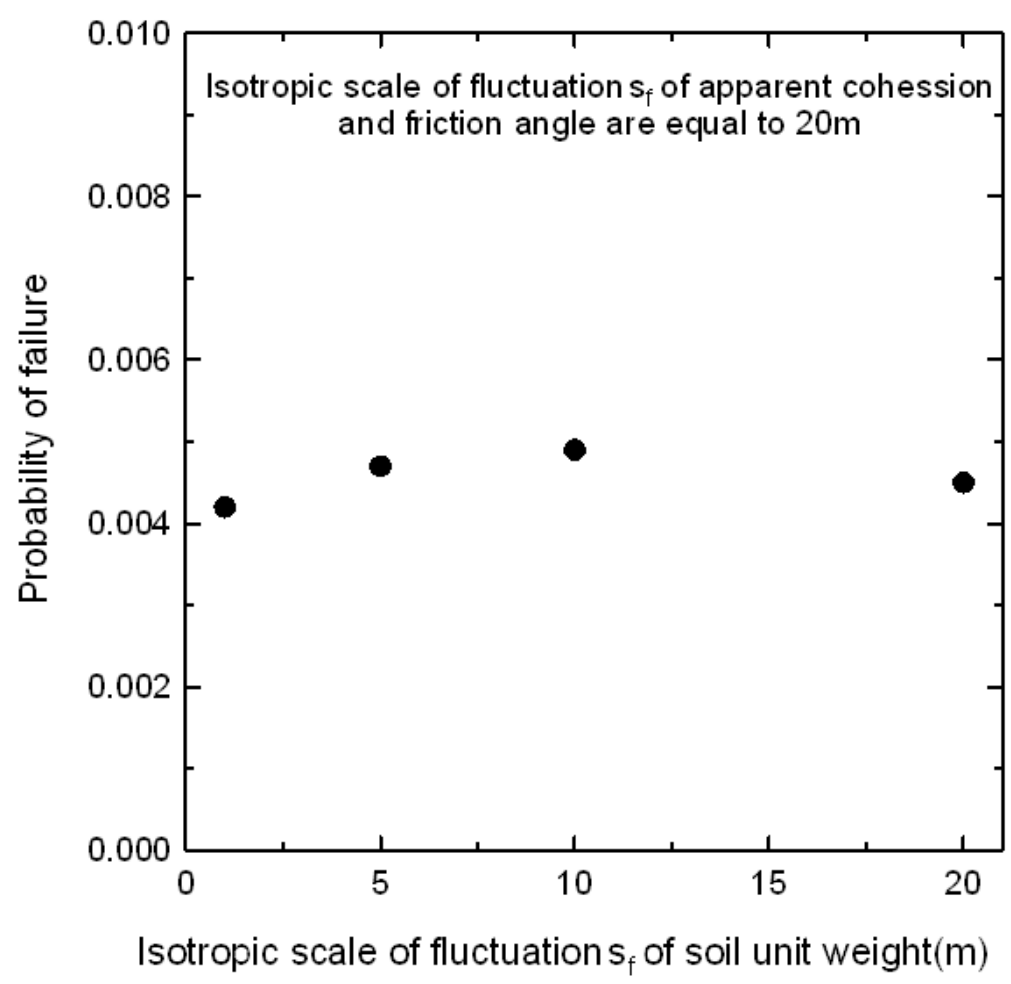

Figure 5.3 Probability of failure of the slope shown in Figure 5.1 for different isotropic scale of fluctuation of soil unit weight

\subsection{Effect of the Isotropic Scales of Fluctuation of the Soil Properties on the Probability of Failure}

In the previous section (section 5.2), we have seen that the effect of the isotropic scale of fluctuation of soil unit weight on the probability of failure is insignificant. However, to examine the effect of the isotropic scale of fluctuation of $c, \phi$, and $\gamma$ on the probability of failure assuming that the scales of fluctuation of the parameters (c, $\phi$, and $\gamma)$ are the same, calculations of probability of failure using Monte Carlo simulations were 
conducted for different values $(0,1,5,10,20$, and $40 \mathrm{~m})$ of isotropic scale of fluctuation. The geometry of the slope, and the means and COVs of the spatial variabilities of soil properties are the same as those used in the example in the previous sections (section 5.1 and 5.2). Comparing the results of each simulation, Figure 5.4 illustrates that the probability of failure of the slope increased significantly with increasing scale of fluctuation.

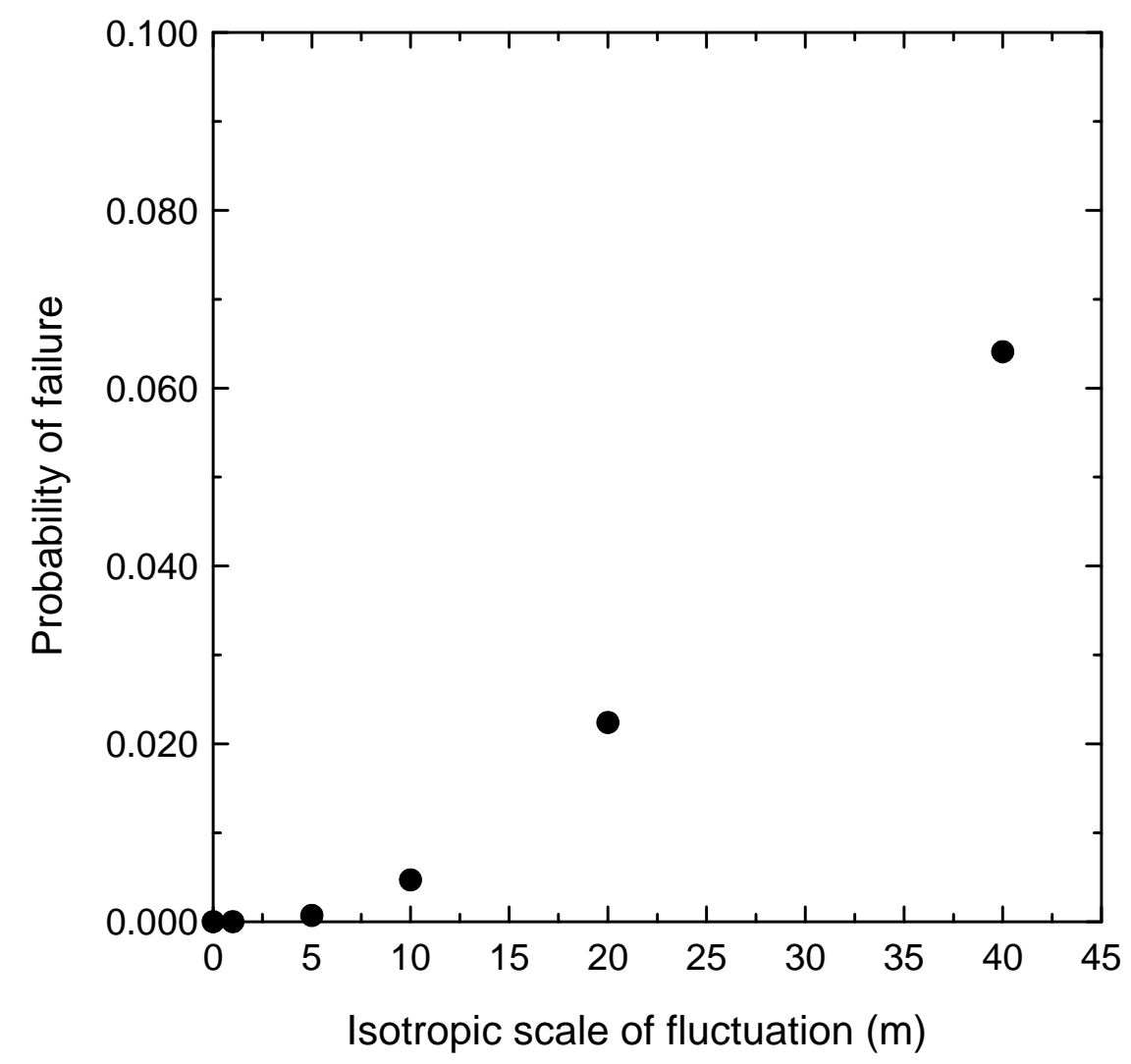

Figure 5.4 Effect of the isotropic scale of fluctuation on a probability of failure

The reason for this observation is as follows: a higher scale of fluctuation $\mathrm{s}_{\mathrm{f}}$ for a soil parameter indicates a higher correlation of the soil parameter at two points at some fixed distance; therefore, the values of the soil property at these points will deviate similarly from the mean value of the soil parameter. This means that a Gaussian random 
field with a higher $s_{f}$ may result significantly weaker across the entire slope or large parts of it more often, which in turn leads to lower probability of failure.

\subsection{Examples for Slopes and Embankments}

In this section, the optimum resistance and load factors are calculated following the algorithm shown in Figure 3.3. Two different target probabilities of failure $P_{f}$ are considered $\left(P_{f}=0.001\right.$ and 0.01$)$. Even though the suggestion of COV values for apparent cohesion and friction angle is not advisable, the COV values for apparent cohesion, friction angle, and soil unit weight are assumed as $0.4,0.4,0.2$, and 0.1 , respectively, for the purpose of developing LRFD for slopes. The isotropic scales of fluctuation for the soil parameters (c, $\phi$, and $\gamma$ ) are taken as $20 \mathrm{~m}$, as mentioned in the previous chapter.

5.4.1. Slope example 1: $\mathrm{P}_{\mathrm{f}}=0.001$, no live uniform surcharge load on the crest of the slope

The algorithm for LRFD of slopes shown in Figure 3.3 is used for a slope with the geometry of Figure 5.5. In the analysis, 30,000 realizations (or FS calculations) were done, each for one combination of random fields for all the soil parameters of every soil layer, and the results were used for each calculation of the probability of failure for the slope. 


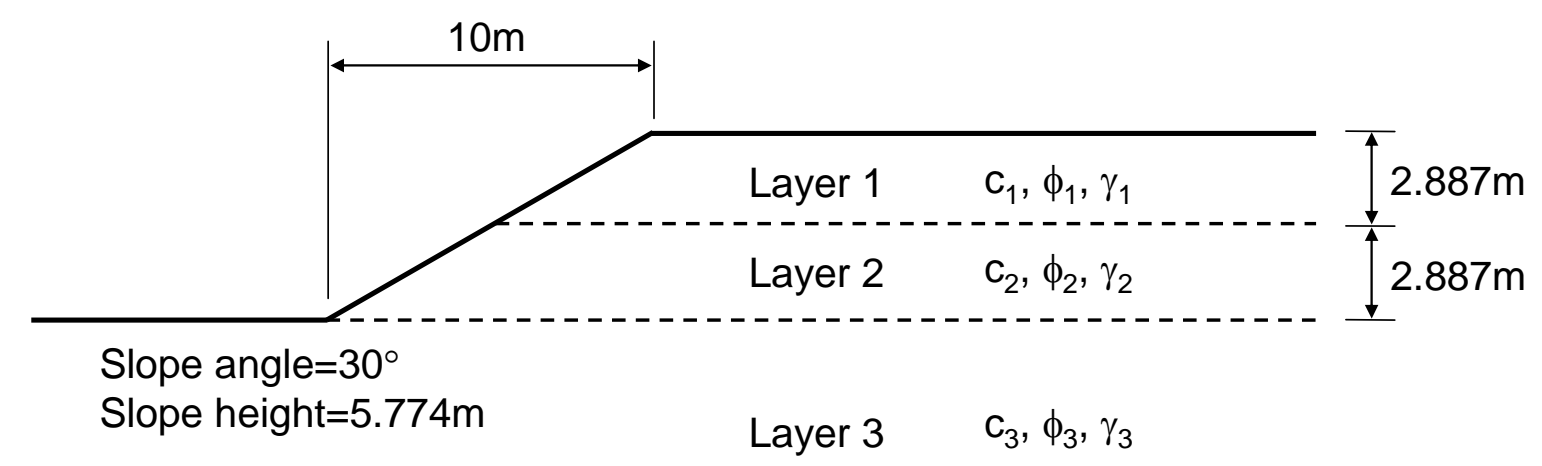

Figure 5.5 Geometry of a three-layer soil slope

To find the combination of the expect values of the soil parameters (c, $\phi$, and $\gamma)$ of each layer that produce the target probability of failure $\left(\mathrm{P}_{\mathrm{f}}=0.001\right)$, the initial guess for the soil parameters was as follow: (1) layer 1: $\mathrm{c}_{1}=5 \mathrm{kPa}, \phi_{1}=10^{\circ}, \gamma_{1}=18 \mathrm{kN} / \mathrm{m}^{3}$; (2) layer 2: $\mathrm{c}_{2}=2 \mathrm{kPa}, \phi_{2}=25^{\circ}, \gamma_{2}=19 \mathrm{kN} / \mathrm{m}^{3}$; and (3) layer $3: \mathrm{c}_{3}=10 \mathrm{kPa}, \phi_{3}=15^{\circ}, \gamma_{3}$ $=19.5 \mathrm{kN} / \mathrm{m}^{3}$. The calculated probability of failure in this case was 0.0031 . By changing these expected values, we found the expected values of the soil parameters that produced the target probability of failure (0.001): (1) layer 1: $\mathrm{c}_{1}=11.2 \mathrm{kPa}, \phi_{1}=10^{\circ}, \gamma_{1}=18$ $\mathrm{kN} / \mathrm{m}^{3}$; (2) layer $2: \mathrm{c}_{2}=5 \mathrm{kPa}, \phi_{2}=20^{\circ}, \gamma_{2}=19 \mathrm{kN} / \mathrm{m}^{3}$; and (3) layer $3: \mathrm{c}_{3}=10 \mathrm{kPa}, \phi_{3}=$ $20^{\circ}, \gamma_{3}=19.5 \mathrm{kN} / \mathrm{m}^{3}$.

Due to the absence of external loads, the driving moment was induced only by the self-weight of the soil. Therefore, only one optimum load factor exists in this example. For a given slip surface, if the soil strengths have friction angle components, the soil selfweights within the potential sliding mass influence both the driving and resisting moments. For example, the soil self-weight of the potential sliding mass increases both the driving and resisting moments. Therefore, the driving moment and resisting moment are correlated. However, if the soil strengths only result from cohesion (with $\phi=0$ ), the self-weight of the soil within the potential sliding mass affects only the driving moment, not the resisting moment. 
The distribution of the FS is shown in Figure 5.6. This distribution matches well with a normal distribution. The probability of failure is very close to the target probability of failure of 0.001 (29 failure cases out of 30,000 realizations). In the program, the driving and resisting moments are normalized with respect to the corresponding radius of the circular slip surface. This normalization has no influence on the FS calculation. The ULS corresponds to the case that is equal to or closest to FS of one (FS=1); for this particular Monte Carlo simulation, the ULS values of the driving and resisting moments divided by the radius of the circular slip surface $r_{\text {slip }}$ are 145.392 and $145.382 \mathrm{kNm} / \mathrm{m} / \mathrm{m}$ respectively.

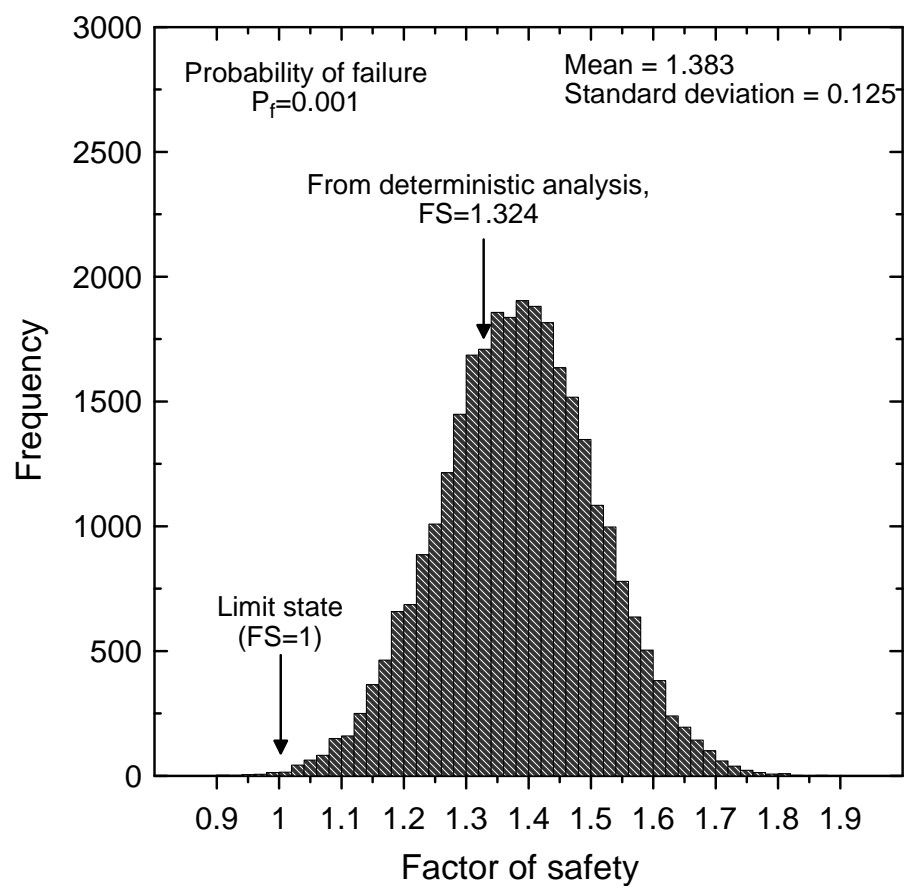

Figure 5.6 Distribution of FS value and the ULS of the slope $\left(\mathrm{P}_{\mathrm{f}}=0.001\right.$ and without live uniform surcharge load)

For the calculation of nominal values of the driving and resisting moments, a conventional (deterministic) slope stability analysis was performed using the nominal values of the soil parameters and geometry of the slope. For the soil parameters $\mathrm{c}, \phi$, and $\gamma$, in these analysis, the bias factors are equal to one; therefore, the nominal values of 
these parameters are the same as their mean values. However, the mean values of external loads are different from their nominal values because the bias factors of external loads are not equal to one.

From the results of the deterministic slope stability analysis, the FS and the nominal values of the driving and resisting moments divided by the radius of the circular slip surface $r_{\text {slip }}$ from the deterministic slope stability analysis are:

- $\quad$ Factor of safety $=1.324$

- Total driving moment $/ \mathrm{r}_{\text {slip }}=169.303 \mathrm{kNm} / \mathrm{m} / \mathrm{m}$

Driving moment due to self-weight of soil $/ \mathrm{r}_{\text {slip }}=169.303 \mathrm{kNm} / \mathrm{m} / \mathrm{m}$

Driving moment due to live load $/ \mathrm{r}_{\text {slip }}=0.000 \mathrm{kNm} / \mathrm{m} / \mathrm{m}$

- Resisting moment $/ \mathrm{r}_{\text {slip }}=224.074 \mathrm{kNm} / \mathrm{m} / \mathrm{m}$

The optimum factors are calculated using Eq. (2.5) and Eq. (2.6).

$$
\begin{gathered}
(\mathrm{LF})_{\mathrm{DL}}^{*}=\frac{\mathrm{M}_{\mathrm{DL}, \mathrm{LS}}}{\mathrm{M}_{\mathrm{DL}}}=\frac{169.303 \mathrm{kN} \cdot \mathrm{m} / \mathrm{m} / \mathrm{m}}{195.099 \mathrm{kN} \cdot \mathrm{m} / \mathrm{m} / \mathrm{m}}=0.859 \\
\mathrm{RF}^{*}=\frac{\mathrm{M}_{\mathrm{R}, \mathrm{LS}}}{\mathrm{M}_{\mathrm{R}}}=\frac{145.382 \mathrm{kN} \cdot \mathrm{m} / \mathrm{m} / \mathrm{m}}{224.074 \mathrm{kN} \cdot \mathrm{m} / \mathrm{m} / \mathrm{m}}=0.649
\end{gathered}
$$

Using the AASHTO LF values (AASHTO specifies that LF is equal to one regardless of the type of loads), the RF value is

$$
\mathrm{RF}=\frac{\mathrm{RF}^{*}}{\frac{(\mathrm{LF})_{\mathrm{DL}}{ }^{*}}{(\mathrm{LF})_{\mathrm{DL}}}}=\frac{0.649}{0.859}=0.756
$$

Now, we only have one ULS. However, the ULS (and thus the driving and resisting moments at ULS) changes from simulation to simulation. This "nonuniqueness" 
issue can be solved if we generate a large number of ULSs and find the expected (or mean) values of optimum load and resistance factors. These optimum load and resistance factors can be considered as the load and resistance factors that are valid for this particular case. By performing multiple simulations, we collected the cases whose factors of safety are very close to one $(0.99<\mathrm{FS}<1.01)$. These cases are considered as ULSs. The distribution of the optimum load factor for the load due to the self-weight of soil inside the potential slip surface is plotted, as shown in Figure 5.7. The mean was 0.907 .

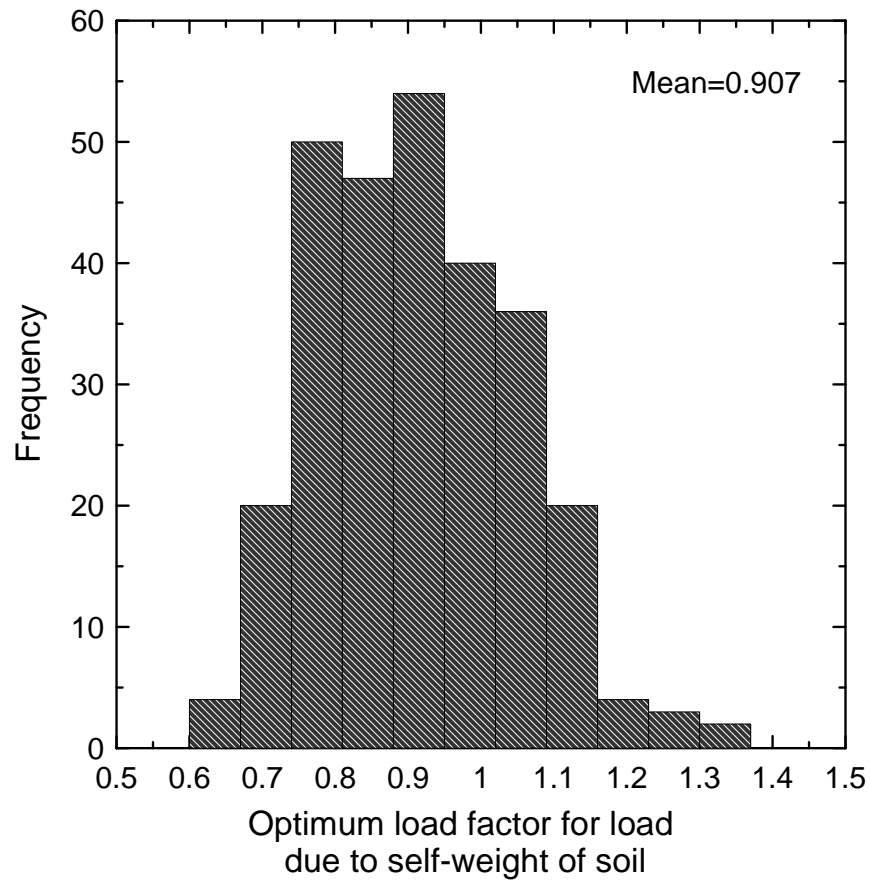

Figure 5.7 Distribution of optimum load factor $(\mathrm{LF})^{*}$ DL for load due to self-weight of soil

The distribution of the optimum resistance factor is shown in Figure 5.8 $(0.99<\mathrm{FS}<1.01)$. The mean was 0.686 . 


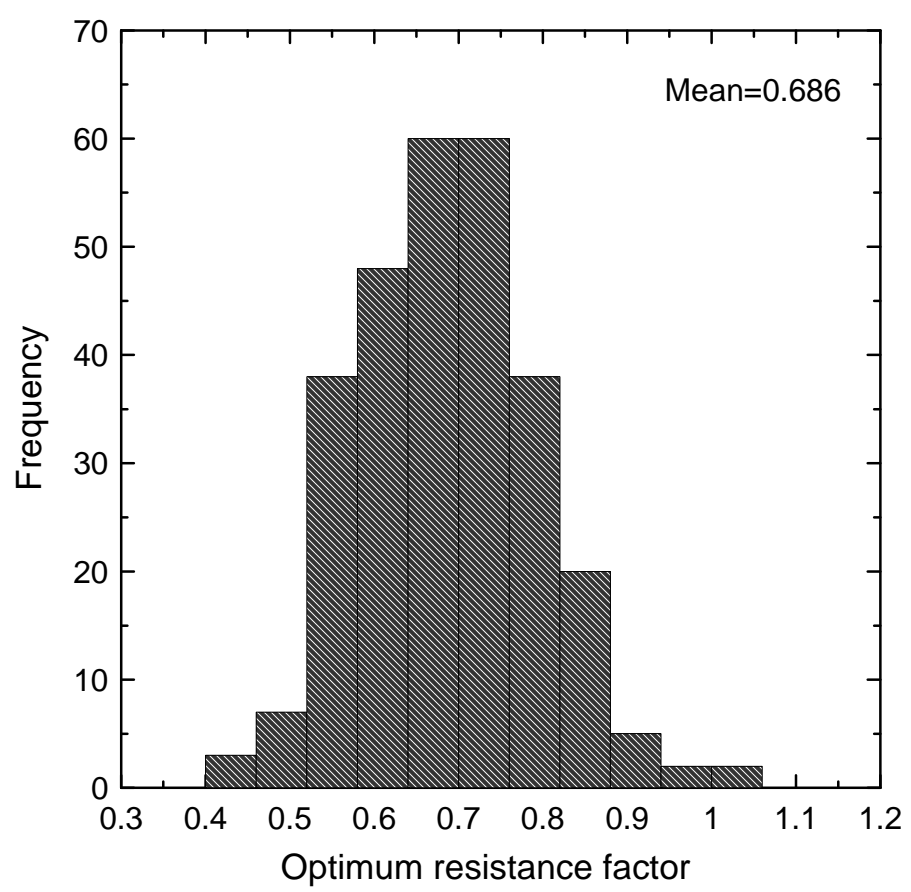

Figure 5.8 Distribution of optimum resistance factor RF*

If we use these mean values for the load and resistance factors, the factored load and the factored resistance are:

$$
\begin{gathered}
\sum(\mathrm{LF})_{\mathrm{i}} \mathrm{Q}_{\mathrm{i}}=0.907 \times 169.303=153.558 \mathrm{kN} \mathrm{m} / \mathrm{m} / \mathrm{m} \\
(\mathrm{RF}) \mathrm{R}_{\mathrm{n}}=0.686 \times 224.074=154.715 \mathrm{kN} \mathrm{m} / \mathrm{m} / \mathrm{m}
\end{gathered}
$$

Therefore, the LRFD criterion [inequality (2.2)] is satisfied:

$$
(\mathrm{RF}) \mathrm{R}_{\mathrm{n}}[=154.715 \mathrm{kN} \mathrm{m} / \mathrm{m} / \mathrm{m}] \geq \sum(\mathrm{LF})_{\mathrm{i}} \mathrm{Q}_{\mathrm{i}}[=153.558 \mathrm{kN} \mathrm{m} / \mathrm{m} / \mathrm{m}]
$$

Finding a large number of ULSs for each example takes considerable time. Generating sufficient ULSs to have appropriate expected values of optimum factors is 
important for the determination of the LFs and RF that we could propose for any slope design.

5.4.2. Slope example 2: $\mathrm{P}_{\mathrm{f}}=0.01$, no live uniform surcharge load on the crest of the slope Monte Carlo simulations are conducted for the slope with the same geometry as that used in example 1. By adjusting the expected values of soil parameters, we found that the following expected values of the soil parameters produced the target probability of failure $\left(\mathrm{P}_{\mathrm{f}}=0.01\right)$ : (1) layer $1: \mathrm{c}_{1}=5 \mathrm{kPa}, \phi_{1}=10^{\circ}, \gamma_{1}=18 \mathrm{kN} / \mathrm{m}^{3}$; (2) layer $2: \mathrm{c}_{2}=5 \mathrm{kPa}, \phi_{2}=$ $23.7^{\circ}, \gamma_{2}=19 \mathrm{kN} / \mathrm{m}^{3}$; and (3) layer 3: $\mathrm{c}_{3}=10 \mathrm{kPa}, \phi_{3}=10^{\circ}, \gamma_{3}=19.5 \mathrm{kN} / \mathrm{m}^{3}$. The probability of failure was calculated as 0.010 (299 failure cases out of 30,000 realizations.

Figure 5.9 represents the distribution of the FS from the analysis. Similar to the previous example, the distribution of the FS value is close to a normal distribution. The ULS values of the driving and resisting moments divided by $r_{\text {slip }}$ are $179.990 \mathrm{kNm} / \mathrm{m} / \mathrm{m}$ and $179.954 \mathrm{kNm} / \mathrm{m} / \mathrm{m}$. 


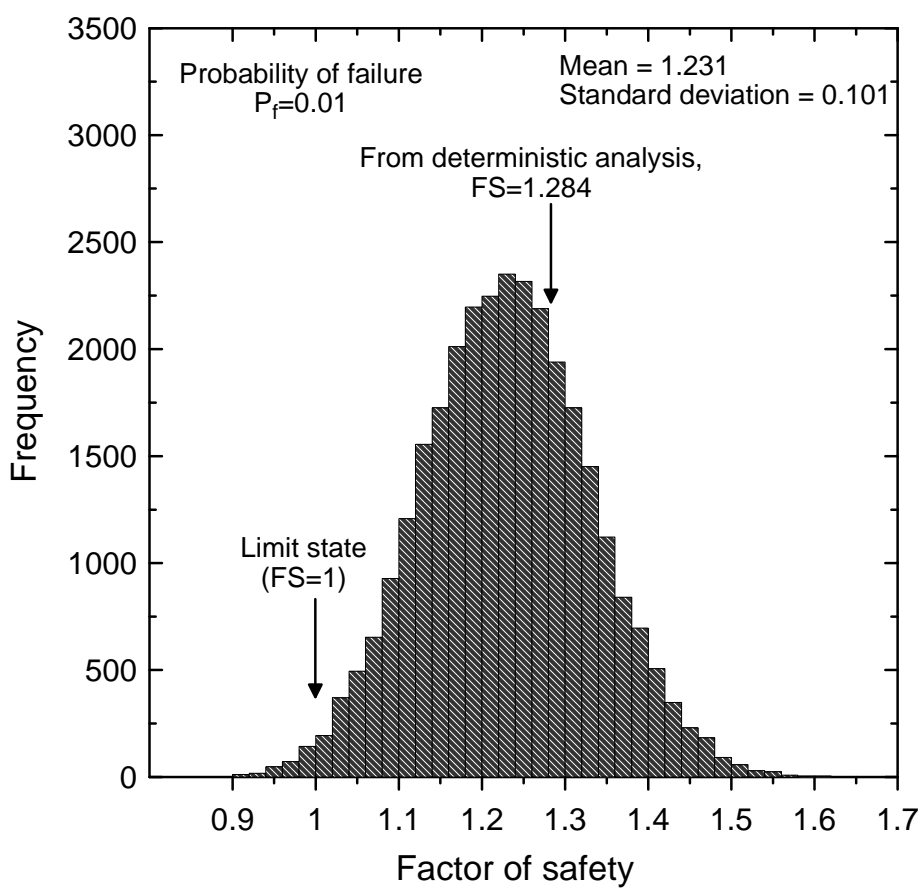

Figure 5.9 Distribution of FS value and the ULS of the slope $\left(\mathrm{P}_{\mathrm{f}}=0.01\right.$, no live uniform surcharge load)

The results of deterministic analysis provide FS value and the nominal values of the driving and resisting moments:

- $\quad$ Factor of safety $=1.284$

- Total driving moment $/ \mathrm{r}_{\mathrm{slip}}=259.692 \mathrm{kNm} / \mathrm{m} / \mathrm{m}$

Driving moment due to self-weight of soil / $\mathrm{r}_{\text {slip }}=259.692 \mathrm{kNm} / \mathrm{m} / \mathrm{m}$

Driving moment due to live load $/ \mathrm{r}_{\text {slip }}=0.000 \mathrm{kNm} / \mathrm{m} / \mathrm{m}$

- Resisting moment $/ \mathrm{r}_{\text {slip }}=333.352 \mathrm{kNm} / \mathrm{m} / \mathrm{m}$

Therefore, the optimum factors can be obtained as

$$
(\mathrm{LF})_{\mathrm{DL}}^{*}=\frac{\mathrm{M}_{\mathrm{DL}, \mathrm{LS}}}{\mathrm{M}_{\mathrm{DL}}}=\frac{179.990 \mathrm{kN} \cdot \mathrm{m} / \mathrm{m} / \mathrm{m}}{256.692 \mathrm{kN} \cdot \mathrm{m} / \mathrm{m} / \mathrm{m}}=0.693
$$




$$
\mathrm{RF}^{*}=\frac{\mathrm{M}_{\mathrm{R}, \mathrm{LS}}}{\mathrm{M}_{\mathrm{R}}}=\frac{179.954 \mathrm{kN} \cdot \mathrm{m} / \mathrm{m} / \mathrm{m}}{333.352 \mathrm{kN} \cdot \mathrm{m} / \mathrm{m} / \mathrm{m}}=0.540
$$

Using the AASHTO LF values ( $\mathrm{LF}=1$ regardless of the type of loads), the RF value is

$$
\mathrm{RF}=\frac{\mathrm{RF}^{*}}{\frac{(\mathrm{LF})_{\mathrm{DL}}{ }^{*}}{(\mathrm{LF})_{\mathrm{DL}}}}=\frac{0.540}{0.693}=0.779
$$

Similarly to the previous example, we collected the cases whose factors of safety are very close to one $(0.99<\mathrm{FS}<1.01)$. Figure 5.10 shows the distribution of the optimum load factor for the load due to the self-weight of soil. The mean value of this optimum load factor was 0.999 .

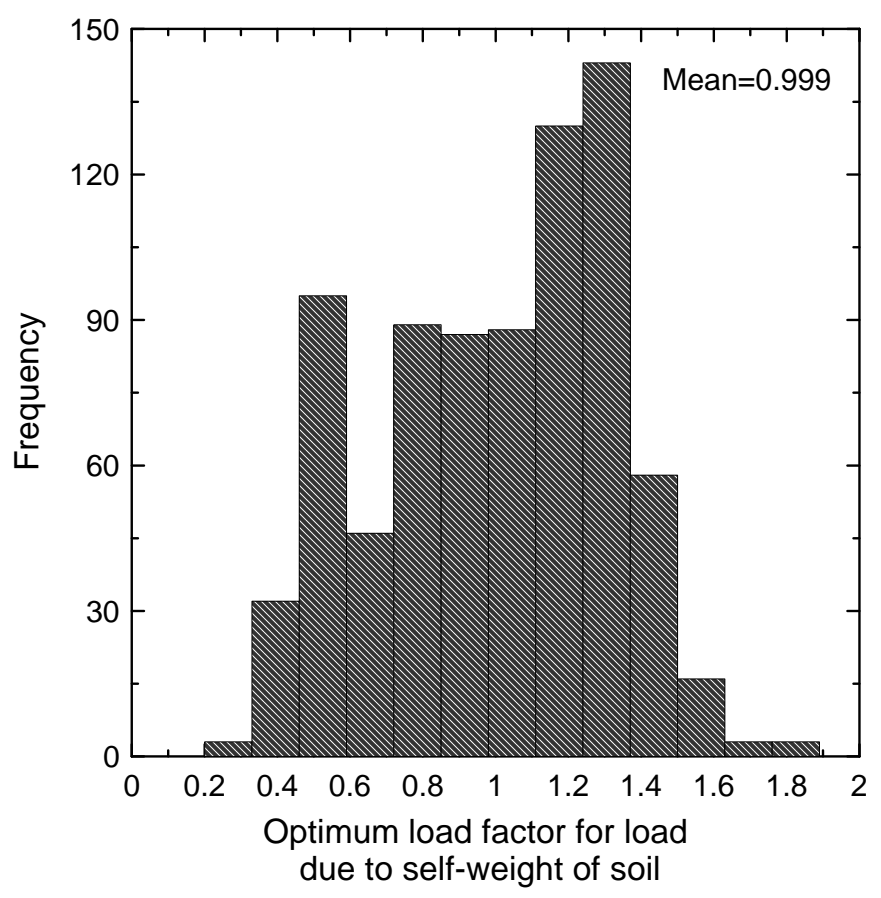

Figure 5.10 Distribution of optimum load factor (LF) ${ }_{\text {LD }}$ for load due to self-weight of soil 
Figure 5.11 represents the distribution of the optimum resistance factor $(0.99<\mathrm{FS}<1.01)$. The mean value was 0.779 .

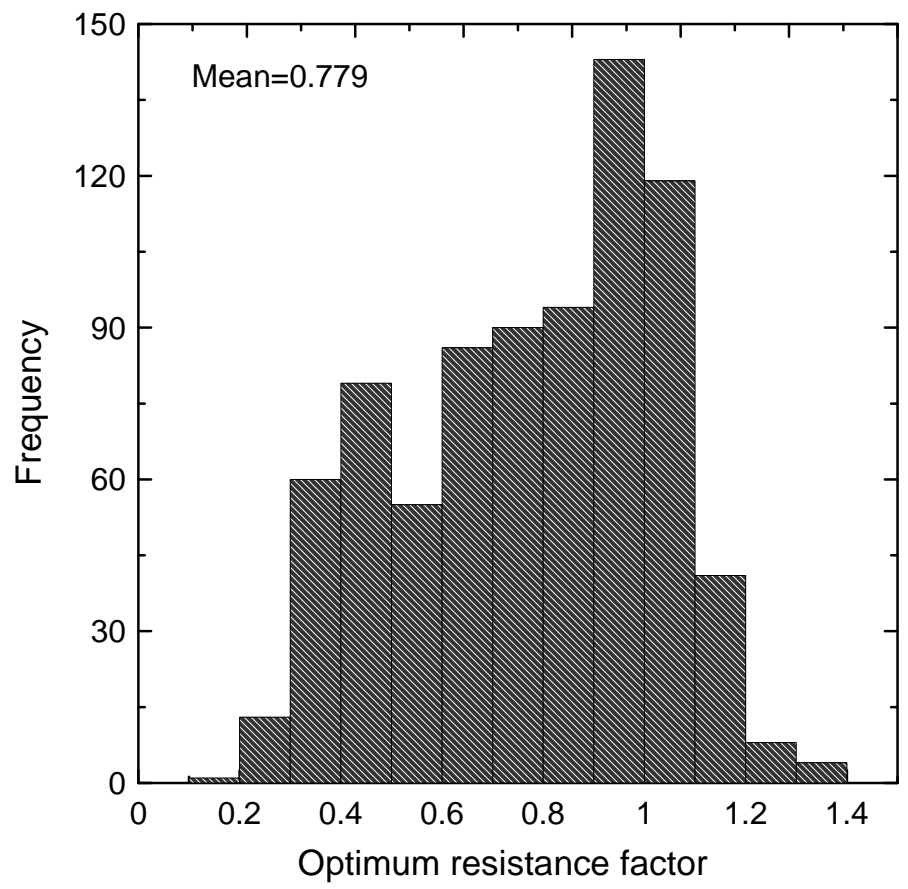

Figure 5.11 Distribution of optimum resistance factor $\mathrm{RF}^{*}$

If we use these mean values for the load and resistance factors, the factored load and the factored resistance are:

$$
\begin{gathered}
\sum(\mathrm{LF})_{\mathrm{i}} \mathrm{Q}_{\mathrm{i}}=0.999 \times 259.692=259.432 \mathrm{kN} \mathrm{m} / \mathrm{m} / \mathrm{m} \\
(\mathrm{RF}) \mathrm{R}_{\mathrm{n}}=0.779 \times 333.352=259.681 \mathrm{kN} \mathrm{m} / \mathrm{m} / \mathrm{m}
\end{gathered}
$$

The LRFD criterion [inequality (2.2)] is satisfied:

$$
(\mathrm{RF}) \mathrm{R}_{\mathrm{n}}[=259.681 \mathrm{kN} \mathrm{m} / \mathrm{m} / \mathrm{m}] \geq \sum(\mathrm{LF})_{\mathrm{i}} \mathrm{Q}_{\mathrm{i}}[=259.432 \mathrm{kN} \mathrm{m} / \mathrm{m} / \mathrm{m}]
$$


5.4.3. Slope example 3: $\mathrm{P}_{\mathrm{f}}=0.001$ with a live uniform surcharge load on the crest of the slope

A live uniform surcharge load $\mathrm{q}_{0}(12 \mathrm{kN} / \mathrm{m})$ is acting on the crest of the slope. The slope in this example has the same geometry that is used in the previous examples. By adjusting the expected values of soil parameters, the expected values of the soil parameters reflecting the target probability of failure $\left(\mathrm{P}_{\mathrm{f}}=0.001\right)$ are found to be: $(1)$ layer 1: $\mathrm{c}_{1}=11.2 \mathrm{kPa}, \phi_{1}=10^{\circ}, \gamma_{1}=18 \mathrm{kN} / \mathrm{m}^{3}$; (2) layer $2: \mathrm{c}_{2}=5 \mathrm{kPa}, \phi_{2}=24.6^{\circ}, \gamma_{2}=19$ $\mathrm{kN} / \mathrm{m}^{3}$; and (3) layer 3: $\mathrm{c}_{3}=10 \mathrm{kPa}, \phi_{3}=20^{\circ}, \gamma_{3}=19.5 \mathrm{kN} / \mathrm{m}^{3}$.

Figure 5.12 illustrates the distribution of FS value. It matches well with a normal distribution. The ULS values for the driving moments due to the self-weight of the soil and due to the live uniform surcharge load that are divided by $\mathrm{r}_{\text {slip }}$ are 126.906 and 18.268 $\mathrm{kNm} / \mathrm{m} / \mathrm{m}$, respectively. The ULS value for the resisting moment divided by $\mathrm{r}_{\text {slip }}$ is $145.208 \mathrm{kNm} / \mathrm{m} / \mathrm{m}$.

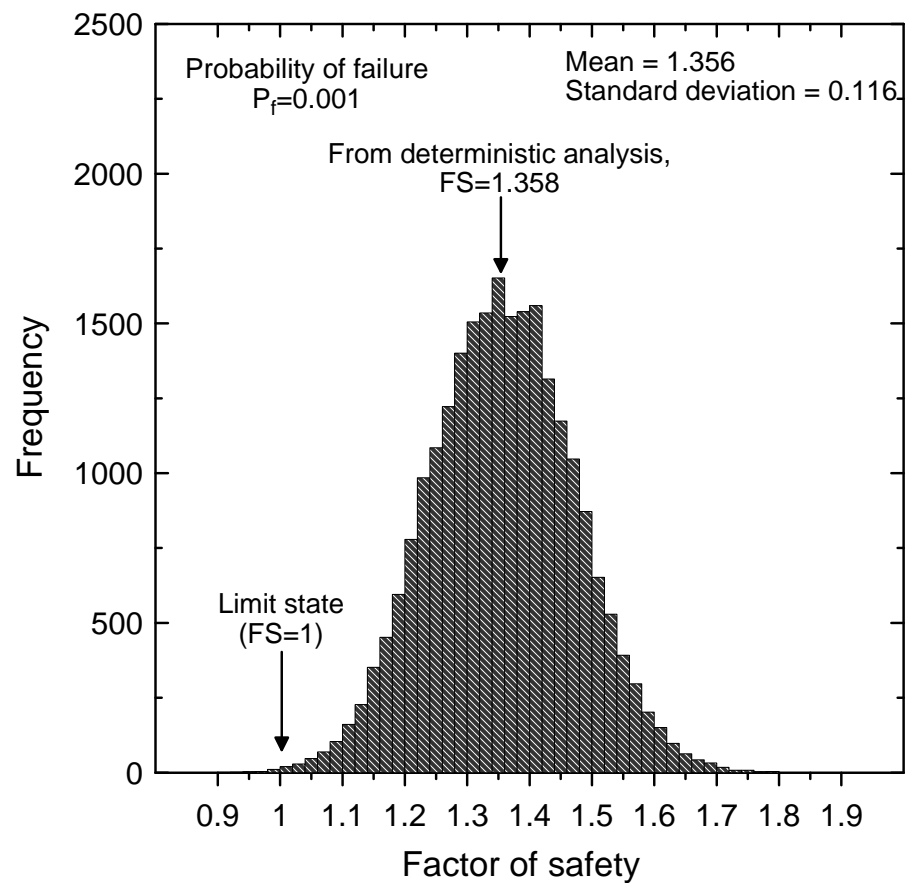

Figure 5.12 Distribution of FS value and the ULS of the slope $\left(\mathrm{P}_{\mathrm{f}}=0.001\right.$ and live uniform surcharge load $\mathrm{q}_{0}=12 \mathrm{kN} / \mathrm{m}$ ) 
The FS value and the nominal values of the driving and resisting moments from deterministic analysis are:

- $\quad$ Factor of safety $=1.358$

- Total driving moment $/ \mathrm{r}_{\mathrm{slip}}=170.533 \mathrm{kNm} / \mathrm{m} / \mathrm{m}$

Driving moment due to self-weight of soil $/ \mathrm{r}_{\text {slip }}=151.442 \mathrm{kNm} / \mathrm{m} / \mathrm{m}$

Driving moment due to live load $/ \mathrm{r}_{\text {slip }}=19.091 \mathrm{kNm} / \mathrm{m} / \mathrm{m}$

- Resisting moment $/ \mathrm{r}_{\text {slip }}=231.528 \mathrm{kNm} / \mathrm{m} / \mathrm{m}$

The optimum load factors for self-weight of soil and live load are

$$
\begin{gathered}
(\mathrm{LF})_{\mathrm{DL}}^{*}=\frac{\mathrm{M}_{\mathrm{DL}, \mathrm{LS}}}{\mathrm{M}_{\mathrm{DL}}}=\frac{126.906 \mathrm{kN} \cdot \mathrm{m} / \mathrm{m} / \mathrm{m}}{151.442 \mathrm{kN} \cdot \mathrm{m} / \mathrm{m} / \mathrm{m}}=0.838 \\
(\mathrm{LF})_{\mathrm{LL}}^{*}=\frac{\mathrm{M}_{\mathrm{LL}, \mathrm{LS}}}{\mathrm{M}_{\mathrm{LL}}}=\frac{18.268 \mathrm{kN} \cdot \mathrm{m} / \mathrm{m} / \mathrm{m}}{19.091 \mathrm{kN} \cdot \mathrm{m} / \mathrm{m} / \mathrm{m}}=0.957
\end{gathered}
$$

The optimum resistance factor is

$$
\mathrm{RF}^{*}=\frac{\mathrm{M}_{\mathrm{R}, \mathrm{LS}}}{\mathrm{M}_{\mathrm{R}}}=\frac{145.208 \mathrm{kN} \cdot \mathrm{m} / \mathrm{m} / \mathrm{m}}{231.528 \mathrm{kN} \cdot \mathrm{m} / \mathrm{m} / \mathrm{m}}=0.627
$$

Using these optimum factors and AASHTO LF values $(\mathrm{LF}=1$ regardless of the type of loads), RF is

$$
\mathrm{RF}=\frac{\mathrm{RF}^{*}}{\max \left[\frac{(\mathrm{LF})_{\mathrm{DL}}{ }^{*}}{(\mathrm{LF})_{\mathrm{DL}}}, \frac{(\mathrm{LF})_{\mathrm{LL}}{ }^{*}}{(\mathrm{LF})_{\mathrm{LL}}}\right]}=\frac{0.627}{0.957}=0.655
$$


Figure 5.13 and Figure 5.14 show the distributions of the optimum load factor for the load due to the self-weight of soil and that for the live surcharge load for the cases whose factors of safety are very close to one $(0.99<\mathrm{FS}<1.01)$. The mean values of these optimum load factors were 1.033 and 1.603 , respectively.

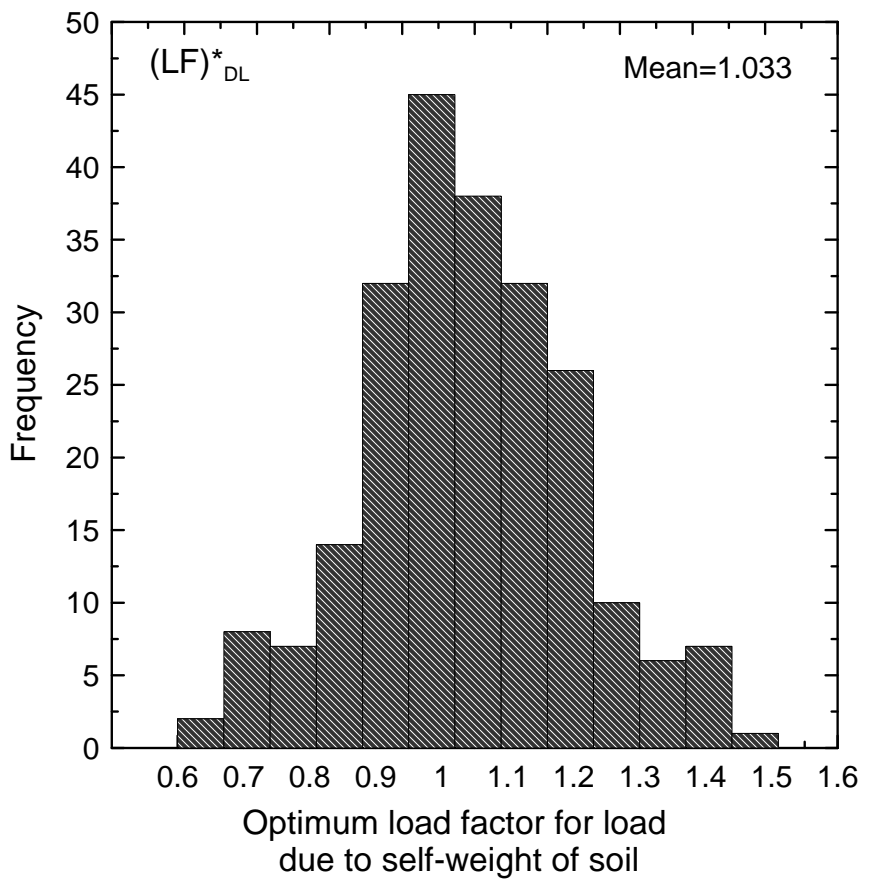

Figure 5.13 Distribution of optimum load factor (LF) ${ }^{*}$ DL for load due to self-weight of soil 


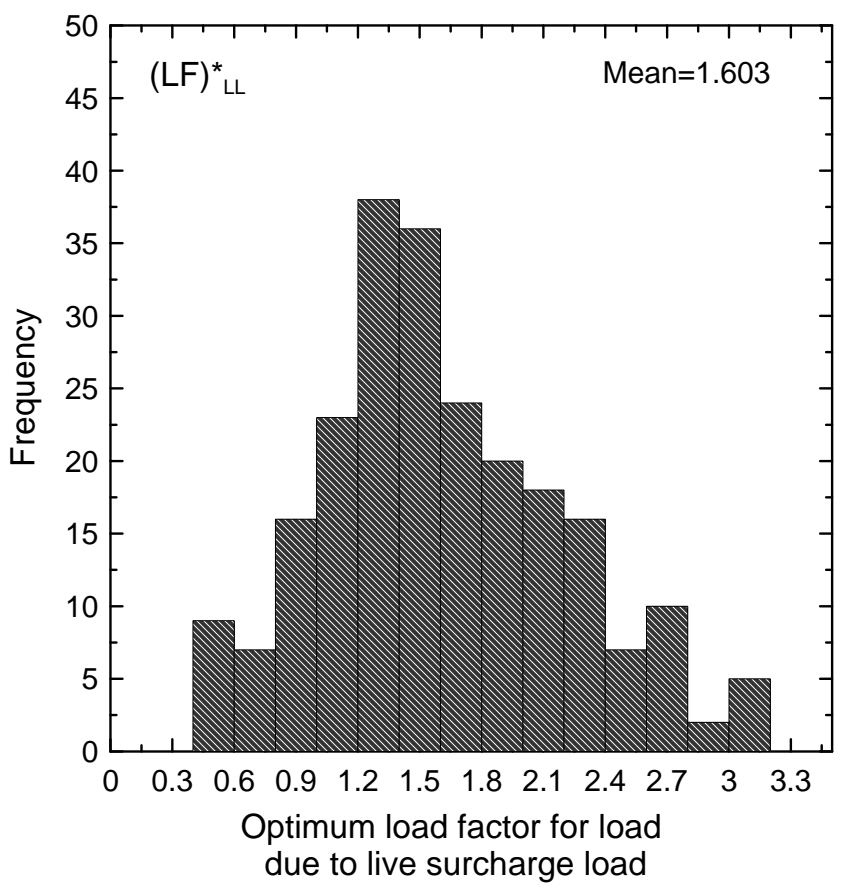

Figure 5.14 Distribution of optimum load factor (LF) ${ }^{*}$ LL for load due to live surcharge load

Figure 5.15 represents the distribution of optimum resistance factor. The mean value was 0.809 . 


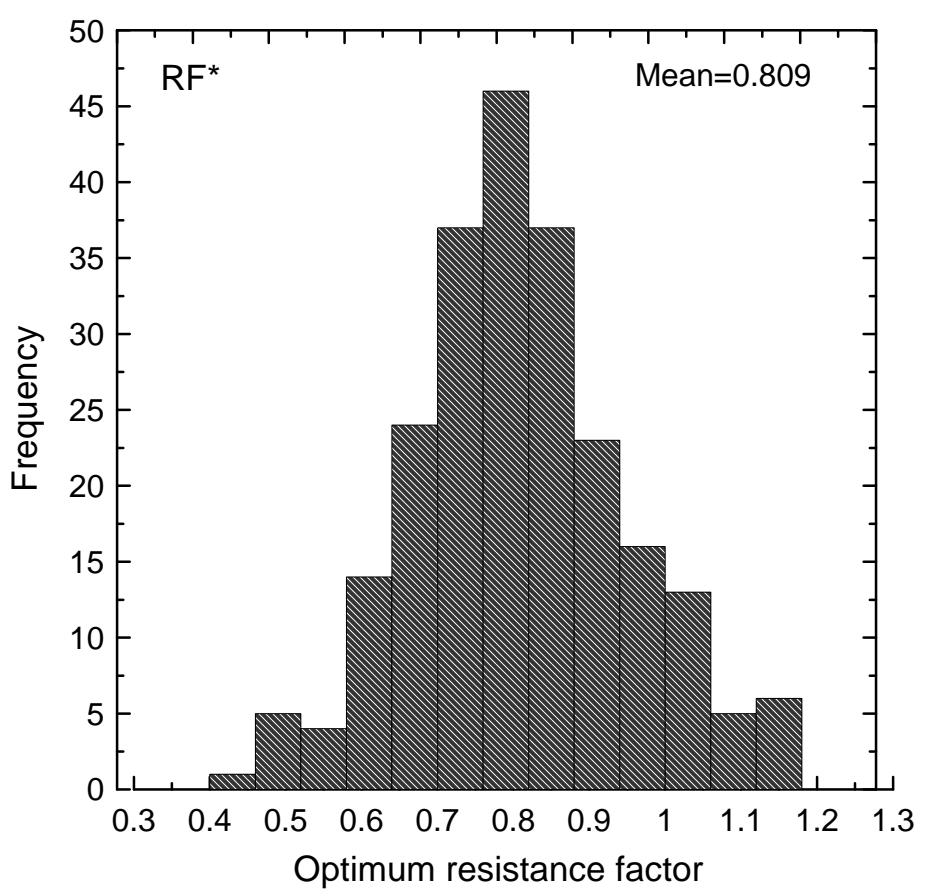

Figure 5.15 Distribution of optimum resistance factor $\mathrm{RF}^{*}$

If we use these mean values for the load and resistance factors, the factored load and the factored resistance are:

$\sum(\mathrm{LF})_{\mathrm{i}} \mathrm{Q}_{\mathrm{i}}=1.033 \times 151.442+1.603 \times 30.603=187.043 \mathrm{kN} \mathrm{m} / \mathrm{m} / \mathrm{m}$

(RF) $R_{n}=0.809 \times 231.528=187.306 \mathrm{kN} \mathrm{m} / \mathrm{m} / \mathrm{m}$

The LRFD criterion [inequality (2.2)] is satisfied:

(RF) $R_{\mathrm{n}}[=187.306 \mathrm{kN} \mathrm{m} / \mathrm{m} / \mathrm{m}] \geq \sum(\mathrm{LF})_{\mathrm{i}} \mathrm{Q}_{\mathrm{i}}[=187.043 \mathrm{kN} \mathrm{m} / \mathrm{m} / \mathrm{m}]$ 
5.4.4. Slope example 4: $\mathrm{P}_{\mathrm{f}}=0.01$ with a live uniform surcharge load on the crest of the slope

The same magnitude of a live uniform surcharge load $\left(\mathrm{q}_{0}=12 \mathrm{kN} / \mathrm{m}\right)$ used in the previous example is applied on the crest of the slope. By adjusting the expected values of soil parameters, the expected values of the soil parameters that produce the target probability of failure $\left(\mathrm{P}_{\mathrm{f}}=0.01\right)$ are found to be: (1) layer $1: \mathrm{c}_{1}=11.2 \mathrm{kPa}, \phi_{1}=10^{\circ}, \gamma_{1}=18 \mathrm{kN} / \mathrm{m}^{3}$; (2) layer 2: $\mathrm{c}_{2}=5 \mathrm{kPa}, \phi_{2}=21^{\circ}, \gamma_{2}=19 \mathrm{kN} / \mathrm{m}^{3}$; and (3) layer $3: \mathrm{c}_{3}=10 \mathrm{kPa}, \phi_{3}=20^{\circ}, \gamma_{3}$ $=19.5 \mathrm{kN} / \mathrm{m}^{3}$.

The distribution of FS is shown in Figure 5.16. The ULS values for the driving moments due to the self-weight of the soil and due to the live uniform surcharge load that are divided by $r_{\text {slip }}$ are 169.420 and $30.459 \mathrm{kNm} / \mathrm{m} / \mathrm{m}$, respectively. In addition, the ULS value for the resisting moment divided by $r_{\text {slip }}$ is $199.855 \mathrm{kNm} / \mathrm{m} / \mathrm{m}$.

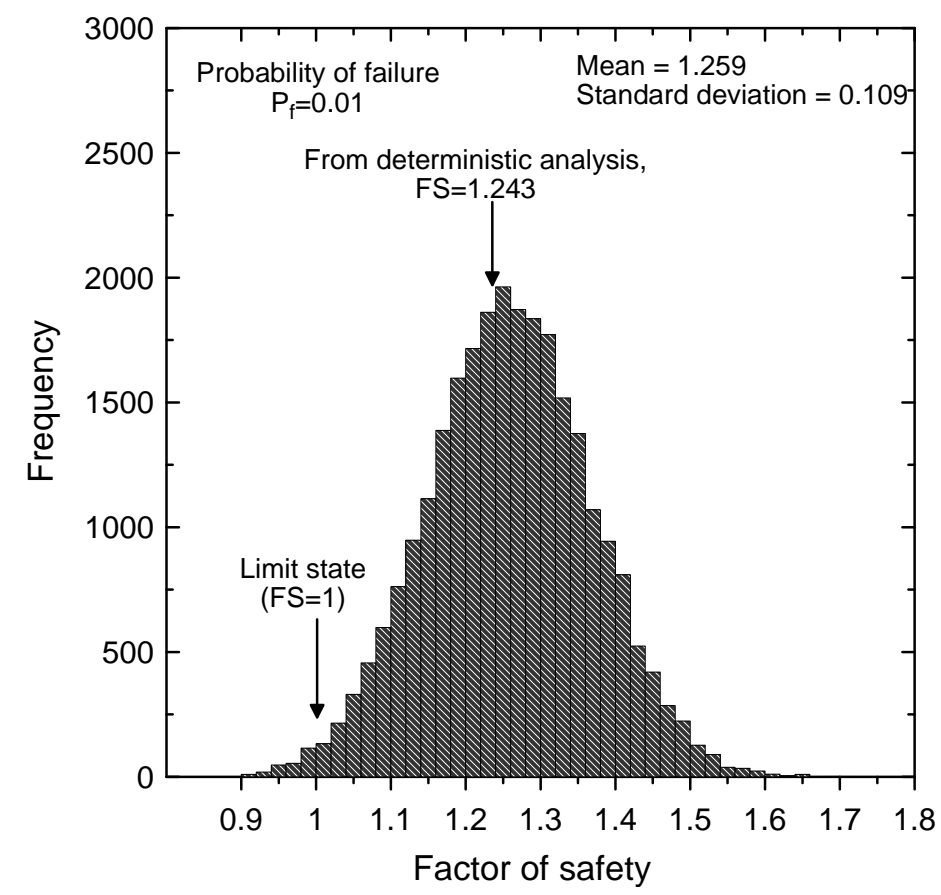

Figure 5.16 Distribution of FS value and the ULS of the slope $\left(\mathrm{P}_{\mathrm{f}}=0.01\right.$ and live uniform surcharge load $\mathrm{q}_{0}=12 \mathrm{kN} / \mathrm{m}$ ) 
The results of the deterministic analysis are summarized as:

- $\quad$ Factor of safety $=1.243$

- Total driving moment $/ \mathrm{r}_{\text {slip }}=204.841 \mathrm{kNm} / \mathrm{m} / \mathrm{m}$

Driving moment due to self-weight of soil $/ \mathrm{r}_{\text {slip }}=179.469 \mathrm{kNm} / \mathrm{m} / \mathrm{m}$

Driving moment due to live load $/ \mathrm{r}_{\text {slip }}=25.372 \mathrm{kNm} / \mathrm{m} / \mathrm{m}$

- Resisting moment $/ \mathrm{r}_{\text {slip }}=254.624 \mathrm{kNm} / \mathrm{m} / \mathrm{m}$

The optimum values are

$$
\begin{gathered}
(\mathrm{LF})_{\mathrm{DL}}^{*}=\frac{\mathrm{M}_{\mathrm{DL}, \mathrm{LS}}}{\mathrm{M}_{\mathrm{DL}}}=\frac{169.420 \mathrm{kN} \cdot \mathrm{m} / \mathrm{m} / \mathrm{m}}{179.469 \mathrm{kN} \cdot \mathrm{m} / \mathrm{m} / \mathrm{m}}=0.944 \\
(\mathrm{LF})_{\mathrm{LL}}^{*}=\frac{\mathrm{M}_{\mathrm{LL}, \mathrm{LS}}}{\mathrm{M}_{\mathrm{LL}}}=\frac{30.459 \mathrm{kN} \cdot \mathrm{m} / \mathrm{m} / \mathrm{m}}{25.372 \mathrm{kN} \cdot \mathrm{m} / \mathrm{m} / \mathrm{m}}=1.200 \\
\mathrm{RF}^{*}=\frac{M_{\mathrm{R}, \mathrm{LS}}}{\mathrm{M}_{\mathrm{R}}}=\frac{199.855 \mathrm{kN} \cdot \mathrm{m} / \mathrm{m} / \mathrm{m}}{254.624 \mathrm{kN} \cdot \mathrm{m} / \mathrm{m} / \mathrm{m}}=0.785
\end{gathered}
$$

Using these optimum factors and AASHTO LF values $(\mathrm{LF}=1$ regardless of the type of loads), RF is

$$
\mathrm{RF}=\frac{\mathrm{RF}^{*}}{\max \left[\frac{(\mathrm{LF})_{\mathrm{DL}}{ }^{*}}{(\mathrm{LF})_{\mathrm{DL}}}, \frac{(\mathrm{LF})_{\mathrm{LL}}{ }^{*}}{(\mathrm{LF})_{\mathrm{LL}}}\right]}=\frac{0.785}{1.200}=0.654
$$

Figure 5.17 and Figure 5.18 are the distributions of the optimum load factor for the load due to the self-weight of soil and that for the live surcharge load for the cases whose factors of safety are very close to one $(0.99<\mathrm{FS}<1.01)$. The mean values of these optimum load factors were 0.897 and 1.188 , respectively. 


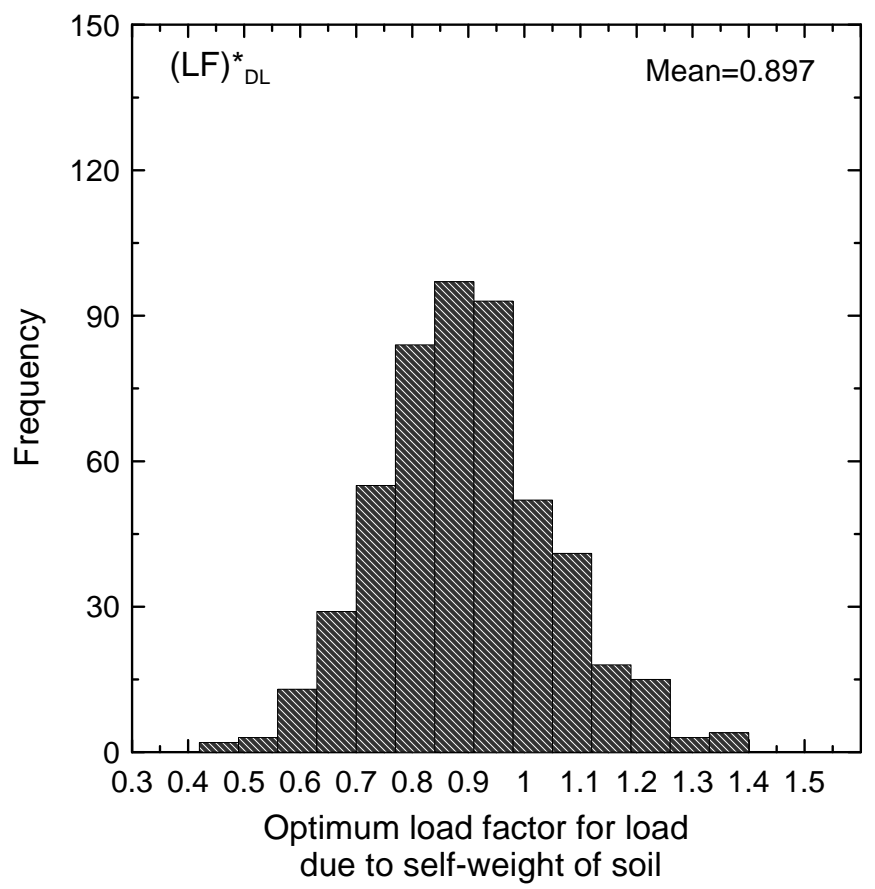

Figure 5.17 Distribution of optimum load factor (LF) ${ }^{*}$ DL for load due to self-weight of soil

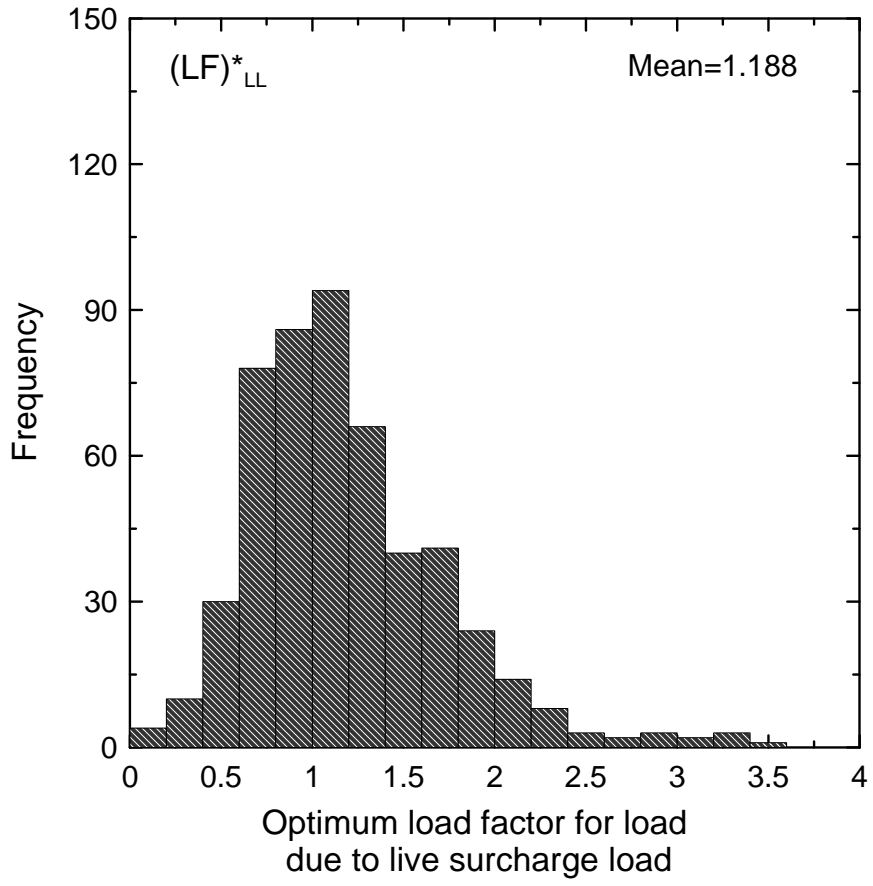

Figure 5.18 Distribution of optimum load factor $(\mathrm{LF})^{*}{ }_{\mathrm{LL}}$ for load due to live surcharge load 
Figure 5.19 is the distribution of the optimum resistance factor. The mean value was 0.752 .

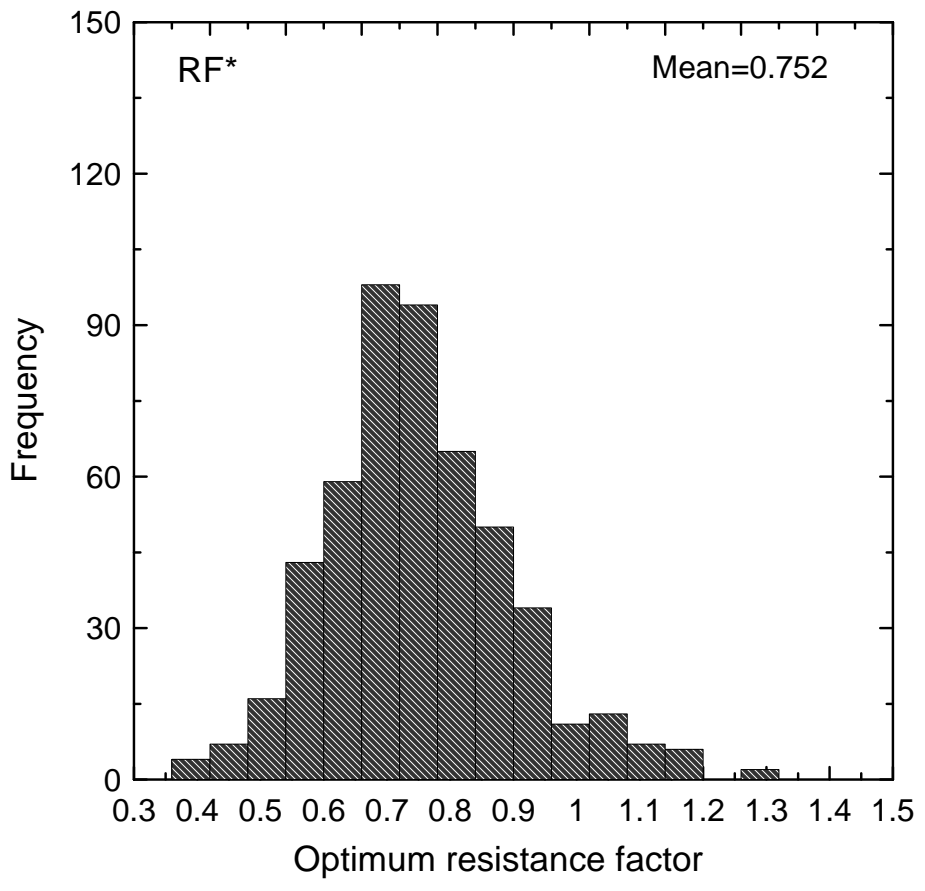

Figure 5.19 Distribution of optimum resistance factor $\mathrm{RF}^{*}$

If we use these mean values for the load and resistance factors, the factored load and the factored resistance are:

$$
\begin{gathered}
\sum(\mathrm{LF})_{\mathrm{i}} \mathrm{Q}_{\mathrm{i}}=0.897 \times 179.469+1.188 \times 25.372=191.126 \mathrm{kN} \mathrm{m} / \mathrm{m} / \mathrm{m} \\
(\mathrm{RF}) \mathrm{R}_{\mathrm{n}}=0.752 \times 254.624=191.477 \mathrm{kN} \mathrm{m} / \mathrm{m} / \mathrm{m}
\end{gathered}
$$

The LRFD criterion [inequality (2.2)] is satisfied:

$$
\text { (RF) } R_{\mathrm{n}}[=191.477 \mathrm{kN} \mathrm{m} / \mathrm{m} / \mathrm{m}] \geq \sum(\mathrm{LF})_{\mathrm{i}} \mathrm{Q}_{\mathrm{i}}[=191.126 \mathrm{kN} \mathrm{m} / \mathrm{m} / \mathrm{m}]
$$




\subsubsection{Embankment example 1: $\mathrm{P}_{\mathrm{f}}=0.001$}

A road embankment in Figure 5.20 is used for this example. The road embankment has side slopes at 1:1 and its height and width on the top are $5 \mathrm{~m}$ and $10 \mathrm{~m}$, respectively. Although, AASHTO and FHWA specifications propose the equivalent uniform surcharge load to the vehicular load on the top of retaining structures, they do not provide the equivalent uniform surcharge to the vehicular load for embankments. Therefore, to account for the vehicular load acting on the top of the embankment, the equivalent live uniform surcharge load is assumed as $12 \mathrm{kN} / \mathrm{m}$.

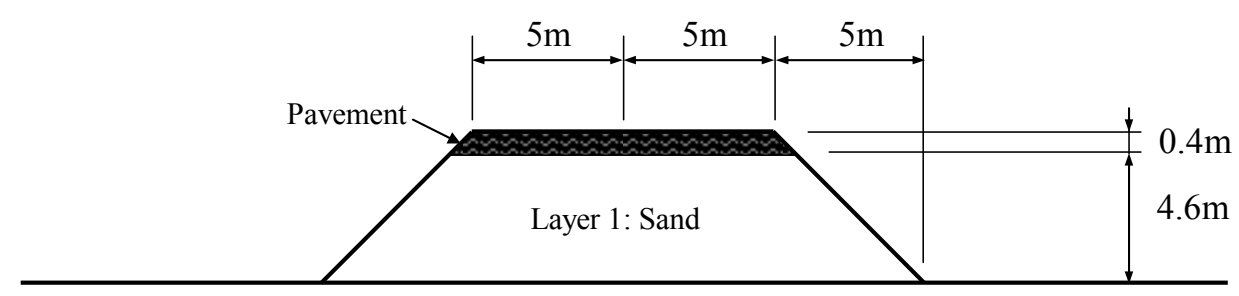

Layer 2: Foundation soil

Figure 5.20 Geometry of a road embankment (1:1 side slopes)

The algorithm for LRFD of slopes shown in Figure 3.3 is used for the development of LRFD for the side slopes of embankments. Because the thickness of the pavement is relatively thin than that of soil layers composing the embankment, we assumed that the strength parameters ( $\mathrm{c}$ and $\phi$ ) and the unit weight of pavement are the same as those of sand. By adjusting the expected values of soil parameters, the expected values of the soil parameters that produce the target probability of failure $\left(\mathrm{P}_{\mathrm{f}}=0.001\right)$ are found to be: (1) layer 1: $\mathrm{c}_{1}=6 \mathrm{kPa}, \phi_{1}=36.25^{\circ}, \gamma_{1}=20 \mathrm{kN} / \mathrm{m}^{3}$ and (2) layer 2: $\mathrm{c}_{2}=5 \mathrm{kPa}$, $\phi_{2}=30^{\circ}, \gamma_{2}=19 \mathrm{kN} / \mathrm{m}^{3}$. 
The distribution of FS is shown in Figure 5.21. The ULS values for the driving moments due to the self-weight of the soil and due to the live uniform surcharge load that are divided by $\mathrm{r}_{\text {slip }}$ are 92.825 and $14.115 \mathrm{kNm} / \mathrm{m} / \mathrm{m}$, respectively. In addition, the ULS value for the resisting moment divided by $r_{\text {slip }}$ is $106.954 \mathrm{kNm} / \mathrm{m} / \mathrm{m}$.

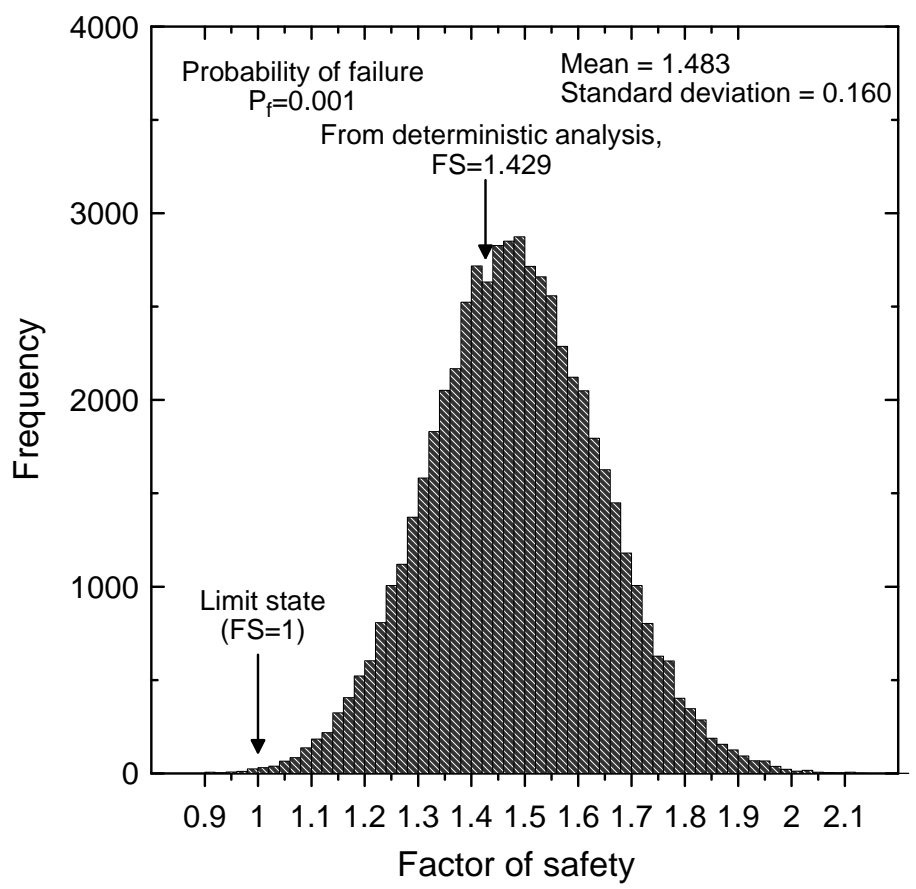

Figure 5.21 Distribution of FS value and the ULS of the slope $\left(\mathrm{P}_{\mathrm{f}}=0.001\right.$ and live uniform surcharge load $\mathrm{q}_{0}=12 \mathrm{kN} / \mathrm{m}$ )

The results of the deterministic analysis are summarized as:

Factor of safety $=1.429$

- Total driving moment $/ \mathrm{r}_{\mathrm{slip}}=121.291 \mathrm{kNm} / \mathrm{m} / \mathrm{m}$

Driving moment due to self-weight of soil $/ \mathrm{r}_{\text {slip }}=104.863 \mathrm{kNm} / \mathrm{m} / \mathrm{m}$

Driving moment due to live load $/ \mathrm{r}_{\text {slip }}=16.428 \mathrm{kNm} / \mathrm{m} / \mathrm{m}$

- Resisting moment $/ \mathrm{r}_{\text {slip }}=173.352 \mathrm{kNm} / \mathrm{m} / \mathrm{m}$ 
The optimum values are

$$
\begin{gathered}
(\mathrm{LF})_{\mathrm{DL}}^{*}=\frac{\mathrm{M}_{\mathrm{DL}, \mathrm{LS}}}{\mathrm{M}_{\mathrm{DL}}}=\frac{92.825 \mathrm{kN} \cdot \mathrm{m} / \mathrm{m} / \mathrm{m}}{104.863 \mathrm{kN} \cdot \mathrm{m} / \mathrm{m} / \mathrm{m}}=0.885 \\
(\mathrm{LF})_{\mathrm{LL}}^{*}=\frac{\mathrm{M}_{\mathrm{LL}, \mathrm{LS}}}{\mathrm{M}_{\mathrm{LL}}}=\frac{14.115 \mathrm{kN} \cdot \mathrm{m} / \mathrm{m} / \mathrm{m}}{16.428 \mathrm{kN} \cdot \mathrm{m} / \mathrm{m} / \mathrm{m}}=0.859 \\
\mathrm{RF}^{*}=\frac{M_{\mathrm{R}, \mathrm{LS}}}{\mathrm{M}_{\mathrm{R}}}=\frac{173.352 \mathrm{kN} \cdot \mathrm{m} / \mathrm{m} / \mathrm{m}}{249.379 \mathrm{kN} \cdot \mathrm{m} / \mathrm{m} / \mathrm{m}}=0.695
\end{gathered}
$$

Using these optimum factors and AASHTO LF values, RF is

$$
\mathrm{RF}=\frac{\mathrm{RF}^{*}}{\max \left[\frac{(\mathrm{LF})_{\mathrm{DL}}^{*}}{(\mathrm{LF})_{\mathrm{DL}}}, \frac{(\mathrm{LF})_{\mathrm{LL}}{ }^{*}}{(\mathrm{LF})_{\mathrm{LL}}}\right]}=\frac{0.695}{0.885}=0.785
$$

Figure 5.22 and Figure 5.23 are the distributions of optimum load factor for the load due to the self-weight of soil and that for the live surcharge load for the cases whose factors of safety are very close to one $(0.99<\mathrm{FS}<1.01)$. The mean values of these optimum load factors were 0.930 and 1.088 , respectively. 


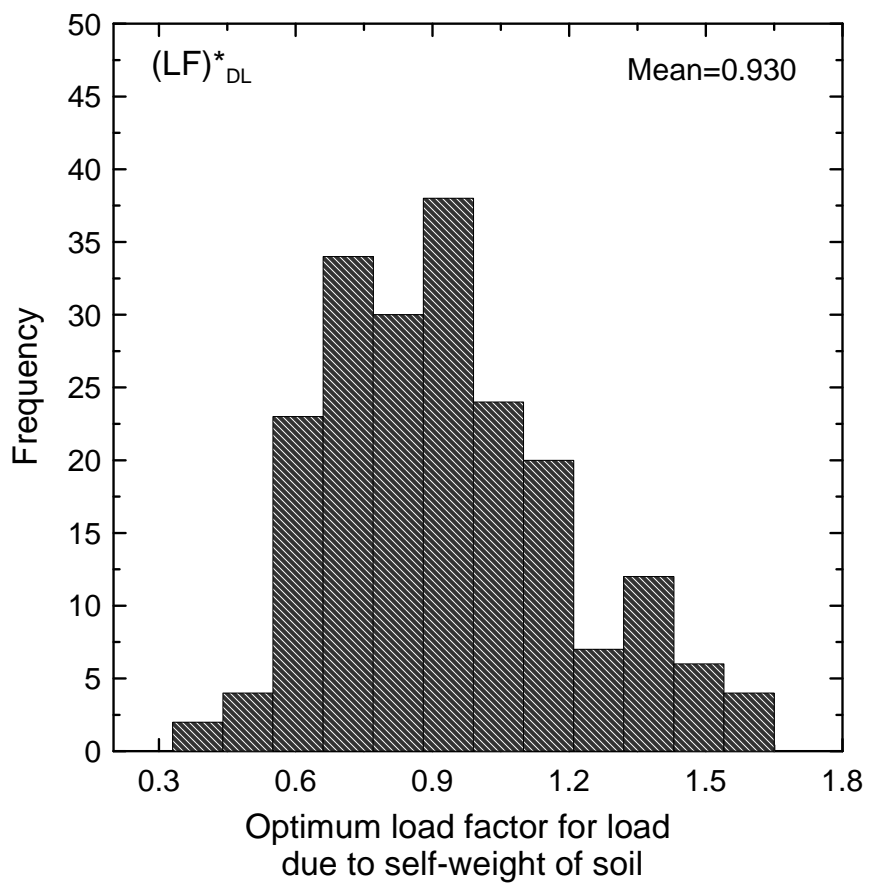

Figure 5.22 Distribution of optimum load factor (LF) ${ }^{*}$ DL for load due to self-weight of soil

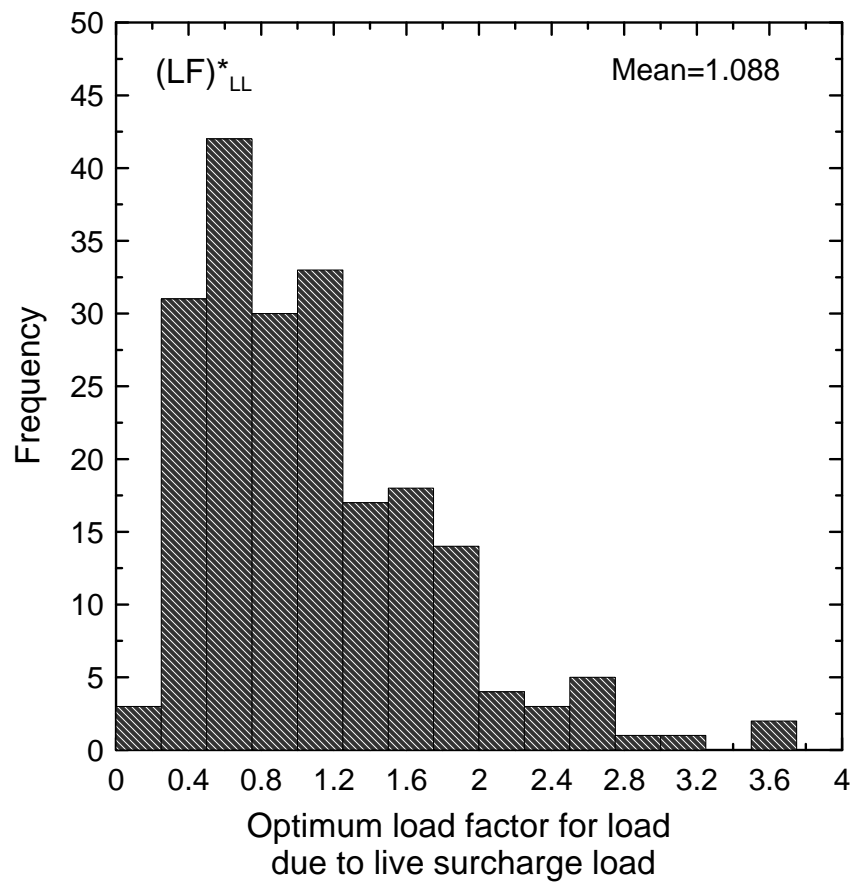

Figure 5.23 Distribution of optimum load factor $(\mathrm{LF})^{*}{ }_{\mathrm{LL}}$ for load due to live surcharge load 
Figure 5.24 is the distribution of optimum resistance factor. The mean value was 0.666 .

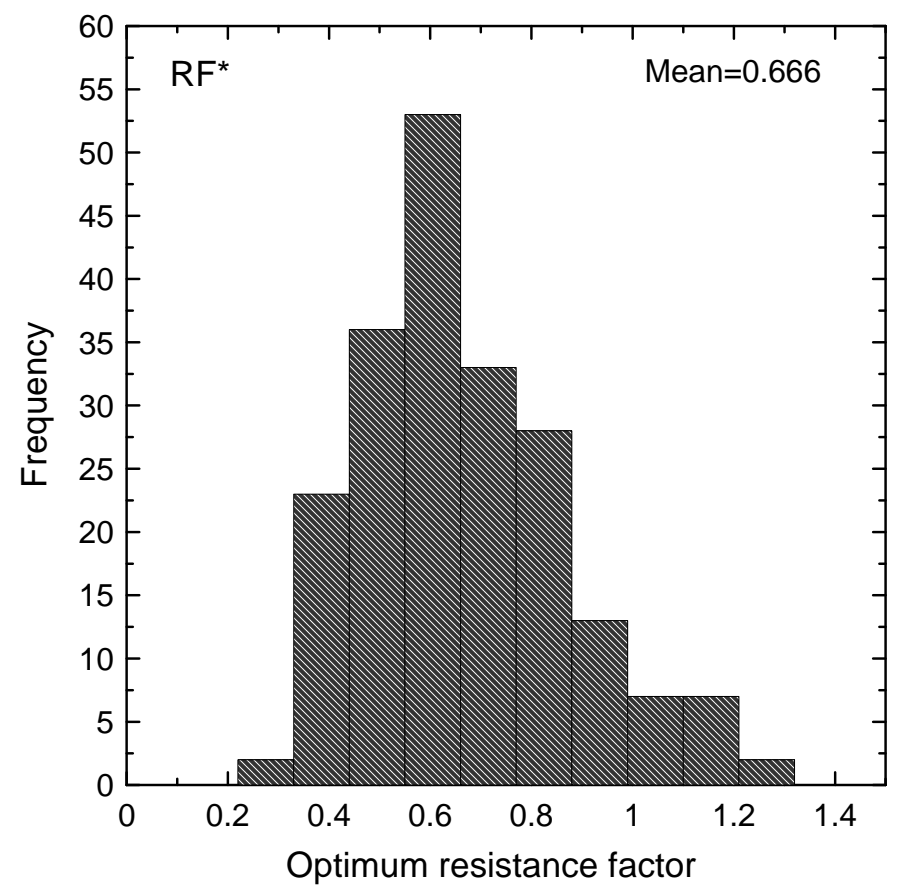

Figure 5.24 Distribution of optimum resistance factor $\mathrm{RF}^{*}$

If we use these mean values for load and resistance factor, the factored load and the factored resistance are:

$$
\begin{gathered}
\sum(\mathrm{LF})_{\mathrm{i}} \mathrm{Q}_{\mathrm{i}}=0.930 \times 104.863+1.088 \times 16.428=115.396 \mathrm{kN} \mathrm{m} / \mathrm{m} / \mathrm{m} \\
(\mathrm{RF}) \mathrm{R}_{\mathrm{n}}=0.666 \times 173.352=115.452 \mathrm{kN} \mathrm{m} / \mathrm{m} / \mathrm{m}
\end{gathered}
$$

The LRFD criterion [inequality (2.2)] is satisfied:

$$
\text { (RF) } \mathrm{R}_{\mathrm{n}}[=115.452 \mathrm{kN} \mathrm{m} / \mathrm{m} / \mathrm{m}] \geq \sum(\mathrm{LF})_{\mathrm{i}} \mathrm{Q}_{\mathrm{i}}[=115.396 \mathrm{kN} \mathrm{m} / \mathrm{m} / \mathrm{m}]
$$




\subsubsection{Embankment example 2: $\mathrm{P}_{\mathrm{f}}=0.01$}

The same geometry of the slope in the previous example is used in this example with different target probability of failure $\left(\mathrm{P}_{\mathrm{f}}=0.01\right)$. The design live uniform surcharge load on the top of the embankment is also assumed as $12 \mathrm{kN} / \mathrm{m}$. By adjusting expected values of soil parameters, the expected values of the soil parameters that produce the target probability of failure equal to 0.01 are found to be: (1) layer 1: $\mathrm{c}_{1}=6 \mathrm{kPa}, \phi_{1}=33^{\circ}, \gamma_{1}$ $=20 \mathrm{kN} / \mathrm{m}^{3}$ and (2) layer $2: \mathrm{c}_{2}=5 \mathrm{kPa}, \phi_{2}=17.2^{\circ}, \gamma_{2}=19 \mathrm{kN} / \mathrm{m}^{3}$.

The distribution of FS is shown in Figure 5.25. The ULS values for the driving moment due to the self-weight of the soil and that due to the live uniform surcharge load, which are divided by $\mathrm{r}_{\text {slip }}$, are 190.993 and $19.957 \mathrm{kNm} / \mathrm{m} / \mathrm{m}$, respectively. In addition, the ULS value for the resisting moment divided by $r_{\text {slip }}$ is $210.957 \mathrm{kNm} / \mathrm{m} / \mathrm{m}$.

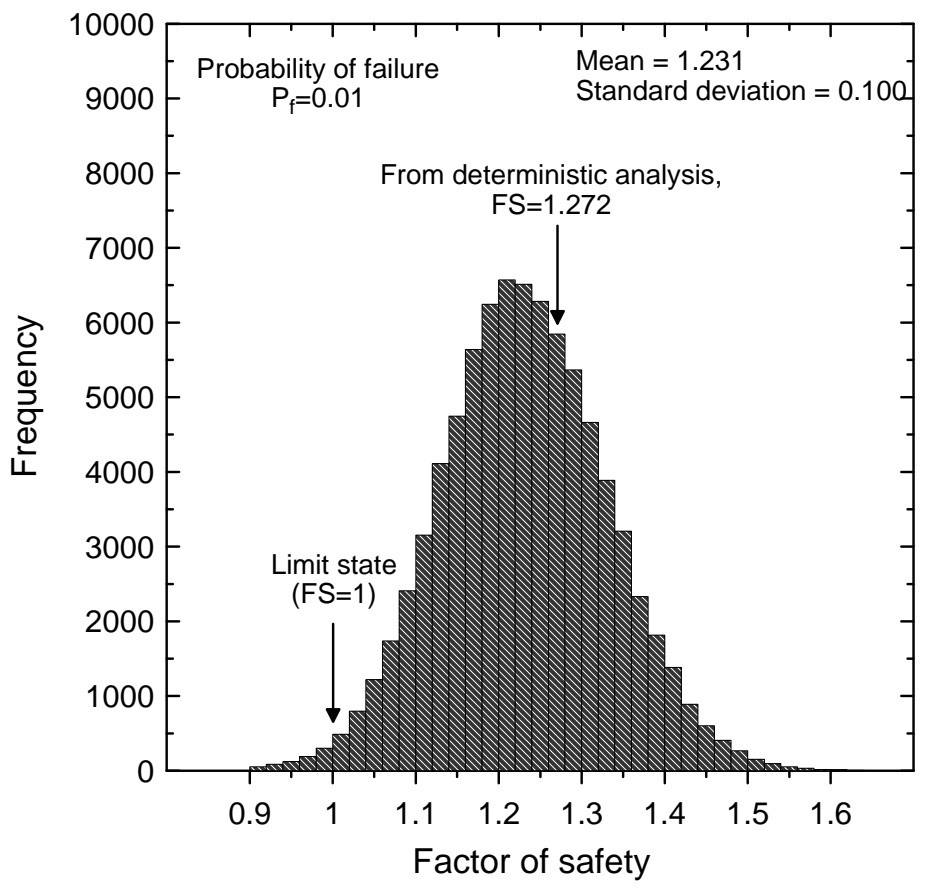

Figure 5.25 Distribution of FS value and the ULS of the slope $\left(\mathrm{P}_{\mathrm{f}}=0.01\right.$ and live uniform surcharge load $\mathrm{q}_{0}=12 \mathrm{kN} / \mathrm{m}$ )

The result of the deterministic analysis summarizes as follows: 
- $\quad$ Factor of safety $=1.272$

- Total driving moment $/ \mathrm{r}_{\text {slip }}=208.322 \mathrm{kNm} / \mathrm{m} / \mathrm{m}$

Driving moment due to self-weight of soil / $\mathrm{r}_{\text {slip }}=189.582 \mathrm{kNm} / \mathrm{m} / \mathrm{m}$

Driving moment due to live load $/ \mathrm{r}_{\text {slip }}=18.740 \mathrm{kNm} / \mathrm{m} / \mathrm{m}$

- Resisting moment $/ \mathrm{r}_{\text {slip }}=264.908 \mathrm{kNm} / \mathrm{m} / \mathrm{m}$

The optimum values are

$$
\begin{gathered}
(\mathrm{LF})_{\mathrm{DL}}^{*}=\frac{\mathrm{M}_{\mathrm{DL}, \mathrm{LS}}}{\mathrm{M}_{\mathrm{DL}}}=\frac{190.993 \mathrm{kN} \cdot \mathrm{m} / \mathrm{m} / \mathrm{m}}{189.582 \mathrm{kN} \cdot \mathrm{m} / \mathrm{m} / \mathrm{m}}=1.007 \\
(\mathrm{LF})_{\mathrm{LL}}^{*}=\frac{\mathrm{M}_{\mathrm{LL}, \mathrm{LS}}}{\mathrm{M}_{\mathrm{LL}}}=\frac{19.957 \mathrm{kN} \cdot \mathrm{m} / \mathrm{m} / \mathrm{m}}{18.740 \mathrm{kN} \cdot \mathrm{m} / \mathrm{m} / \mathrm{m}}=1.065 \\
\mathrm{RF}^{*}=\frac{\mathrm{M}_{\mathrm{R}, \mathrm{LS}}}{\mathrm{M}_{\mathrm{R}}}=\frac{210.957 \mathrm{kN} \cdot \mathrm{m} / \mathrm{m} / \mathrm{m}}{264.908 \mathrm{kN} \cdot \mathrm{m} / \mathrm{m} / \mathrm{m}}=0.796
\end{gathered}
$$

Using these optimum factors and AASHTO LF values, RF is

$$
\mathrm{RF}=\frac{\mathrm{RF}^{*}}{\max \left[\frac{(\mathrm{LF})_{\mathrm{DL}}{ }^{*}}{(\mathrm{LF})_{\mathrm{DL}}}, \frac{(\mathrm{LF})_{\mathrm{LL}}{ }^{*}}{(\mathrm{LF})_{\mathrm{LL}}}\right]}=\frac{0.796}{1.065}=0.747
$$

Figure 5.26 and Figure 5.27 are the distributions of optimum load factor for the load due to the self-weight of soil and that for the live surcharge load for the cases whose factors of safety are very close to one $(0.99<\mathrm{FS}<1.01)$. The mean values of these optimum load factors were 0.876 and 1.849 , respectively. 


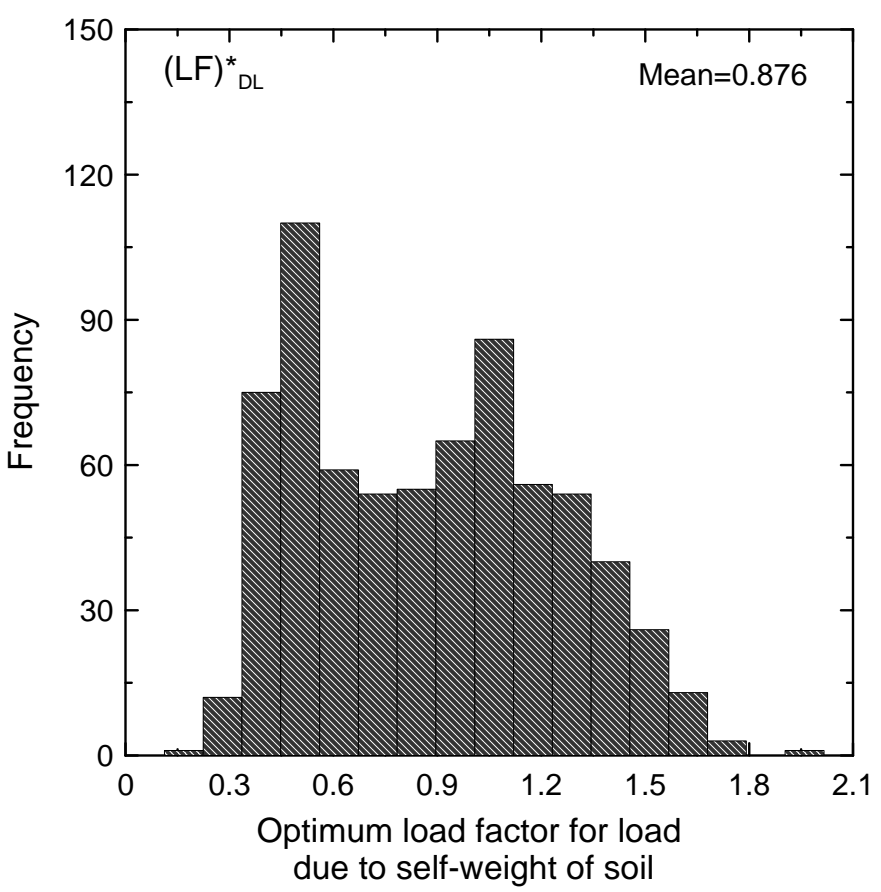

Figure 5.26 Distribution of optimum load factor $(\mathrm{LF})^{*}$ DL for load due to self-weight of soil

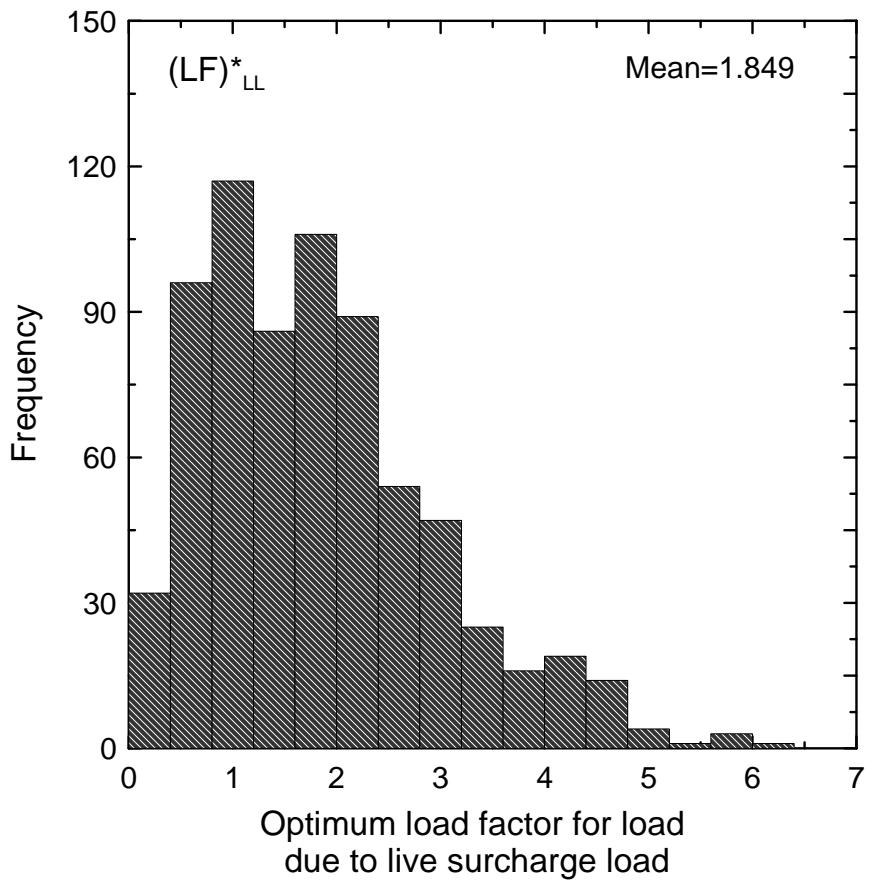

Figure 5.27 Distribution of optimum load factor $(\mathrm{LF})^{*}$ LL for load due to live surcharge load 
Figure 5.28 is the distribution of optimum resistance factor. The mean value was 0.758 .

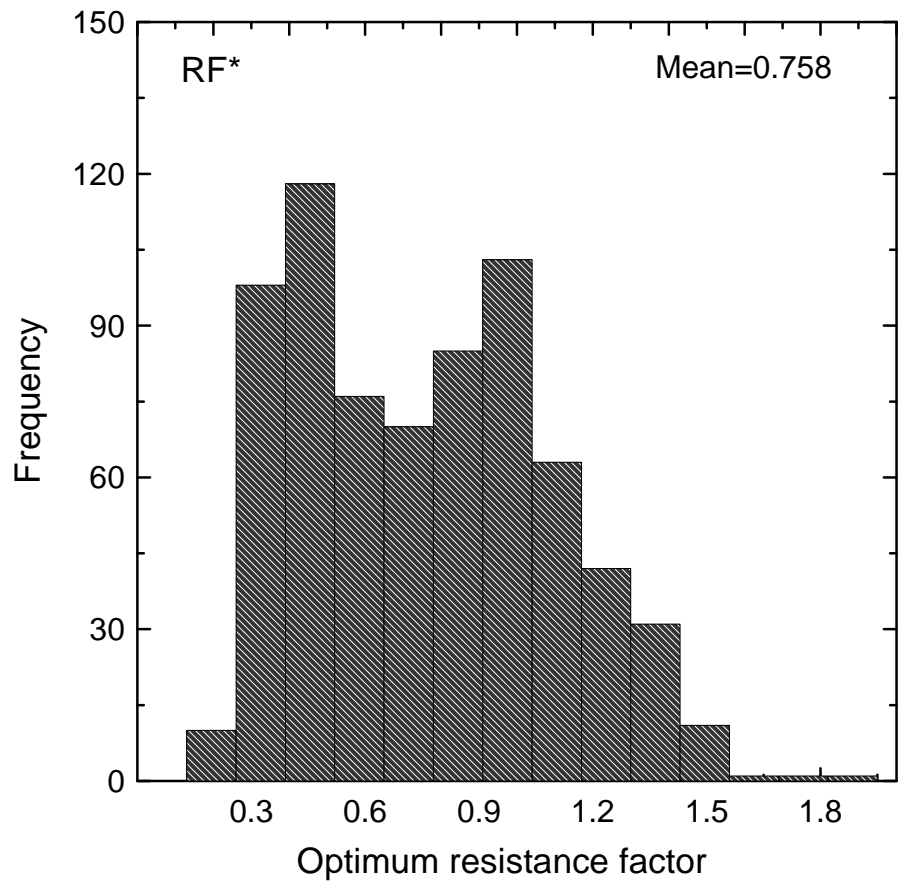

Figure 5.28 Distribution of optimum resistance factor $\mathrm{RF}^{*}$

If we use these mean values for load and resistance factor, the factored load and the factored resistance are:

$$
\begin{gathered}
\sum(\mathrm{LF})_{\mathrm{i}} \mathrm{Q}_{\mathrm{i}}=0.896 \times 189.582+1.849 \times 18.740=200.724 \mathrm{kN} \mathrm{m} / \mathrm{m} / \mathrm{m} \\
(\mathrm{RF}) \mathrm{R}_{\mathrm{n}}=0.758 \times 264.908=200.800 \mathrm{kN} \mathrm{m} / \mathrm{m} / \mathrm{m}
\end{gathered}
$$

The LRFD criterion [inequality (2.2)] is satisfied:

$$
\text { (RF) } R_{\mathrm{n}}[=200.800 \mathrm{kN} \mathrm{m} / \mathrm{m} / \mathrm{m}] \geq \sum(\mathrm{LF})_{\mathrm{i}} \mathrm{Q}_{\mathrm{i}}[=200.724 \mathrm{kN} \mathrm{m} / \mathrm{m} / \mathrm{m}]
$$




\subsubsection{Consolidation of calculation results}

The values of the optimum factors change from simulation to simulation. These optimum factors are variable because the representations of soil parameters using Gaussian random field theory and the location of the corresponding most critical slip surface at the ULS vary from simulation to simulation. The fluctuations of these optimum factors from simulation to simulation also results in the fluctuation of RF. This nonuniqueness of ULS issue can be resolved when we generate a large number of ULSs and calculated the mean values of optimum factors of these ULSs.

The optimum resistance and load factors and RF values from the six examples are summarized in Table 5.1. The RF values that are calculated based on Eq. (5.16) and the AASHTO LF values ( $L F=1$ for all types of loads) are used. Even for the same target probability of failure, the RF values in Table 5.1 changes within a wide range.

Table 5.1 Optimum factors from the examples ( $\mathrm{LF}=1$ for all types of loads)

\begin{tabular}{|c|c|c|c|c|c|c|c|}
\hline \multicolumn{2}{|c|}{ Example } & $\begin{array}{c}\mathrm{q}_{0} \\
(\mathrm{kN} / \mathrm{m})\end{array}$ & $\mathrm{P}_{\mathrm{f}}$ & $\mathrm{LF}^{*}$ DL & $\mathrm{LF}^{*}{ }_{\mathrm{LL}}$ & $\mathrm{RF}^{*}$ & $\mathrm{RF}$ \\
\hline \multirow{3}{*}{ Slope } & Example 1 & - & 0.001 & 0.907 & & 0.686 & 0.756 \\
\cline { 2 - 9 } & Example 2 & - & 0.01 & 0.999 & & 0.779 & 0.780 \\
\cline { 2 - 9 } & Example 3 & 12 & 0.001 & 1.033 & 1.603 & 0.809 & 0.505 \\
\cline { 2 - 9 } & Example 4 & 12 & 0.01 & 0.897 & 1.188 & 0.752 & 0.633 \\
\hline \multirow{3}{*}{ Embankment } & Example 5 & 12 & 0.001 & 0.930 & 1.088 & 0.666 & 0.612 \\
\cline { 2 - 9 } & Example 6 & 12 & 0.01 & 0.876 & 1.849 & 0.758 & 0.410 \\
\hline
\end{tabular}

( $\mathrm{q}_{0}$ : live surcharge load, $\mathrm{P}_{\mathrm{f}}$ : target probability of failure, $\mathrm{LF}^{*}{ }_{\mathrm{DL}}$ : optimum load factor for load due to self-weight of soil. $\mathrm{LF}_{\mathrm{LL}}{ }_{\mathrm{LL}}$ : optimum load factor for load due to live surcharge load, $\mathrm{RF}^{*}$ : optimum resistance factor, and $\mathrm{RF}$ : resistance factor)

Although AASHTO LRFD specifications (2007) suggest that all the load factors for slope designs are equal to one, it is not reasonable to use those load factors. The use of $L F=1$ for all types of loads may be because there has been limited study on load factor 
determination for LRFD for slopes. When $L F=1$ is assumed for all types of loads, RF value in LRFD for slopes is just the inverse of the FS. Therefore, for the development of LRFD for slopes, appropriate LF values for different types of loads should be assessed. Table 5.2 shows how the RF value changes with respect to changes in LF values.

Table 5.2 RF values for different LF values for dead and live load

\begin{tabular}{|c|c|c|c|c|c|c|c|}
\hline \multicolumn{2}{|c|}{$(\mathrm{LF})_{\mathrm{DL}}$} & 1.0 & 1.0 & 1.0 & 1.25 & 1.25 & 1.25 \\
\hline \multicolumn{2}{|c|}{$(\mathrm{LF})_{\mathrm{LL}}$} & 1.0 & 1.5 & 2.0 & 1.0 & 1.5 & 2.0 \\
\hline \multirow{4}{*}{ Slope } & Example 1 & 0.75 & 0.75 & 0.75 & 0.94 & 0.94 & 0.94 \\
\hline & Example 2 & 0.78 & 0.78 & 0.78 & 0.97 & 0.97 & 0.97 \\
\hline & Example 3 & 0.50 & 0.75 & 0.78 & 0.50 & 0.75 & 0.97 \\
\hline & Example 4 & 0.63 & 0.83 & 0.83 & 0.63 & 0.94 & 1.04 \\
\hline \multirow{2}{*}{ Embankment } & Example 5 & 0.61 & 0.71 & 0.71 & 0.61 & 0.89 & 0.89 \\
\hline & Example 6 & 0.41 & 0.61 & 0.82 & 0.41 & 0.61 & 0.82 \\
\hline
\end{tabular}

$\left[(\mathrm{LF})_{\mathrm{DL}}\right.$ and $(\mathrm{LF})_{\mathrm{LL}}$ are the load factors for loads due to self-weight of soil and those due to live surcharge load]

Determination of an appropriate LF value for each type of load can be done by using the solver mode in Microsoft Excel; by requiring that all the load factors for dead and live loads be greater or equal to one $(L F \geq 1)$, the solver mode finds the best combination of LFs that results in the narrowest range of RF for two different levels of target probability of failure $\left(\mathrm{P}_{\mathrm{f}}=0.001\right.$ and 0.01$)$. From the six examples in the previous section, the best LF values were

$$
\begin{gathered}
(\mathrm{LF})_{\mathrm{DL}}=1.0 \\
(\mathrm{LF})_{\mathrm{LL}}=1.98 \approx 2.0
\end{gathered}
$$


Using these LF values, the RF values for the examples are calculated and summarized in Table 5.3.

Table 5.3 RF values when $(\mathrm{LF})_{\mathrm{DL}}=1$ and $(\mathrm{LF})_{\mathrm{LL}}=2.0$

\begin{tabular}{|c|c|c|c|c|}
\hline \multicolumn{2}{|c|}{ Example } & $\begin{array}{c}\mathrm{q}_{0} \\
(\mathrm{kN} / \mathrm{m})\end{array}$ & $\mathrm{P}_{\mathrm{f}}$ & $\mathrm{RF}$ \\
\hline \multirow{3}{*}{ Slope } & Example 1 & - & 0.001 & 0.75 \\
\cline { 2 - 5 } & Example 2 & - & 0.01 & 0.78 \\
\cline { 2 - 5 } & Example 3 & 12 & 0.001 & 0.78 \\
\cline { 2 - 5 } & Example 4 & 12 & 0.01 & 0.83 \\
\hline \multirow{3}{*}{ Embankment } & Example 5 & 12 & 0.001 & 0.71 \\
\cline { 2 - 5 } & Example 6 & 12 & 0.01 & 0.82 \\
\hline
\end{tabular}

( $\mathrm{q}_{0}$ : live surcharge load, $\mathrm{P}_{\mathrm{f}}$ : target probability of failure, and RF: resistance factor)

The result in Table 5.3 shows that, when appropriate LFs are determined, the RF for each target probability of failure varies within a relatively narrow range; the RF value for target probability of failure equal to 0.001 ranges from 0.71 to 0.78 and that for a target probability of failure equal to 0.01 varies from 0.78 to 0.83 . However, we have examined the RF values from only 6 examples. To propose appropriate LF values for each type of loads and RF values for LRFD for slopes, we need to perform extensive reliability-based slope stability simulations with different conditions in terms of slope geometry, soil parameters, and external loads. 


\section{PART III - LRFD OF MSE WALLS}

In the early 1960s, Mechanically Stabilized Earth (MSE) walls were devised by Henri Vidal, a French engineer and architect, and later patented as "Reinforced Earth." The first construction of low MSE walls in the United States was in California in 1972. MSE walls are now the most popular type of retaining structure, and, for transportation applications, more than half of the retaining structures are MSE walls. The big advantage of an MSE wall is its economical efficiency. Moreover, MSE wall construction is much easier than that of other retaining structures.

An MSE wall consists of facing, reinforcement, reinforced soil, retained soil, and foundation soil (Figure P.1). A backfill material in the "reinforced soil zone" is placed between layers of horizontal reinforcement. There are several types of reinforcements, such as steel strips, steel grids, geotextile sheets, and geogrids. However, in this report, we only consider steel strips as the reinforcement.

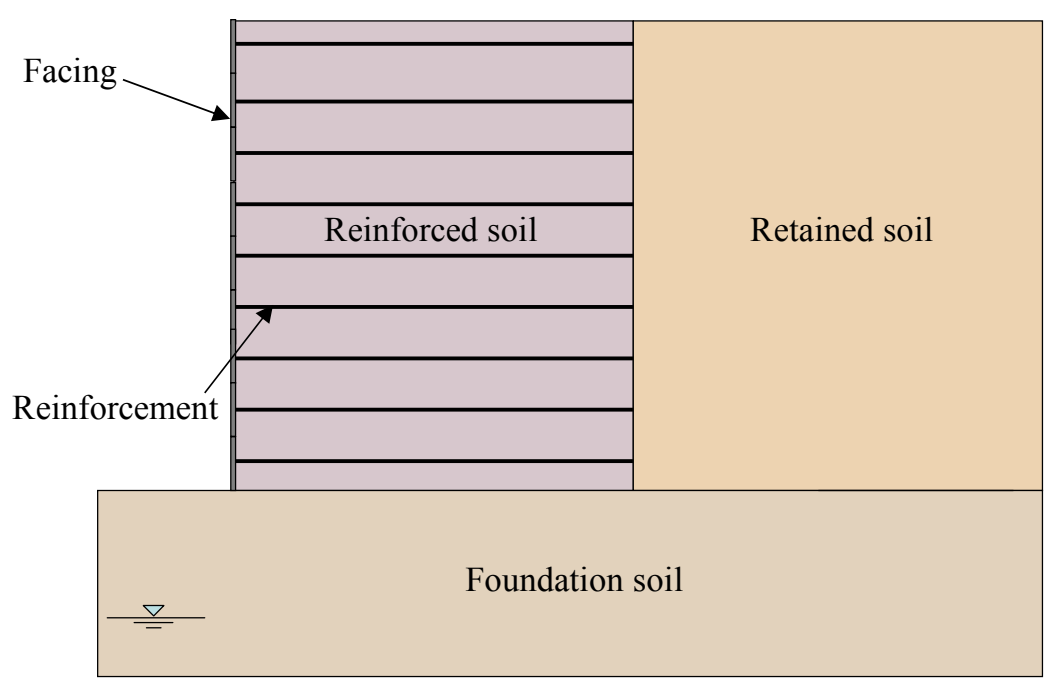

Figure P.1 Cross-sectional view of an MSE wall

MSE walls must satisfy both the external and internal stability criteria. The external stability criteria include: (1) sliding, (2) overturning, (3) limit bearing capacity 
failure, and (4) general loss of stability. Internal stability criteria include: (1) structural failure (rupture) and (2) pullout of the reinforcements. For the LRFD check of the limit bearing capacity failure of an MSE wall, refer to the literature (Foye, et al. 2006; Foye, 2004; and Scott, 2002).

Each stability criterion (both the external and internal stability criteria) has its own ULS that may be defined by limit equilibrium analyses. The parameters represented in Figure P.2 are the variables that are used in defining the ULS equations. For convenience in notation, the subscripts $\mathrm{rf}, \mathrm{rt}$, and fn are used to indicate that the variables are related to reinforced soil, retained soil, and foundation soil, respectively.

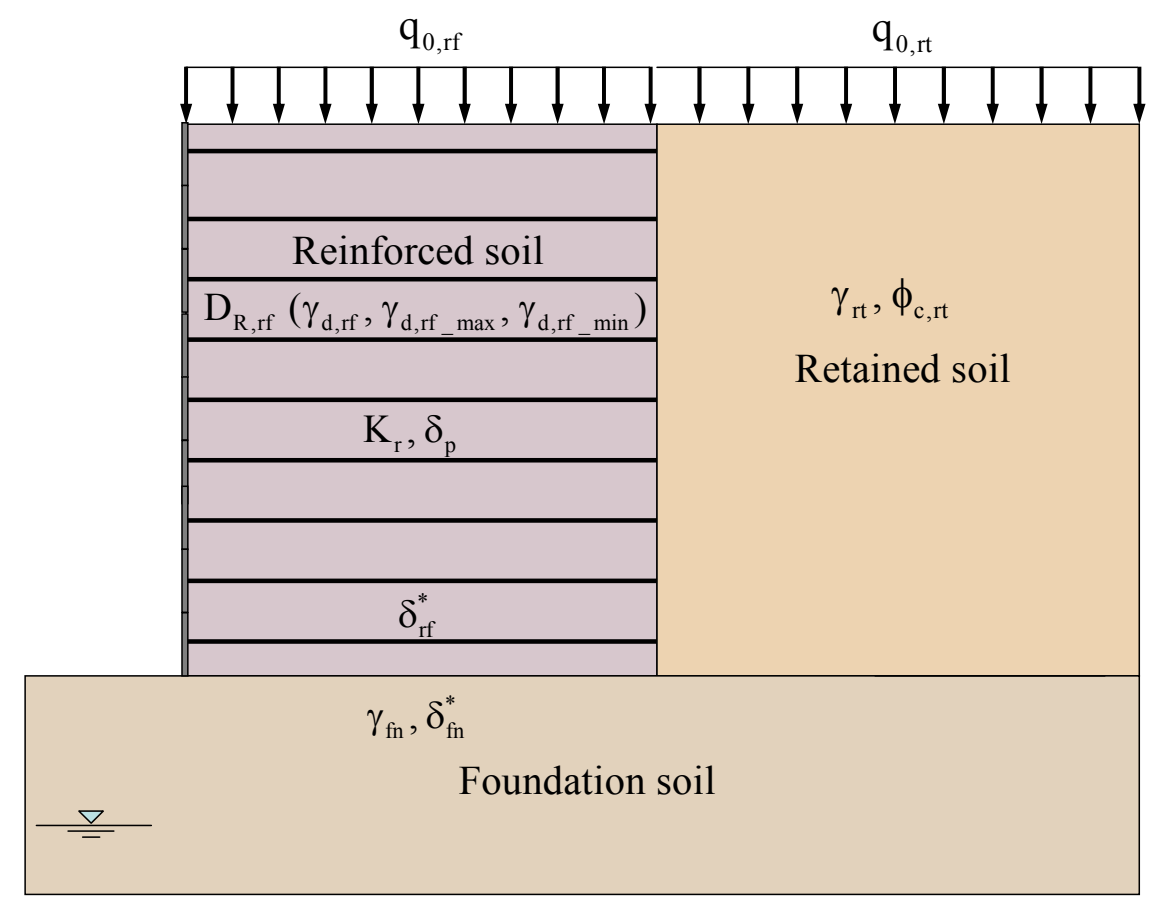

Figure P.2 Parameters used in ULS equations for MSE walls $\left(\mathrm{D}_{R}\right.$ is the relative density, $\gamma_{d}$ is the dry unit weight, $K_{r}$ is the coefficient of lateral earth pressure, $\delta_{p}$ is the interface friction angle between the backfill material in the reinforced soil and the reinforcement, $\phi_{\mathrm{c}}$ is the critical-state friction angle, and $\delta^{*}$ is the interface friction angle at the bottom of the MSE wall) 
All the variables in Figure P.2 are subject to uncertainties. In this study, the uncertainties of the parameters $\delta_{\mathrm{rf}}^{*}, \phi_{\mathrm{c}, \mathrm{rt}}, \delta_{\mathrm{fn}}^{*}, \gamma_{\mathrm{rf}}, \gamma_{\mathrm{rt}}, \gamma_{\mathrm{fn}}, \mathrm{D}_{\mathrm{R}, \mathrm{rf}}, \delta_{\mathrm{p}}$, and $\mathrm{q}_{0}$ are assessed. Using these variables and their uncertainties, a series of reliability analyses are performed, and RF values for each stability criterion of MSE wall systems proposed based on the results of these analyses. 


\section{CHAPTER 6. EXTERNAL STABILITY OF MSE WALLS}

\subsection{Introduction}

This chapter introduces the development of the LRFD method for MSE walls for the two external stability criteria (sliding and overturning) that are specific to retaining wall structures. The calculation of RF values for each stability criterion is done in the following sequence:

1. Identify the ULS equation and the models used in the ULS equation.

2. Identify the component variables that are related to the ULS equation and models.

3. Select the LFs from the AASHTO LRFD specifications.

4. Evaluate the uncertainties of the component variables and the models themselves (determine the types of distribution, bias factors, and COVs).

5. Perform reliability analyses until a calculated reliability index is equal to the target reliability index.

6. Calculate the loads and resistance at the ULS.

7. Calculate the nominal loads and resistance.

8. Compute the optimum RF and LFs.

9. Determine the RF value using the optimum factors.

The assessment of the uncertainties of the soil parameters for MSE walls is quite different from that for slopes. For the soil parameters for slopes, Gaussian random field theory was used for the representation of the soil parameters of a statistically homogeneous soil layer. This is because a statistically homogeneous soil layer of slopes 
may be extensive, and the mean, bias factor and COV of a specific soil parameter are not sufficient to capture the effects of the uncertainty in the soil parameter. However, for MSE walls, the uncertainties of the soil parameters were expressed using their means and COVs (bias factors, if necessary). This is because the dimensions of an MSE wall are relatively small, backfill materials for MSE wall construction are quality-controlled not only by using high quality backfill materials for the reinforced soil and retained soil, but also by performing proper compaction on them. This means that use of random field theory would add little value to the analysis.

\subsection{Ultimate Limit States Associated with External Stability}

A crucial assumption is made in defining the ULS equations for the external stability ULSs of MSE walls: the reinforced soil mass is assumed to be a solid block, such as a gravity retaining wall. Ingold (1982) stated that this assumption has worked successfully in MSE wall designs for external stability criteria. Therefore, the conventional limit equilibrium analysis for the external stability of a gravity retaining wall can be employed to define the ULS equations for each of the external stability criteria of an MSE wall (sliding, overturning, bearing capacity and overall stability criteria).

ULS equations for sliding and overturning criteria are introduced in this section. The bearing capacity criterion of an MSE wall is similar to that for a shallow foundation. We could substitute the previous JTRP reports done by Foye and Scott (Foye 2004 and Scott 2002) for the bearing capacity criterion of MSE walls. In addition, LRFD-based analysis of overall stability of an MSE wall can be done using the slope stability guidelines discussed earlier.

\subsubsection{Sliding criterion}

For MSE wall sliding checks, the live uniform surcharge load acting on the top of the reinforced soil $\mathrm{q}_{0, \mathrm{rf}}$ is neglected, while that acting on the top of the retained soil $\mathrm{q}_{0, \mathrm{rt}}$ is 
considered (Article 11.5.5 of AASHTO LRFD specifications, 2007). This is because, in reality, we may have this situation ( $\mathrm{q}_{0, \mathrm{rt}}$ exists while $\mathrm{q}_{0, \mathrm{rf}}$ does not), which is the worst case in terms of an external load condition.

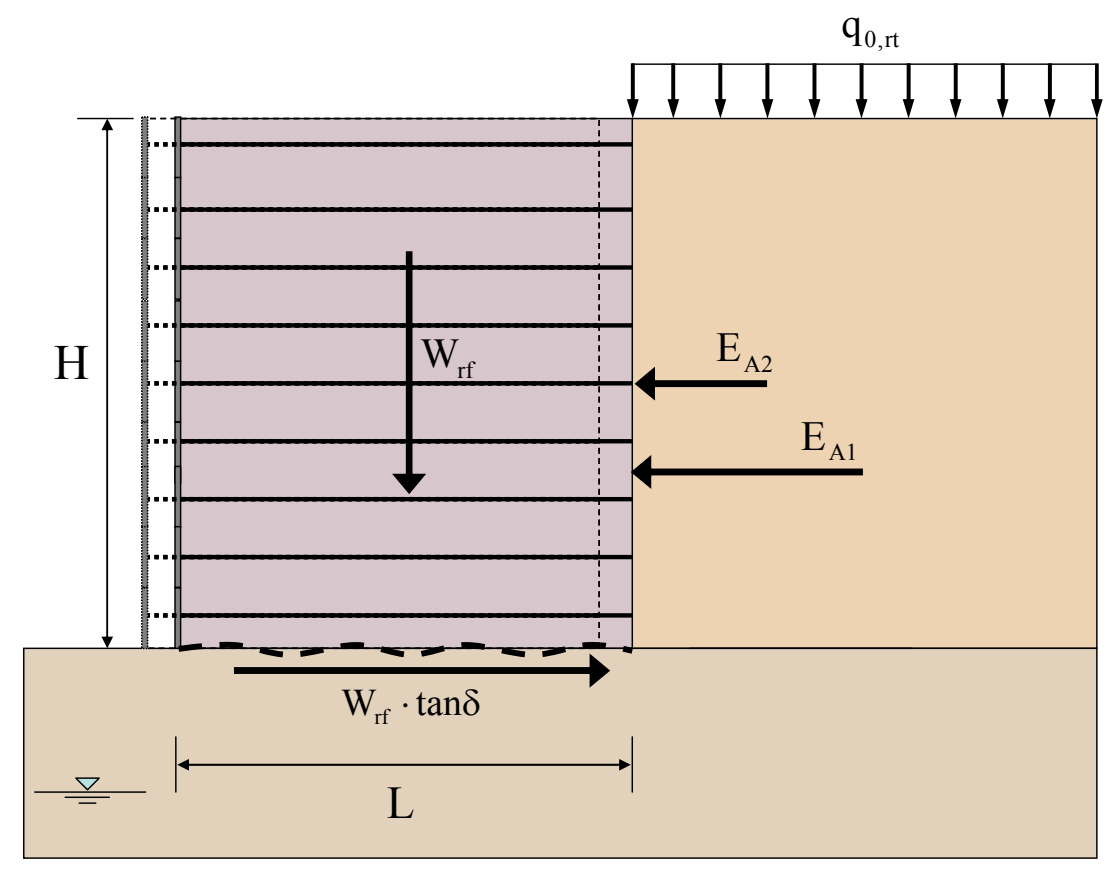

Figure 6.1 Forces defining the sliding ULS equation $\left(\mathrm{E}_{\mathrm{A} 1}\right.$ and $\mathrm{E}_{\mathrm{A} 2}$ are the lateral forces due to the active earth pressures caused by the self-weight of the retained soil and the live uniform surcharge load $\mathrm{q}_{0, \mathrm{rt}} ; \mathrm{W}_{\mathrm{rf}}$ is the self-weight of the reinforced soil; $\mathrm{H}$ is the MSE wall height; $\mathrm{H}$ is the reinforcement length; and $\delta$ is the interface friction angle at the bottom of the MSE wall)

Therefore, the ULS equation for sliding is

$$
\mathrm{E}_{\mathrm{A} 1}+\mathrm{E}_{\mathrm{A} 2}-\mathrm{W}_{\mathrm{rf}} \cdot \tan \delta=0
$$

where $\mathrm{E}_{\mathrm{A} 1}$ and $\mathrm{E}_{\mathrm{A} 2}$ are the lateral forces due to the active earth pressures caused by the self-weight of the retained soil and the live uniform surcharge load $\mathrm{q}_{0, \mathrm{rt}}, \mathrm{W}_{\mathrm{rf}}$ is the selfweight of the reinforced soil, and $\mathrm{L}$ is the reinforcement length. 
$\mathrm{E}_{\mathrm{A} 1}+\mathrm{E}_{\mathrm{A} 2}$ is the load inducing a sliding of an MSE wall and $\mathrm{W}_{\mathrm{rf}} \tan \delta$ is the resistance against the sliding. The active earth pressure coefficient $\mathrm{K}_{\mathrm{A}}$ is used in the calculation of $\mathrm{E}_{\mathrm{A} 1}$ and $\mathrm{E}_{\mathrm{A} 2}$. The active earth pressure coefficient of retained soil is

$$
\mathrm{K}_{\mathrm{A}}=\frac{1-\sin \phi}{1+\sin \phi}
$$

$\mathrm{E}_{\mathrm{A} 1}$ and $\mathrm{E}_{\mathrm{A} 2}$ are

$$
\begin{aligned}
& \mathrm{E}_{\mathrm{A} 1}=\frac{1}{2} \mathrm{~K}_{\mathrm{A}} \gamma_{\mathrm{rt}} \mathrm{H}^{2} \\
& \mathrm{E}_{\mathrm{A} 2}=\mathrm{K}_{\mathrm{A}} \mathrm{q}_{0, \mathrm{rt}} \mathrm{H}
\end{aligned}
$$

where $\mathrm{H}$ is the height of the MSE wall.

In the MSE wall system, generally, an active state occurs when the soil mass is just about to collapse under a constant vertical stress. The active earth pressure acting on the reinforced soil develops after some deformation of the retained soil. However, if the retained soil is in a dense state and is subjected to relatively large strain due to high overburden pressure and to the wall moment, the mobilized of the retained soil will be somewhere between the peak and critical-state values. Therefore, the use of peak friction angle $\phi_{\mathrm{p}}$ to estimate $\mathrm{K}_{\mathrm{A}}$, which is recommended in current design guides (AASHTO, 2007 and FHWA, 2001), is questionable because $\phi_{\mathrm{p}}$ is mobilized at small strains and will drop from $\phi_{\mathrm{p}}$ to the critical-state value $\phi_{\mathrm{c}}$ as sliding develops. Moreover, it is dangerous to use $\phi_{\mathrm{p}}$ to estimate $\mathrm{K}_{\mathrm{A}}$ because it will underestimate the lateral forces $\left(\mathrm{E}_{\mathrm{A} 1}\right.$ and $\left.\mathrm{E}_{\mathrm{A} 2}\right)$ acting on the reinforced soil $\left(\mathrm{K}_{\mathrm{A}}\right.$ calculated using $\phi_{\mathrm{p}}$ is less than that calculated using $\left.\phi_{\mathrm{c}}\right)$. To be consistent in our design, $\phi_{\mathrm{c}}$ is used to estimate $\mathrm{K}_{\mathrm{A}}$ using Eq. (6.2). It is known that the $\phi_{\mathrm{c}}$ in triaxial compression is less than that in plane-strain compression. 
The self-weight of the reinforced soil is

$$
\mathrm{W}_{\mathrm{rf}}=\gamma_{\mathrm{rf}} \mathrm{HL}
$$

In FHWA (2001) and AASHTO (2007) specifications, the interface friction angle $\delta$ at the bottom of an MSE wall is determined as the minimum value between the peak friction angle of the reinforced soil $\phi_{\mathrm{p}, \mathrm{rf}}$ and that of the foundation soil $\phi_{\mathrm{p}, \mathrm{fn}}$ :

$$
\delta=\min \left(\phi_{\mathrm{p}, \mathrm{ff}}, \phi_{\mathrm{p}, \mathrm{fn}}\right)
$$

The minimum value between $\phi_{\mathrm{p}, \mathrm{ff}}$ and $\phi_{\mathrm{p}, \mathrm{fn}}$ for $\delta$ is taken because the sliding of the reinforced soil can occur either along the foundation soil or the reinforced soil in the vicinity of the bottom of MSE walls. However, the use of $\phi_{p}$ in Eq. (6.6) overestimates the resistance against the sliding of an MSE wall because $\phi_{\mathrm{p}}$ is higher than the actual interface friction angle at the bottom of MSE walls. Therefore, instead of using $\phi_{\mathrm{p}}$ in Eq. (6.6) for the $\delta$ at the bottom of an MSE wall, it is more reasonable to use $\delta^{*}$ which is defined as

$$
\delta^{*}=\tan ^{-1}\left(\frac{\tau}{\sigma_{\mathrm{a}}^{\prime}}\right)
$$

where $\tau$ is the shear stress in the horizontal plane and $\sigma_{a}^{\prime}$ is the constant vertical stress on the horizontal plane during sliding. The interface friction angle $\delta$ at the bottom of an MSE wall is:

$$
\delta=\min \left(\delta_{\mathrm{rf}}^{*}, \delta_{\mathrm{fn}}^{*}\right)
$$




\subsubsection{Overturning criterion}

The analysis of the overturning ULS is simpler than that of sliding in terms of defining the parameters in the ULS equation. Again, the live uniform surcharge load acting on the top of the reinforced soil is neglected (Article 11.5.5 of AASHTO LRFD specifications, 2007). The ULS equation for overturning is

$$
\mathrm{E}_{\mathrm{A} 1} \frac{\mathrm{H}}{3}+\mathrm{E}_{\mathrm{A} 2} \frac{\mathrm{H}}{2}-\mathrm{W}_{\mathrm{rf}}\left(\frac{L}{2}\right)=0
$$

The equations for the calculation of $\mathrm{E}_{\mathrm{A} 1}, \mathrm{E}_{\mathrm{A} 2}$, and $\mathrm{W}_{\mathrm{rf}}$ are the same as those used in the sliding criterion. [Eq. (6.3), Eq. (6.4), and Eq. (6.5)]. In Eq. (6.9), $\mathrm{E}_{\mathrm{A} 1 \mathrm{H} / 3 \text { and }}$ $\mathrm{E}_{\mathrm{A} 2} \mathrm{H} / 2$ are the driving moment due to the self-weight of the retained soil and that due to the live uniform surcharge load $\mathrm{q}_{0, \mathrm{rt}}$ on the top of an MSE wall, while $\mathrm{W}_{\mathrm{rf}} \mathrm{L} / 2$ is the resisting moment due to the self-weight of the reinforced soil.

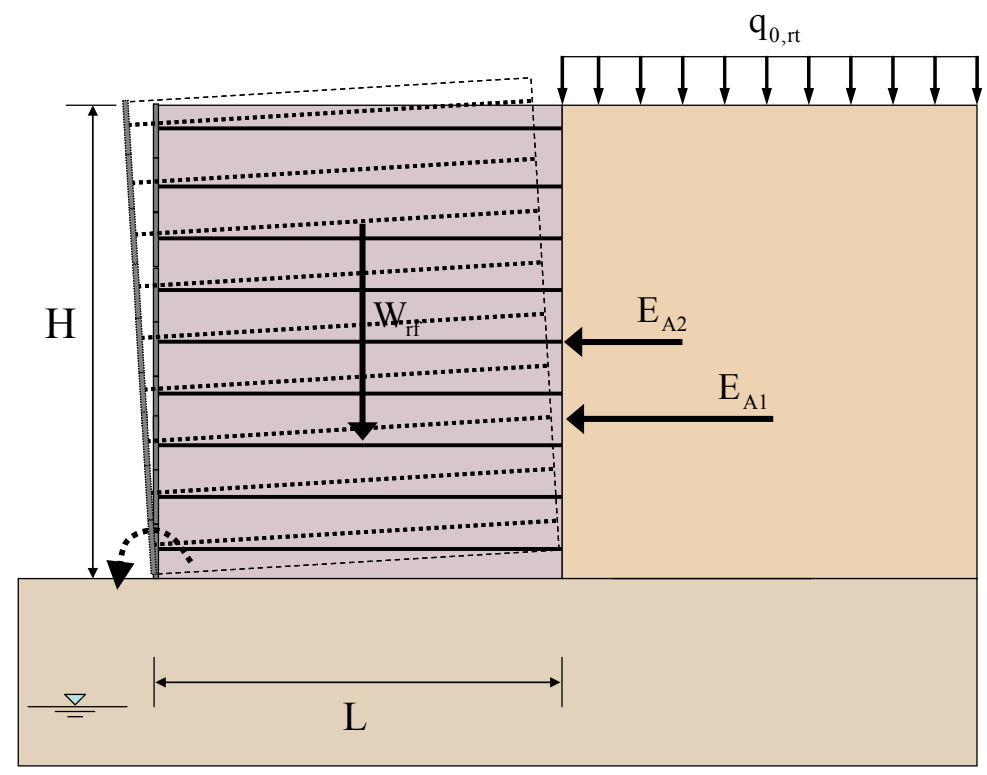

Figure 6.2 Forces defining the overturning ULS equation $\left(\mathrm{E}_{\mathrm{A} 1}\right.$ and $\mathrm{E}_{\mathrm{A} 2}$ are the lateral forces due to the active earth pressures caused by the self-weight of the retained soil and 
the live uniform surcharge load $\mathrm{q}_{0, \mathrm{rt}} ; \mathrm{W}_{\mathrm{rf}}$ is the self-weight of the reinforced soil; $\mathrm{H}$ is the MSE wall height; and $\mathrm{H}$ is the reinforcement length)

\subsection{Determination of LFs for External Stability}

The method to determine the LF values from AASHTO LRFD specifications (2007) was briefly explained in chapter 2. There are two types of loads that induce sliding and overturning in MSE walls (Figure 6.3): (1) the lateral load $\mathrm{E}_{\mathrm{A} 1}$ acting on the reinforced soil due to the self-weight of the retained soil and (2) the lateral load $\mathrm{E}_{\mathrm{A} 2}$ acting on the reinforced soil due to the live uniform surcharge load $\mathrm{q}_{0, \mathrm{rt}}$ on the top of the retained soil. Since $\mathrm{E}_{\mathrm{A} 1}$ is induced by a permanent load, the corresponding load factor (the load factor for active horizontal earth pressure EH given in Table 2.2:) is to be in the 0.9-1.5 range. $\mathrm{E}_{\mathrm{A} 2}$ in turn is induced by a live uniform surcharge load; therefore, the load factor of 1.75 given in Table 2.1 should be used. The LF values for the permanent loads are selected such that, the factored load (LF times permanent load) induces the highest instability on the wall. In this case, the $\mathrm{LF}$ for $\mathrm{E}_{\mathrm{A} 1}$ is 1.5 because the factored load $1.5 \mathrm{E}_{\mathrm{A} 1}$ is the highest possible factored load that will lead to the most instability of an MSE wall against sliding and overturning. 


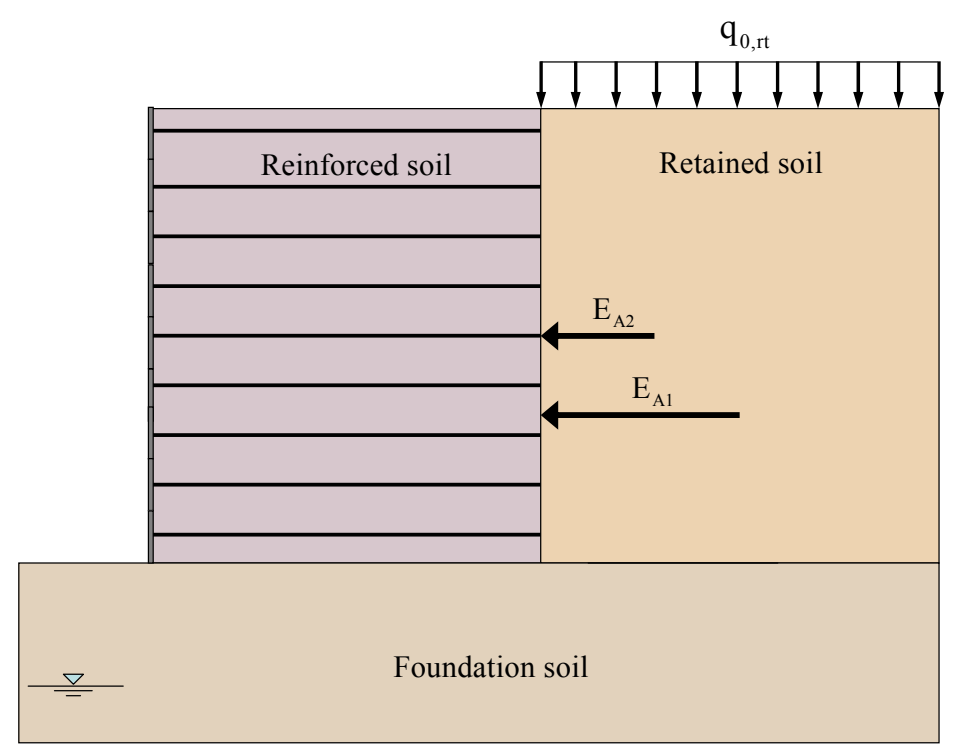

Figure 6.3 Loads inducing sliding and overturning of an MSE wall $\left(\mathrm{E}_{\mathrm{A} 1}\right.$ and $\mathrm{E}_{\mathrm{A} 2}$ are the lateral forces due to the active earth pressures caused by the self-weight of the retained soil and the live uniform surcharge load $\mathrm{q}_{0, \mathrm{rt}}$ )

\subsection{Uncertainties of the Parameters That are Used in the Analysis}

The following variables are the parameters in the sliding and overturning ULS equations that have uncertainty: (1) dry unit weight of the noncompacted soil $\gamma_{d}$, (2) critical-state friction angle $\phi_{c}$, (3) live uniform surcharge load $q_{0}$, and (4) interface friction angles $\delta$ at the base of an MSE wall.

6.4.1. Uncertainty of dry unit weight $\gamma_{\mathrm{d}}$ of the noncompacted retained soil

Hammitt (1966) examined the variability of soil unit weight determined independently in nearly one hundred different laboratories. Based on Hammitt's report, the COV of the soil unit weight was 0.03 (Foye, 2004). In addition, the typical ranges of the unit weights of loose, medium and dense sands are (15.7-18.9 kN/m $\left.\mathrm{m}^{3}\right),\left(17.3-20.5 \mathrm{kN} / \mathrm{m}^{3}\right)$ and (18.9$22.0 \mathrm{kN} / \mathrm{m}^{3}$ ) (Das, 1995). If we pessimistically assume that the sand in the field is in one of these three states (loose, medium or dense), the COV of the unit weight of sand can be 
assessed using the $6 \sigma$ method, which is explained in Appendix D. Applying the $6 \sigma$ method to the three states of sand, a loose sand has the highest COV of 0.03 among them. Therefore, we will assume, conservatively, that the $\operatorname{COV}$ of $\gamma_{\mathrm{d}}$ is 0.03 .

\subsubsection{Uncertainty of critical-state friction angle $\phi_{\mathrm{c}}$}

The critical-state friction angle $\phi_{\mathrm{c}}$ is used to estimate the active earth pressure coefficient $\mathrm{K}_{\mathrm{A}}$; it can be estimated using different apparatuses, such as the triaxial chamber, the direct shear box or the ring shear apparatus under undrained or drained conditions.

From forty-seven undrained triaxial tests performed on standard Toyoura sand $\left(\mathrm{D}_{50}=0.17 \mathrm{~mm}, \mathrm{e}_{\mathrm{max}}=0.977, \mathrm{e}_{\min }=0.597, \mathrm{G}_{\mathrm{s}}=2.65\right)$ performed by Verdugo and Ishihara (1996), the mean $\phi_{c}$ of this sand was $31.7^{\circ}$ with a standard deviation of $0.805^{\circ}$ resulting in a COV value equal to 0.025 . In addition, ring shear drained tests on Ottawa sand with different initial relative densities, normal stresses and both dry and wet soil samples, the maximum COV of $\phi_{\mathrm{c}}$ was reported to be 0.0172 (Negussey et al., 1987). The corresponding values of COVs are summarized in Table 6.1. The COV of $\phi_{\mathrm{c}}$ in our analysis is conservatively selected as 0.02 , which is slightly higher than the maximum COV (0.172) in Table 6.1.

Table 6.1 COVs of $\phi_{c}$ of Ottawa sand from ring shear tests (after Negussey et al., 1987)

\begin{tabular}{|c|c|c|c|c|}
\hline Type of sand & Sample condition & Soil state & COV & Note \\
\hline \multirow{2}{*}{$\begin{array}{c}\text { Medium } \\
\text { Ottawa } \\
\text { Sand }\end{array}$} & Dry & $\mathrm{D}_{\mathrm{R}}=30 \%$ & 0.0146 & 9 tests \\
\cline { 2 - 5 } & Saturated & $\mathrm{D}_{\mathrm{R}}=30 \%$ & 0.0172 & 9 tests \\
\hline $\begin{array}{c}\text { Fine } \\
\text { Ottawa } \\
\text { Sand }\end{array}$ & Dry & $\begin{array}{c}\mathrm{D}_{\mathrm{R}} \text { varied } \\
(30-90 \%)\end{array}$ & 0.0081 & 6 tests \\
\hline
\end{tabular}




\subsubsection{Uncertainty of live uniform surcharge load $\mathrm{q}_{0}$}

According to Article 3.11.6.4 of the AASHTO LRFD specifications (2007), the design (nominal) uniform surcharge load $\mathrm{q}_{0}$ acting on top of an MSE wall due to vehicular load is given as an equivalent height $\mathrm{h}_{\mathrm{eq}}$ of soil at the location below the loading. The equivalent height of soil $h_{\mathrm{eq}}$ for vehicular loading on an abutment perpendicular to traffic (Table 6.2) is different from that on retaining walls parallel to traffic (Table 6.3). In Table 6.2 and Table 6.3 , the $\mathrm{h}_{\mathrm{eq}}$ for intermediate retaining wall heights can be estimated using the linear interpolation method.

Table 6.2 Equivalent height of soil for vehicular loading on abutment perpendicular to traffic

\begin{tabular}{|c|c|c|}
\hline $\begin{array}{c}\text { Abutment height } \\
(\mathrm{mm})\end{array}$ & $\begin{array}{c}\mathrm{h}_{\mathrm{eq}} \\
(\mathrm{mm})\end{array}$ & $\begin{array}{c}\mathrm{q}_{0} \text { when soil unit weight is } 20 \mathrm{kN} / \mathrm{m}^{3} \\
(\mathrm{kN} / \mathrm{m})\end{array}$ \\
\hline 1500 & 1200 & 24 \\
\hline 3000 & 900 & 18 \\
\hline$\geq 6000$ & 600 & 12 \\
\hline
\end{tabular}

Table 6.3 Equivalent height of soil for vehicular loading on retaining walls parallel to traffic

\begin{tabular}{|c|c|c|}
\hline \multirow{2}{*}{$\begin{array}{c}\text { Retaining wall } \\
\text { Height } \\
(\mathrm{mm})\end{array}$} & $\begin{array}{c}\text { Distance from wall backface } \\
\text { to edge of traffic }=0.0 \mathrm{~mm}\end{array}$ & $\begin{array}{c}\text { Distance from wall backface } \\
\text { to edge of traffic } \geq 300 \mathrm{~mm}\end{array}$ \\
\hline 1500 & 1500 & 600 \\
\hline 3000 & 1050 & 600 \\
\hline$\geq 6000$ & 600 & 600 \\
\hline
\end{tabular}

The bias factor and the COV of $\mathrm{q}_{0}$ are given in chapter 4 (Table 4.3). It is assumed that dead load follows a normal distribution with a bias factor of 1.05 and a COV of 0.15 , while live load follows a lognormal distribution with a bias factor of 1.15 and a COV of 0.25 . 
When a variable ( $\mathrm{x}$ ) has a lognormal probability distribution, its natural logarithm $(\ln (\mathrm{x}))$ is normally distributed. The probability density function of a lognormal distribution is

$$
\mathrm{p}(\mathrm{x})=\frac{1}{\mathrm{x} \sigma \sqrt{2 \pi}} \exp \left[-\frac{1}{2}\left(\frac{\ln \mathrm{x}-\lambda}{\zeta^{2}}\right)^{2}\right]
$$

where $\lambda$ and $\zeta$ are the mean and standard deviation of the lognormal distribution, $\ln (\mathrm{x})$.

The mean $\mu$ and standard deviation $\sigma$ of $\mathrm{x}$ are

$$
\begin{gathered}
\mu=\exp \left[\lambda+\frac{\zeta^{2}}{2}\right] \\
\sigma=\sqrt{\exp \left(2 \lambda+\zeta^{2}\right)\left(\exp \left(\zeta^{2}\right)-1\right)}
\end{gathered}
$$

Thus, $\zeta$ and $\lambda$ can be modified as

$$
\begin{gathered}
\zeta=\sqrt{\ln \left[1+\left(\frac{\sigma}{\mu}\right)^{2}\right]} \\
\lambda=\ln (\mu)-\frac{1}{2} \zeta^{2}
\end{gathered}
$$

To define a lognormal distribution, these two parameters ( $\zeta$ and $\lambda)$ are necessary. These values are needed when we perform reliability analysis using a Microsoft Excel spreadsheet to calculate the equivalent mean and standard deviation of lognormal distributed data. For example, when the nominal live uniform surcharge load $\mathrm{q}_{0}$ is 12 
$\mathrm{kN} / \mathrm{m}$ and the bias factor and $\mathrm{COV}$ are 1.15 and 0.25 , respectively, the mean $\mu$ and standard deviation $\sigma$ of $\mathrm{q}_{0}$ are

$$
\begin{gathered}
\mu=\text { bias factor } \times \text { nominal value }=1.15 \times 12=13.8 \mathrm{kN} / \mathrm{m} \\
\sigma=C O V \times \mu=0.25 \times 13.8=3.45 \mathrm{kN} / \mathrm{m}
\end{gathered}
$$

Thus, the standard deviation $\zeta$ and mean $\lambda$ of $\ln (\mathrm{x})$ are

$$
\begin{aligned}
& \zeta=\sqrt{\ln \left[1+\left(\frac{\sigma}{\mu}\right)^{2}\right]}=\sqrt{\ln \left[1+\left(\frac{3.45}{13.8}\right)^{2}\right]}=0.246 \\
& \lambda=\ln (\mu)-\frac{1}{2} \zeta^{2}=\ln (13.8)-\frac{1}{2} 0.246^{2}=2.594
\end{aligned}
$$

6.4.4. Uncertainty of interface friction angle $\delta\left(\delta^{*}\right)$ at the base of an MSE wall

Pradhan et al. (1988) conducted experiments to estimate the interface friction angles $\delta$ of hollow cylindrical specimens with different initial void ratios and confining stresses using a torsional shear apparatus. A Plane Strain (PS) condition prevails in the case of an MSE wall undergoing sliding failure. Using the Torsional Simple Shear (TSS) apparatus, an element inside a specimen can be sheared under PS conditions with constant vertical stress, as shown in Figure 6.4. The TSS apparatus does not allow radial displacement of the sample and automatically controls the vertical stress $\sigma_{a}$, which remains constant during shearing. Thus, the results from the TSS tests can be used to emulate closely the condition prevailing in the field (the vertical force acting at the bottom of an MSE wall due to the self-weight of reinforced soil does not change but total lateral force increases to have sliding of an MSE wall) for the sliding case of an MSE wall and to estimate an interface friction angle when sliding failure occurs. 
Pradhan et al. (1988) performed TSS tests on one-dimensionally consolidated Toyoura sand under different "constant" vertical stresses $\sigma_{\mathrm{a}}\left(29.4-196.2 \mathrm{kN} / \mathrm{m}^{2}\right)$. The relationship between the stress ratio $\tau / \sigma_{\mathrm{a}}$ (the ratio of the shear stress $\tau$ to the constant vertical stress $\sigma_{\mathrm{a}}$ on the horizontal plane) and the shear strain $\gamma$ for the dense specimens showed that $\tau / \sigma_{\mathrm{a}}$ increases to reach a peak value at a small shear strain and then approximates the critical-state value $\left(\tau / \sigma_{\mathrm{a}}\right)_{\mathrm{r}}\left(=\tan \delta_{\mathrm{r}}{ }_{\mathrm{r}}\right)$. For the loose samples, $\tau / \sigma_{\mathrm{a}}$ monotonically increases to reach the critical-state stress ratio $\left(\tau / \sigma_{\mathrm{a}}\right)_{\mathrm{r}}$. The critical-state stress ratio $\left(\tau / \sigma_{\mathrm{a}}\right)_{\mathrm{r}}$ is independent of the initial void ratio and confining stress. During simple shearing, the angle $\alpha_{1}$ of the maximum principal stress direction to the vertical plane changed within a very small strain ( $\gamma$ less than 1\%) and remained constant in the range of $45^{\circ}-50^{\circ}$ to the critical-state state. Later on, $\alpha_{1}$ will be denoted as the major principal stress direction angle.

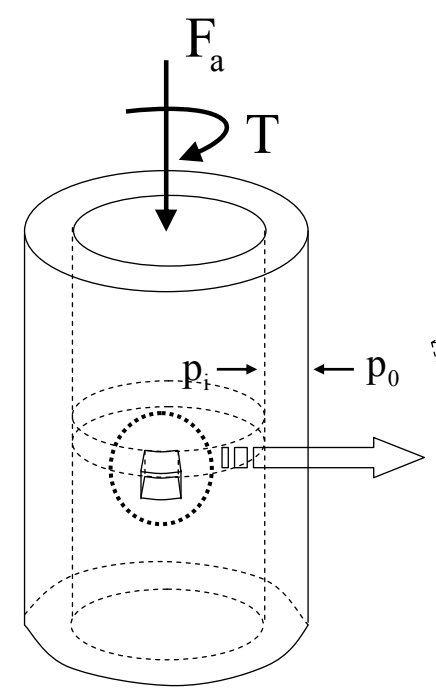

Pradhan \& Tatsuoka (1988) Torsional simple shear apparatus

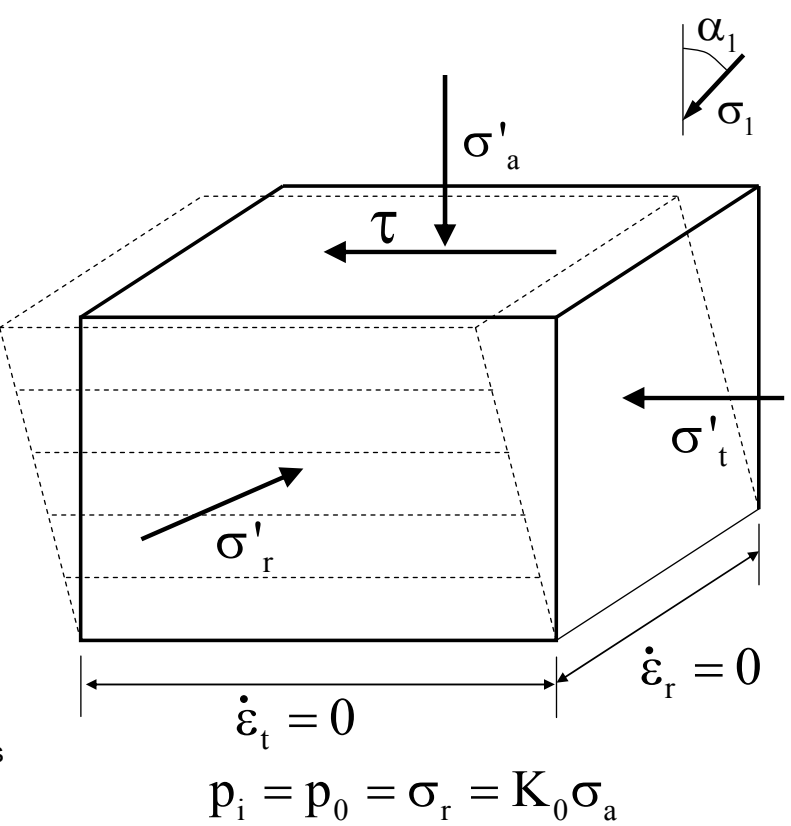

Figure 6.4 Torsional shearing under constant vertical stress $\sigma_{\mathrm{a}}^{\prime}$ on the horizontal plane using the TSS apparatus $\left(\sigma_{\mathrm{a}}^{\prime}\right.$ : vertical effective stress; $\sigma_{\mathrm{t}}^{\prime}$ : effective stress in torsional direction; $\sigma_{r}^{\prime}$ : effective stress in radial direction; $\alpha_{1}$ : major principal stress direction angle; and $\mathrm{K}_{0}$ : coefficient of lateral earth pressure at rest ) 
For the purpose of developing the relationship between the friction angle $\phi$ and the corresponding interface friction angle $\delta$, we compared $\phi$ to the corresponding $\delta$ based on data from the literature (Pradhan et al., 1988). Figure 6.5 represents the peak friction angle $\phi_{\mathrm{p}}$ and the maximum interface friction angle $\delta_{\mathrm{p}}^{*}$ during shearing when the vertical stress $\sigma_{\mathrm{a}}$ is $98 \mathrm{kN} / \mathrm{m}^{2}$. Figure 6.6 shows the same for different vertical stresses $\left(\sigma_{\mathrm{a}}=98\right.$ $196.2 \mathrm{kN} / \mathrm{m}^{2}$ ). A purely contractive specimen (initial void ratio e $=0.893$ when $\sigma_{\mathrm{c}}=$ $5 \mathrm{kN} / \mathrm{m}^{2}$ ) will not show a peak behavior during shearing and in that case $\phi_{\mathrm{p}}$ is equal to $\phi_{\mathrm{c}}$. Similarly, the maximum stress ratio $\left(\tau / \sigma_{a}\right)_{\max }$ for this specimen will be equal to the critical-state stress ratio $\left(\tan \delta^{*}\right)$. Therefore, from Figure 6.5 and Figure 6.6, we can approximate the values of $\phi_{\mathrm{c}}$ and $\delta_{\mathrm{r}}^{*}$ for Toyoura sand to be $35^{\circ}$ and $30^{\circ}$.

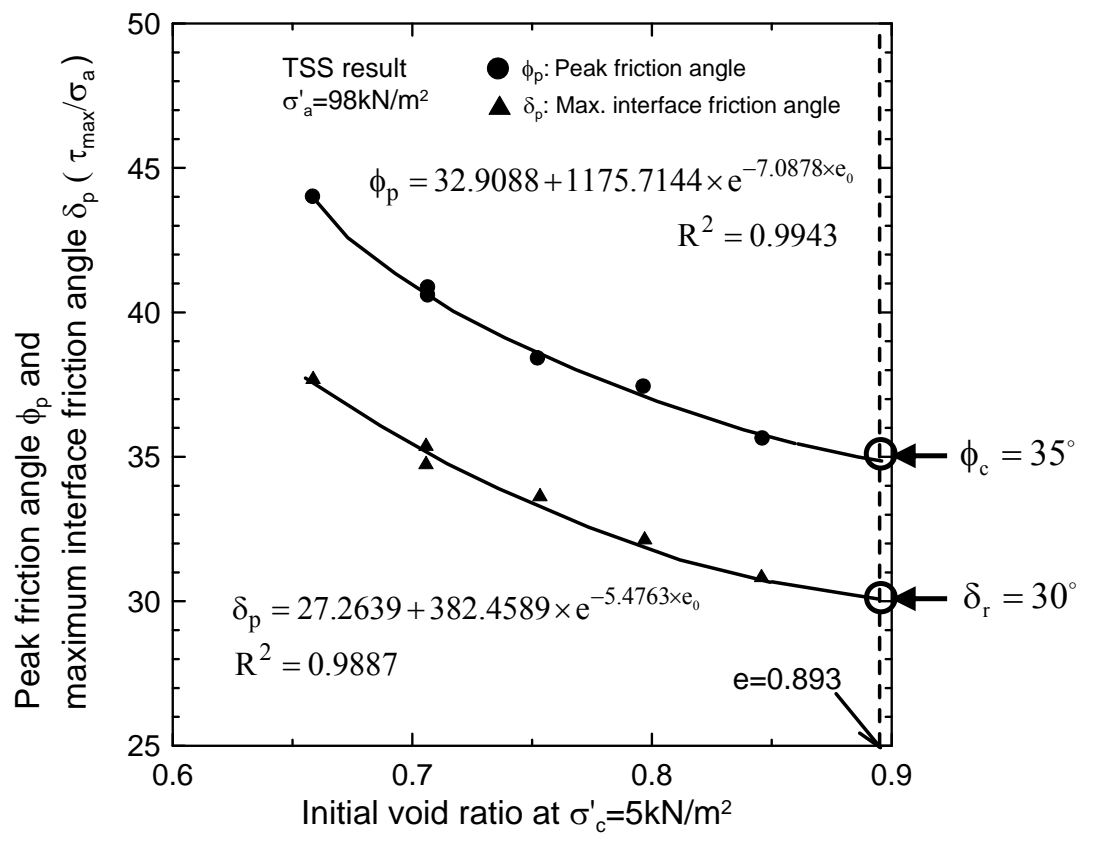

Figure 6.5 Estimation of $\phi_{\mathrm{c}}$ and $\delta_{\mathrm{r}}$ from the relationship between $\phi_{\mathrm{p}}$ and $\delta_{\mathrm{p}}$ with different initial void ratio when $\sigma_{\mathrm{a}}=98 \mathrm{kN} / \mathrm{m}^{2}\left(\phi_{\mathrm{p}}\right.$ and $\delta_{\mathrm{p}}$ of a purely contractive specimen are equal to $\phi_{\mathrm{c}}$ and $\delta_{\mathrm{r}}$, respectively) 


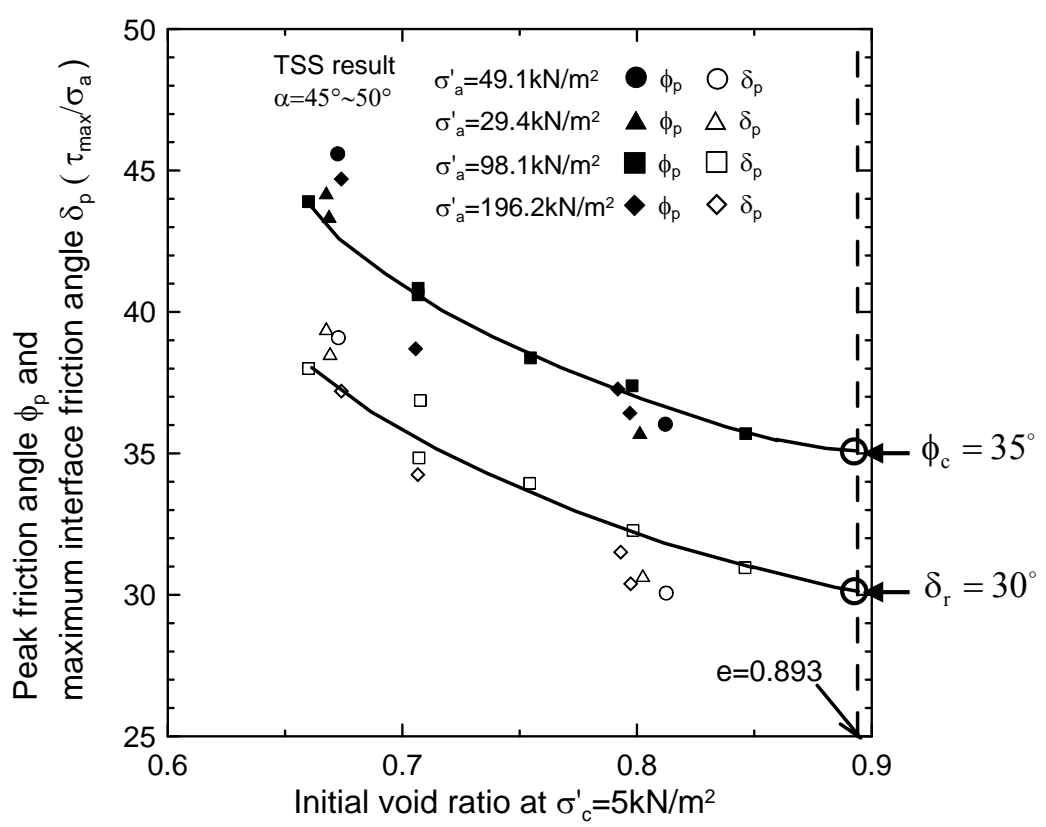

Figure 6.6 Estimation of $\phi_{\mathrm{c}}$ and $\delta_{\mathrm{r}}$ from the relationship between $\phi_{\mathrm{p}}$ and $\delta_{\mathrm{p}}$ with different initial void ratio for different vertical stresses $\left(\sigma_{\mathrm{a}}=98-196.2 \mathrm{kN} / \mathrm{m}^{2}\right)$ on the horizontal plane ( $\phi_{\mathrm{p}}$ and $\delta_{\mathrm{p}}$ of a purely contractive specimen are equal to $\phi_{\mathrm{c}}$ and $\delta_{\mathrm{r}}$, respectively)

The peak interface friction angle $\delta_{\mathrm{p}}^{*}$ may or may not be mobilized along the bottom of an MSE wall at sliding failure. In other words, it is unlikely that $\delta_{p}^{*}$ is mobilized and sustained for every point along the sliding surface at the moment of sliding. For sliding of MSE walls, large horizontal movements of the reinforced soil mass must occur; therefore, $\delta^{*}$ may be expected to be closer to $\delta_{\mathrm{r}}^{*}$. In addition, it is safer to use $\delta_{\mathrm{r}}^{*}$ in design.

The relationship between $\phi_{\mathrm{c}}$ and $\delta_{\mathrm{r}}^{*}$ can be explained using the Mohr circle diagram for stress given in Figure 6.7. The Mohr circle is drawn for the stresses at the critical state. Given that the angle that the maximum principal stress direction makes with the vertical direction is equal to $\alpha_{1}$, from the Mohr circle, the critical-state shear stress $\tau_{\mathrm{r}}$ and the vertical stress $\sigma_{\mathrm{a}}$ on the sliding plane can be expressed as:

$$
\tau_{\mathrm{r}}=\frac{\tan \alpha_{1}}{1+\tan ^{2} \alpha_{1}}\left(\sigma_{1}-\sigma_{3}\right)
$$




$$
\sigma_{\mathrm{a}}=\sigma_{1}-\frac{\tau_{\mathrm{r}}}{\tan \alpha_{1}}=\frac{\left(\tan ^{2} \alpha_{1}\right) \sigma_{1}+\sigma_{3}}{1+\tan ^{2} \alpha_{1}}
$$

where $\sigma_{1}$ and $\sigma_{3}$ are the major and minor principal stresses.

Then, the stress ratio $\sigma_{1} / \sigma_{3}$ can be expressed in terms of $\phi_{\mathrm{c}}$ as:

$$
\frac{\sigma_{1}}{\sigma_{3}}=\frac{1+\sin \phi_{\mathrm{c}}}{1-\sin \phi_{\mathrm{c}}}
$$

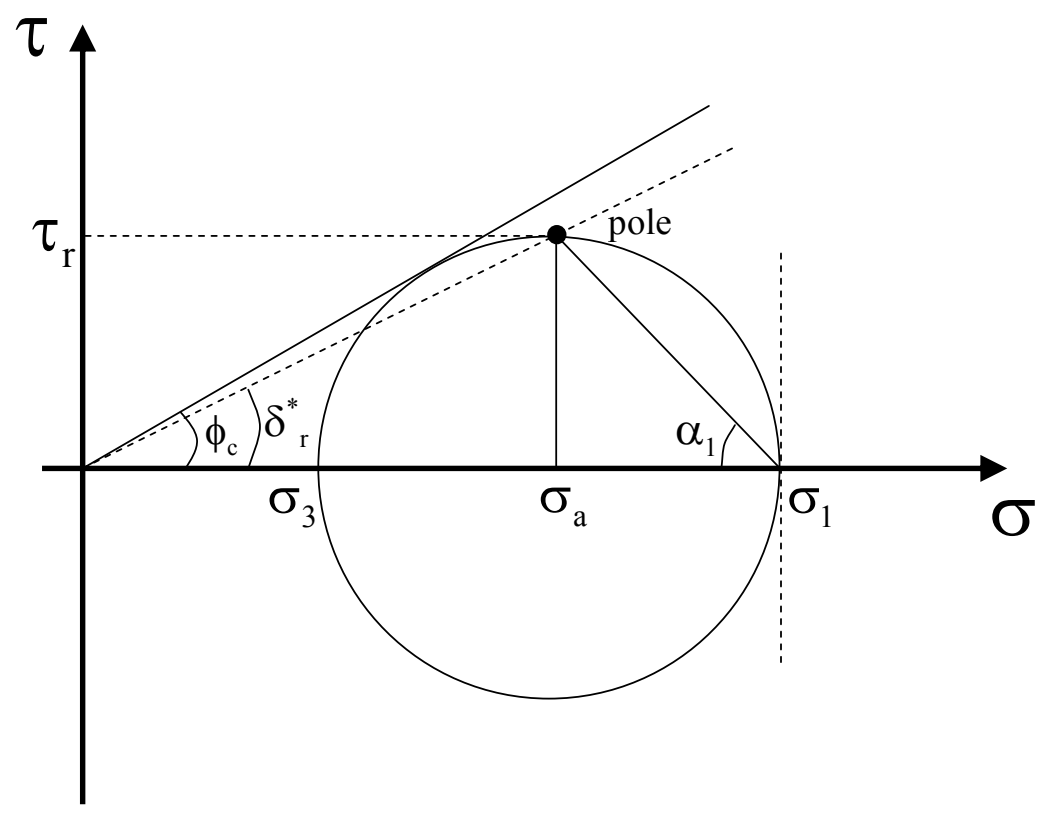

Figure 6.7 Relationship between critical-state friction angle $\phi_{\mathrm{c}}$ and critical-state interface friction angle $\delta_{r}^{*}$ explained using the Mohr circle diagram $\left(\tau_{\mathrm{r}}\right.$ and $\sigma_{\mathrm{a}}$ are the critical-state shear stress and the vertical stress on the sliding plane; $\sigma_{1}$ and $\sigma_{3}$ are the major and minor principal stresses; and $\alpha_{1}$ is the major principal stress direction angle) 
From Eq. (6.19), Eq. (6.20), and Eq. (6.21), the $\delta_{r}^{*}$ can be deduced as

$$
\tan \delta_{r}^{*}=\frac{\tau_{r}}{\sigma_{a}}=\frac{\tan \alpha_{1}\left(2 \sin \phi_{c}\right)}{\left(\tan ^{2} \alpha_{1}\right)\left(1+\sin \phi_{c}\right)+1-\sin \phi_{c}}
$$

For $\alpha_{1}=45^{\circ}, \delta_{\mathrm{r}}^{*}$ can be expressed as a function of $\phi_{\mathrm{c}}$ as

$$
\delta_{\mathrm{r}}^{*}=\tan ^{-1}\left(\sin \phi_{\mathrm{c}}\right)
$$

Following Eq. (6.23), for $\phi_{\mathrm{c}}=35^{\circ}$, the $\delta_{\mathrm{r}}^{*}$ is calculated to be $29.8^{\circ}$ and this value matches well with the value of $30^{\circ}$ obtained from Figure 6.5 and Figure 6.6. From Eq. (6.22), it is evident that $\delta_{\mathrm{r}}^{*}$ decreases with increasing values of $\alpha_{1}$. Thus, for $\alpha_{1}$ varying within the range between 45 and $50^{\circ}, \delta^{*}$ is at maximum when $\alpha$ is $45^{\circ}$ and minimum when the major principal stress direction angle $\alpha_{1}$ is $50^{\circ}$. Therefore, $\delta^{*}$, calculated for $\alpha_{1}$ is $50^{\circ}$, can be considered to be a conservative estimate.

$$
\begin{aligned}
\delta_{\mathrm{r}}^{*} & =\tan ^{-1}\left(\frac{\tan 55^{\circ}\left(2 \sin \phi_{\mathrm{c}}\right)}{\left(\tan ^{2} 55^{\circ}\right)\left(1+\sin \phi_{\mathrm{c}}\right)+1-\sin \phi_{\mathrm{c}}}\right) \\
& =\tan ^{-1}\left(\frac{2.3835 \sin \phi_{\mathrm{c}}}{0.4202 \sin \phi_{\mathrm{c}}+2.4202}\right)
\end{aligned}
$$

The uncertainty of $\delta_{\mathrm{r}}^{*}$ is assessed using Monte Carlo simulations varying $\alpha_{1}$ between $45^{\circ}$ and $50^{\circ}$. This is because we want to find the highest COV of $\delta_{\mathrm{r}}{ }_{\mathrm{r}}$ among the COV values of $\delta_{r}^{*}$ calculated for different $\alpha_{1}\left(45^{\circ} \leq \alpha_{1} \leq 50^{\circ}\right)$ and conservatively propose it as the $\operatorname{COV}$ of $\delta_{\mathrm{r}}^{*}$. To perform these simulations, we need to know the COV for $\phi_{\mathrm{c}}$ of the reinforced and foundation soils (we are assuming that the foundation soil is a frictional soil). From the previous discussion, we already established that the COV for $\phi_{c}$ can be considered to be 0.02 . 
Figure 6.8 shows the distribution of $\delta_{\mathrm{r}}^{*}$ resulting from the simulation with normally distributed $\phi_{\mathrm{c}}$ and the mean equal to $30^{\circ}$ having a $\mathrm{COV}$ of 0.02 . From the simulations, the bias factors and COVs of the $\delta_{\mathrm{r}}^{*}$ are given in Table 6.4 for the cases of $\alpha_{1}=45^{\circ}$ and $\alpha_{1}=50^{\circ}$. The highest COV was 0.0156 for $\alpha_{1}=45^{\circ}$. Conservatively, the COV for the $\delta^{*}$ is selected as 0.02 .

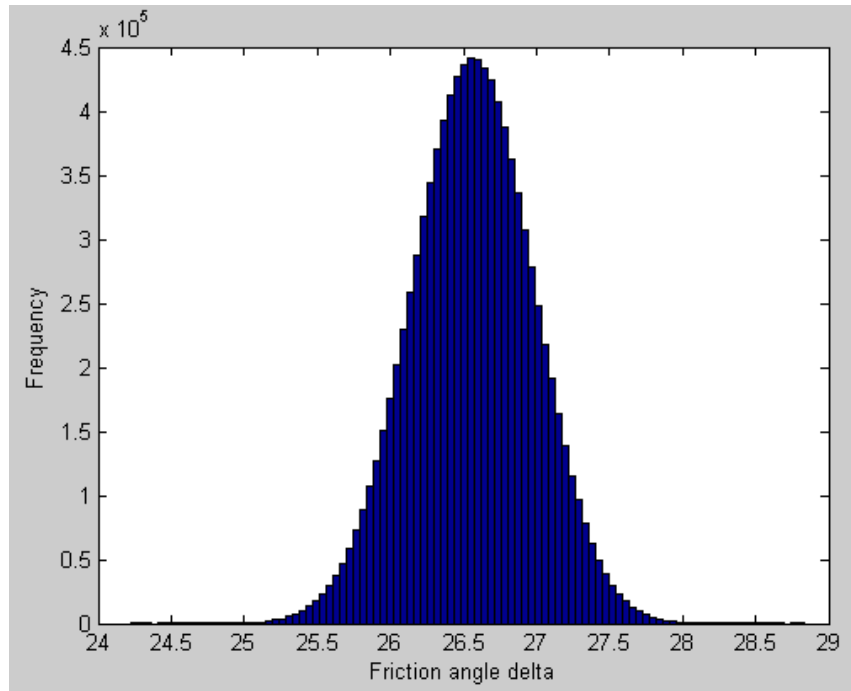

Figure 6.8 Distribution of the critical-state interface friction angle $\delta^{*}$ r when $\phi_{\mathrm{c}}=30^{\circ}$ using Monte Carlo simulations

Table 6.4 Bias factor and COV of the critical-state interface friction angle $\delta_{\mathrm{r}}^{*}\left(\alpha_{1}\right.$ is the major principal stress direction angle)

\begin{tabular}{|c|c|c|c|c|c|}
\hline$?_{1}^{*} ?_{1}$ & $\begin{array}{c}\phi_{\mathrm{c}} \\
\left(^{\circ}\right.\end{array}$ & $\begin{array}{c}\delta_{\mathrm{r}}^{*} \\
\left(^{\circ}\right)\end{array}$ & $\begin{array}{c}\text { Standard } \\
\text { deviation }\left(^{\circ}\right)\end{array}$ & COV & Bias factor \\
\hline \multirow{3}{*}{$45^{\circ}$} & 30 & 26.6 & 0.414 & 0.0156 & 1.000 \\
\cline { 2 - 6 } & 32 & 27.9 & 0.424 & 0.0152 & 1.000 \\
\cline { 2 - 6 } & 34 & 29.2 & 0.430 & 0.0147 & 1.000 \\
\cline { 2 - 6 } & 36 & 30.4 & 0.434 & 0.0142 & 1.000 \\
\hline \multirow{3}{*}{$50^{\circ}$} & 30 & 24.4 & 0.360 & 0.0147 & 1.000 \\
\cline { 2 - 6 } & 32 & 25.5 & 0.365 & 0.0143 & 1.000 \\
\cline { 2 - 6 } & 34 & 26.7 & 0.369 & 0.0138 & 1.000 \\
\cline { 2 - 6 } & 36 & 27.7 & 0.371 & 0.0134 & 1.000 \\
\hline
\end{tabular}




\subsection{Examples}

Using the bias factors and COVs of the parameters $\delta_{\mathrm{rf}}^{*}, \delta_{\mathrm{fn}}^{*}, \phi_{\mathrm{c}, \mathrm{rt}}, \gamma_{\mathrm{rf}}, \gamma_{\mathrm{rt}}, \mathrm{q}_{0, \mathrm{rt}}$, we performed reliability analyses following FORM (First-Order Reliability-Method), as set forth by Hasofer and Lind (1974) and Low and Tang (1997). From these reliability analyses, we could have the ULS values of the parameters as well as loads and resistance. The nominal loads and resistance are available from the deterministic analysis. Having the nominal and ULS values of loads and resistance, we can calculate the optimum resistance and load factors using Eq. (2.5) and Eq. (2.6). Finally, the RF values are determined using the optimum factors and the LFs from specifications (Eq. (2.11)).

In this section, RF values are calculated for sliding and overturning for different MSE wall heights $(\mathrm{H}=5,7.5,10,12.5,15,17.5$, and $20 \mathrm{~m})$. The nominal values of the soil properties are as follows: $\phi_{\mathrm{c}, \mathrm{rf}}=36^{\circ}, \phi_{\mathrm{c}, \mathrm{fn}}=33^{\circ}, \phi_{\mathrm{c}, \mathrm{rt}}=30^{\circ}, \mathrm{D}_{\mathrm{R}, \mathrm{rf}}=80 \%, \gamma_{\mathrm{rf}}=20 \mathrm{kN} / \mathrm{m}^{3}, \gamma_{\mathrm{rt}}=18$ $\mathrm{kN} / \mathrm{m}^{3}$. The equivalent height $\mathrm{h}_{\mathrm{eq}}$ of soil for vehicular loading varies with the MSE wall height, two values of live uniform surcharge load $\mathrm{q}_{0}$ are considered from Table 6.2 and Table 6.3: $14 \mathrm{kN} / \mathrm{m}$ for the MSE wall height is $5 \mathrm{~m}$ and $12 \mathrm{kN} / \mathrm{m}$ for the MSE walls that are equal to or higher than $6 \mathrm{~m}$. For the calculation of equivalent height $h_{\text {eq }}$ of soil for vehicular loading, we conservatively assumed that the unit weight of the retained soil is $20 \mathrm{kN} / \mathrm{m}^{3}$, which is slightly higher than the value given earlier $\left(\gamma_{\mathrm{rt}}=18 \mathrm{kN} / \mathrm{m}^{3}\right)$.

\subsubsection{Sliding}

A series of reliability analyses were performed using the Microsoft Excel Solver. Table 6.5 is the view of the spreadsheet for the reliability analysis conducted for the sliding criterion. Details of the method (Low and Tang, 1997) are well explained in Foye (2004). 
Table 6.5 Result of reliability analysis for sliding criterion (when $\mathrm{H}=10 \mathrm{~m}, \beta_{\mathrm{T}}=2.0$, and $\left.\mathrm{q}_{0}=12 \mathrm{kN} / \mathrm{m}\right)$

\begin{tabular}{|c|c|c|c|c|c|}
\hline & $\mathrm{m}$ & $\begin{array}{c}\text { equivalent } \\
\text { normal mean }\end{array}$ & $\begin{array}{c}\text { ULS } \\
\text { values }\end{array}$ & stdev & $\begin{array}{c}\text { equivalent } \\
\text { normal stdev }\end{array}$ \\
\hline$\delta_{\mathrm{rf}}^{*}$ & 27.711 & 27.711 & 27.711 & 0.554 & 0.554 \\
\hline$\phi_{\mathrm{c}, \mathrm{rt}}$ & 30.000 & 30.000 & 29.811 & 0.360 & 0.360 \\
\hline$\delta_{\mathrm{fn}}^{*}$ & 26.107 & 26.107 & 25.665 & 0.522 & 0.522 \\
\hline $\mathrm{q}_{0, \mathrm{rt}}$ & 13.800 & 19.452 & 19.845 & 3.450 & 0.246 \\
\hline$\gamma_{\mathrm{rf}}$ & 20.000 & 20.000 & 19.895 & 0.240 & 0.240 \\
\hline$\gamma_{\mathrm{rt}}$ & 18.000 & 18.000 & 18.159 & 0.311 & 0.311 \\
\hline
\end{tabular}

\begin{tabular}{|l|l|l|l|l|l|}
\hline \multicolumn{7}{|c|}{ Covariance matrix, C } \\
\hline 0.307 & 0.000 & 0.000 & 0.000 & 0.000 & 0.000 \\
\hline 0.000 & 0.130 & 0.000 & 0.000 & 0.000 & 0.000 \\
\hline 0.000 & 0.000 & 0.273 & 0.000 & 0.000 & 0.000 \\
\hline 0.000 & 0.000 & 0.000 & 0.061 & 0.000 & 0.000 \\
\hline 0.000 & 0.000 & 0.000 & 0.000 & 0.058 & 0.000 \\
\hline 0.000 & 0.000 & 0.000 & 0.000 & 0.000 & 0.097 \\
\hline
\end{tabular}

\begin{tabular}{|c|c|}
\hline$G(x)$ & 0.000 \\
\hline$\beta$ & 2.000 \\
\hline$P_{f}$ & 0.023 \\
\hline
\end{tabular}

\begin{tabular}{|l|l|}
\hline$\lambda$ & 2.594 \\
\hline$\zeta$ & 0.246 \\
\hline
\end{tabular}

\begin{tabular}{|c|c|}
\hline $\mathrm{H}(\mathrm{m})$ & 10 \\
\hline $\mathrm{L}(\mathrm{m})$ & 3.887 \\
\hline
\end{tabular}

$(\mathrm{m}$ : mean value, stdev: standard deviation, $\mathrm{G}(\mathrm{x})$ : function of margin of safety, $\beta$ : reliability index, $\mathrm{P}_{\mathrm{f}}$ : target probability of failure, $\lambda$ and $\zeta$ are the parameters related to lognormal distribution, $\mathrm{H}$ : height of the MSE wall, and L: reinforcement length)

The symbols in the first column of the first (upper) table in Table 6.5 are the parameters that are used in the sliding ULS equation (Eq. (6.1)). The values in the second and fifth column in the same table are the means and standard deviations of the parameters, and the values in the third and sixth columns are the equivalent normal means and the equivalent normal standard deviations. The values in the fourth column in the same table are the values of the parameters at the ULS. The array of values in the second (middle) table is the corresponding covariance matrix $\mathrm{C}$ of the parameters. In addition, $\mathrm{G}(\mathrm{x})$ is the left-hand side of the ULS equation (total load minus total resistance), Eq. (6.1), $\beta$ is the reliability index, $P_{\mathrm{f}}$ is the target probability of failure, $\mathrm{H}$ is the height of an MSE wall, $L$ is the length of reinforcement, and $\zeta$ and $\lambda$ (Eq. (6.13) and Eq. (6.14)) are 
the parameters that define the lognormal distribution of the live uniform surcharge load on the top of an MSE wall.

The lateral force $\mathrm{E}_{\mathrm{A} 1}$ due to active action of the self-weight of the retained soil and the lateral force $\mathrm{E}_{\mathrm{A} 2}$ due to active action by the live uniform surcharge load as well as the total resistance at the ULS are shown in Table 6.6. In Table 6.7, the FS and the nominal values of the $\mathrm{E}_{\mathrm{A} 1}, \mathrm{E}_{\mathrm{A} 2}$, and resistance against sliding are calculated using the nominal values of the soil parameters. Finally, the RF value is computed using the AASHTO LFs, the ULS values of loads and resistance (Table 6.6), and the nominal values of loads and resistance (Table 6.7).

Table 6.6 ULS values of loads and resistance for sliding

\begin{tabular}{rrr}
\hline$E_{A 1}$ & 313.329 & $\mathrm{kN} / \mathrm{m}$ \\
\hline$E_{A 2}$ & 64.032 & $\mathrm{kN} / \mathrm{m}$ \\
\hline $\mathrm{W}_{\text {rf }}$ & 784.089 & $\mathrm{kN} / \mathrm{m}$ \\
\hline $\tan \delta$ & 0.481 & \\
\hline
\end{tabular}

\begin{tabular}{lrl}
\hline Dead load $\left(E_{\mathrm{A} 1}\right)$ & 313.329 & $\mathrm{kN} / \mathrm{m}$ \\
\hline Live load $\left(E_{\mathrm{A} 2}\right)$ & 64.032 & $\mathrm{kN} / \mathrm{m}$ \\
\hline Total resistance $\left(\mathrm{W}_{\mathrm{rf}} \tan \delta\right)$ & 377.361 & $\mathrm{kN} / \mathrm{m}$ \\
\hline
\end{tabular}

Table 6.7 Nominal values of loads and resistance and FS for sliding

\begin{tabular}{rrr}
\hline$E_{\mathrm{A} 1}$ & 300.000 & $\mathrm{kN} / \mathrm{m}$ \\
\hline$E_{\mathrm{A} 2}$ & 40.000 & $\mathrm{kN} / \mathrm{m}$ \\
\hline $\mathrm{W}_{\mathrm{rf}}$ & 787.900 & $\mathrm{kN} / \mathrm{m}$ \\
\hline $\tan \delta$ & 0.490 & \\
\hline
\end{tabular}

\begin{tabular}{lrl}
\hline Dead load $\left(E_{\mathrm{A} 1}\right)$ & 300.000 & $\mathrm{kN} / \mathrm{m}$ \\
\hline Live load $\left(\mathrm{E}_{\mathrm{A} 2}\right)$ & 40.000 & $\mathrm{kN} / \mathrm{m}$ \\
\hline Total resistance $\left(\mathrm{W}_{\mathrm{rf}} \tan \delta\right)$ & 386.103 & $\mathrm{kN} / \mathrm{m}$ \\
\hline $\mathrm{FS}=$ & 1.136 & \\
\hline
\end{tabular}

Table 6.8 Calculation of optimum factors and RF using AASHTO LFs for sliding

\begin{tabular}{ccccc}
\hline$(\mathrm{LF})_{\mathrm{DL}}{ }^{*}=1.04$ & $(\mathrm{LF})_{\mathrm{DL}}=$ & 1.5 & $(\mathrm{LF})_{\mathrm{DL}}{ }^{*} /(\mathrm{LF})_{\mathrm{DL}}=$ & 0.70 \\
\hline$(\mathrm{LF})_{\mathrm{LL}}{ }^{*}=1.60$ & $(\mathrm{LF})_{\mathrm{LL}}=$ & 1.75 & $(\mathrm{LF})_{\mathrm{LL}}{ }^{*} /(\mathrm{LF})_{\mathrm{LL}}=$ & 0.91 \\
\hline $\mathrm{RF}^{*}=0.98$ & & & $\mathrm{RF}=$ & 1.07 \\
\hline
\end{tabular}

$\left[(\mathrm{LF})_{\mathrm{DL}}{ }^{*}\right.$ and $(\mathrm{LF})_{\mathrm{LL}}{ }^{*}$ are the optimum load factors for dead and live load, $\mathrm{RF}^{*}$ is the optimum resistance factor, $(\mathrm{LF})_{\mathrm{DL}}$ and $(\mathrm{LF})_{\mathrm{LL}}$ are the AASHTO load factors, and RF is the resistance factor] 
The RF values are calculated and plotted in Figure 6.9 for different values of the target reliability index $\left(\beta_{\mathrm{T}}=2.0,2.5,3.0\right.$, and 3.5) and different MSE wall heights $(\mathrm{H}=5$, $7.5,10,12.5,15,17.5$, and $20 \mathrm{~m}$ ). In Figure 6.9, the RF value decreases with increasing target reliability index. The RF value increases with increasing MSE wall height $\mathrm{H}$.

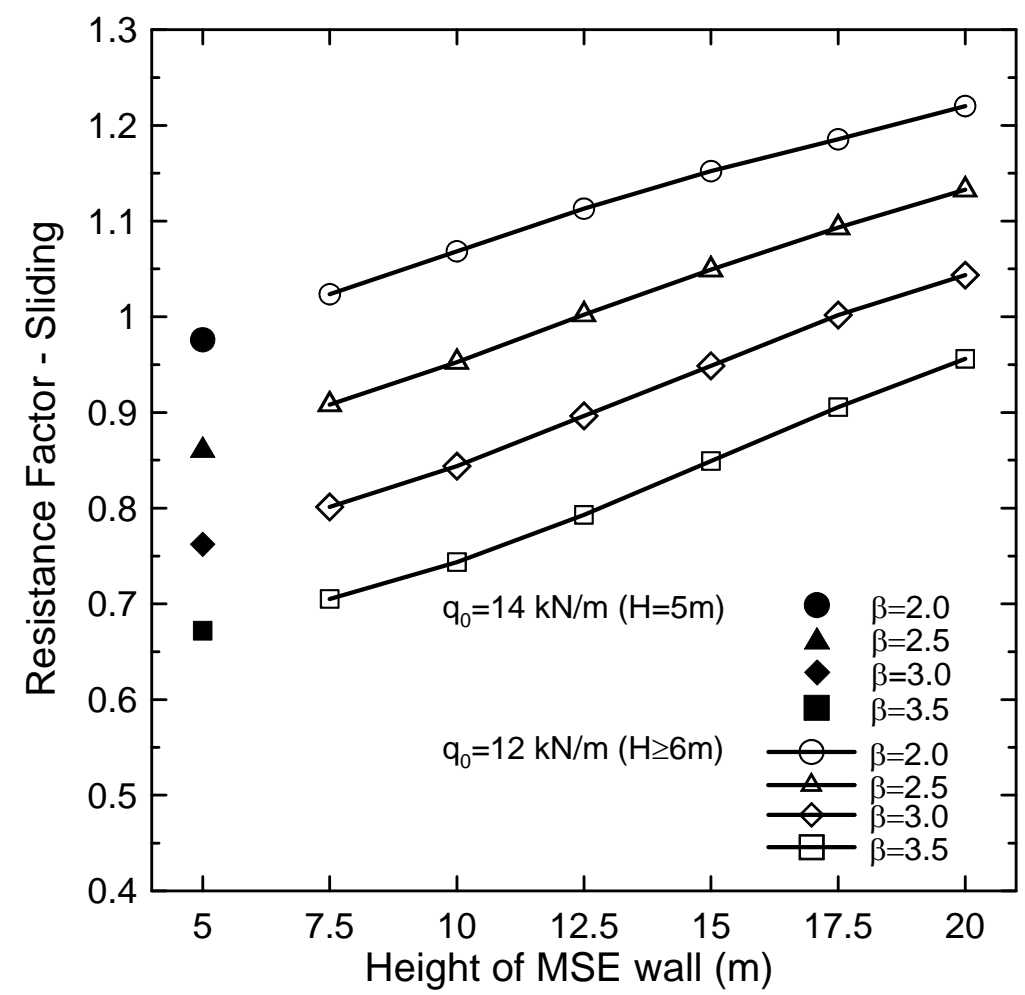

Figure 6.9 RF for different target reliability indices and different MSE wall heights for sliding

Figure 6.10 represents the changes of the optimum factors for $\mathrm{E}_{\mathrm{A} 1}, \mathrm{E}_{\mathrm{A} 2}$ and the resistance to sliding with increasing $\mathrm{H}$. The optimum factor for $\mathrm{E}_{\mathrm{A} 2}$ is greater than that for $\mathrm{E}_{\mathrm{A} 1}$. Uncertainty of $\mathrm{E}_{\mathrm{A} 1}$ is much higher than that of $\mathrm{E}_{\mathrm{A} 2}$ because the $\operatorname{COV}(0.25)$ of $\mathrm{q}_{0}$ is much higher than that of $\gamma_{\mathrm{rt}}$ (which is 0.03). Due to the higher uncertainty of $\mathrm{E}_{\mathrm{A} 2}$, the ULS value of $\mathrm{E}_{\mathrm{A} 2}$ is determined at much higher value than its nominal value compared to the case of $\mathrm{E}_{\mathrm{A} 1}$. Therefore, the ratio (optimum factor for $\mathrm{E}_{\mathrm{A} 2}$ ) of the ULS value to the mean value of $\mathrm{E}_{\mathrm{A} 2}$ is is much greater than that for $\mathrm{E}_{\mathrm{A} 1}$. 
The increase of RF values with increasing $\mathrm{H}$ results from the decrease of the optimum factor for $\mathrm{E}_{\mathrm{A} 2}$ because the changes of the other optimum factors are insignificant with increasing $\mathrm{H}$. As $\mathrm{H}$ increases, the mean value of $\mathrm{E}_{\mathrm{A} 1}$ increases more rapidly than that of $\mathrm{E}_{\mathrm{A} 2}$ because $\mathrm{E}_{\mathrm{A} 1}$ increases in proportion to the square of $\mathrm{H}$, while $\mathrm{E}_{\mathrm{A} 2}$ increases in proportion to $\mathrm{H}$ [Eq. (6.3) and Eq. (6.4)]. As the relative contribution of $\mathrm{E}_{\mathrm{A} 2}$ to the sliding of the MSE wall decreases with increasing $\mathrm{H}$, the optimum factor for $\mathrm{E}_{\mathrm{A} 2}$ also decreases.

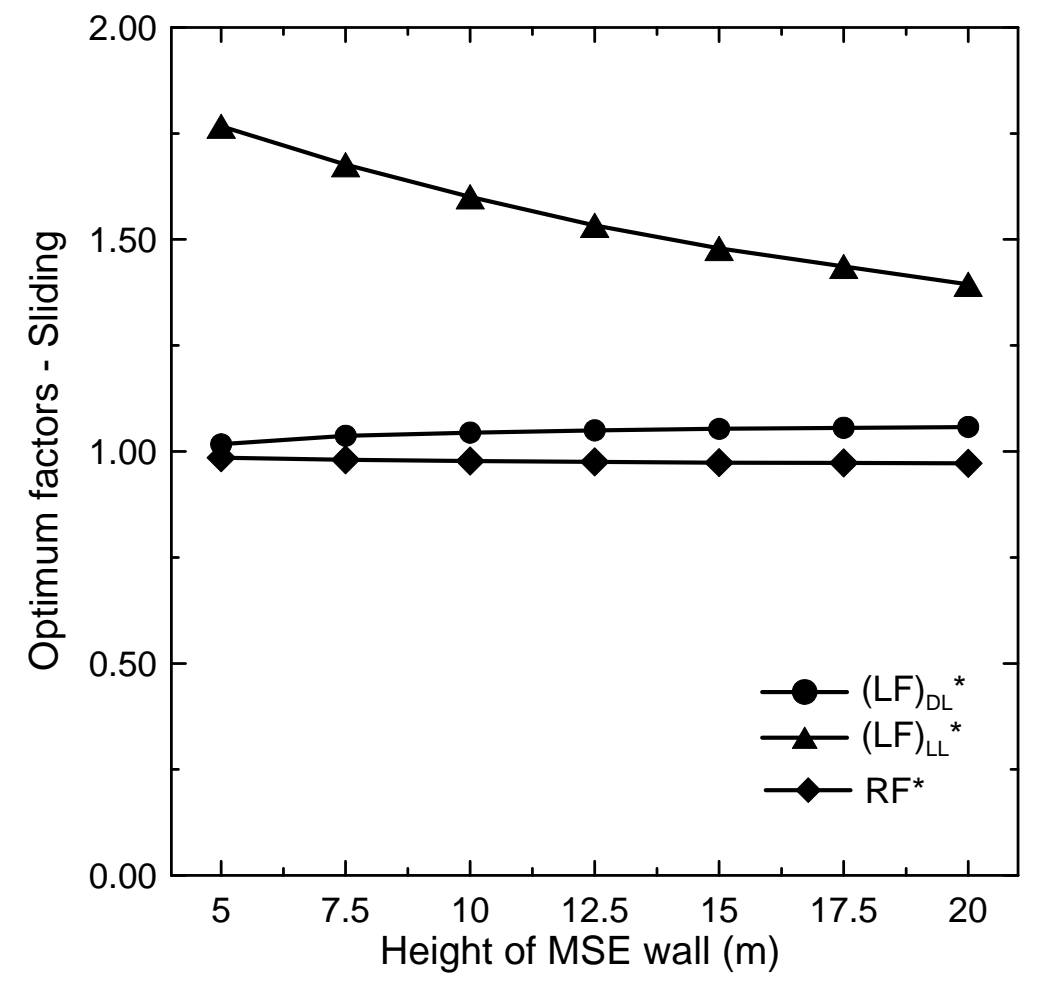

Figure 6.10 Optimum factors for $\mathrm{E}_{\mathrm{A} 1}, \mathrm{E}_{\mathrm{A} 2}$ and the sliding resistance versus MSE wall height $\mathrm{H}$ (for $\left.\beta_{\mathrm{T}}=2.0\right)\left[(\mathrm{LF})_{\mathrm{DL}}{ }^{*}\right.$ and $(\mathrm{LF})_{\mathrm{LL}}{ }^{*}$ are the optimum load factors for dead and live load, and $\mathrm{RF}^{*}$ is the optimum resistance factor]

Figure 6.11 shows the FS values for four different values of the target reliability index and different MSE wall heights. FHWA (2001) and AASHTO (2007) require that the factor of safety for the sliding criterion should be equal to or higher than 1.5. We have seen that these two specifications overestimate the resistance against sliding by using the 
peak friction angle $\phi_{\mathrm{p}}$ instead of using $\delta^{*}$ (Eq. (6.7)) for the interface friction angle $\delta$, and underestimate the active force by using $\phi_{\mathrm{p}}$ in calculating the active earth pressure coefficient $\mathrm{K}_{\mathrm{A}}$ (Eq. (6.2)) instead of using $\phi_{\mathrm{c}}$. For this reason, the minimum required $\mathrm{FS}$ value of 1.5 in the specifications must be revised to a lower value in our design. Thus, the FS values in Figure 6.11 are not directly comparable to the 1.5 minimum.

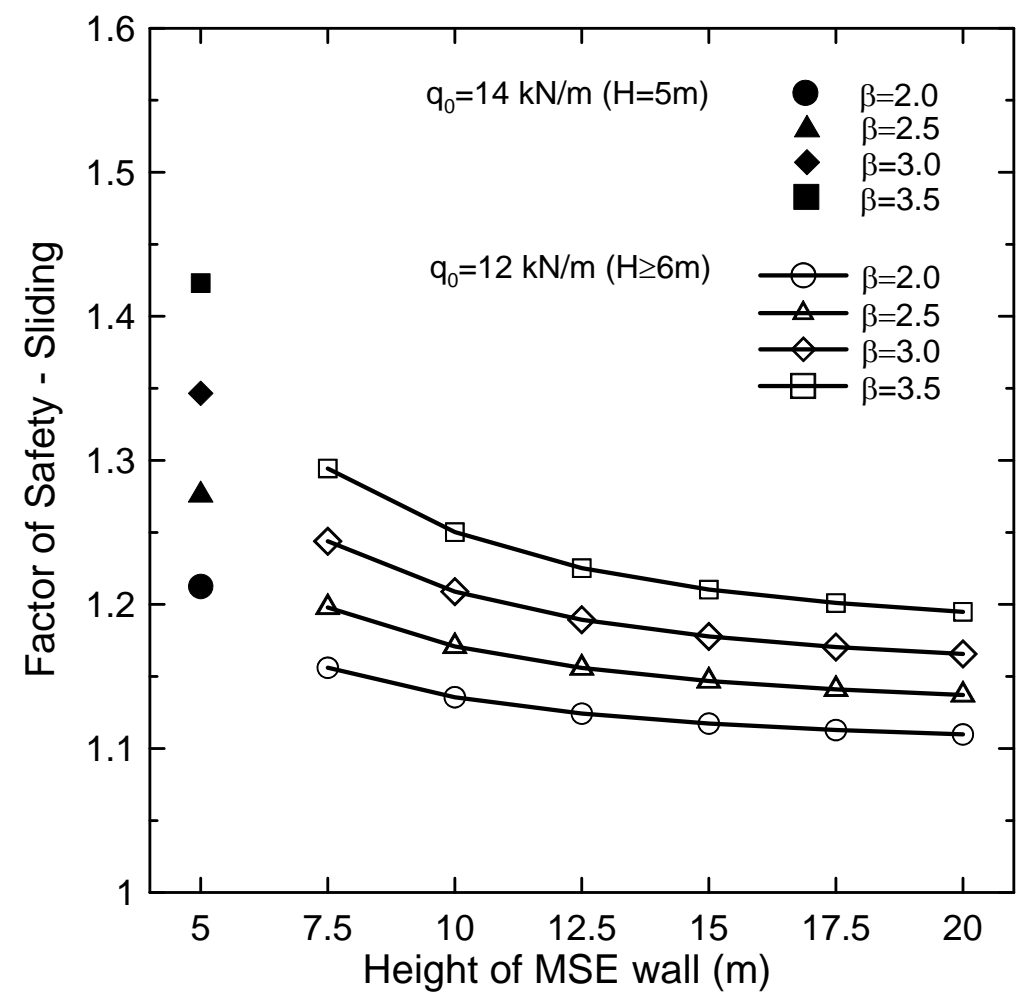

Figure 6.11 FS as a function of target reliability index and MSE wall height for sliding

\subsubsection{Overturning}

The same procedure that was used for sliding was applied to the calculation of the RF values for overturning. Table 6.9 shows the Microsoft Excel spreadsheet used to perform the reliability analysis. For the 10m-high MSE wall, the reinforcement length is determined to be $3.38 \mathrm{~m}$, satisfying the target reliability index $\beta_{\mathrm{T}}$ of 2.0 when the mean values and standard deviations of the parameters are the values shown in Table 6.9. 
Table 6.9 Result of reliability analysis for overturning criterion (when the height of MSE wall $\mathrm{H}=10 \mathrm{~m}$, target reliability index $\beta_{\mathrm{T}}=2.0$ and nominal $\mathrm{q}_{0}=12 \mathrm{kN} / \mathrm{m}$ )

\begin{tabular}{|c|c|c|c|c|c|c|c|c|c|}
\hline & mean & $\begin{array}{c}\text { equivalent } \\
\text { normal mean }\end{array}$ & $\begin{array}{c}\text { ULS } \\
\text { values }\end{array}$ & stdev & $\begin{array}{c}\text { equivalent } \\
\text { normal stdev }\end{array}$ & \multicolumn{4}{|c|}{ Covariance matrix, C } \\
\hline$\phi_{2}$ & 30.000 & 30.000 & 29.847 & 0.360 & 0.360 & 0.130 & 0.000 & 0.000 & 0.000 \\
\hline $\mathrm{q}_{0, \mathrm{rt}}$ & 13.800 & 20.833 & 21.297 & 3.450 & 0.246 & 0.000 & 0.061 & 0.000 & 0.000 \\
\hline$\gamma_{\mathrm{rt}}$ & 20.000 & 20.000 & 19.915 & 0.240 & 0.240 & 0.000 & 0.000 & 0.058 & 0.000 \\
\hline$\gamma_{\mathrm{rt}}$ & 18.000 & 18.000 & 18.116 & 0.311 & 0.311 & 0.000 & 0.000 & 0.000 & 0.097 \\
\hline
\end{tabular}

\begin{tabular}{|c|c|}
\hline$G(x)$ & 0.000 \\
\hline$\beta$ & 2.000 \\
\hline$P_{f}$ & 0.023 \\
\hline
\end{tabular}

\begin{tabular}{|c|c|}
\hline$H(m)$ & 10 \\
\hline$L(m)$ & 3.709 \\
\hline
\end{tabular}

\begin{tabular}{|l|l|}
\hline$\lambda$ & 2.594 \\
\hline$\zeta$ & 0.246 \\
\hline
\end{tabular}

(m: mean value, stdev: standard deviation, $\mathrm{G}(\mathrm{x})$ : function of margin of safety, $\beta$ : reliability index, $\mathrm{P}_{\mathrm{f}}$ : target probability of failure, $\lambda$ and $\zeta$ are the parameters related to lognormal distribution, $\mathrm{H}$ : height of the MSE wall, and L: reinforcement length)

The values in the fourth column in Table 6.9 are the values of the parameters at the ULS. The driving and resisting moments at the ULS are calculated using these values. In Table 6.10, the sum of the driving moments due to $\mathrm{E}_{\mathrm{A} 1}$ (lateral load from the selfweight of retained soil) and $\mathrm{E}_{\mathrm{A} 2}$ (lateral load from the live uniform surcharge load) is equal to the resisting moment against overturning $(1012.679 \mathrm{kN} / \mathrm{m}+357.143 \mathrm{kN} / \mathrm{m}=$ $1369.822 \mathrm{kN} / \mathrm{m})$, as the definition of the ULS.

Table 6.10 Driving and resisting moments at the overturning ULS

\begin{tabular}{lr}
\hline Driving moment due to the dead load $\left(E_{\mathrm{A} 1} \mathrm{H} / 3\right)$ & $1012.679 \mathrm{kN} / \mathrm{m}$ \\
\hline Driving moment due to the live load $\left(\mathrm{E}_{\mathrm{A} 2} \mathrm{H} / 2\right)$ & $357.143 \mathrm{kN} / \mathrm{m}$ \\
\hline Resistance moment against overturning $\left(\mathrm{W}_{\mathrm{rf}} \mathrm{L} / 2\right)$ & $1369.822 \mathrm{kN} / \mathrm{m}$ \\
\hline
\end{tabular}

The values of the nominal driving and resisting moments are given in Table 6.11. These moments were calculated using the nominal values of the parameters. The factor of safety for this particular case was 1.15 . 
Table 6.11 Nominal driving and resisting moments and FS for overturning

\begin{tabular}{lc}
\hline Driving moment due to the dead load $\left(\mathrm{E}_{\mathrm{A} 1} \mathrm{H} / 3\right)$ & $1000.000 \mathrm{kN} / \mathrm{m}$ \\
\hline Driving moment due to the live load $\left(\mathrm{E}_{\mathrm{A} 2} \mathrm{H} / 2\right)$ & $200.000 \mathrm{kN} / \mathrm{m}$ \\
\hline Resistance moment against overturning $\left(\mathrm{W}_{\mathrm{rf}} \mathrm{L} / 2\right)$ & $1375.668 \mathrm{kN} / \mathrm{m}$ \\
\hline $\mathrm{FS}=$ & 1.15 \\
\hline
\end{tabular}

Table 6.12 Calculation of optimum factors and RF using AASHTO LFs for overturning

\begin{tabular}{cccc}
\hline$(\mathrm{LF})_{\mathrm{DL}}{ }^{*}=1.01$ & $(\mathrm{LF})_{\mathrm{DL}}=1.50$ & $(\mathrm{LF})_{\mathrm{DL}}{ }^{*} /(\mathrm{LF})_{\mathrm{DL}}=0.68$ \\
\hline$(\mathrm{LF})_{\mathrm{LL}}{ }^{*}=1.79$ & $(\mathrm{LF})_{\mathrm{LL}}=1.75$ & $(\mathrm{LF})_{\mathrm{LL}}{ }^{*} /(\mathrm{LF})_{\mathrm{LL}}=1.02$ \\
\hline $\mathrm{RF}^{*}=0.996$ & & $\mathrm{RF}=$ & 0.98 \\
\hline
\end{tabular}

$\left[(\mathrm{LF})_{\mathrm{DL}}{ }^{*}\right.$ and $(\mathrm{LF})_{\mathrm{LL}}{ }^{*}$ are the optimum load factors for dead and live load, $\mathrm{RF}^{*}$ is the optimum resistance factor, $(\mathrm{LF})_{\mathrm{DL}}$ and $(\mathrm{LF})_{\mathrm{LL}}$ are the AASHTO load factors, and RF is the resistance factor]

The RF values for different target reliability indices and different MSE wall heights are shown in Figure 6.12. Similarly to sliding, the RF value increases with decreasing target reliability index and increasing MSE wall height. However, the increase of RF value for overturning is less significant than that for sliding. 


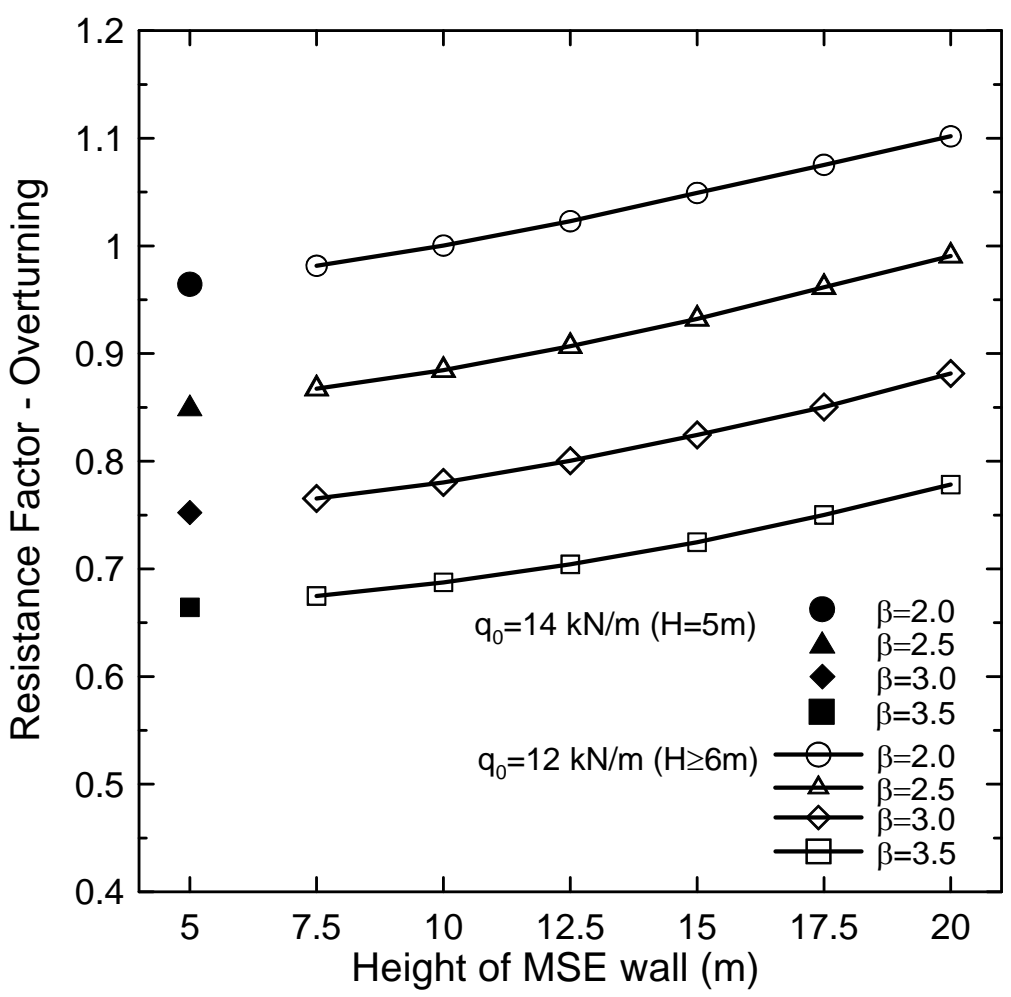

Figure 6.12 RF for different target reliability indices and different MSE wall heights for overturning

Figure 6.13 shows the changes of the optimum factors for $\mathrm{E}_{\mathrm{A} 1}, \mathrm{E}_{\mathrm{A} 2}$ and the overturning resistance with increasing MSE wall height $\mathrm{H}$. The trend of the changes in these optimum factors for overturning is similar to those for sliding. Similarly to sliding, the reason for the RF increase with increasing $\mathrm{H}$ is the significant decrease of the optimum factor $(\mathrm{LF})_{\mathrm{LL}}{ }^{*}$ for $\mathrm{E}_{\mathrm{A} 2}$ with an increasing $\mathrm{H}$. The increase of $(\mathrm{LF})_{\mathrm{LL}}{ }^{*}$ with increasing $\mathrm{H}$ can be explained as follows: As $\mathrm{H}$ increases, the relative contribution of $\mathrm{E}_{\mathrm{A} 2}$, to total loading decreases compared to that of $\mathrm{E}_{\mathrm{A} 1}$ to total loading; therefore, $(\mathrm{LF})_{\mathrm{LL}}{ }^{*}$ also decreases. 


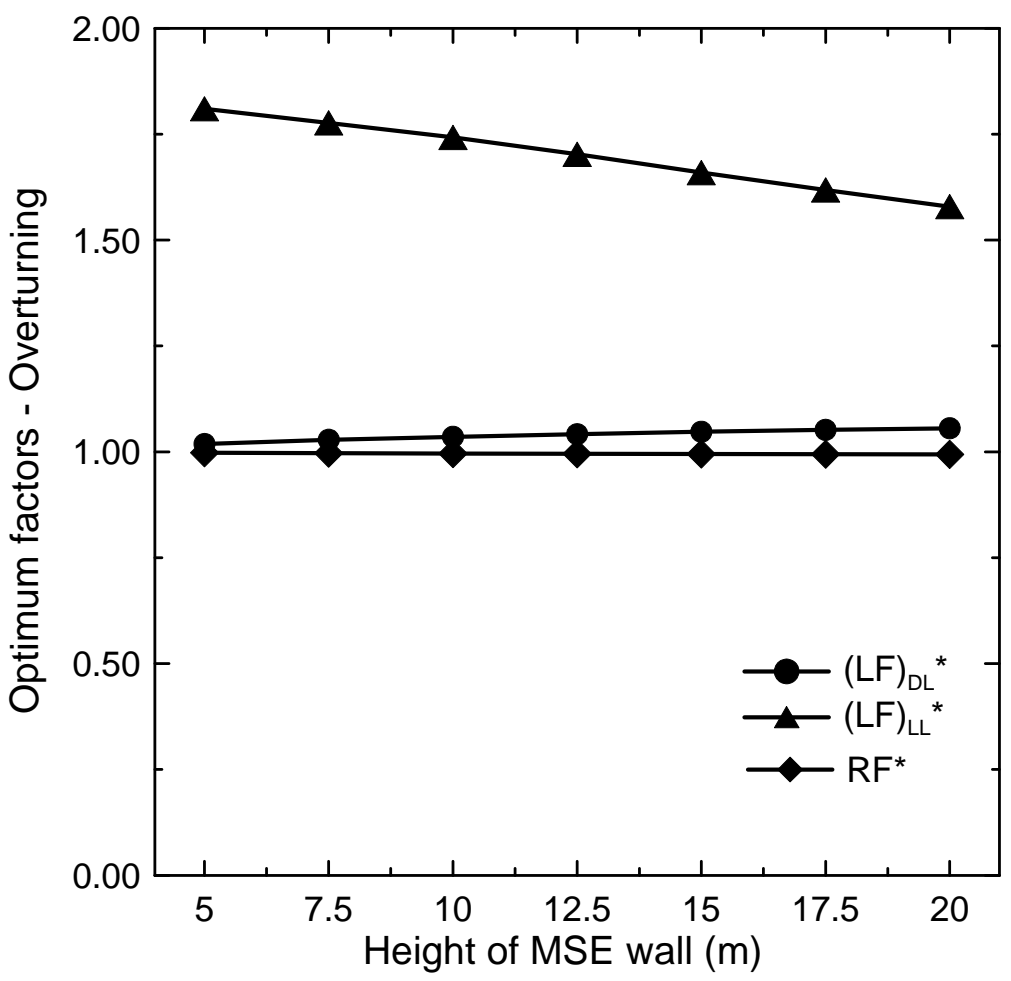

Figure 6.13 Optimum factors for $\mathrm{E}_{\mathrm{A} 1}, \mathrm{E}_{\mathrm{A} 2}$ and the overturning resistance versus MSE wall height (for $\left.\beta_{\mathrm{T}}=2.0\right)\left[(\mathrm{LF})_{\mathrm{DL}}{ }^{*}\right.$ and $(\mathrm{LF})_{\mathrm{LL}}{ }^{*}$ are the optimum load factors for dead and live load, and $\mathrm{RF}^{*}$ is the optimum resistance factor]

Figure 6.14 illustrates the FS values for different target reliability indices and different H. The highest FS was about 1.43. From the FHWA (2001) and AASHTO (2007) specifications, it is required that a factor of safety for overturning criterion should be equal to or higher than 2.0. In section 6.5.1, we found that these two specifications underestimate the active force acting on the reinforced soil because of the use of $\phi_{p}$ in calculating $\mathrm{K}_{\mathrm{A}}$ (Eq. (6.2)). The minimum required FS value in these two specifications $(\mathrm{FS}=2.0)$ would be less if $\mathrm{K}_{\mathrm{A}}$ were calculated using $\phi_{\mathrm{c}}$. 


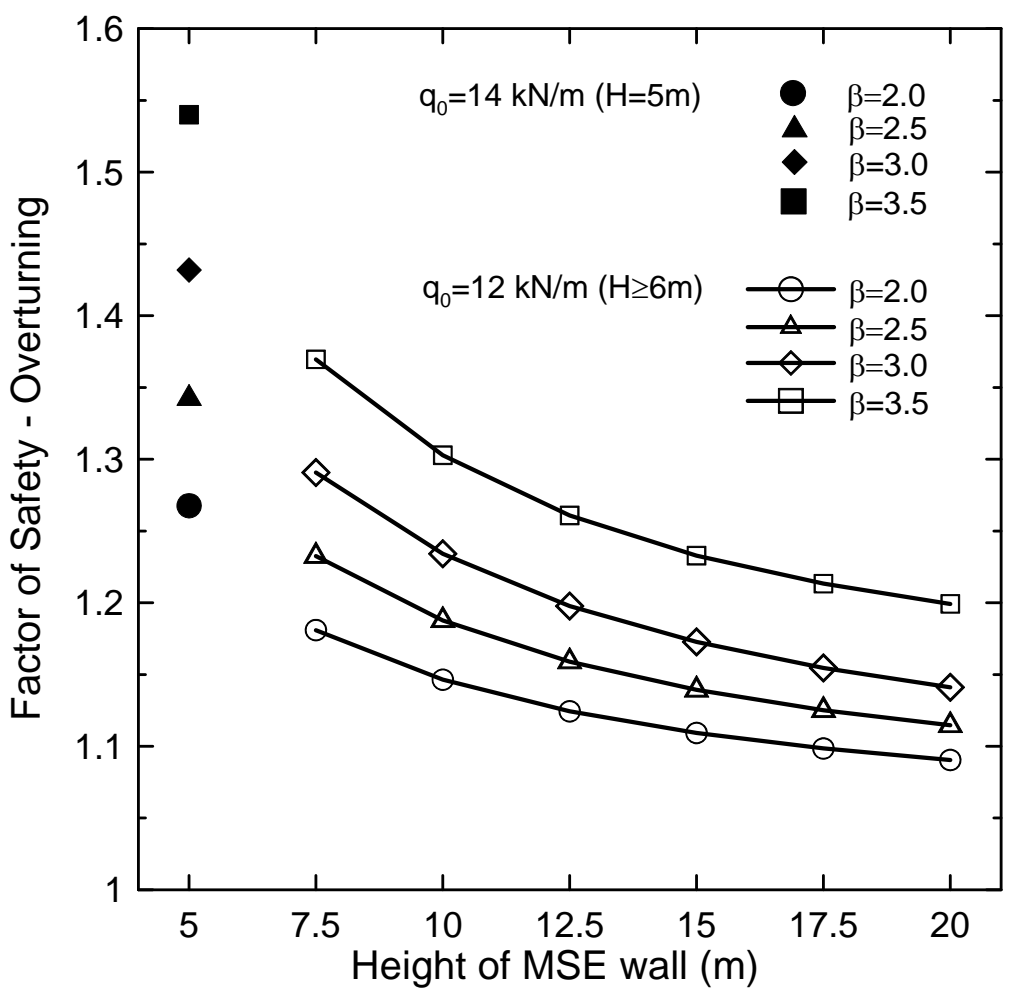

Figure 6.14 FS as a function of target reliability index and MSE wall height for overturning 


\section{CHAPTER 7. INTERNAL STABILITY OF MSE WALLS}

\subsection{Introduction}

This chapter addresses the LRFD checks for internal stability of MSE walls (pullout and structural failure of the steel-strip reinforcement). The framework and procedure for the RF value calculation for internal stability are the same as those for external stability.

\subsection{Internal Stability Ultimate Limit States}

ULS equations are developed using limit equilibrium analysis for the two internal stability limit states of an MSE wall (pullout and structural failure of the steel-strip reinforcement). At the ULSs of these two internal stability criteria, the load $\mathrm{T}_{\max }$ is the maximum tensile force on the steel-strip reinforcement. To calculate $T_{\max }$ for one particular steel-strip reinforcement, the overburden pressure is multiplied by the coefficient of lateral earth pressure $\mathrm{K}_{\mathrm{r}}$ and the tributary area of the reinforcement. The tributary area is defined as an influence area for each steel-strip reinforcement that is equal to the horizontal spacing $\mathrm{s}_{\mathrm{h}}$ times the vertical spacing $\mathrm{s}_{\mathrm{v}}$ of the reinforcement. The assessment of the uncertainty of $\mathrm{T}_{\max }$ is the most difficult step in our analysis, not only because of limited data but also because of the very high level of uncertainty in the coefficient of lateral earth pressure $\mathrm{K}_{\mathrm{r}}$. The current design specifications (FHWA, 2001 and AASHTO, 2007) use a simplified method to compute $K_{r}$. In our design method, the existing "Coherent gravity method" is modified so that we can predict $\mathrm{K}_{\mathrm{r}}$ with less uncertainty compared to the simplified method. 


\subsubsection{Pullout of steel-strip reinforcement}

The steel-strip reinforcement pullout ULS takes place when the maximum tensile force $\mathrm{T}_{\max }$ acting on the reinforcement reaches the pullout resistance of the reinforcement. $\mathrm{T}_{\max }$ is described as the maximum lateral force acting on the backfill soil over the tributary area of the reinforcement. Therefore, $\mathrm{T}_{\max }$ at a depth $\mathrm{z}$ from the top of an MSE wall is

$$
\mathrm{T}_{\max }=\sigma_{\mathrm{h}}^{\prime} \mathrm{s}_{\mathrm{v}} \mathrm{s}_{\mathrm{h}}=\mathrm{K}_{\mathrm{r}} \sigma_{\mathrm{v}}^{\prime} \mathrm{s}_{\mathrm{v}} \mathrm{s}_{\mathrm{h}}=\mathrm{K}_{\mathrm{r}}\left(\gamma_{\mathrm{rf}} \mathrm{z}+\mathrm{q}_{0, \mathrm{rf}}\right) \mathrm{s}_{\mathrm{v}} \mathrm{s}_{\mathrm{h}}
$$

where $\sigma_{h}^{\prime}$ is the horizontal effective stress; $s_{\mathrm{v}}$ and $s_{h}$ are the vertical and horizontal spacing of the steel-strip reinforcement, respectively; $K_{r}$ is the coefficient of lateral earth pressure; and $\sigma_{\mathrm{V}}^{\prime}$ is the vertical effective stress.

Pullout resistance of the steel-strip reinforcement is defined as the frictional resisting force against the maximum tensile force acting on the reinforcement:

$$
\mathrm{R}_{\mathrm{PO}}=2 \mathrm{C}_{\mathrm{R}} \sigma^{\prime}{ }_{\mathrm{v}} \mathrm{L}_{\mathrm{e}} \mathrm{b}
$$

where $C_{R}$ is the pullout resistance factor that is comparable to the coefficient of friction, $L_{e}$ is the effective length of the reinforcement, and $b$ is the width of the steel-strip reinforcement.

The live uniform surcharge $\mathrm{q}_{0, \mathrm{rf}}$ acting on the top of reinforced soil is neglected in the pullout resistance $\mathrm{R}_{P O}$ calculation (Eq. (7.2)) according to the AASHTO and FHWA specifications. According to these two specifications, vehicular loads and other live loads are excluded in the pullout resistance calculations (FHWA, 2001, section 4.3 and AASHTO, 2007, section 11.5.5). However, $\mathrm{q}_{0, \mathrm{rf}}$ is considered when we estimate $\mathrm{T}_{\max }$. The reason for neglecting $\mathrm{q}_{0, \mathrm{rf}}$ in the pullout resistance calculation and considering $\mathrm{q}_{0, \mathrm{rf}}$ in assessing $\mathrm{T}_{\max }$ may be because of the concern that $\mathrm{q}_{0, \mathrm{rf}}$ may not be distributed evenly along the reinforcement or $\mathrm{q}_{0, \mathrm{rf}}$ may not contribute to full mobilization of the pullout 
resistance. Either way, we retain that design provision here. Pullout resistance of the steel-strip reinforcement is modified as

$$
\mathrm{R}_{\mathrm{PO}}=2 \mathrm{C}_{\mathrm{R}}\left(\gamma_{\mathrm{rf}} \mathrm{z}\right) \mathrm{L}_{\mathrm{e}} \mathrm{b}
$$

Since we are comparing $\mathrm{T}_{\max }$ acting on the steel-strip reinforcement to the maximum resisting force against the pullout of the reinforcement, the pullout ULS equation at a reinforcement level equal to $\mathrm{z}$ from the top of the MSE wall can be written as:

$$
K_{r}\left(\gamma_{r f} z+q_{0, r f}\right) s_{v} s_{h}-2 C_{R}\left(\gamma_{r f} z\right) L_{e} b=0
$$

\subsubsection{Structural failure of steel-strip reinforcement}

The steel-strip structural failure ULS occurs when the maximum tensile force acting on a steel-strip reinforcement reaches the yield force of the reinforcement. The tensile force $\mathrm{T}_{\mathrm{y}}$ at yield of a steel-strip reinforcement is

$$
\mathrm{T}_{\mathrm{y}}=\mathrm{f}_{\mathrm{y}} \mathrm{A}_{\mathrm{c}}
$$

where $f_{y}$ is the yield strength of the steel-strip reinforcement, and $A_{c}$ is the cross-sectional area of the steel-strip reinforcement.

The maximum tensile force acting on a steel-strip reinforcement was defined in the previous section (Eq. (7.1)). Therefore, the steel-strip structural failure ULS at a depth $\mathrm{z}$ from the top of the MSE wall is

$$
K_{r}\left(\gamma_{r f} z+q_{0, r f}\right) s_{v} s_{h}-\left(f_{y}\right) A_{c}=0
$$




\subsection{Determination of LFs for Internal Stability Calculations}

The maximum tensile force $\mathrm{T}_{\max }$ acting on a steel-strip reinforcement can be divided into two loads, as shown in Figure 7.1: (1) the lateral load $F_{r, D L}$ acting on the reinforcement due to the self-weight of the reinforced soil and (2) the lateral force $F_{r, L L}$ due to the live uniform surcharge load on the top of the reinforced soil. $\mathrm{T}_{\max }$ can be written as

$$
\mathrm{T}_{\max }=\mathrm{K}_{\mathrm{r}}\left(\gamma_{\mathrm{rf}} \mathrm{z}+\mathrm{q}_{0, \mathrm{rf}}\right) \mathrm{s}_{\mathrm{v}} \mathrm{s}_{\mathrm{h}}=\mathrm{K}_{\mathrm{r}} \gamma_{\mathrm{rf}} \mathrm{z} \mathrm{s}_{\mathrm{v}} \mathrm{s}_{\mathrm{h}}+\mathrm{K}_{\mathrm{r}} \mathrm{q}_{0, \mathrm{rf}} \mathrm{s}_{\mathrm{v}} \mathrm{s}_{\mathrm{h}}=\mathrm{F}_{\mathrm{r}, \mathrm{DL}}+\mathrm{F}_{\mathrm{r}, \mathrm{LL}}
$$

Similarly to the cases of sliding and overturning, the $L F$ for $F_{r, L L}$ is 1.75 because $\mathrm{F}_{\mathrm{r}, \mathrm{LL}}$ is induced by a live uniform surcharge load on the top of the MSE wall (Figure 7.1). Determination of the LF for $\mathrm{F}_{\mathrm{r}, \mathrm{DL}}$ is more complicated. The condition near the top of the reinforced soil is more likely to be an at-rest state; while the condition for greater depths approaches an active condition. From Table 2.4, the ranges of LF for lateral earth pressure at rest condition and active condition are 0.90-1.35 and 0.90-1.50, respectively. LF is determined in a way that the factored load will induce the most instability against the structural failure and pullout of the reinforcement of the MSE wall. Therefore, for conservativeness, we are using the maximum LF of active earth pressure (1.5) as the LF for $F_{r, D L}$ because the load factored by the maximum load factor will destabilize the internal stabilities of MSE walls. 


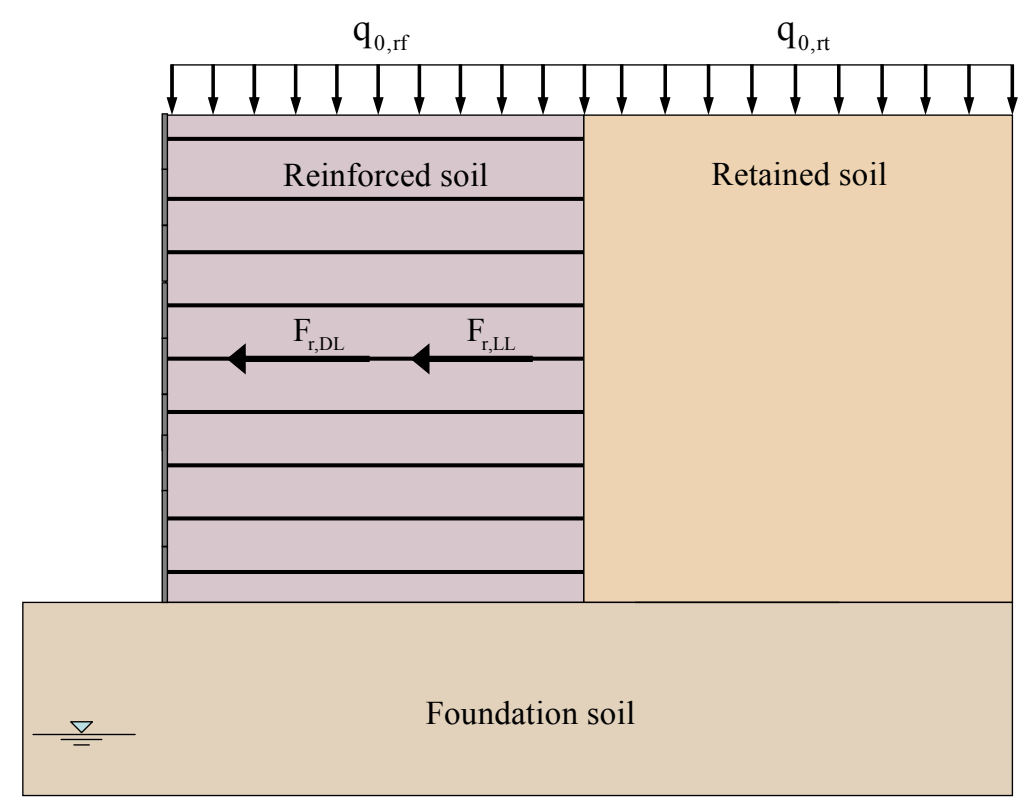

Figure 7.1 Loads for pullout and structural failure of the steel-strip reinforcement $\left(\mathrm{F}_{\mathrm{r}, \mathrm{DL}}\right.$ and $F_{r, L L}$ are the lateral loads acting on the reinforcement due to the self-weight of the reinforced soil and due to the live uniform surcharge load on the top of the reinforced soil $\left.\mathrm{q}_{0, \mathrm{rf}}\right)$

\subsection{Uncertainty of Locus of Maximum Tensile Force along the Steel-Strip $\underline{\text { Reinforcements }}$}

The potential failure zone inside the reinforced soil that separates the active zone and the stationary zone is assumed to coincide with the locus of the maximum tensile forces $\mathrm{T}_{\max }$ at each reinforcement level, as shown in Figure 7.2. The reinforcement length inside the active zone is indicated as $\mathrm{L}_{\mathrm{a}}$ and that inside the stationary zone is named the effective length and indicated as $\mathrm{L}_{\mathrm{e}}$. Therefore, the total length of the reinforcement is the sum of $\mathrm{L}_{\mathrm{a}}$ and $\mathrm{L}_{\mathrm{e}}$. The AASHTO (2007) and FHWA (2001) design specifications for MSE walls specify that the minimum required length of reinforcement (L) is $70 \%$ of the height $\mathrm{H}$ of an MSE wall. Also, FHWA (2001) prescribes that the minimum effective length of reinforcement $\mathrm{L}_{\mathrm{e}}$ is $1 \mathrm{~m}$. Only the pullout resistance along the effective length of the reinforcement is considered and used as the total resistance against pullout of the reinforcements. To calculate the total length of the required reinforcement length $\mathrm{L}$, the 
uncertainty of the reinforcement length $\mathrm{L}_{\mathrm{a}}$ embedded in the active wedge should be assessed.

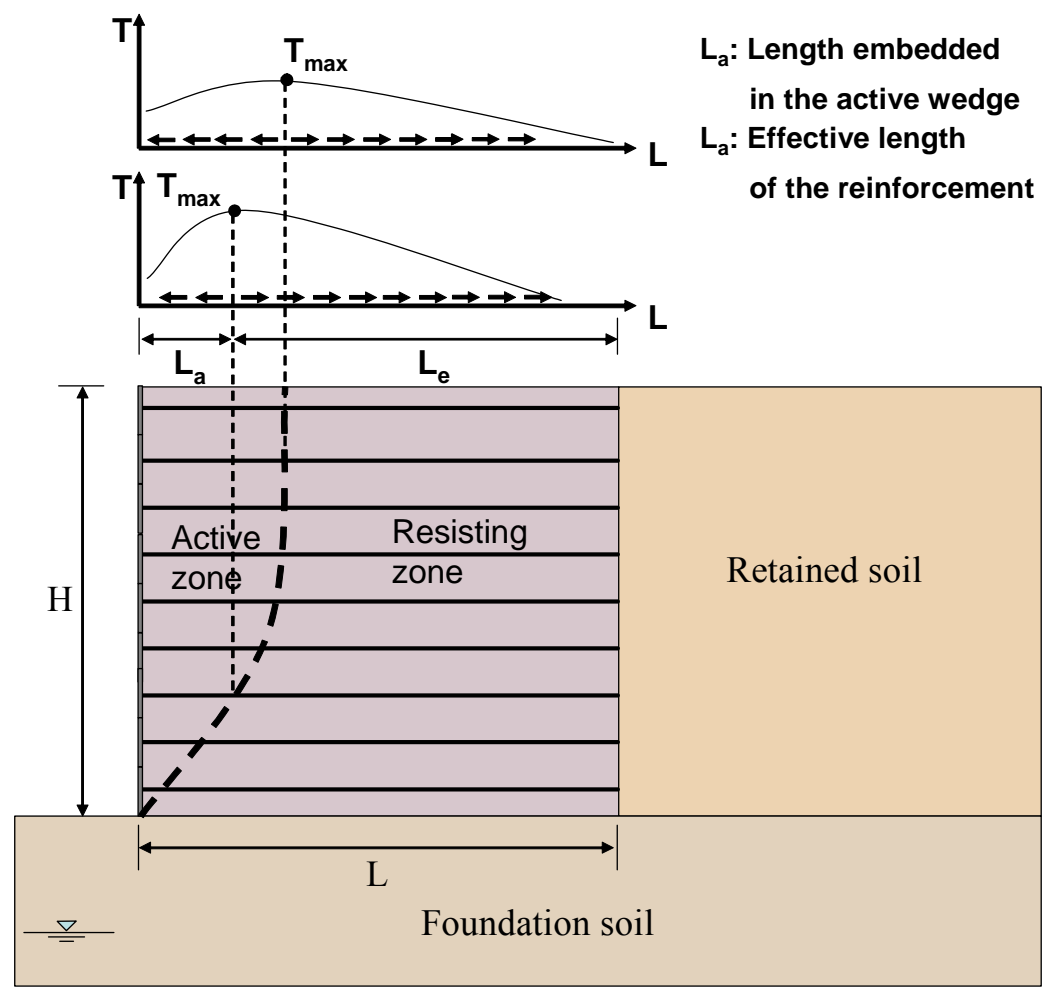

Figure 7.2 Location of maximum tensile forces on the reinforcements and distribution of tensile force along the reinforcements

Juran (1977) found from laboratory studies that the failure surface resembled a logarithmic spiral. In addition, Corte (1977) confirmed that the locus of the maximum tensile forces is a logarithmic spiral using finite element analysis (Figure 7.2). The design specifications (AASHTO, 2007 and FHWA, 2001) approximate the failure zone as bilinear. Therefore, $\mathrm{L}_{\mathrm{a}}$, the distance from the facing of the MSE wall, can be expressed as: 


$$
\mathrm{L}_{\mathrm{a}}(\mathrm{z})= \begin{cases}0.3 \mathrm{H}, & 0 \leq \mathrm{z} \leq \frac{\mathrm{H}}{2} \\ 0.6(\mathrm{H}-\mathrm{z}), & \frac{\mathrm{H}}{2} \leq \mathrm{z} \leq \mathrm{H}\end{cases}
$$

where $\mathrm{z}$ is the depth from the top of the MSE wall.

Schlosser et al. (1978) presented the measurements of the location of the maximum tensile force $\mathrm{T}_{\max }$ from five completed MSE walls. The uncertainty of the locus of the maximum tensile force was assessed using the data in his literature. Out of five completed MSE walls, the measurements of the maximum tensile forces of one MSE wall were excluded because the values of those measurements were very low. Four measurements of the maximum tensile forces near the base of MSE walls were also excluded while assessing the uncertainty of the locus of the maximum tensile force because, even though the difference between the measured and the corresponding predicted $\mathrm{L}_{\mathrm{a}}$ are small, the high ratios of the measured to the corresponding predicted $\mathrm{L}_{\mathrm{a}}$ induce higher bias factors. Finally, twenty-four measurements were used in assessing the uncertainty of the maximum tensile force, and the bias factor and COV turned out to be 0.825 and 0.16 , respectively. The location of the measurements is normalized by the height of MSE wall $\mathrm{H}$ and shown in Figure 7.3. $\mathrm{L}_{\mathrm{a}}$ (dashed-doted line in Figure 7.3) is the length of reinforcement inside the active wedge obtained from a regression analysis by fitting the measurements of the locations of $\mathrm{T}_{\max }$ to a bilinear equation. 


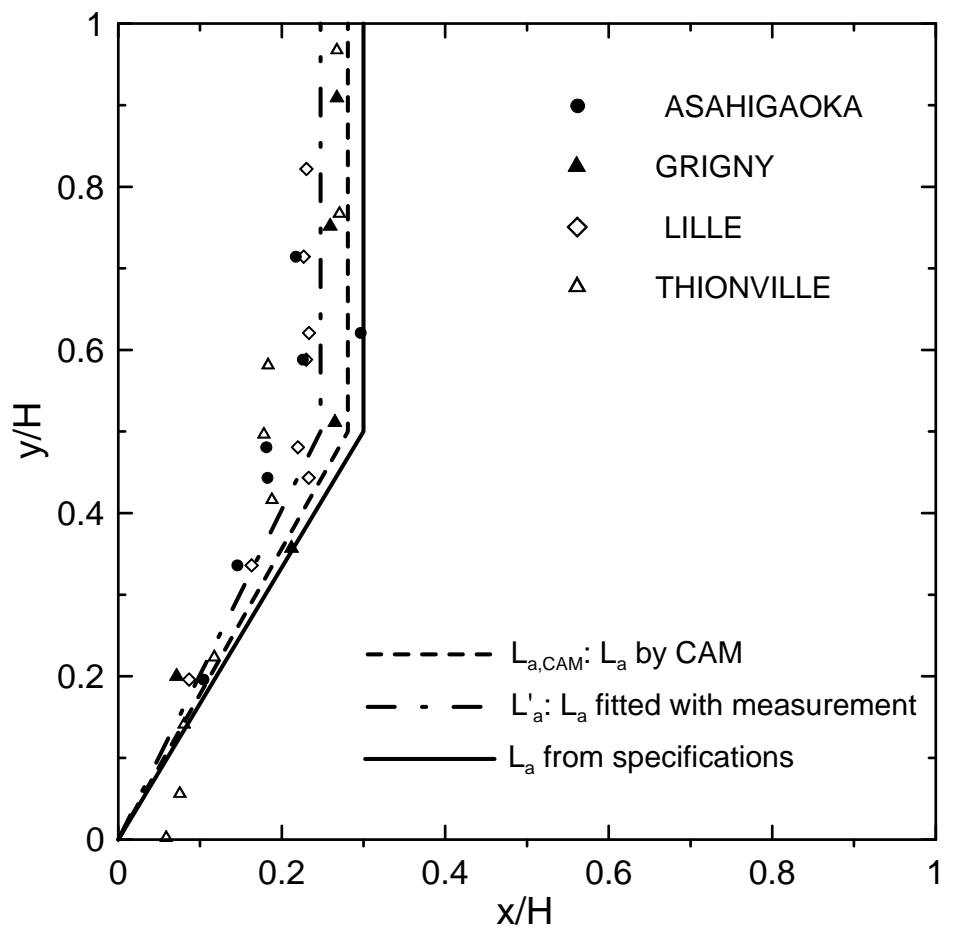

Figure 7.3 Location of the maximum tensile force normalized by the height of MSE walls

Except the two points near the base of the MSE walls, the locations of $\mathrm{L}_{\mathrm{a}}$ defined by Eq. (7.8) can be considered as the upper boundary of the measured data. Therefore, conservatively, we could use the location of $\mathrm{L}_{\mathrm{a}}$ defined by Eq. (7.8) in design of MSE walls.

\subsection{Uncertainties of the Parameters That are Used in the Analysis of the Internal $\underline{\text { Stability of MSE Walls }}$}

The uncertainties of several parameters that are used in the ULS equations for pullout and structural failure of the steel-strip reinforcement were already assessed in the previous chapter. The following variables are the additional parameters which uncertainties that have to be assessed to perform reliability analyses for internal stability of MSE walls: (1) dry unit weight of the compacted soil, (2) maximum dry unit weight and minimum dry unit weight for frictional soils, (3) relative density of backfill soil in the reinforced soil, 
(4) coefficient of lateral earth pressure $K_{r}$, (5) pullout resistance factor $C_{R}$ of steel-strip reinforcement, and (6) yield strength of steel-strip reinforcement.

\subsubsection{Uncertainty of dry unit weight of the compacted soil}

The backfill material in the reinforced soil of MSE walls requires a highly frictional material that has durability, good drainage, and a low Plasticity Index (PI less than 6). To prevent corrosion of reinforcements, the backfill material in the reinforced soil should not contain organic matter or detrimental materials (AASHTO, 2007 and FHWA, 2001). Therefore, well-graded frictional soil is used to build the MSE wall because it has higher strength and thus maximizes the friction between the soil and the steel-strip reinforcements. AASHTO standard T-27 imposes constraints on limits the particle size distribution of backfill soils of MSE walls, as shown in Table 7.1. The backfill soil of an MSE wall is an A-1 soil according to the AASHTO classification system (ASTM D3282; AASHTO M145) and GP-GM (poorly graded gravel - silty gravel) according to the Unified classification system (ASTM D2487).

Table 7.1 Particle size distribution for backfill soils of MSE walls (AASHTO T-27)

\begin{tabular}{|c|c|c|}
\hline Sieve size (mm) & Percent passing (\%) & $\begin{array}{c}\text { Diameter or } \\
\text { Sieve number }\end{array}$ \\
\hline 102 & 100 & 4 in. \\
\hline 0.425 & $0-60$ & Sieve No. 40 \\
\hline 0.075 & $0-15$ & Sieve No. 200 \\
\hline
\end{tabular}

Backfill soils in the reinforced soil zone are compacted to more than $95 \%$ relative compaction. A nuclear device is typically used to control the degree of compaction of the fills. From 230 field tests on a dam construction site (Mt. Cenis Dam in France), the COV of the dry unit weight of the compacted silty-sandy gravel soil was found to be 0.012 
(Lacroix and Horn, 1973). The truck-mounted French AGS probe nuclear device was used to measure the unit weights. From these results, we assume that the COV of dry unit weight of the compacted backfill material for the reinforced zone is similar to the COV value (0.012) that Lacroix and Horn (1973) observed.

Since silty-sandy gravel is typically classified as GP-GM in the Unified Classification System, it is acceptable to use this value (0.012) as the COV of the compacted backfill soil because the soil used in dam construction is comparable. The uncertainty of the dry unit weight of the compacted granular soil $(\mathrm{COV}=0.012)$ is less than that of the natural soil $(\mathrm{COV}=0.03$, see section 6.4.1) because controlled compaction results in less variability of the void ratio of the soil.

7.5.2. Uncertainty of maximum dry unit weight and minimum dry unit weight for frictional soils

Muszynski (2006) performed tests following the ASTM standards (ASTM D 4253 and ASTM D4254) to evaluate $\gamma_{\mathrm{dmax}}$ and $\gamma_{\mathrm{dmin}}$ of three different types of sand (Manistee Dune sand, Traverse City Fill sand, and Concrete sand). For each type of sand, two tests were performed. Table 7.2 shows the COVs for $\gamma_{\mathrm{dmax}}$ of those three sands that are assessed using $\mathrm{N}_{\sigma}$ method. The $\mathrm{N}_{\sigma}$ method is explained in detail in Appendix D.

Table $7.2 \gamma_{\mathrm{dmax}}$ measured using ASTM D4253

\begin{tabular}{|c|c|c|c|c|}
\hline Type of sand & $\begin{array}{c}\text { Mean } \\
\left(\mathrm{kN} / \mathrm{m}^{3}\right)\end{array}$ & $\begin{array}{l}\text { Difference in } \gamma_{\mathrm{dmax}} \text { between } \\
\text { two measurements }(\%)\end{array}$ & $\mathrm{COV}$ & Note \\
\hline $\begin{array}{c}\text { Manistee Dune } \\
\text { Sand }\end{array}$ & 17.22 & 0.017 & 0.0009 & \multirow{3}{*}{$\begin{array}{l}\text { COV estimated } \\
\text { using } \mathrm{N}_{\sigma} \\
\text { method }\end{array}$} \\
\hline $\begin{array}{l}\text { Traverse City } \\
\text { Fill Sand }\end{array}$ & 17.51 & 0.172 & 0.0087 & \\
\hline Concrete Sand & 18.93 & 0.019 & 0.0009 & \\
\hline
\end{tabular}


Six tests were conducted for each sand to find $\gamma_{\mathrm{dmin}}$ following the ASTM D4254 standard. The means and the corresponding standard deviations of $\gamma_{\mathrm{dmin}}$ for these three sands are provided in Table 7.3. To propose general guidelines that are conservative, we take the COVs of $\gamma_{\mathrm{dmax}}$ and $\gamma_{\mathrm{dmin}}$ to be 0.0087 and 0.0024 , the highest of the values for the three sands.

Table $7.3 \gamma_{\mathrm{dmin}}$ measured using ASTM D4254

\begin{tabular}{|c|c|c|c|c|}
\hline Type of sand & $\begin{array}{c}\text { Mean } \\
\left(\mathrm{kN} / \mathrm{m}^{3}\right)\end{array}$ & $\begin{array}{c}\text { Standard deviation } \\
\left(\mathrm{kN} / \mathrm{m}^{3}\right)\end{array}$ & $\mathrm{COV}$ & Note \\
\hline Manistee Dune Sand & 14.69 & 0.021 & 0.0015 & \multirow{3}{*}{$\begin{array}{l}6 \text { tests } \\
\text { for each } \\
\text { type of } \\
\text { sand }\end{array}$} \\
\hline Traverse City Fill Sand & 15.33 & 0.038 & 0.0024 & \\
\hline Concrete Sand & 15.68 & 0.033 & 0.0021 & \\
\hline
\end{tabular}

7.5.3. Uncertainty of relative density of backfill soil in the reinforced soil

As mentioned earlier, the backfill soil is to be compacted to $95 \%$ relative compaction. Poulos and Hed (1973) demonstrated that there is an approximately linear correlation between the relative density $\mathrm{D}_{\mathrm{R}}$ and relative compaction (Figure 7.4). The data points used in Figure 7.4 are obtained from different types of soils varying from very uniform, medium sand to coarse sand. The relative density $\mathrm{D}_{\mathrm{R}}$ of the backfill soil corresponding to $95 \%$ or higher relative compaction ranges approximately from $70 \%$ to $100 \%$, as indicated by the shaded region in Figure 7.4. 


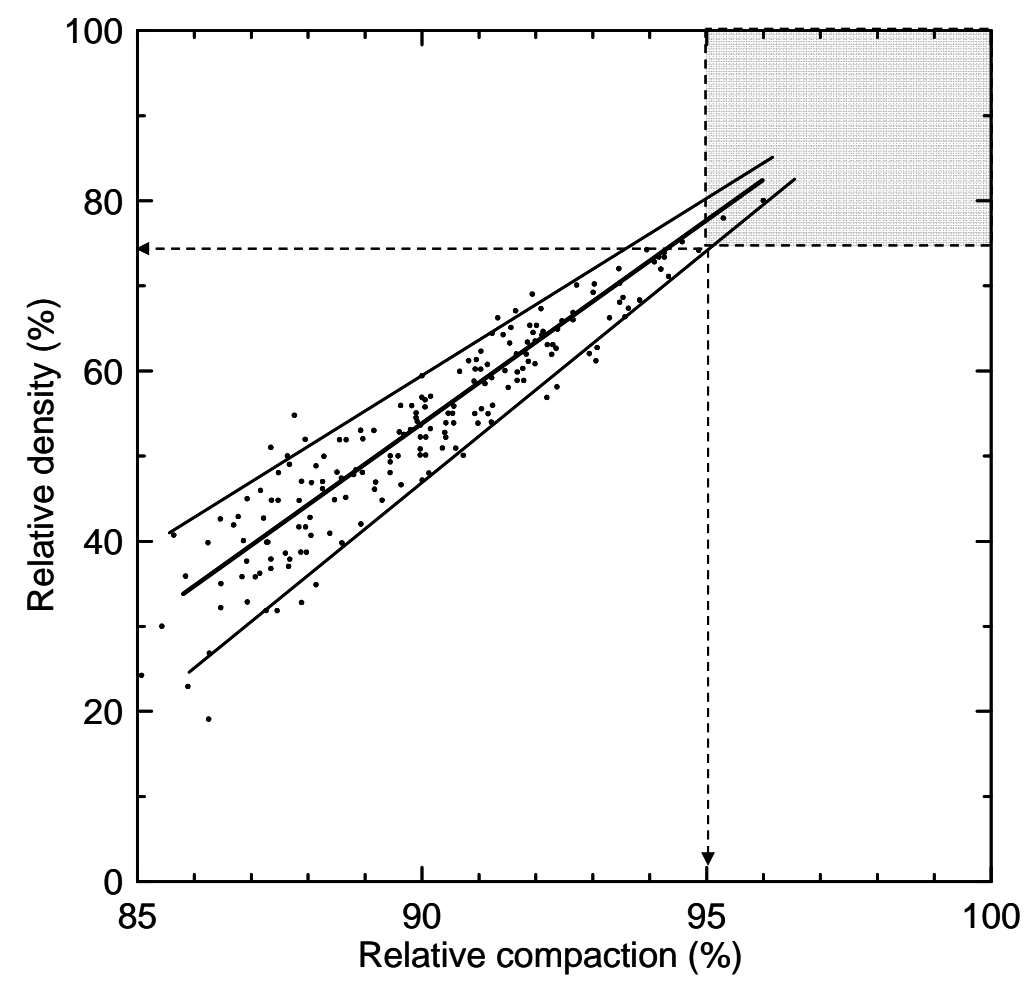

Figure 7.4 Relationship between relative density and relative compaction

$D_{R}$ is expressed in terms of unit weight as follows:

$$
D_{R}=\frac{\gamma_{d \max }}{\gamma_{d}} \times \frac{\gamma_{d}-\gamma_{d \min }}{\gamma_{d \max }-\gamma_{d \min }}
$$

The uncertainty involved in the dry unit weight $\gamma_{\mathrm{d}}$, the maximum dry unit weight $\gamma_{\mathrm{dmax}}$, and the minimum dry unit weight $\gamma_{\mathrm{dmin}}$ can be used to assess the uncertainty of relative density. Monte Carlo simulations using Eq. (7.9) were performed to estimate the means and standard deviations of $D_{R}$. In the simulation, $\gamma_{d m a x}, \gamma_{d m i n}$, and $\gamma_{d}$ of the compacted backfill soil in the reinforced soil can be considered as independent variables.

According to the previous sections (sections 7.5.1 and 7.5.2), the COVs of $\gamma_{\mathrm{dmax}}$ and $\gamma_{\mathrm{dmin}}$ are 0.0087 and 0.0024 , and that of $\gamma_{\mathrm{d}}$ of the compacted backfill material in the reinforced soil is 0.012 . Since we do not know $\gamma_{\mathrm{dmax}}$ and $\gamma_{\mathrm{dmin}}$ in the field, we consider 
$\gamma_{\mathrm{dmax}}$ and $\gamma_{\mathrm{dmin}}$ of both fine sand and gravelly sand (source: ASTM D2049-69). The particle size distributions of the fine sand and gravelly sand are shown in Figure 7.5. Both sands satisfy the limits of the particle size distribution of the backfill materials in the reinforced soil suggested by AASHTO T-27 (Table 7.1). The values of $\gamma_{\mathrm{dmax}}$ and $\gamma_{\mathrm{dmin}}$ of fine sand $\left(\gamma_{\mathrm{dmax}}=18.032 \mathrm{kN} / \mathrm{m}^{3}\right.$ and $\left.\gamma_{\mathrm{dmin}}=15.009 \mathrm{kN} / \mathrm{m}^{3}\right)$ are lower than those of gravelly sand $\left(\gamma_{\mathrm{dmax}}=20.972 \mathrm{kN} / \mathrm{m}^{3}\right.$ and $\left.\gamma_{\mathrm{dmin}}=17.952 \mathrm{kN} / \mathrm{m}^{3}\right)$.

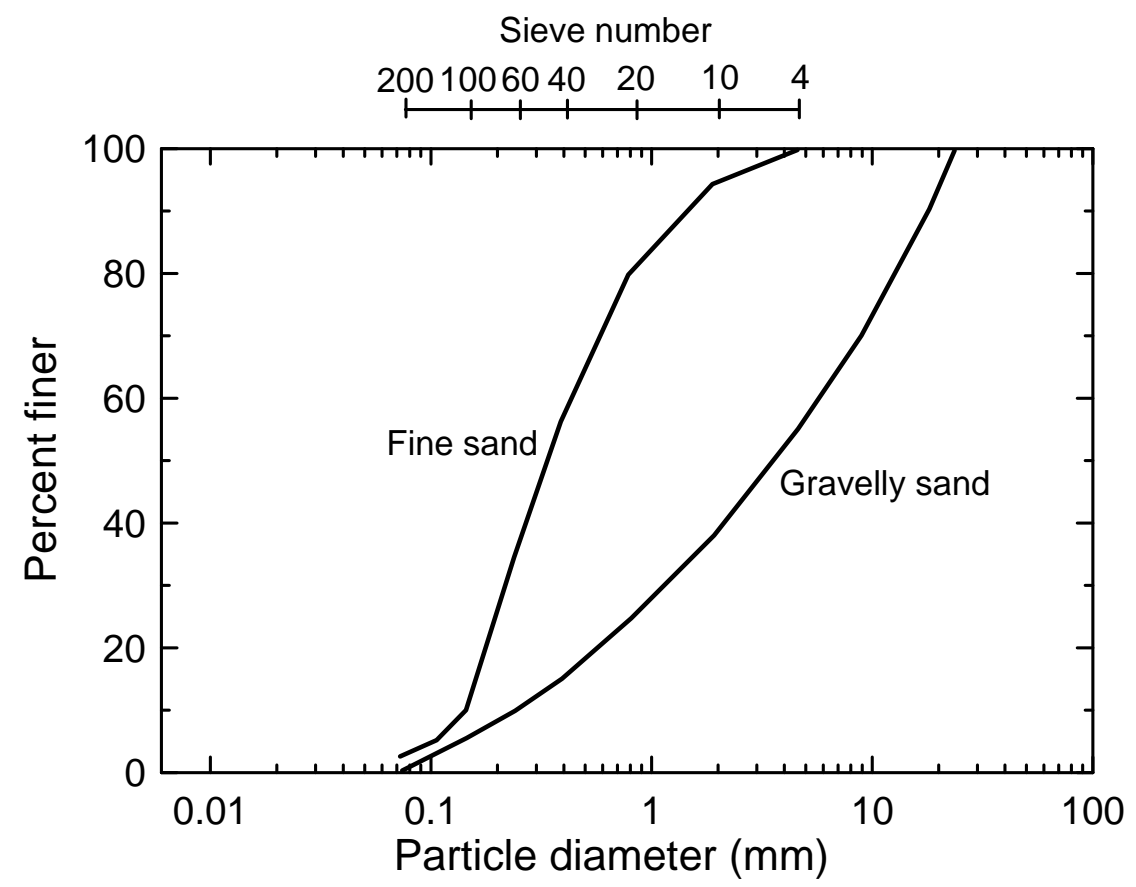

Figure 7.5 Particle size distributions of fine sand and gravelly sand introduced in ASTM D2049-69

The means and COVs of the relative density for both compacted fine sand and compacted gravelly sand are calculated for relative density ranging from $10 \%$ to $100 \%$ (Table 7.4 and Table 7.5). The bias factors for all the calculations are 1.00. 
Table 7.4 COVs of relative density of compacted fine sand

\begin{tabular}{|c|c|c|c|c|}
\hline $\mathrm{D}_{\mathrm{R}}$ & $\begin{array}{c}\gamma_{\mathrm{d}} \\
\left(\mathrm{kN} / \mathrm{m}^{3}\right)\end{array}$ & $\begin{array}{c}\text { mean } \\
\left(\mathrm{D}_{\mathrm{R}}\right)\end{array}$ & $\begin{array}{c}\text { Stdev } \\
\left(\mathrm{D}_{\mathrm{R}}\right)\end{array}$ & COV \\
\hline $100 \%$ & 18.032 & $100 \%$ & $7.41 \%$ & 0.074 \\
\hline $90 \%$ & 17.676 & $90 \%$ & $7.25 \%$ & 0.081 \\
\hline $80 \%$ & 17.334 & $80 \%$ & $7.14 \%$ & 0.089 \\
\hline $70 \%$ & 17.005 & $70 \%$ & $7.06 \%$ & 0.101 \\
\hline $60 \%$ & 16.688 & $60 \%$ & $7.00 \%$ & 0.117 \\
\hline $50 \%$ & 16.382 & $50 \%$ & $6.97 \%$ & 0.139 \\
\hline $40 \%$ & 16.088 & $40 \%$ & $6.98 \%$ & 0.175 \\
\hline $30 \%$ & 15.804 & $30 \%$ & $7.01 \%$ & 0.234 \\
\hline $20 \%$ & 15.530 & $20 \%$ & $7.11 \%$ & 0.356 \\
\hline $10 \%$ & 15.265 & $10 \%$ & $7.18 \%$ & 0.718 \\
\hline
\end{tabular}

Table 7.5 COVs of relative density of compacted gravelly sand

\begin{tabular}{|c|c|c|c|c|}
\hline$D_{R}$ & $\begin{array}{c}\gamma_{d} \\
\left(\mathrm{kN} / \mathrm{m}^{3}\right)\end{array}$ & $\begin{array}{c}\text { mean } \\
\left(D_{R}\right)\end{array}$ & $\begin{array}{c}\text { Stdev } \\
\left(D_{R}\right)\end{array}$ & CoV \\
\hline $100 \%$ & 20.972 & $100 \%$ & $8.89 \%$ & 0.089 \\
\hline $90 \%$ & 20.625 & $90 \%$ & $8.70 \%$ & 0.097 \\
\hline $80 \%$ & 20.289 & $80 \%$ & $8.51 \%$ & 0.106 \\
\hline $70 \%$ & 19.965 & $70 \%$ & $8.40 \%$ & 0.120 \\
\hline $60 \%$ & 19.650 & $60 \%$ & $8.30 \%$ & 0.138 \\
\hline $50 \%$ & 19.345 & $50 \%$ & $8.24 \%$ & 0.165 \\
\hline $40 \%$ & 19.049 & $40 \%$ & $8.22 \%$ & 0.206 \\
\hline $30 \%$ & 18.763 & $30 \%$ & $8.25 \%$ & 0.275 \\
\hline $20 \%$ & 18.485 & $20 \%$ & $8.31 \%$ & 0.416 \\
\hline $10 \%$ & 18.215 & $10 \%$ & $8.42 \%$ & 0.842 \\
\hline
\end{tabular}

For a given relative density, the COV of compacted gravelly sand is higher than that of compacted fine sand. Conservatively, we are proposing the COV values (Table 7.5) of compacted gravelly sand with a relative density ranging from $70 \%$ to $100 \%$ as the uncertainty of relative density of the backfill soil in the reinforced zone. 


\subsubsection{Uncertainty of coefficient of lateral earth pressure $K_{r}$}

Much care is required in estimating the coefficient of lateral earth pressure $\mathrm{K}_{\mathrm{r}}$ because it has the highest uncertainty from all the parameters used in the ULSs of internal stability of MSE walls.

\subsubsection{The conventional methods of $\mathrm{K}_{\mathrm{r}}$ estimation}

Allen, T. et al. (2001) introduced four methods to estimate $\mathrm{K}_{\mathrm{r}}$ : (1) coherent gravity method; (2) tieback wedge method; (3) FHWA structure stiffness method; and (4) simplified method. The FHWA structure stiffness method was used to estimate $\mathrm{K}_{\mathrm{r}}$ in the previous version of the MSE wall design and construction guidelines (FHWA-RD-89043); the so-called simplified method has been used in a more recent version of the guidelines (FHWA-SA-96-071 \& FHWA-NHI-00-043). Among those four methods, the simplified method works best for MSE walls with steel-strip reinforcement because the method has the least uncertainty. However, we found that the modification of the existing "coherent gravity method" enables $\mathrm{K}_{\mathrm{r}}$ prediction with less uncertainty compared to that of the "simplified method" reported by Allen et al. (2001).

\subsubsection{Modified coherent gravity method}

The original "coherent gravity method" was developed from the work done by Juran and Schlosser (1978), Schlosser (1978), and Schlosser and Segrestin (1979) to estimate $K_{r}$ in precast panel-faced MSE wall systems (Allen et al., 2001).

The coherent gravity method assumes that $K_{r}$ varies linearly from $K_{0}$ at the top of an MSE wall to $\mathrm{K}_{\mathrm{A}}$ at a depth $\mathrm{z}_{\mathrm{cr}}=6 \mathrm{~m}$ from the top of an MSE wall and $\mathrm{K}_{\mathrm{r}}$ remains constant for depths greater than $6 \mathrm{~m}$ (Figure 7.6). The depth $\mathrm{z}_{\mathrm{cr}}$ will be allowed to vary later in this chapter. 


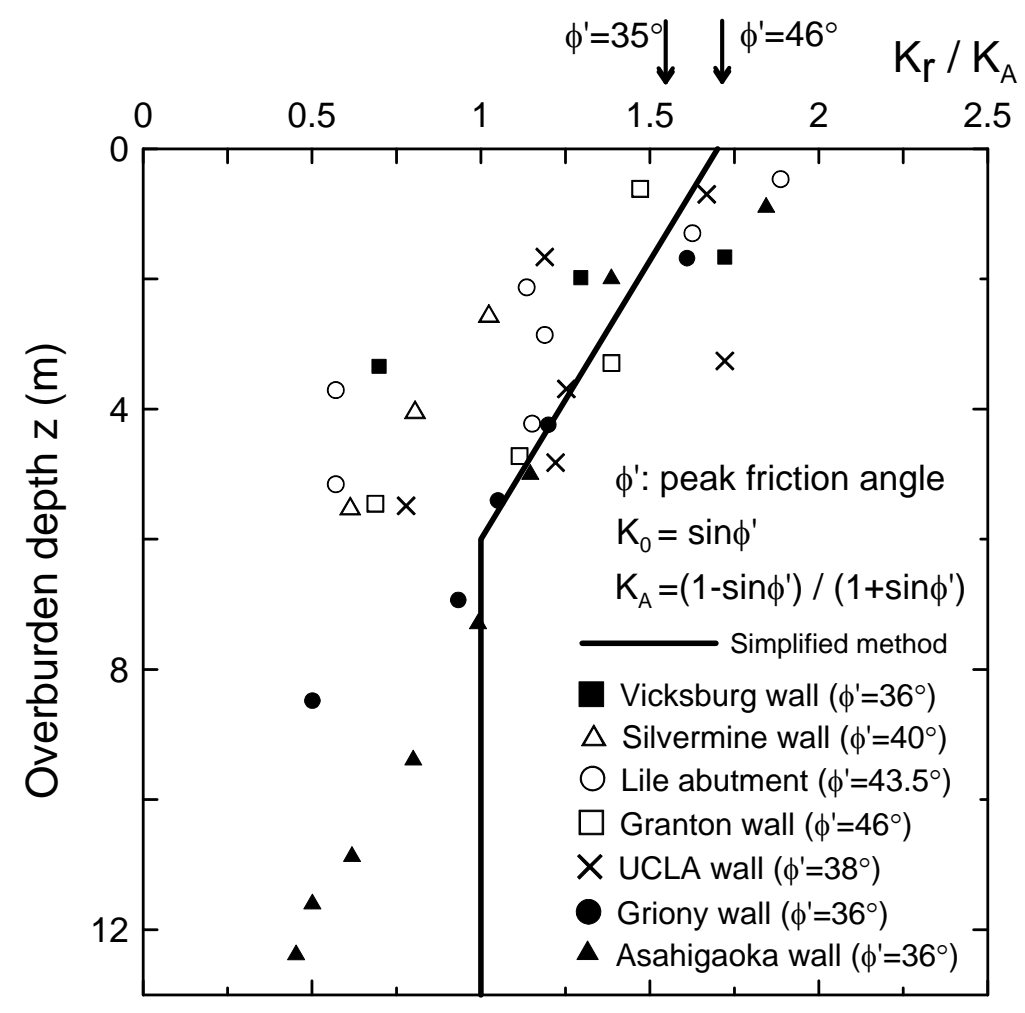

Figure 7.6 Variation of $\mathrm{K}_{\mathrm{r}} / \mathrm{K}_{\mathrm{A}}$ for MSE walls with steel-strip reinforcements ( $\phi^{\prime}$ is peak friction angle; after Schlosser, 1978)

Near the top of MSE walls, due to the low overburden stresses, the restraint offered by the steel-strip reinforcement to the soil mass is high and thus the horizontal strains in the reinforced soil mass in this zone of the MSE wall are very small or negligible. Thus, the $\mathrm{K}_{0}$ condition prevails in the upper part of the MSE wall because reinforcements prevent an active stress condition from fully developing. An active condition may develop in regions where a higher overburden pressure induces higher horizontal stress that is large enough to overcome the restraint offered by steel-strip reinforcements. Therefore, enough deformation of the reinforced soil mass for an active condition to develop at greater depths is possible. Data in Figure 7.6 suggest that the coefficient of lateral earth pressure is close to $\mathrm{K}_{0}$ condition near the top of MSE walls and $\mathrm{K}_{\mathrm{A}}$ condition at greater depths from the top of MSE walls. 
The original coherent gravity method assumes that an active condition has developed at depths greater than $6 \mathrm{~m}$ from the top of the MSE walls. Regression analysis using the available field measurement data for $\mathrm{T}_{\max }$ was conducted as part of the present study to ascertain the depth below which an active condition would prevail. This will be explained later in detail.

\subsubsection{1. $\mathrm{K}_{0}$ estimation}

The original coherent gravity method uses the following equation to estimate $\mathrm{K}_{0}$ (proposed by Jaky, 1944):

$$
\mathrm{K}_{0}=1-\sin \phi
$$

The method uses $\phi_{\mathrm{p}}$ to estimate $\mathrm{K}_{0}$ using Eq. (7.10). $\mathrm{K}_{0}$ estimation using Eq. (7.10) involves a large uncertainty as the measured data points are widely scattered with respect to the values calculated using the equation. In addition, Eq. (7.10) does not work well for high friction angles $\left(\phi_{\mathrm{p}}>40^{\circ}\right)$ because the estimated $\mathrm{K}_{0}$ value is then very low.

Fang et al. (1997) back-calculated the coefficients of lateral earth pressure at rest for normally consolidated granular soil $\left(\mathrm{K}_{0 \mathrm{nc}}\right)$ from the measurement of the lateral earth pressure acting against a rigid wall and concluded that $\mathrm{K}_{0 \mathrm{nc}}$ varies from 0.4 to 0.48 . Airpluviated Ottawa sand was used to construct the backfill $\left(\mathrm{G}_{\mathrm{s}}=2.65, \mathrm{e}_{\max }=0.76, \mathrm{e}_{\min }=0.50\right.$, $\mathrm{D}_{60}=0.36 \mathrm{~mm}, \mathrm{D}_{10}=0.23 \mathrm{~mm}$ ). Hendron (1963) evaluated a relationship between $\mathrm{K}_{0}$ and initial void ratio $\mathrm{e}_{0}$. He concluded that $\mathrm{K}_{0}$ of Minnesota sand varied from 0.33 to 0.48 and that $\mathrm{K}_{0}$ increases as the initial void ratio increases, as shown in Figure 7.7. 


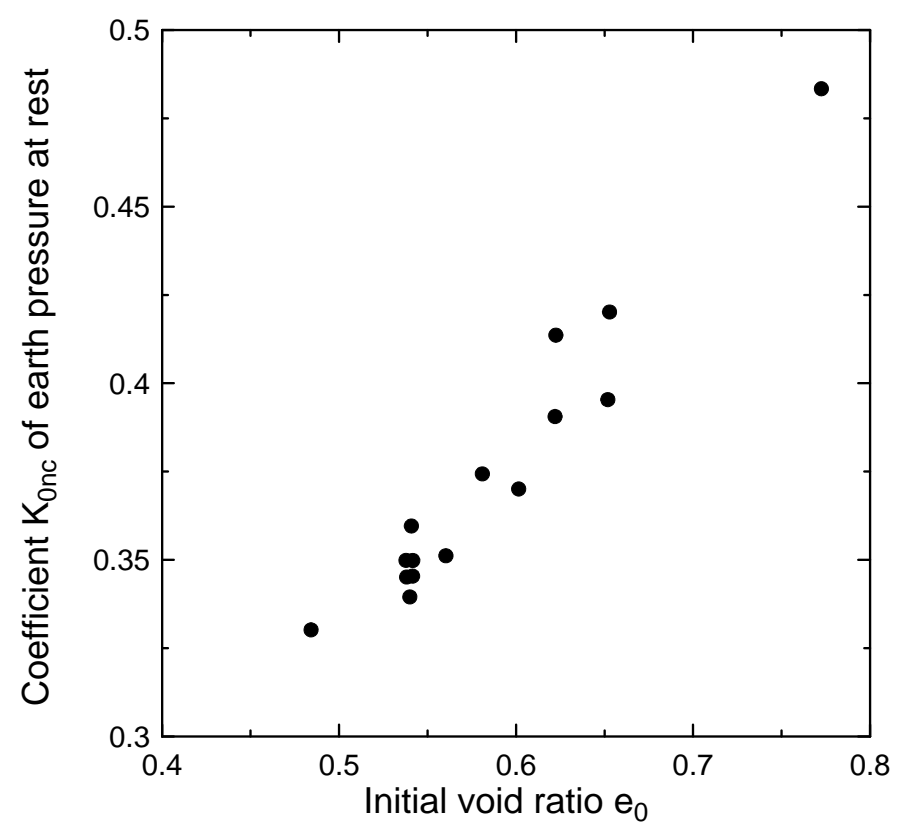

Figure 7.7 Relationship between $\mathrm{K}_{0}$ and $\mathrm{e}_{0}$ of Minnesota sand

In addition, Okochi and Tatsuoka (1984) performed a series of $\mathrm{K}_{0}$-consolidation tests on reconstituted Toyoura sand using a Double-cell $\mathrm{K}_{0}$-triaxial apparatus and found that $\mathrm{K}_{0 \mathrm{nc}}$ varied from 0.34 to 0.49 . From the results of the tests, $\mathrm{K}_{0}$ not only depended on the sample preparation method but also on the initial void ratio. Even though $\mathrm{K}_{0}$ values for the samples prepared using the wet-tamped method is slightly lower than those for the samples prepared using the air-pluviated method, the trend shows that the coefficient of lateral earth pressure at rest increases with increasing initial void ratio $\mathrm{e}_{0}$. 


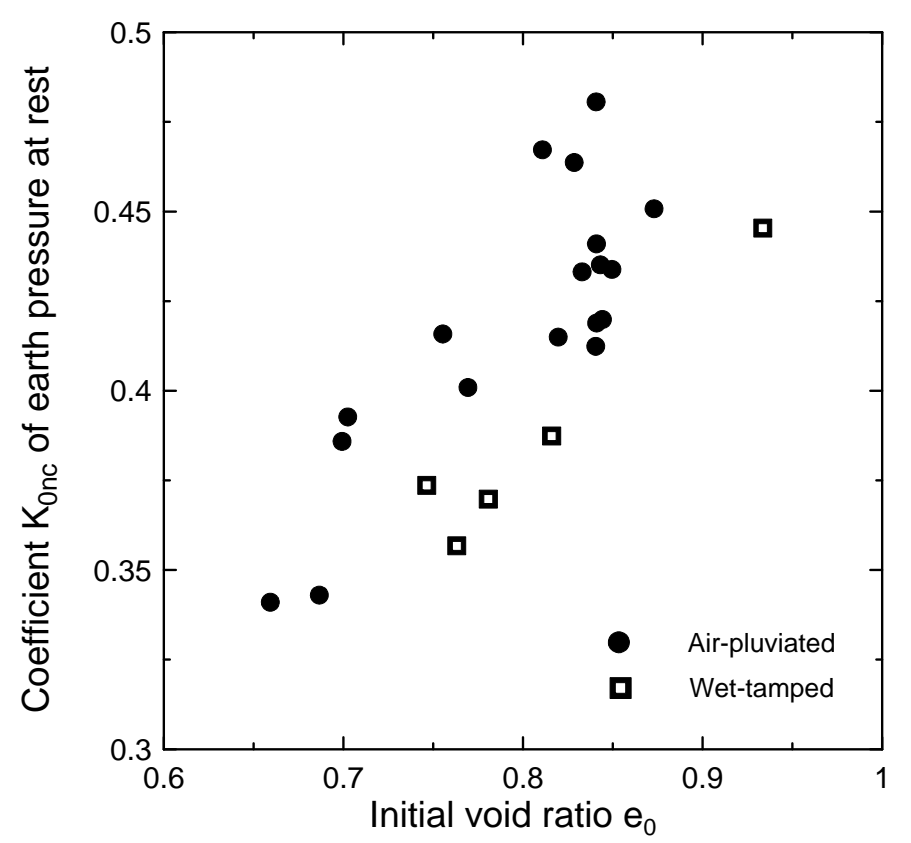

Figure 7.8 Coefficient of lateral earth pressure at rest for normally consolidated Toyoura sand when axial stress is $118 \mathrm{kPa}$

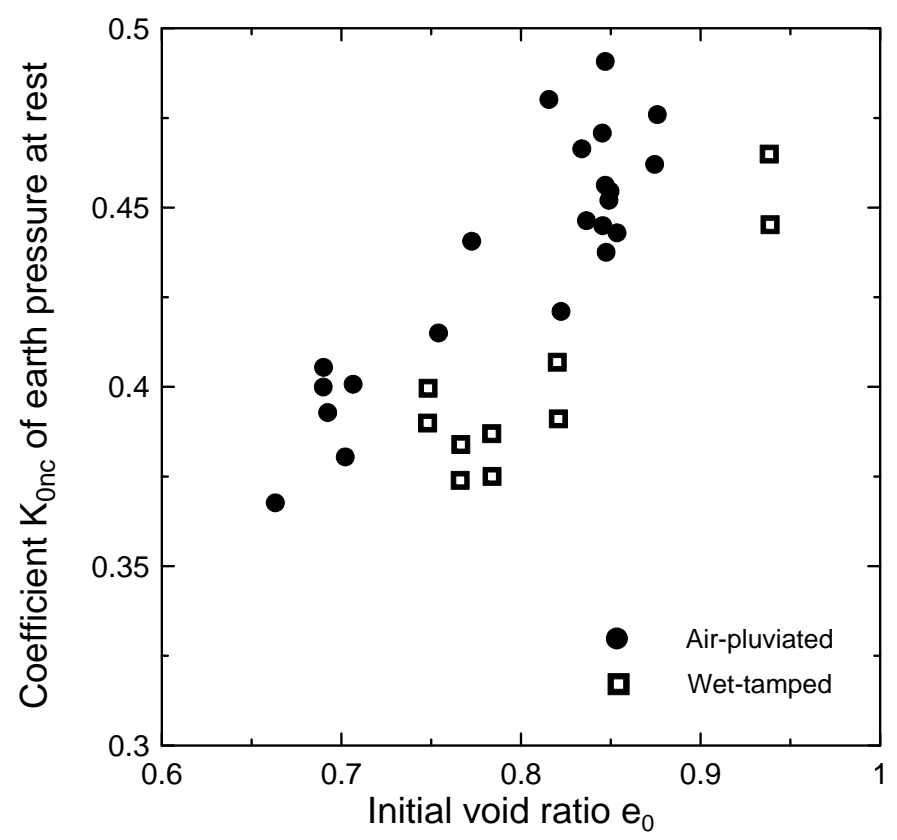

Figure 7.9 Coefficient of lateral earth pressure at rest for normally consolidated Toyoura sand when axial stress is $196 \mathrm{kPa}$ 
From the aforementioned work, we expect high relative densities (70-100\%) for the compacted backfill soil in the reinforced soil, and, therefore, it is acceptable to assume that the upper and lower bounds of $\mathrm{K}_{0}$ for dense sand are 0.35 and 0.45 . Therefore, we can use 0.4 for the expected value of $K_{0}$ for the backfill soil in the reinforced soil.

Researchers (e.g. Broms and Ingelson, 1971; Sherif et al., 1984; Carder et al., 1977) reported that compacted sand has a higher $K_{0}$ value when the following two conditions are met: (1) the sand is compacted under a higher overburden stress, as higher confinement prevents the rebound of soil and (2) the sand is densified under a laterally constrained condition (as in the case of soil behind a rigid retaining wall). However, the reinforced soil near the top of an MSE wall is compacted under relatively low overburden stresses and does not have significant lateral constraints. Therefore, we cannot expect a significant increase in $\mathrm{K}_{0}$ due to compaction of the reinforced soil of an MSE wall. Moreover, the measured field data for the maximum tensile forces prove that there is not a significant effect of compaction on $\mathrm{K}_{0}$ for MSE walls.

\subsubsection{2. $\mathrm{K}_{\mathrm{A}}$ estimation}

The critical-state friction angle $\phi_{\mathrm{c}}$ is used in Eq. (6.2) to estimate the coefficient $\mathrm{K}_{\mathrm{A}}$ of active earth pressure. The reason for using $\phi_{\mathrm{c}}$ to estimate $\mathrm{K}_{\mathrm{A}}$ was explained earlier. In general, the values of $\phi_{\mathrm{c}}$ of backfill material for the reinforced soil are not reported in the literature. Therefore, a range of $\phi_{c}$ values $\left(30^{\circ}-36^{\circ}\right)$ is considered. By comparing the field measurements for the $T_{\max }$ of the steel-strip reinforcements reported in Allen et al. (2001) with the corresponding predicted $\mathrm{T}_{\max }$ values varying $\phi_{\mathrm{c}}\left(30^{\circ}-36^{\circ}\right)$, regression analysis is conducted by fixing $\mathrm{z}_{\mathrm{cr}}=6 \mathrm{~m}$ to find the best value of $\phi_{\mathrm{c}}$ which will induce the least uncertainty in predicting $\mathrm{K}_{\mathrm{r}}$. From the results of regression analysis, the best value $\phi_{\mathrm{c}}$ in this respect was found to be $33^{\circ}$, resulting in a value of $\mathrm{K}_{\mathrm{A}}$ equal to 0.295 . 
7.5.4.2.3. Distribution of $\mathrm{K}_{\mathrm{r}}$ with depth from the top of MSE walls

The modifications we make here to the original "coherent gravity method" are: (1) the value of $\mathrm{K}_{0}$ at the top of MSE is assumed to be 0.4 instead of the value given by Eq. (7.10) with $\phi=\phi_{\mathrm{p}}$ and (2) $\phi_{\mathrm{c}}\left(\phi_{\mathrm{c}}=33^{\circ}\right)$ instead of $\phi_{\mathrm{p}}$ is used in estimating the value of $\mathrm{K}_{\mathrm{A}}$.

Figure 7.10 shows the distribution of the coefficient of lateral earth pressure $\mathrm{K}_{\mathrm{r}}$ with depth $\mathrm{z}$ from the top of the steel-strip MSE wall. The corresponding equation is:

$$
K_{r}= \begin{cases}0.4-0.0175 z & \text { for } 0 \leq z<6 m \\ 0.295 & \text { for } z \geq 6 \mathrm{~m}\end{cases}
$$

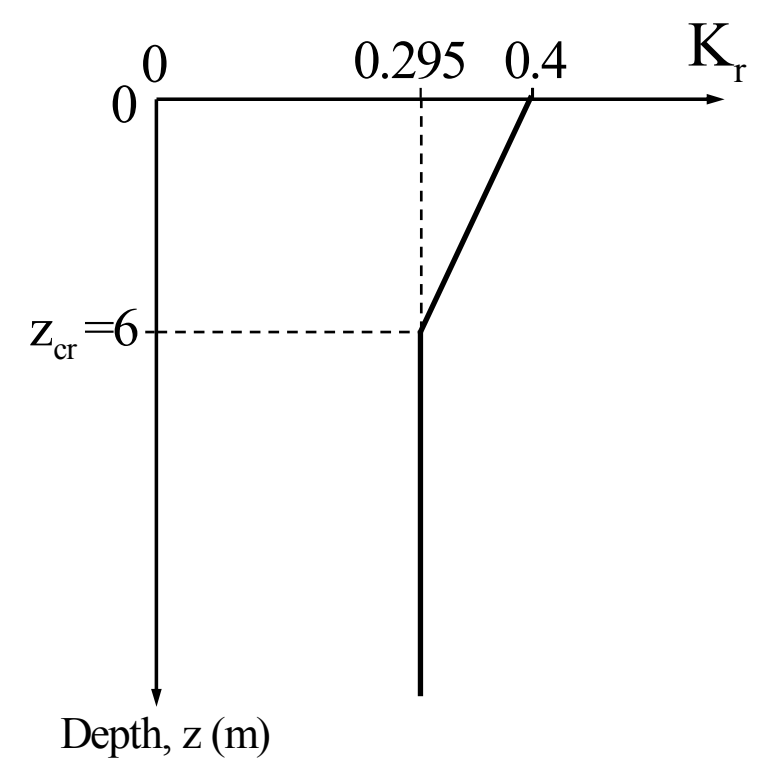

Figure 7.10 Distribution of $K_{r}$ with depth $z$ from the top of an MSE wall using the modified coherent gravity method 
7.5.4.2.4. Bias factor and $\mathrm{COV}$ of $\mathrm{K}_{\mathrm{r}}$ following the modified coherent gravity method

In the full-scale field tests, the maximum strain is measured along the steel-strip reinforcement. After that, the maximum tensile force acting on the steel-strip reinforcement $T_{\max }$ is calculated by multiplying the corresponding strains by the elastic modulus of deformation $\mathrm{E}_{\mathrm{r}}$ of the reinforcement. This method works well because the steel-strip reinforcement can be considered as an elastic material within the small strain range.

Figure 7.11 shows the relationship between the measured and predicted maximum tensile force $T_{\max , p r e d}$. values acting on steel-strip reinforcements. The measured and predicted $\mathrm{T}_{\max }$ are located in the $\mathrm{x}$ and $\mathrm{y}$ axis, respectively. The prediction of the $\mathrm{T}_{\max }$ was calculated using Eq. (7.11). The data for the measured maximum tensile force $T_{\text {max,meas. }}$ were collected from 76 measurements obtained from full-scale tests on thirteen MSE walls reinforced using steel-strip reinforcements. Two measurements of $T_{\max }$ near the bottom of an MSE wall were eliminated in this analysis because, even though the difference between the measured values and the corresponding predicted values are small, the high ratios of the measured data to the corresponding predicted values result in higher bias factors. Figure 7.11 shows that Eq. (7.1) overestimates $T_{\max }$ in the steel-strip reinforcement because most of the points are on the left side of the dashed line $\left(\mathrm{T}_{\text {max }, \text { pred. }}=\mathrm{T}_{\text {max }, \text { meas. }}\right)$. 


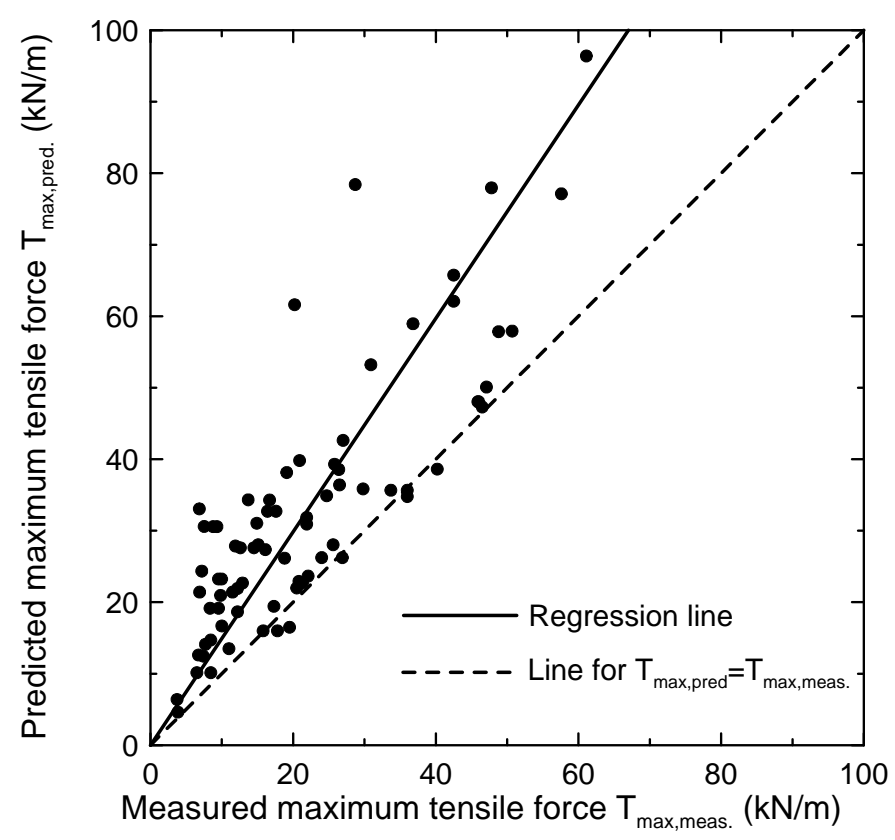

Figure 7.11 Relationship between the measured and predicted maximum tensile forces based on the modified coherent gravity method

The ratio of the measured to the predicted maximum tensile force $\mathrm{T}_{\text {max,meas. }} / \mathrm{T}_{\text {max,pred. }}$ is plotted with respect to depth $\mathrm{z}$ from the top of the MSE wall (Figure 7.12). There is no discernible depth bias to the data but the variability of the prediction seems greater at shallower depths (we will ignore that in our analysis). The bias factor for the prediction of the maximum tensile force at each reinforcement level is 0.666 and the $\mathrm{COV}$ is 0.347 . Therefore, the expected value of the $\mathrm{T}_{\max }$ acting on the steel-strip reinforcement is about two thirds of $\mathrm{K}_{\mathrm{r}}$ calculated from Eq. (7.11). 


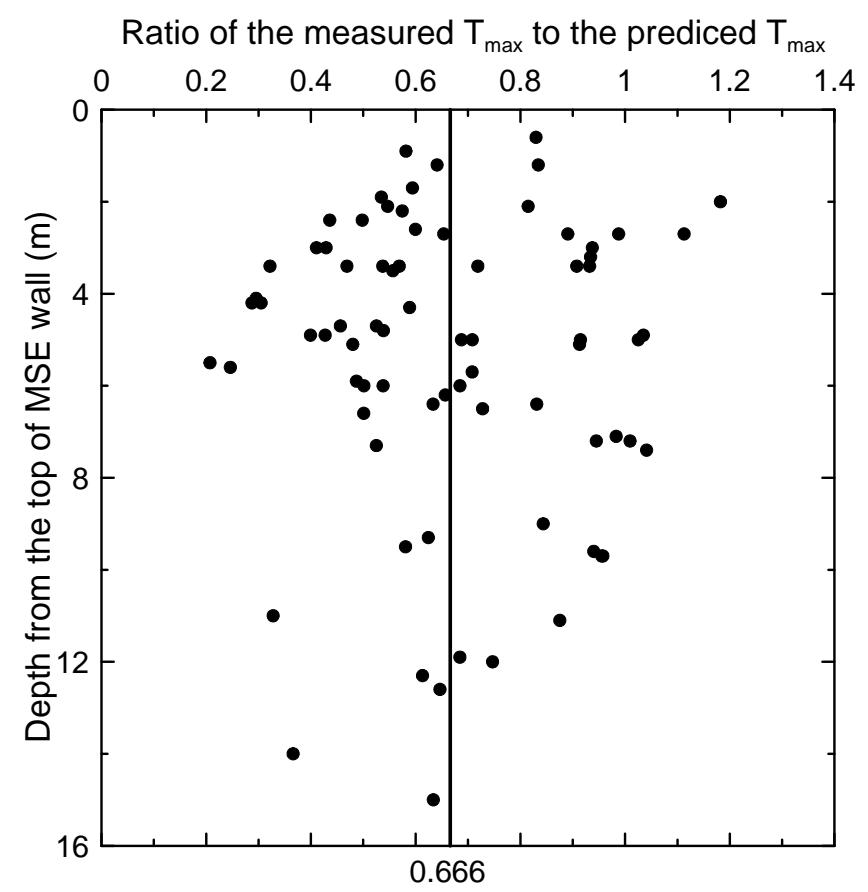

Figure 7.12 Ratio of measured to predicted $\mathrm{T}_{\max }$ with depth from the top of MSE walls (average value $=0.666$ )

$$
\mathrm{K}_{\mathrm{r}, \text { with bias correction }}= \begin{cases}0.666 \times(0.4-0.0175 \mathrm{z})=0.266-0.012 \mathrm{z} & \text { for } 0 \leq \mathrm{z}<6 \mathrm{~m} \\ 0.666 \times 0.295=0.196 & \text { for } \mathrm{z} \geq 6 \mathrm{~m}\end{cases}
$$

The values of the maximum tensile forces predicted using Eq. (7.12) are compared with the measured values in Figure 7.13. The figure shows that the estimation of $\mathrm{T}_{\max }$ is better when the bias factor of 0.666 is applied to the values predicted using Eq. (7.11). Figure 7.14 illustrates that the residuals in the predictions with bias correction follow an almost normal distribution. This agreement provides some assurance that we can be concluded that the present study can successfully predict the coefficient of lateral earth pressure $K_{r}$ with Eq. (7.12). 


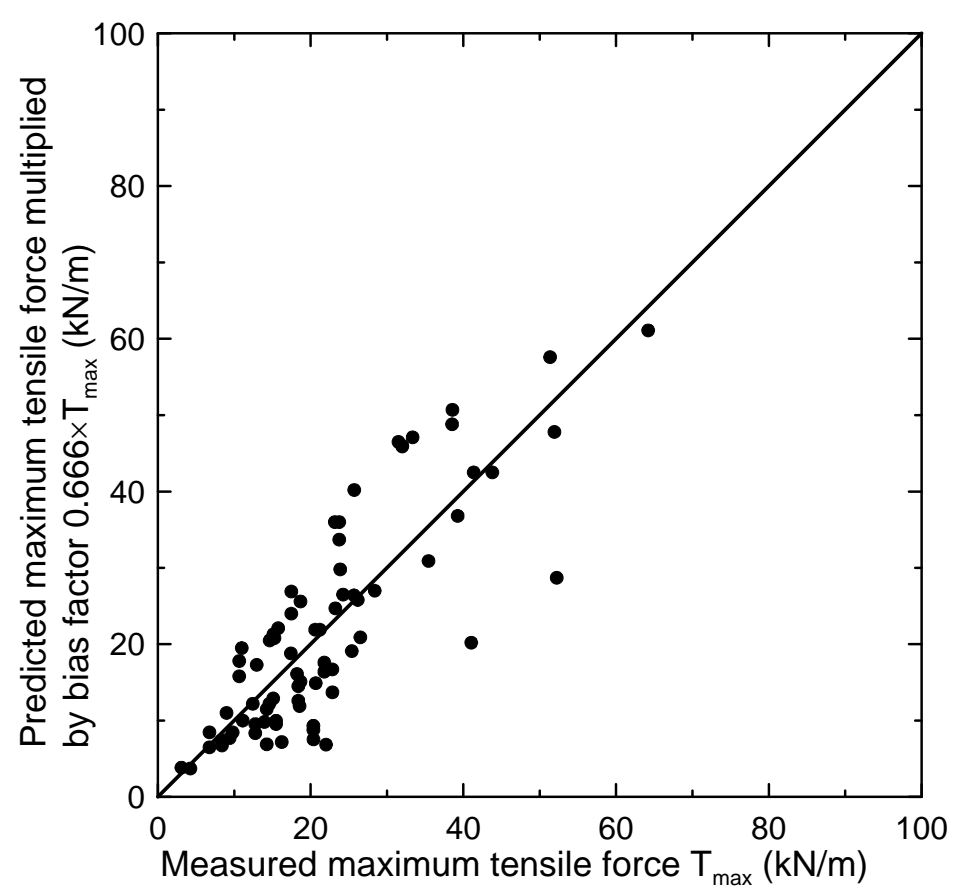

Figure 7.13 Relationship between predicted $\mathrm{T}_{\max }$ multiplied by bias factor and measured $\mathrm{T}_{\max }$ based on the modified coherent gravity method

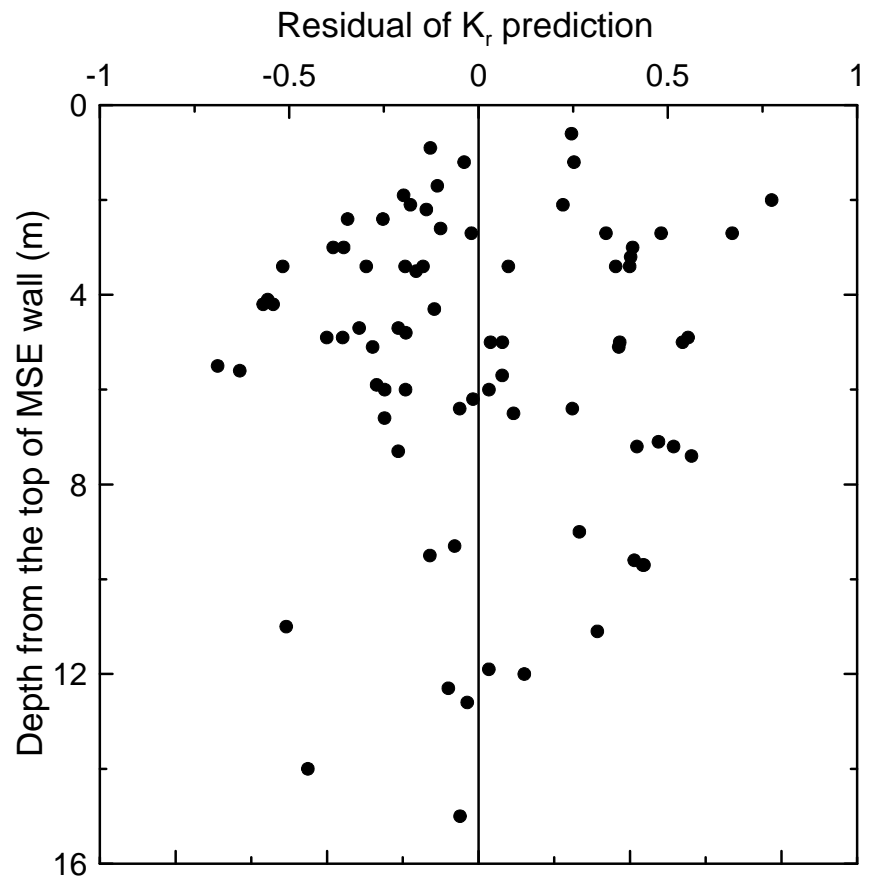

Figure 7.14 Residuals of $\mathrm{K}_{\mathrm{r}}$ estimation with depth from the top of MSE walls 
Previously, we assumed that an active condition prevails below a depth of $6 \mathrm{~m}$ from the top of an MSE wall $\left(\mathrm{K}_{\mathrm{r}}=\mathrm{K}_{\mathrm{A}}\right.$ when depth $\left.\mathrm{z} \geq 6 \mathrm{~m}\right)$. From regression analysis, varying $\phi_{c}$ within the range of $30^{\circ}-36^{\circ}$, the active earth pressure coefficient $\mathrm{K}_{\mathrm{A}}$ offered the best estimation of $\mathrm{K}_{\mathrm{r}}$ when estimated using $\phi_{\mathrm{c}}$ equal to $33^{\circ}$ (section 7.5.4.2.2). The regression was performed for a fixed value $(6 \mathrm{~m})$ of $\mathrm{z}_{\mathrm{cr}}$, below which an active condition prevails. Nevertheless, it is interesting to explore the uncertainties associated with both $\mathrm{z}_{\mathrm{cr}}$ and $\phi_{\mathrm{c}}$ by performing a multivariate regression analysis. The result of the multivariate regression revealed that the combination of $\phi_{\mathrm{c}}=35.7^{\circ}$ and $\mathrm{z}_{\mathrm{cr}}=4.2 \mathrm{~m}$ leads to the least value of COV for the prediction of the coefficient of lateral earth pressure $\mathrm{K}_{\mathrm{r}}$ (Figure 7.16). The equations that estimate the values of $\mathrm{K}_{\mathrm{r}}$ without a bias factor and with a bias factor are

$$
\begin{gathered}
\mathrm{K}_{\mathrm{r}}= \begin{cases}0.4-0.0326 \mathrm{z} & \text { for } 0 \leq \mathrm{z}<4.2 \mathrm{~m} \\
0.263 & \text { for } \mathrm{z} \geq 4.2 \mathrm{~m}\end{cases} \\
\mathrm{K}_{\mathrm{r}, \text { with bias correction }}= \begin{cases}0.758 \times(0.4-0.0175 \mathrm{z})=0.303-0.013 \mathrm{z} & \text { for } 0 \leq \mathrm{z}<6 \mathrm{~m} \\
0.758 \times 0.263=0.199 & \text { for } \mathrm{z} \geq 6 \mathrm{~m}\end{cases}
\end{gathered}
$$

Although $\mathrm{z}_{\mathrm{cr}}=4.2 \mathrm{~m}$ and $\phi_{\mathrm{c}}=35.7^{\circ}$ would appear to produce a better method to $\mathrm{K}_{\mathrm{r}}$ data, the full predictions of $\mathrm{K}_{\mathrm{A}}$, with bias correction, have COV values that are practically the same. Therefore, it is acceptable to use $\mathrm{z}_{\mathrm{cr}}=6 \mathrm{~m}$ and $\phi_{\mathrm{c}}=33^{\circ}$ as done to develop Eq. (7.12) to estimate the coefficient of lateral earth pressure $\mathrm{K}_{\mathrm{r}}$. 
Lateral earth pressure coefficient $\mathrm{K}_{\mathrm{r}}$

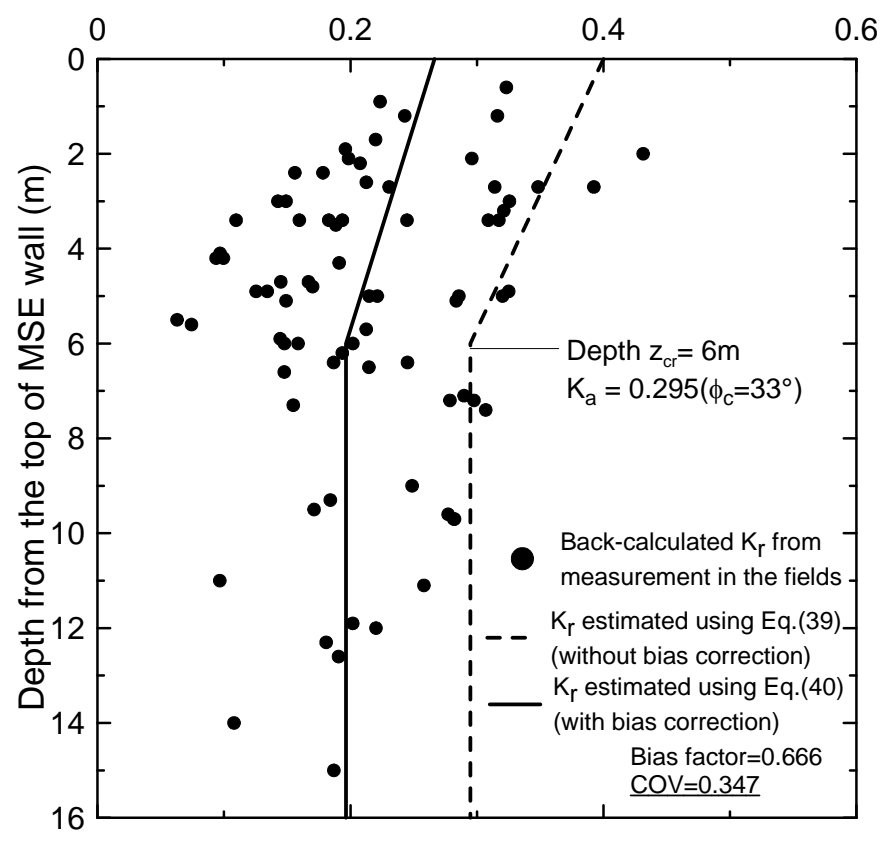

Figure 7.15 Result of the regression analysis of $\mathrm{K}_{\mathrm{r}}$ on $\mathrm{z}$ with $\mathrm{z}_{\mathrm{cr}}=6 \mathrm{~m}$ and $\phi_{\mathrm{c}}=33^{\circ}$

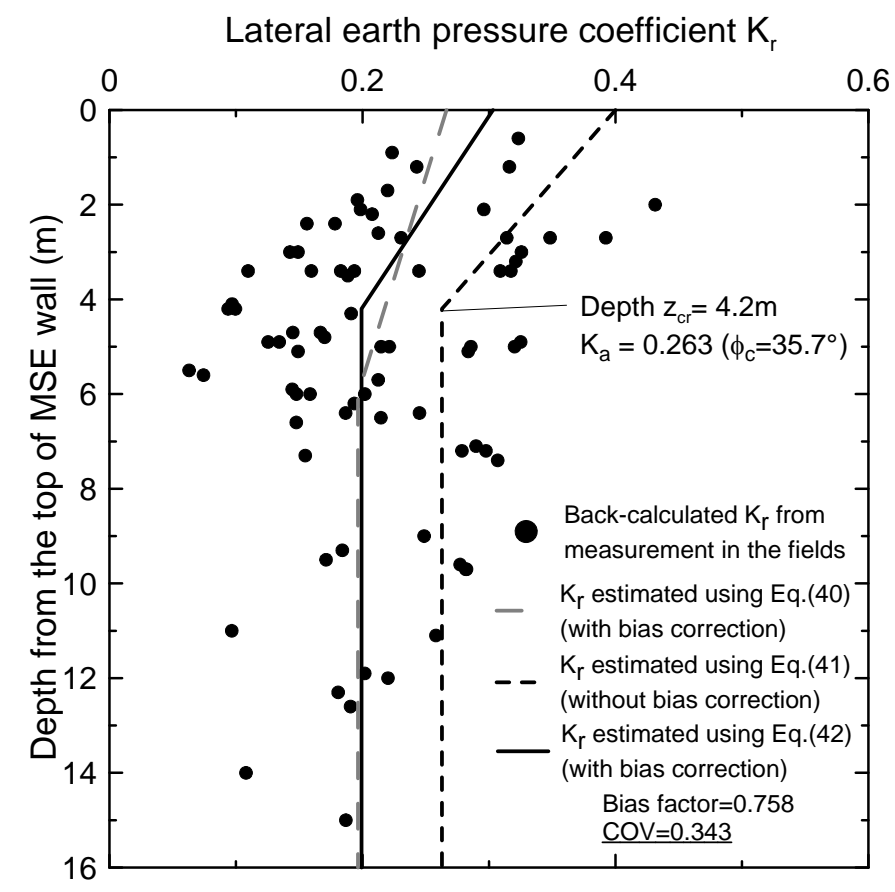

Figure 7.16 Result of the regression analysis of $\mathrm{K}_{\mathrm{r}}$ on $\mathrm{z}_{\mathrm{cr}}=4.2 \mathrm{~m}, \phi_{\mathrm{c}}=35.7^{\circ}$ and $\mathrm{z}$ 


\subsubsection{Uncertainty of pullout resistance factor $C_{R}$}

There are three popular methods to assess the coefficient of friction $C_{R}$ : (1) direct shear test between the reinforcement material and the soil, (2) pullout test using specially designed equipment in the laboratory, and (3) pullout test from a full-scale MSE wall or scaled model.

The $\mathrm{C}_{\mathrm{R}}$ suggested by AASHTO (2007) and FHWA (2001) is:

$$
\mathrm{C}_{\mathrm{R}}=\left\{\begin{array}{l}
\min \left[\mathrm{z}\left(\frac{\tan \phi_{\mathrm{p}}-1.8}{6}\right)+1.8,2.0\right] \text { for } 0 \leq \mathrm{z}<6 \mathrm{~m} \\
\tan \phi_{\mathrm{p}} \quad \text { for } \mathrm{z} \geq 6 \mathrm{~m}
\end{array}\right.
$$

The solid line in Figure 7.17 represents the $C_{R}$ predicted by Eq. (7.15) assuming that $\phi_{\mathrm{p}}$ is $32^{\circ}$. The data points in Figure 7.17 are $C_{R}$ values from pullout tests for steelstrip reinforcements installed in backfill materials ranging from silty sands to coarse gravels. The $C_{R}$ value predicted by Eq. (7.15) is very conservative because Eq. (7.15) was chosen so as to be close to the lower bound for the pullout test data shown in Figure 7.17. So there is a high bias factor in $\mathrm{C}_{\mathrm{R}}$ calculated using Eq. (7.15). 


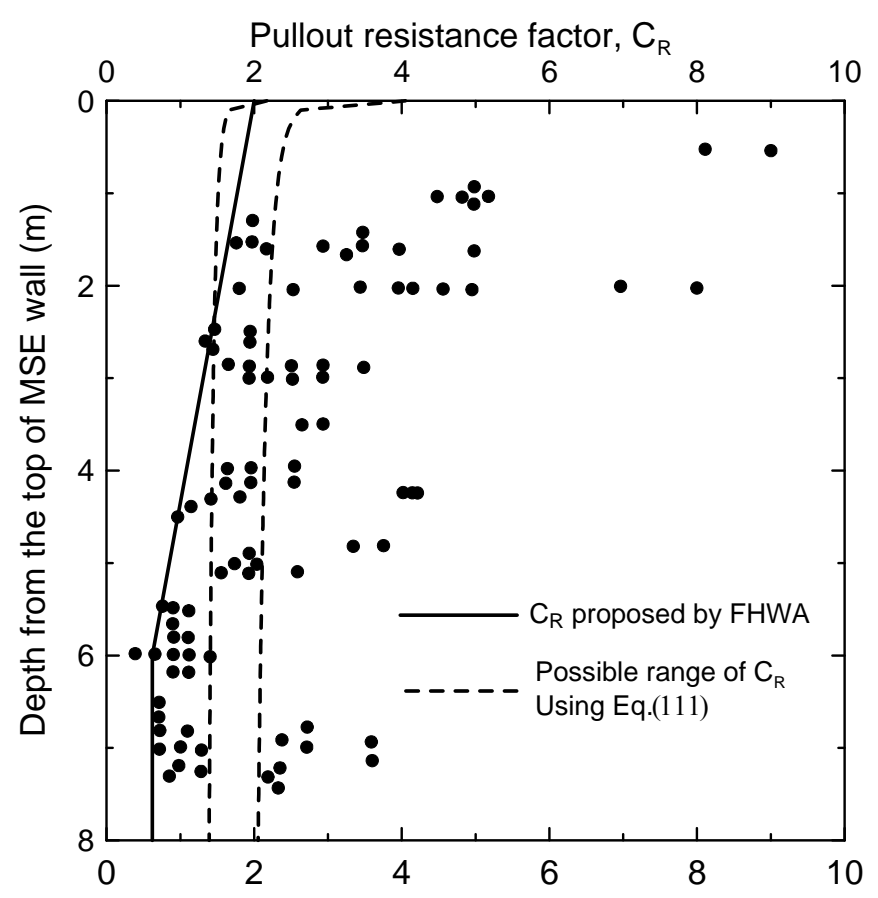

Figure 7.17 Comparison between $\mathrm{C}_{\mathrm{R}}$ suggested by AASHTO and FHWA specifications and $C_{R}$ data point from pullout tests (Data points from Commentary of the 1994

AASHTO Standard Specifications for Highway Bridges)

In our study, we developed a different approach for estimating $C_{R}$. Many researchers have studied the interface friction angle between steels and soils. The interface friction angle was examined with different levels of roughness of steel, confining stress, and relative density. Since the steel-strip reinforcement provided by the Reinforced Earth Company is ribbed, it is acceptable to conclude the reinforcement is relatively rough. Using the data from the literature written by Lings and Dietz (2005), the interface friction angle was estimated considering the effect of the relative density and confining stress (the data are given in Appendix E). The direct shear apparatus with a sample that has the reinforcing material (steel) on one side below or above the shear plane and soil on the other side was used to measure the interface friction angles. The best equation for the prediction of the interface friction angle is 


$$
\delta_{p}=\left\{\left[\frac{D_{R}}{100} \cdot\left(13.1-1.59 \cdot \ln \left(\frac{\sigma_{v}^{\prime}}{P_{A}}\right)\right)+1.15\right]+\delta_{c v}\right\}
$$

where $\mathrm{p}_{\mathrm{A}}$ is the reference pressure, which is $100 \mathrm{kPa}$, and $\delta_{\mathrm{cv}}$ is the critical-state interface friction angle.

The bias factor and the COV of the model (Eq. (7.16)) were 1.00 and 0.07 , respectively. Thus, the pullout resistance factor $C_{R}$ is

$$
C_{R}=\tan \delta_{p}
$$

The possible range for the mean value of $C_{R}$ calculated using Eq. (7.17) varying the parameters in Eq. (7.16) within the following ranges: (1) $D_{R, r f}=70-100 \%$, (2) $\gamma_{d, r f}=$ $17-20 \mathrm{kN} / \mathrm{m}^{3}$, and (3) $\delta_{\mathrm{cv}}=25-32^{\circ}$ is drawn with dashed lines in Figure 7.17. The measured data points of $C_{R}$ are widely scattered. Our predictions of the expected values of $\mathrm{C}_{\mathrm{R}}$ fall within the scattered data.

\subsubsection{Uncertainty of yield strength of steel-strip reinforcement}

The uncertainty of the yield strength of the steel-strip reinforcement was assessed using 90 test results provided by the Reinforced Earth Company. Steel-strip reinforcements were made of Grade 65 steel, and from ASTM A-572, Grade 65 steel should have a yield strength higher than $450 \mathrm{MPa}$. Out of 90 data points, the minimum and maximum yield strength were $453 \mathrm{MPa}$ and $584 \mathrm{MPa}$, and the average was $491 \mathrm{MPa}$, as shown in Figure 7.18 . 


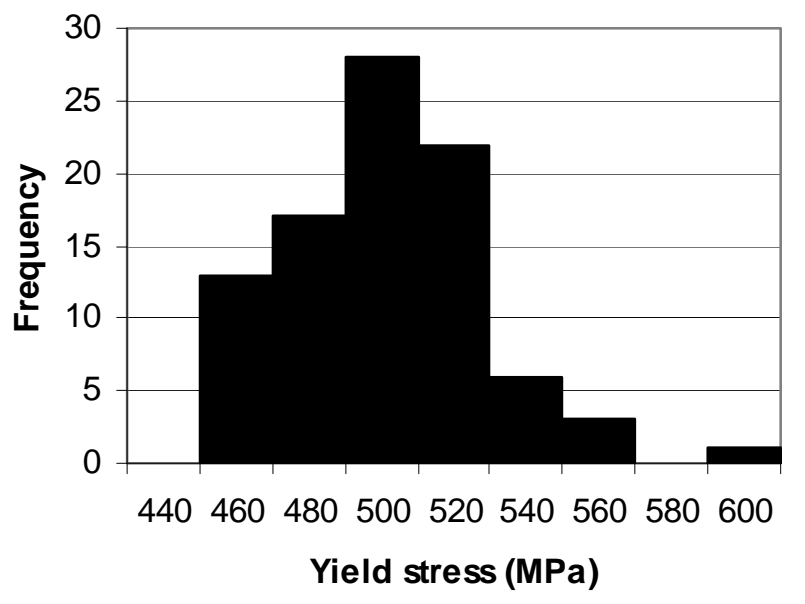

Figure 7.18 Distribution of yield strength of steel-strip reinforcements (data acquired from the Reinforced Earth Company)

Assuming that the nominal yield strength of the steel-strip reinforcement is 450 $\mathrm{MPa}$, the bias factor was 1.09 and the $\mathrm{COV}$ was 0.05 .

$$
\mathrm{f}_{\mathrm{y}}=450 \mathrm{MPa}
$$

\subsection{Examples}

A series of reliability analyses using First-Order Reliability Method (FORM) were performed accounting for the bias factors and COVs of the parameters $\gamma_{r f}, q_{0, r f}, f_{y}, D_{R, r f}$, $\delta_{\mathrm{cv}}, \mathrm{K}_{\mathrm{r}}$, and $\delta_{\mathrm{p}}$ related to the ULS equations for pullout and structural failure of steel-strip reinforcement.

The ULS equation (Eq. (7.4)) for the steel-strip pullout basically compares the maximum tensile force acting on the reinforcement $T_{\max }$ with the maximum pullout resistance $\mathrm{R}_{\mathrm{PO}}$. For a given target reliability index, the RF value is calculated by finding the effective length of the reinforcement that produces the target reliability index. Similarly to the pullout case, the ULS equation (Eq. (7.6)) for the steel-strip structural 
failure compares $T_{\max }$ to the yield force $T_{y}$ of the reinforcement. The RF value is obtained by searching for the reinforcement depth that produces the given target reliability index.

Seven different MSE wall heights $(\mathrm{H}=5,7.5,10,12.5,15,17.5,20 \mathrm{~m})$ and four different target reliability indices $\left(\beta_{\mathrm{T}}=2.0,2.5,3.0\right.$, and 3.5) were considered. The two nominal live uniform surcharge loads $\mathrm{q}_{0}$ are used depending on MSE wall height: (1) $14 \mathrm{kN} / \mathrm{m}$ for $5 \mathrm{~m}$-high MSE walls and (2) $12 \mathrm{kN} / \mathrm{m}$ for MSE walls more than $6 \mathrm{~m}$-tall. In addition, we assume that the pavement has a thickness of $0.3 \mathrm{~m}$.

Within the maximum ranges of horizontal and vertical spacing (FHWA, 2001), the combinations of two different horizontal spacings $\mathrm{s}_{\mathrm{h}}\left(\mathrm{s}_{\mathrm{h}}=0.375\right.$ and $\left.0.75 \mathrm{~m}\right)$ and three different vertical spacings $\mathrm{s}_{\mathrm{v}}\left(\mathrm{s}_{\mathrm{v}}=0.3,0.6\right.$, and $\left.0.8 \mathrm{~m}\right)$ of steel-strip reinforcement are considered for pullout of the reinforcement, while the combinations of two different horizontal spacings $\left(\mathrm{s}_{\mathrm{h}}=0.75\right.$ and $\left.0.375 \mathrm{~m}\right)$ and six different vertical spacings $\left(\mathrm{s}_{\mathrm{v}}=0.3,0.4\right.$, $0.5,0.6,0.7$ and $0.8 \mathrm{~m}$ ) are considered for structural failure of steel-strip reinforcement.

\subsubsection{Pullout of steel-strip reinforcement}

The same procedure used for external stability criteria is applied to the RF value computation for the steel-strip reinforcement pullout. The means of the parameters are the values given in the second column in Table 7.6. The table represents the results of the reliability analysis conducted for the following case: $\mathrm{s}_{\mathrm{v}}=0.6 \mathrm{~m}, \mathrm{~s}_{\mathrm{h}}=0.75 \mathrm{~m}, \mathrm{H}=20 \mathrm{~m}, \beta_{\mathrm{T}}=3.0$, the nominal $\mathrm{q}_{0}=12 \mathrm{kN} / \mathrm{m}$, and the reinforcement depth $\mathrm{z}=0.60 \mathrm{~m}$. The effective length $\mathrm{L}_{\mathrm{e}}$ for $\beta_{\mathrm{T}}=3.0$ is calculated to be $6.87 \mathrm{~m}$. 
Table 7.6 Result of reliability analysis for pullout of steel-strip reinforcement (when $\mathrm{s}_{\mathrm{v}}=0.6 \mathrm{~m}, \mathrm{~s}_{\mathrm{h}}=0.75 \mathrm{~m}, \mathrm{z}=0.60 \mathrm{~m}, \mathrm{H}=20 \mathrm{~m}, \beta_{\mathrm{T}}=3.0$, and the nominal $\left.\mathrm{q}_{0}=12 \mathrm{kN} / \mathrm{m}\right)$

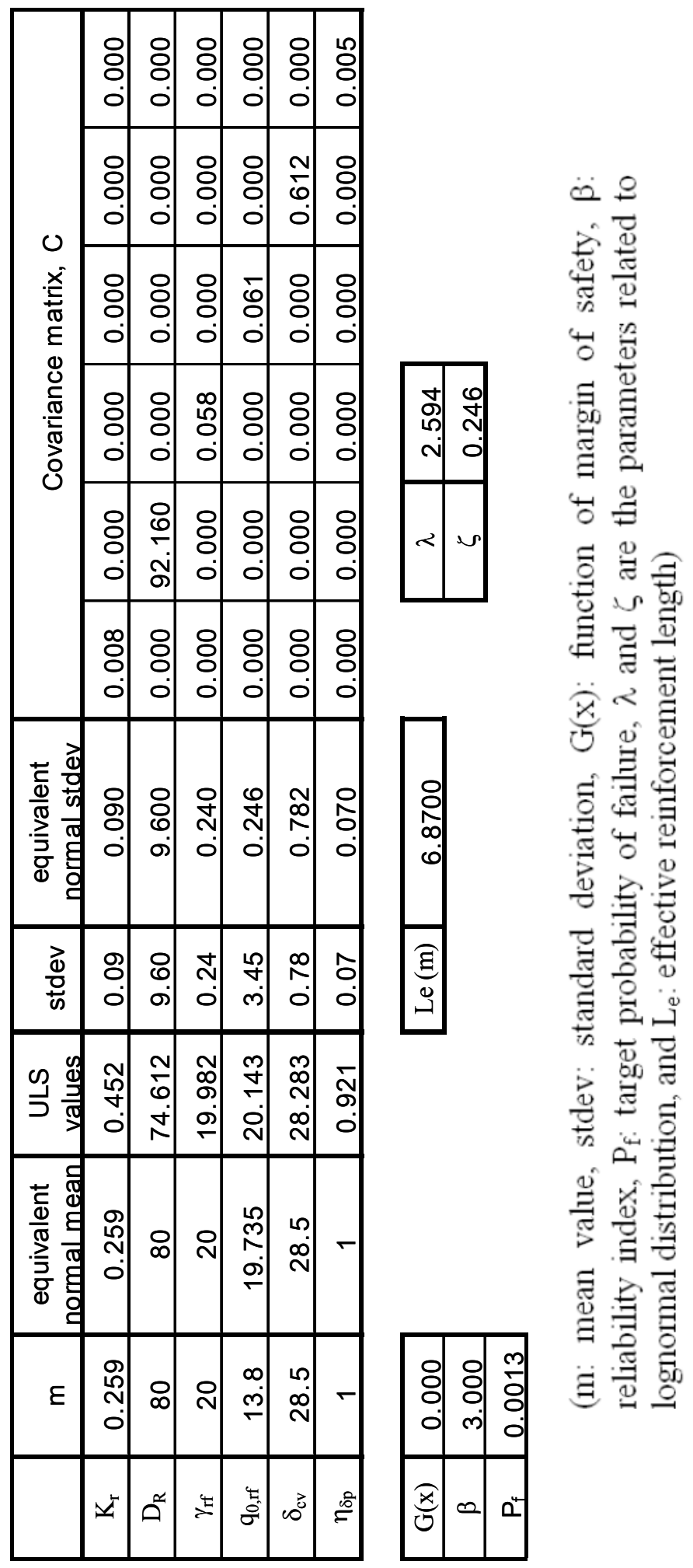


The ULS values of $T_{\max }$ values due to the dead and live loads, and the resistance against the pullout of the reinforcement are listed in Table 7.7. The total $\mathrm{T}_{\max }$ is equal the resistance against the pullout $(3.252 \mathrm{kN} / \mathrm{m}+5.464 \mathrm{kN} / \mathrm{m}=8.716 \mathrm{kN} / \mathrm{m})$.

Table 7.7 ULS values of loads and resistance for pullout of steel-strip reinforcement

\begin{tabular}{lll}
\hline$T_{\max }$ due to the dead load & 3.252 & $\mathrm{kN} / \mathrm{m}$ \\
\hline$T_{\max }$ due to the live surcharge & 5.464 & $\mathrm{kN} / \mathrm{m}$ \\
\hline Total resistance against pullout of reinf. & 8.716 & $\mathrm{kN} / \mathrm{m}$ \\
\hline
\end{tabular}

The nominal values of $\mathrm{T}_{\max }$ due to the dead and live loads and the resistance against pullout of the reinforcement are shown in Table 7.8. These nominal values were computed using the nominal values of the parameters. Factor of safety for this particular case is 2.73 .

Table 7.8 Nominal values of loads and resistance and FS value for pullout of steel-strip reinforcement

\begin{tabular}{lcc}
\hline$T_{\max }$ due to the dead load & 1.868 & $\mathrm{kN} / \mathrm{m}$ \\
\hline$T_{\max }$ due to the live surcharge & 1.868 & $\mathrm{kN} / \mathrm{m}$ \\
\hline Total resistance against pullout of reinf. & 10.188 & $\mathrm{kN} / \mathrm{m}$ \\
\hline $\mathrm{FS}=$ & 2.73 & \\
\hline
\end{tabular}

The optimum load and resistance factors are calculated using Eq. (2.5) and Eq. (2.6). In addition, the RF value for pullout of steel-strip reinforcement is computed using Eq. (2.11) with these optimum factors and the AASHTO LFs [(LF) $)_{\mathrm{DL}}=1.5$ and $\left.(\mathrm{LF})_{\mathrm{LL}}=1.75\right]$. 
Table 7.9 Calculation of optimum factors and RF using AASHTO LFs for pullout of steel-strip reinforcement

\begin{tabular}{rlrlrl}
\hline$(\mathrm{LF})_{\mathrm{LL}}{ }^{*}=$ & 1.74 & $(\mathrm{LF})_{\mathrm{DL}}=$ & 1.5 & $(\mathrm{LF})_{\mathrm{DL}}{ }^{*} /(\mathrm{LF})_{\mathrm{DL}}=$ & 1.16 \\
\hline$(\mathrm{LF})_{L}{ }^{*}=$ & 2.93 & $(\mathrm{LF})_{\mathrm{LL}}=$ & 1.75 & $(\mathrm{LF})_{\amalg L} /(\mathrm{LF})_{L L}=$ & 1.67 \\
\hline $\mathrm{RF}^{*}=$ & 0.86 & & & $\mathrm{RF}=$ & 0.51 \\
\hline
\end{tabular}

$\left[(\mathrm{LF})_{\mathrm{DL}}{ }^{*}\right.$ and $(\mathrm{LF})_{\mathrm{LL}}{ }^{*}$ are the optimum load factors for dead and live load, $\mathrm{RF}^{*}$ is the optimum resistance factor, $(\mathrm{LF})_{\mathrm{DL}}$ and $(\mathrm{LF})_{\mathrm{LL}}$ are the AASHTO load factors, and RF is the resistance factor]

From Figure 7.19 through Figure 7.24, the RF values for pullout of steel-strip reinforcement are calculated for different reinforcement levels and different target reliability index values. RF value increases with increasing reinforcement depth $\mathrm{z}$ from the top of the MSE wall.

Regardless of MSE wall height, the minimum RF value is determined at the first reinforcement layer from the top of the MSE wall. Given that there is $0.3 \mathrm{~m}$ barrier to the pavement grade, the depths of the first reinforcement layers from the top of MSE wall were $0.45,0.6$, and 0.7 for the MSE walls for which vertical spacing is $0.3,0.6$, and $0.8 \mathrm{~m}$, respectively.

The RF value is independent of the vertical or horizontal spacing $\left(s_{v}\right.$ or $\left.s_{h}\right)$ of reinforcement (or the tributary area of the reinforcement) if the reinforcement depth $\mathrm{z}$ is the same because, from Eq. (7.4), the ratio of the effective length $L_{e}$ to the tributary area $\left(\mathrm{s}_{\mathrm{v}} \times \mathrm{s}_{\mathrm{h}}\right)$ was constant $\left(\mathrm{L}_{\mathrm{e}}\right.$ changes in proportion to the change of the tributary area). In other words, for a given reinforcement depth $\mathrm{z}$, if the tributary area increases $\mathrm{n}$ times larger than the initial tributary area, $\mathrm{L}_{\mathrm{e}}$ also changes $\mathrm{n}$ times larger than the initial $\mathrm{L}_{\mathrm{e}}$ without changing the value of reliability index as well as RF. We could observe this from the results of our analysis (compare Figure 7.19 with Figure 7.20, Figure 7.21 with Figure 7.22, and Figure 7.23 with Figure 7.24, respectively). 


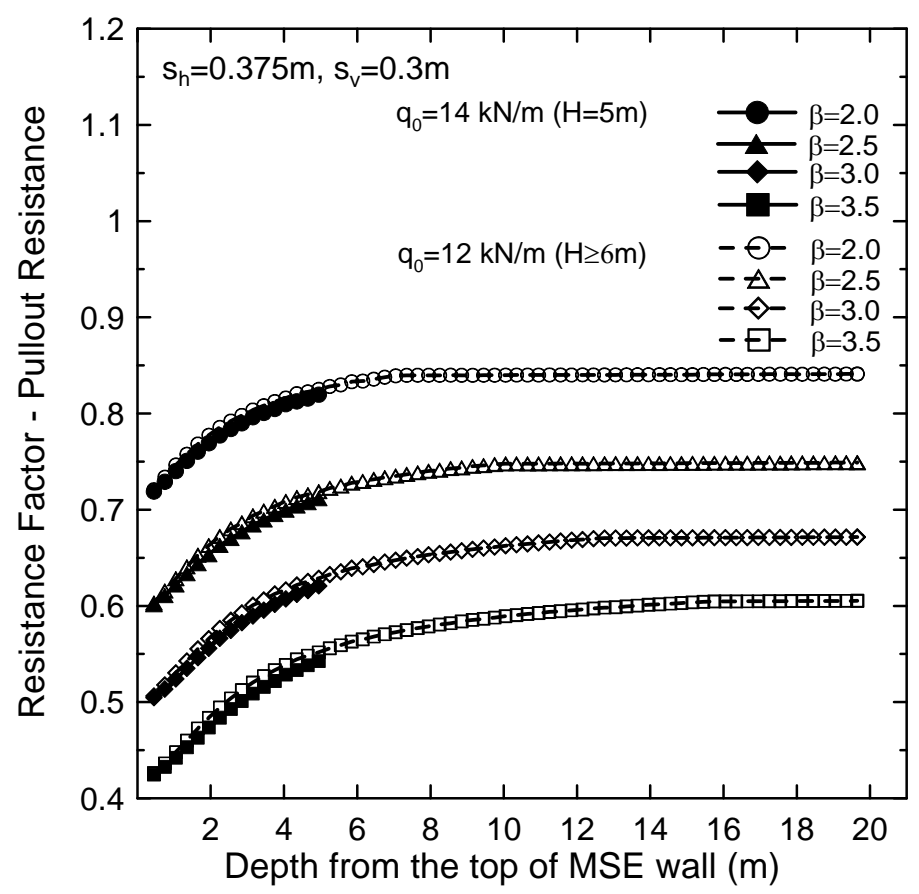

Figure 7.19 RF for pullout of steel-strip reinforcement versus reinforcement depth $\mathrm{z}$ when $\mathrm{s}_{\mathrm{h}}=0.375 \mathrm{~m}$ and $\mathrm{s}_{\mathrm{v}}=0.3 \mathrm{~m}$

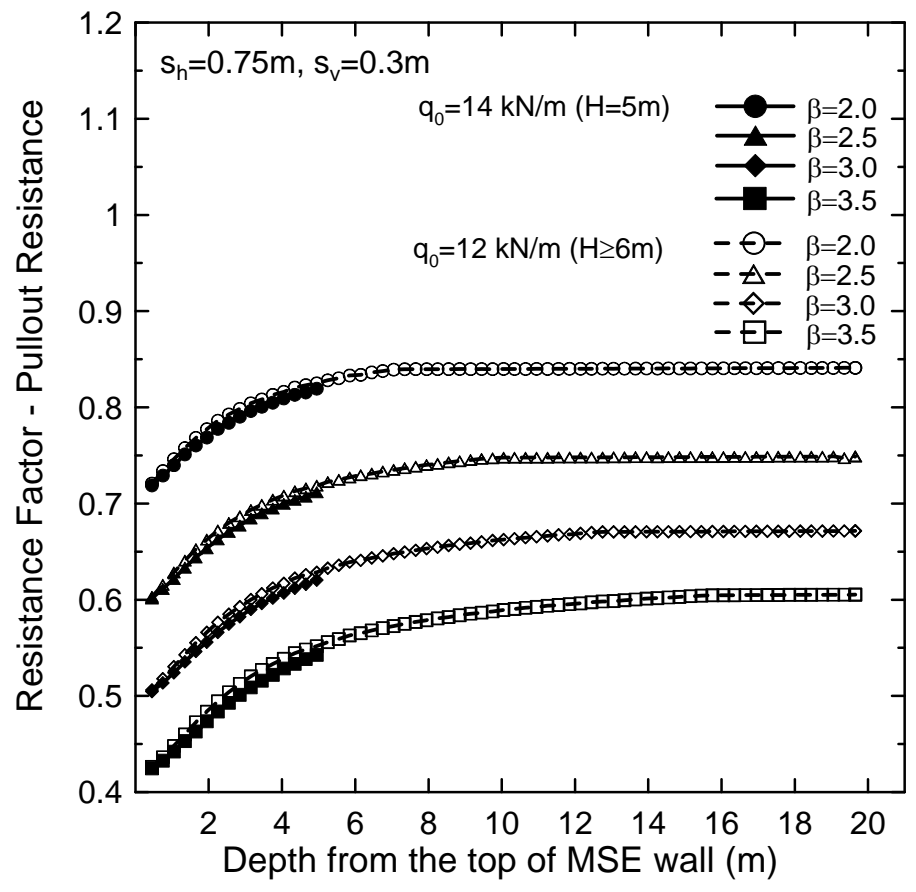

Figure 7.20 RF for pullout of steel-strip reinforcement versus reinforcement depth $\mathrm{z}$ when $\mathrm{s}_{\mathrm{h}}=0.75 \mathrm{~m}$ and $\mathrm{s}_{\mathrm{v}}=0.3 \mathrm{~m}$ 


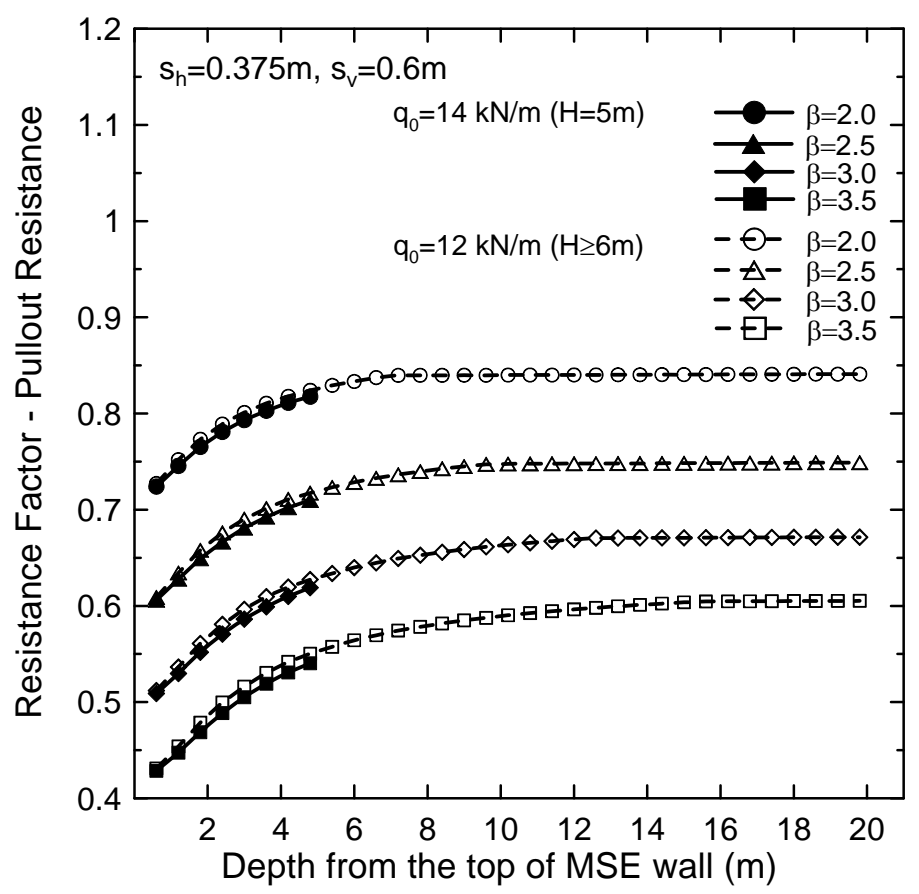

Figure 7.21 RF for pullout of steel-strip reinforcement versus reinforcement depth $\mathrm{z}$ when $\mathrm{s}_{\mathrm{h}}=0.375 \mathrm{~m}$ and $\mathrm{s}_{\mathrm{v}}=0.6 \mathrm{~m}$

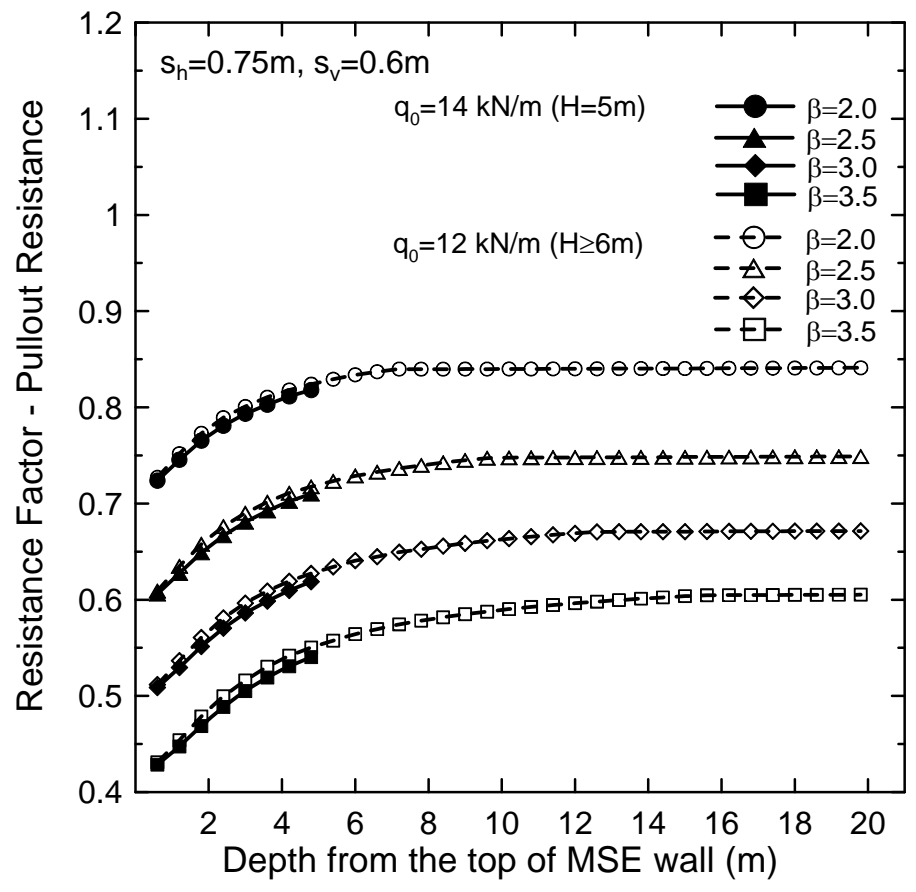

Figure 7.22 RF for pullout of steel-strip reinforcement versus reinforcement depth $\mathrm{z}$ when $\mathrm{s}_{\mathrm{h}}=0.75 \mathrm{~m}$ and $\mathrm{s}_{\mathrm{v}}=0.6 \mathrm{~m}$ 


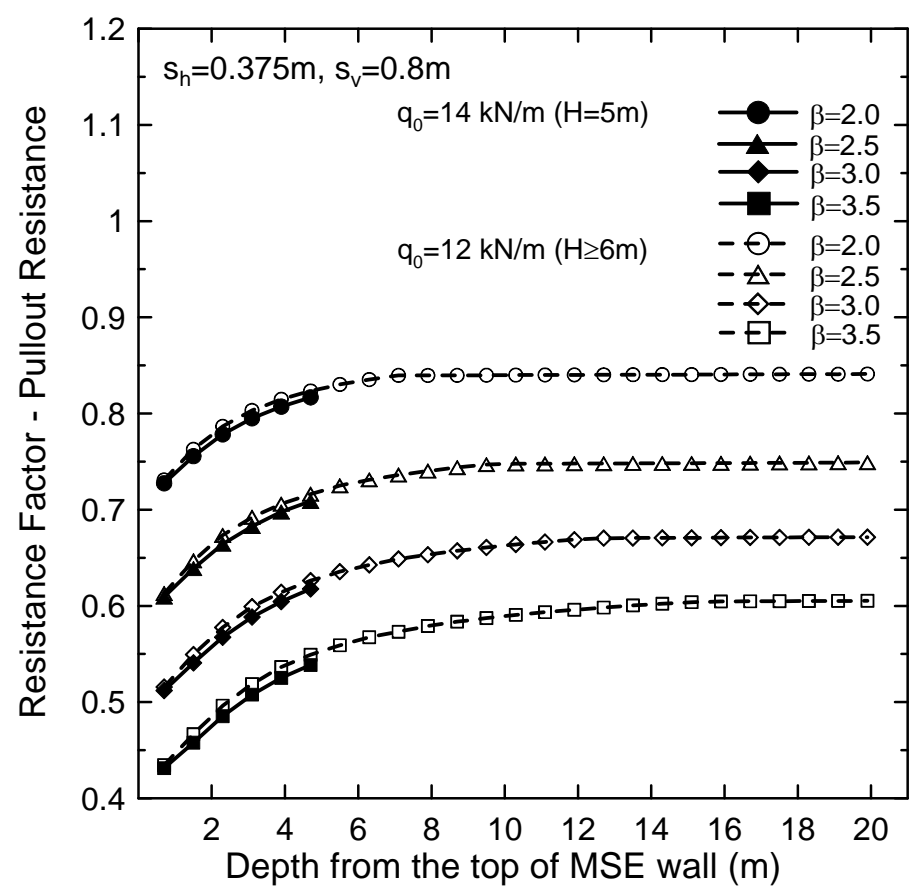

Figure 7.23 RF for pullout of steel-strip reinforcement versus reinforcement depth $\mathrm{z}$ when $\mathrm{s}_{\mathrm{h}}=0.375 \mathrm{~m}$ and $\mathrm{s}_{\mathrm{v}}=0.8 \mathrm{~m}$

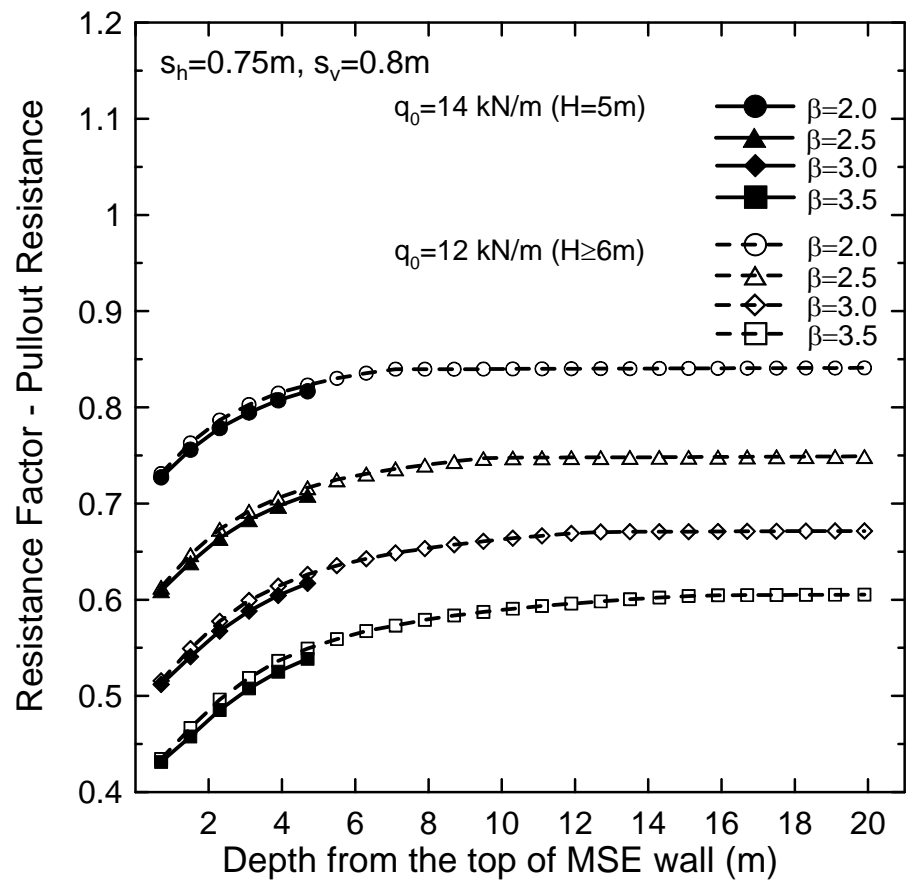

Figure 7.24 RF for pullout of steel-strip reinforcement versus reinforcement depth $\mathrm{z}$ when $\mathrm{s}_{\mathrm{h}}=0.75 \mathrm{~m}$ and $\mathrm{s}_{\mathrm{v}}=0.8 \mathrm{~m}$ 
In order to explain the relationship between the RF value and the reinforcement depth $\mathrm{z}$ from the top of the MSE walls in Figure 7.19 through Figure 7.24, we should examine the changes of the optimum factors (optimum LFs for dead load and live load and optimum resistance factor) with increasing $\mathrm{z}$. Therefore, RF values of a particular case $\left(\mathrm{s}_{\mathrm{v}}=0.60 \mathrm{~m}, \mathrm{H}=20 \mathrm{~m}, \beta_{\mathrm{T}}=3.0\right.$, and $\left.\mathrm{q}_{0}=12 \mathrm{kN} / \mathrm{m}\right)$ were studied. As shown in Figure 7.25, the following is observed: (1) the optimum resistance factor $\mathrm{RF}^{*}$ maintains somewhat consistent level with increasing $\mathrm{z}$, (2) the optimum load factor $\mathrm{LF}^{*}$ DL for the dead load increases slightly with increasing $\mathrm{z}$ and (3) the optimum load factor $\mathrm{LF}^{*} \mathrm{LL}$ for the live load decreases substantially at lower reinforcement depth $\mathrm{z}$ and slowly converge to a certain value with increasing $\mathrm{z}$.

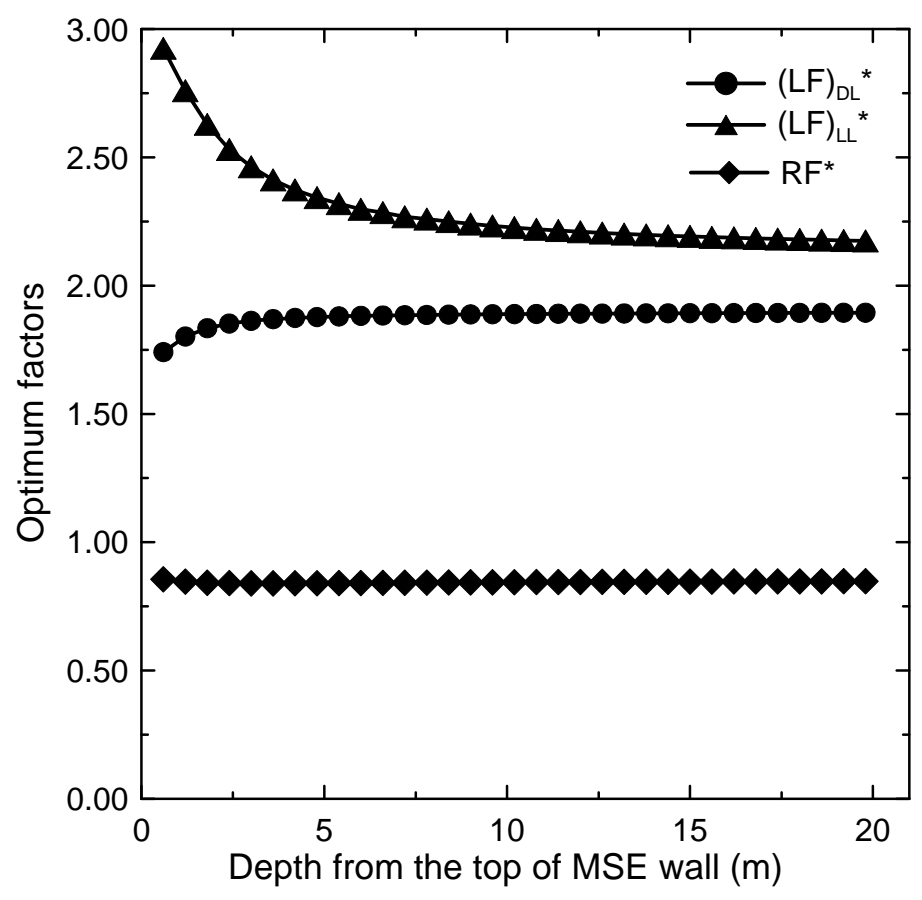

Figure 7.25 Changes of optimum factors (resistance factor, load factors for live load and dead load) with an increasing reinforcement depth from the top of MSE wall $\left(\mathrm{s}_{\mathrm{v}}=0.60 \mathrm{~m}\right.$, $\mathrm{H}=20 \mathrm{~m}, \beta_{\mathrm{T}}=3.0$, and $\left.\mathrm{q}_{0}=12 \mathrm{kN} / \mathrm{m}\right)\left[(\mathrm{LF})_{\mathrm{DL}^{*}}{ }^{*}\right.$ and $(\mathrm{LF})_{\mathrm{LL}}{ }^{*}$ are the optimum load factors for dead and live load, and $\mathrm{RF}^{*}$ is the optimum resistance factor] 
As mentioned in section 7.3, the LFs in AASHTO LRFD specifications (2007) for pullout of steel-strip reinforcement are 1.5 and 1.75 for dead load and live load, respectively $\left[(\mathrm{LF})_{\mathrm{DL}}=1.5\right.$ and $\left.(\mathrm{LF})_{\mathrm{LL}}=1.75\right]$. The $\mathrm{RF}$ value (Eq. (2.11)) can be expressed as

$$
\mathrm{RF}=\frac{\mathrm{RF}^{*}}{\max \left(\frac{(\mathrm{LF})_{\mathrm{DL}}{ }^{*}}{(\mathrm{LF})_{\mathrm{DL}}}, \frac{(\mathrm{LF})_{\mathrm{LL}}{ }^{*}}{(\mathrm{LF})_{\mathrm{LL}}}\right)}
$$

Figure 7.26 represents the changes of the ratios of $(\mathrm{LF})_{\mathrm{DL}}{ }^{*} /(\mathrm{LF})_{\mathrm{DL}}$ and $(\mathrm{LF})_{\mathrm{LL}}{ }^{*} /(\mathrm{LF})_{\mathrm{LL}}$ and $\mathrm{RF}^{*}$ with increasing reinforcement depth $\mathrm{z}$ from the top of MSE wall. The following explains the reason why RF value increases rapidly at a lower $\mathrm{z}$ and maintains at a consistent level after a certain depth $z$ : RF* value does not change significantly with increasing reinforcement depth $\mathrm{z}$ while $(\mathrm{LF})_{\mathrm{DL}}{ }^{*} /(\mathrm{LF})_{\mathrm{DL}}$ and $(\mathrm{LF})_{\mathrm{LL}}{ }^{*} /(\mathrm{LF})_{\mathrm{LL}}$ vary with $\mathrm{z}$. Therefore, the change in $\mathrm{RF}$ value with increasing $\mathrm{z}$ is mainly due to the change of the higher values between $(\mathrm{LF})_{\mathrm{DL}}{ }^{*} /(\mathrm{LF})_{\mathrm{DL}}$ and $(\mathrm{LF})_{\mathrm{LL}}{ }^{*} /(\mathrm{LF})_{\mathrm{LL}}$. At a lower depth $\mathrm{z},(\mathrm{LF})_{\mathrm{LL}}{ }^{*} /(\mathrm{LF})_{\mathrm{LL}}$ is much more higher than $(\mathrm{LF})_{\mathrm{DL}}{ }^{*} /(\mathrm{LF})_{\mathrm{DL}}$ and decreases rapidly; However, after a certain reinforcement depth (in this particular case, z greater than $10 \mathrm{~m})$, the higher value between $(\mathrm{LF})_{\mathrm{LL}}{ }^{*} /(\mathrm{LF})_{\mathrm{LL}}$ and $(\mathrm{LF})_{\mathrm{DL}}{ }^{*} /(\mathrm{LF})_{\mathrm{DL}}$ maintains somewhat consistent level, and therefore RF value also remains consistent. 


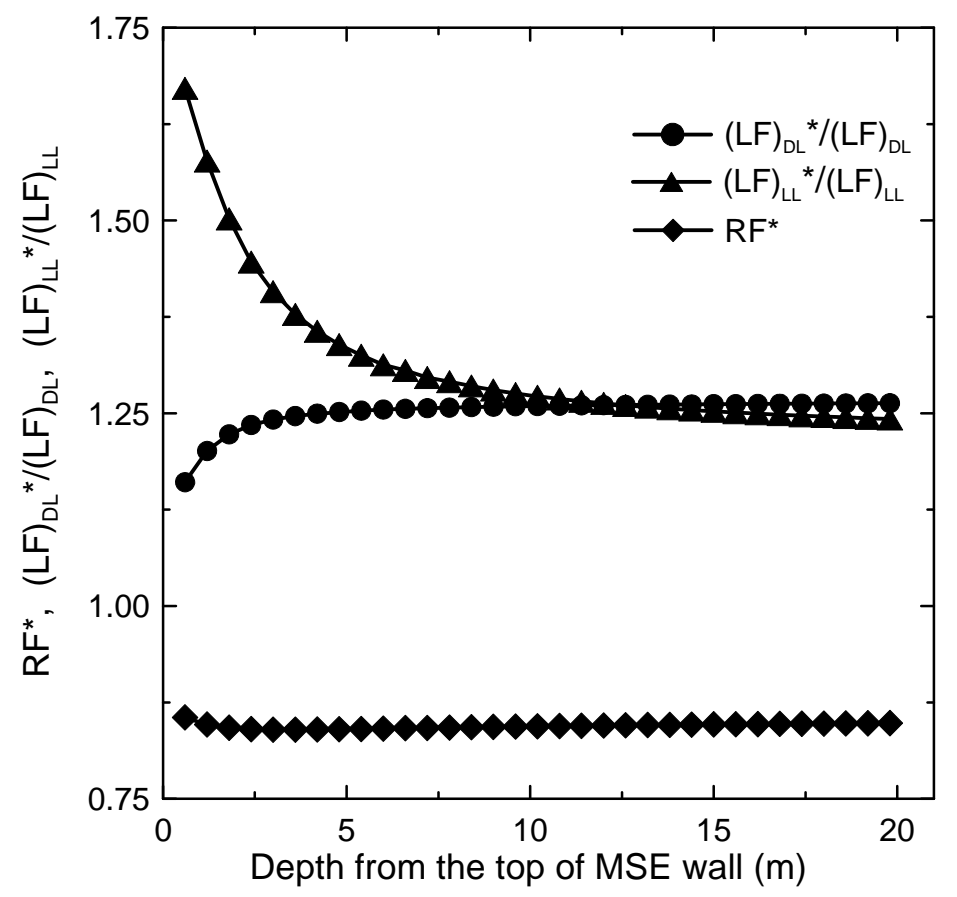

Figure 7.26 Changes of $\mathrm{RF}^{*},(\mathrm{LF})_{\mathrm{DL}}{ }^{*} /(\mathrm{LF})_{\mathrm{DL}}$, and $(\mathrm{LF})_{\mathrm{LL}}{ }^{*} /(\mathrm{LF})_{\mathrm{LL}}$ with increasing reinforcement depth $\mathrm{z}\left(\mathrm{s}_{\mathrm{v}}=0.60 \mathrm{~m}, \mathrm{H}=20 \mathrm{~m}, \beta_{\mathrm{T}}=3.0\right.$, and $\left.\mathrm{q}_{0}=12 \mathrm{kN} / \mathrm{m}\right)\left[(\mathrm{LF})_{\mathrm{DL}}{ }^{*}\right.$ and $(\mathrm{LF})_{\mathrm{LL}}{ }^{*}$ are the optimum load factors for dead and live load, $\mathrm{RF}^{*}$ is the optimum resistance factor, and $(\mathrm{LF})_{\mathrm{DL}}$ and $(\mathrm{LF})_{\mathrm{LL}}$ are the AASHTO load factors]

FS values are calculated using the load and resistance equations proposed in this report. The FS values in Figure 7.27 through Figure 7.32 are the values that correspond to the RF values in Figure 7.19 through Figure 7.24. It is also noticed earlier that FS value is independent of horizontal and vertical spacing of the reinforcement for a given reinforcement level. The FS value is the highest at the first reinforcement depth $\mathrm{z}$ and continuously decreases with increasing $z$. This trend of FS is opposite to that of RF. This is because higher FS value in design allows more margin of safety to the structure; while lower RF value in design assumes less probability of failure of the structure. 


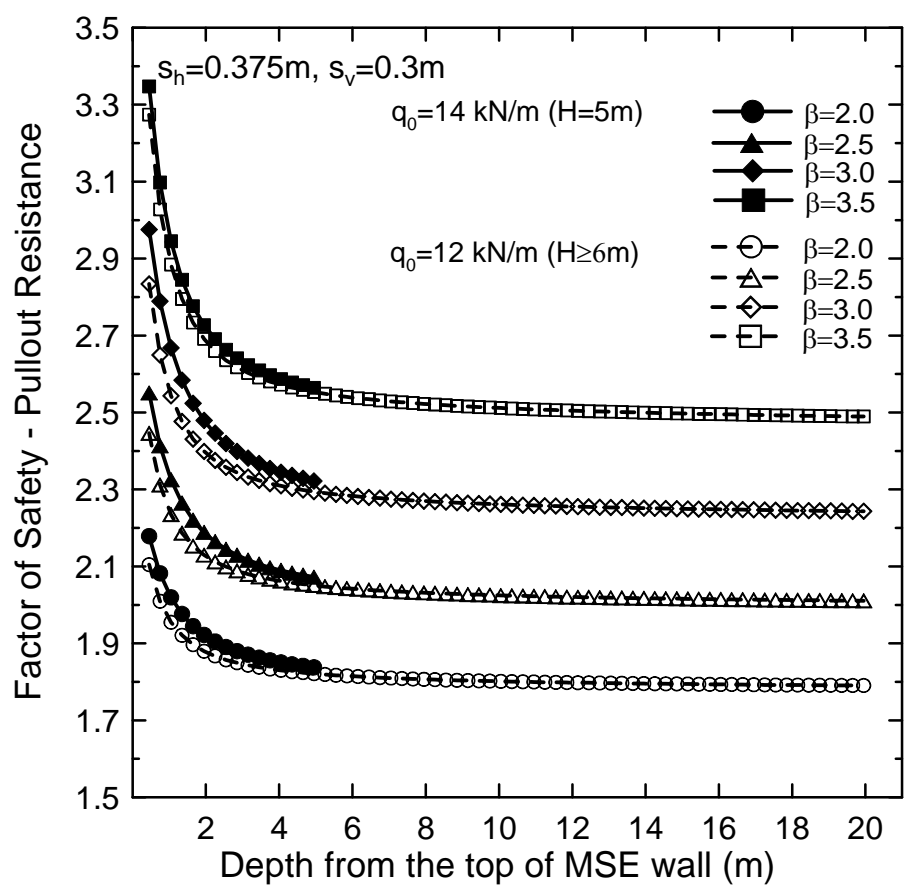

Figure 7.27 FS for pullout of steel-strip reinforcement versus reinforcement depth $\mathrm{z}$ when $\mathrm{s}_{\mathrm{h}}=0.375 \mathrm{~m}$ and $\mathrm{s}_{\mathrm{v}}=0.3 \mathrm{~m}$

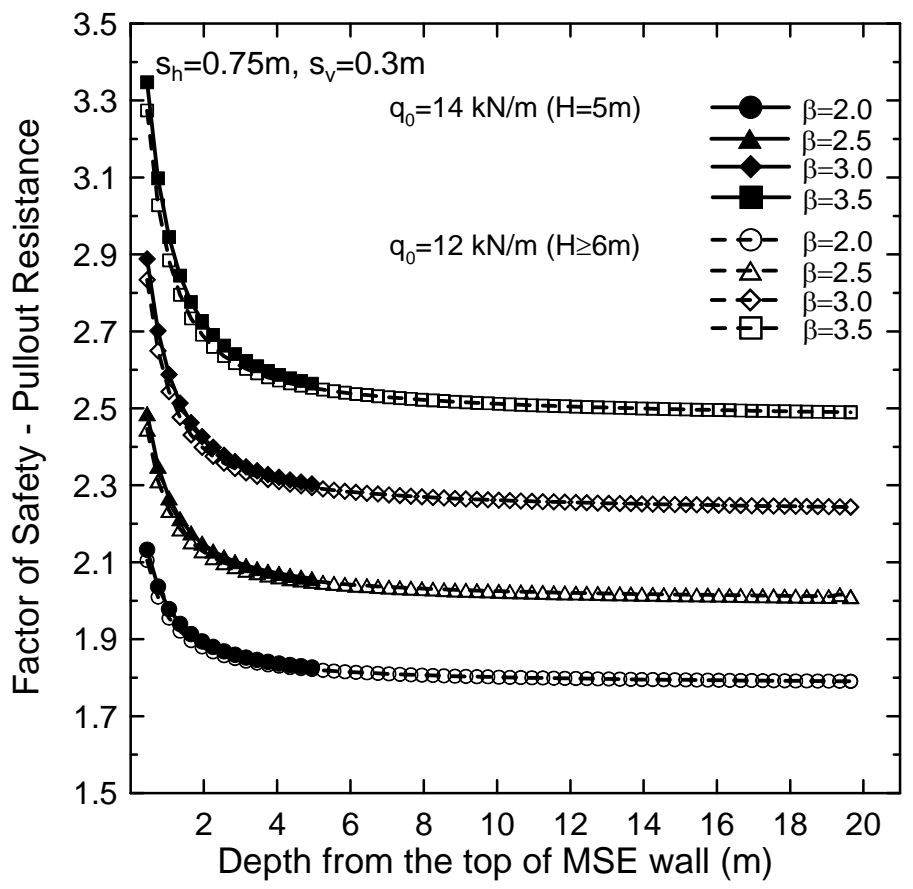

Figure 7.28 FS for pullout of steel-strip reinforcement versus reinforcement depth $\mathrm{z}$ when $\mathrm{s}_{\mathrm{h}}=0.75 \mathrm{~m}$ and $\mathrm{s}_{\mathrm{v}}=0.3 \mathrm{~m}$ 


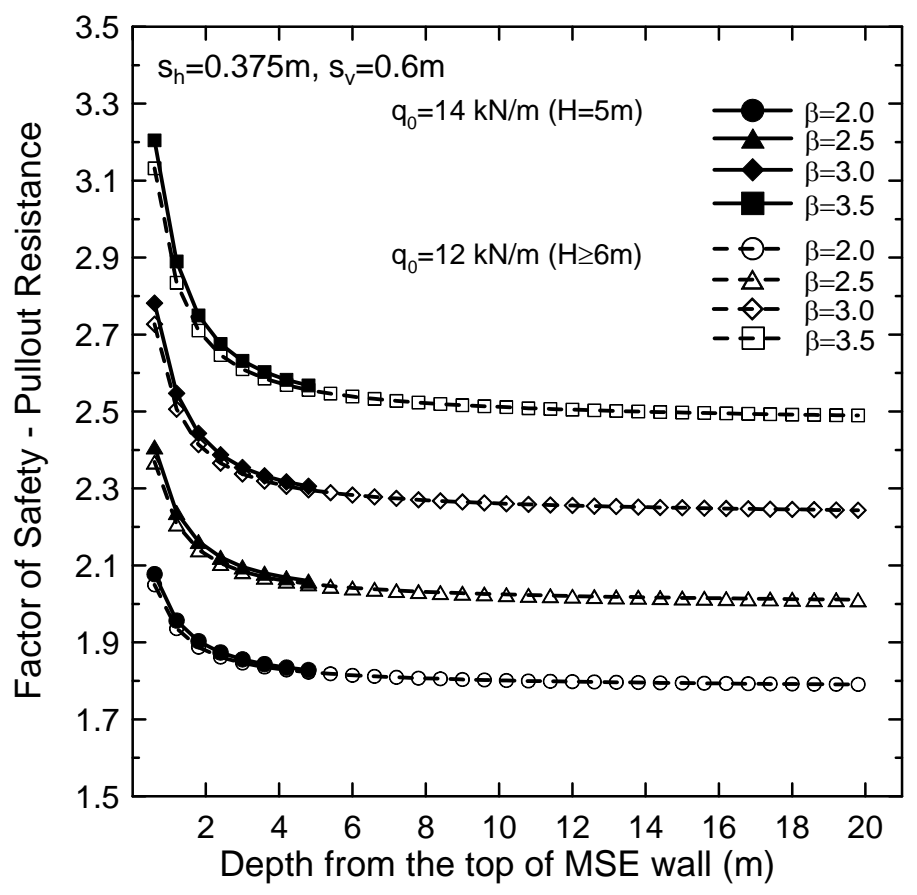

Figure 7.29 FS for pullout of steel-strip reinforcement versus reinforcement depth $\mathrm{z}$ when $\mathrm{s}_{\mathrm{h}}=0.375 \mathrm{~m}$ and $\mathrm{s}_{\mathrm{v}}=0.6 \mathrm{~m}$

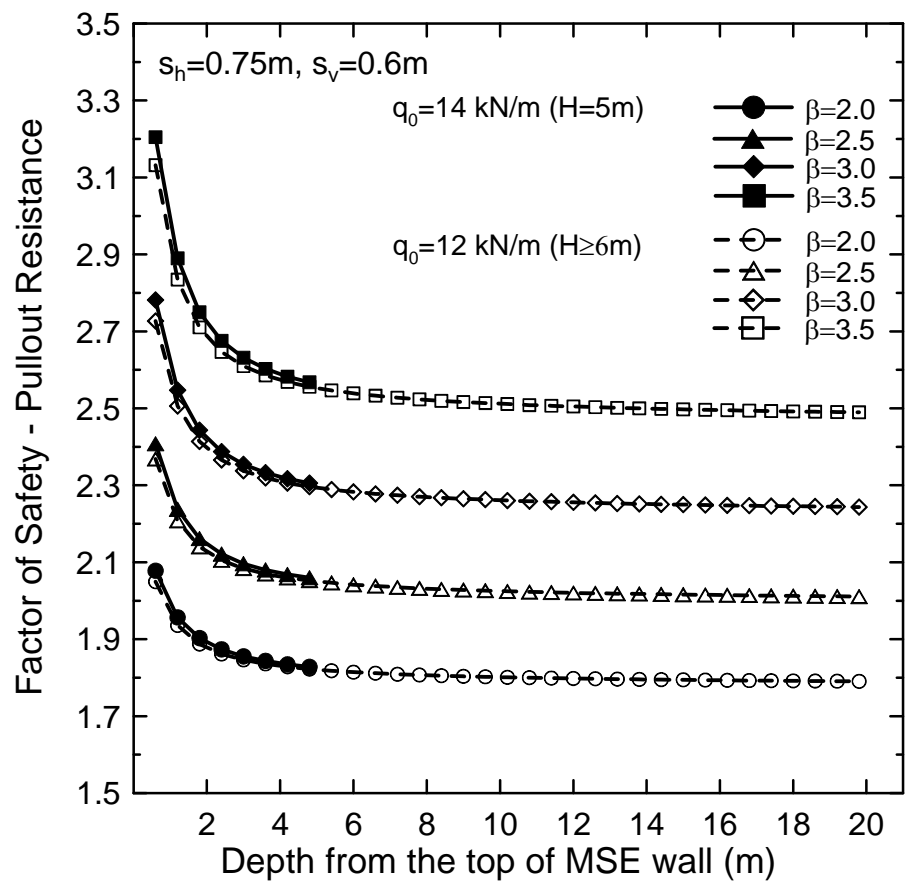

Figure 7.30 FS for pullout of steel-strip reinforcement versus reinforcement depth $\mathrm{z}$ when $\mathrm{s}_{\mathrm{h}}=0.75 \mathrm{~m}$ and $\mathrm{s}_{\mathrm{v}}=0.6 \mathrm{~m}$ 


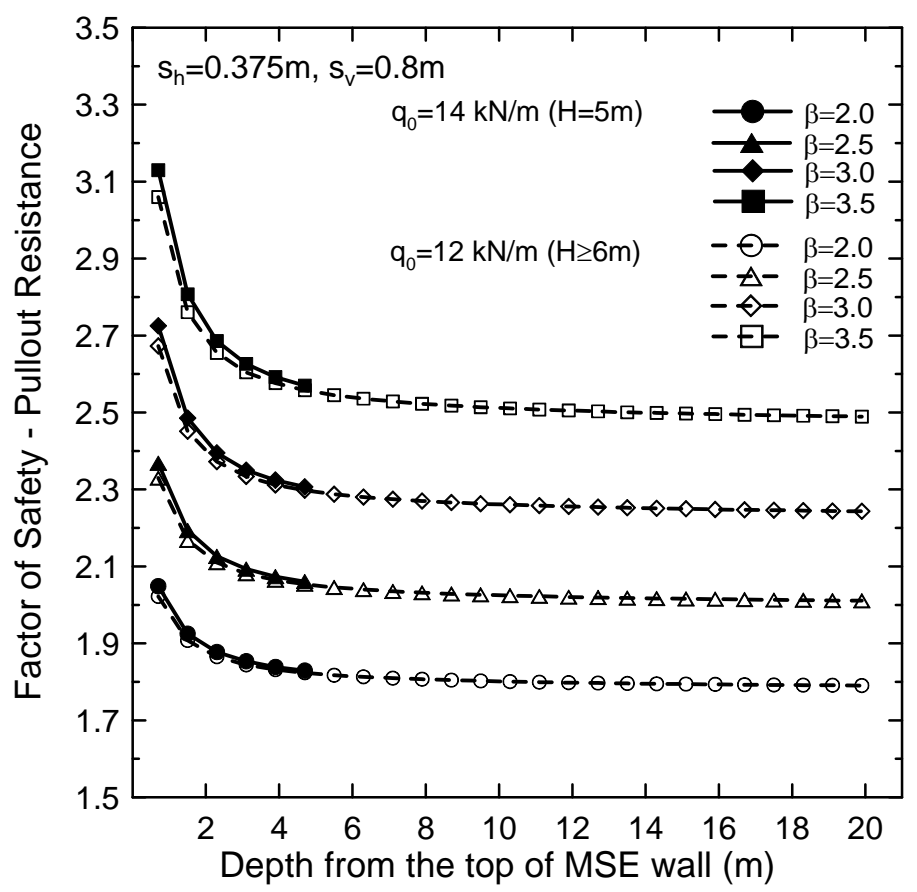

Figure 7.31 FS for pullout of steel-strip reinforcement versus reinforcement depth $\mathrm{z}$ when $\mathrm{s}_{\mathrm{h}}=0.375 \mathrm{~m}$ and $\mathrm{s}_{\mathrm{v}}=0.8 \mathrm{~m}$

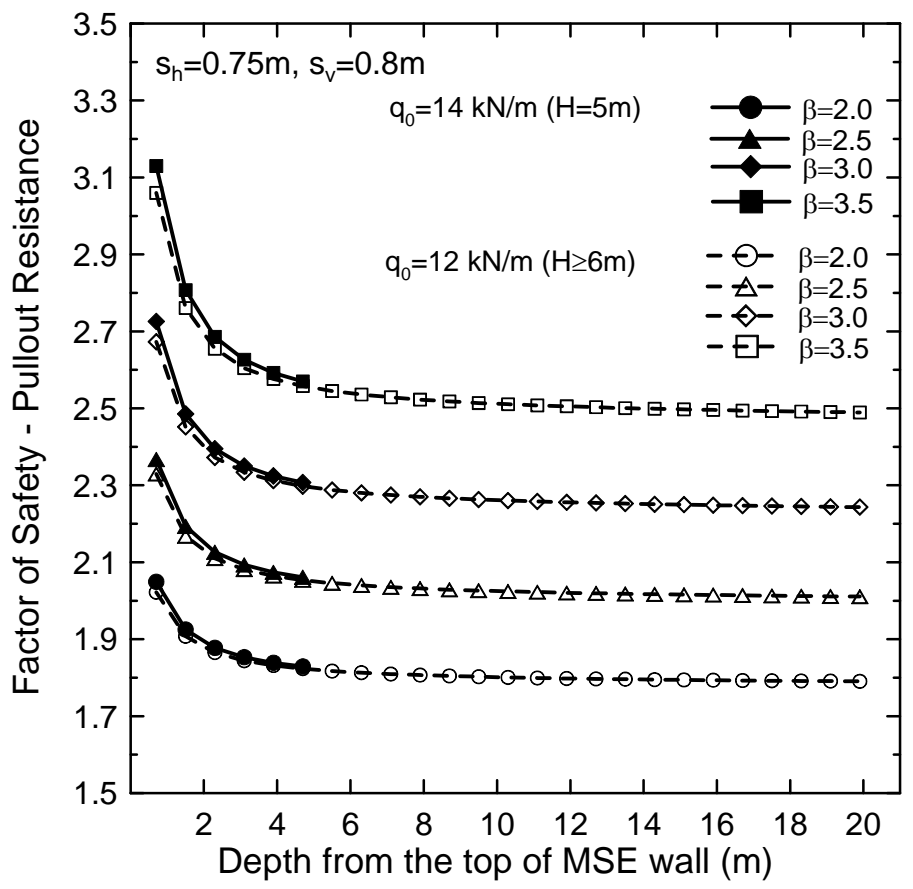

Figure 7.32 FS for pullout of steel-strip reinforcement versus reinforcement depth $\mathrm{z}$ when $\mathrm{s}_{\mathrm{h}}=0.75 \mathrm{~m}$ and $\mathrm{s}_{\mathrm{v}}=0.8 \mathrm{~m}$ 
According to the FHWA (2001) and AASHTO (2007) specifications, the FS for pullout of reinforcement criterion should be equal to or higher than 1.5. However, the FS values that are achieved from all the analyses in these examples are higher than 1.5 (the smallest FS value is about 1.8). The reasons for having higher FS values than 1.5 are as follows: (1) there exists a higher uncertainty associated with assessing $K_{r}$ and (2) the existing design methods [FHWA (2001) and AASHTO (2007)] overestimate $\mathrm{K}_{\mathrm{r}}$ so that the FS values provided in these design specifications may be much higher if the estimation of $\mathrm{K}_{\mathrm{r}}$ has done more realistic or reasonable.

\subsubsection{Structural failure of steel-strip reinforcement}

The distribution of resistance (the yield force $T_{y}$ of a steel-strip reinforcement) does not change with its location. On contrary, the maximum tensile force $T_{\max }$ on the steel-strip reinforcement changes with its location (reinforcement depth). We performed reliability analyses for every reinforcement depth z (up to 20m) using the Microsoft Excel Solver.

When the horinzontal spacing was $0.375 \mathrm{~m}$, regardless of the vertical spacing $\left(\mathrm{s}_{\mathrm{v}}=0.3-0.8 \mathrm{~m}\right)$, all the calculated reliability indices were higher than the highest target reliability index $\left(\beta_{\mathrm{T}}=3.5\right)$ for all the reinforcement depths up to $20 \mathrm{~m}$. For $\mathrm{s}_{\mathrm{h}}=0.75 \mathrm{~m}$, when vertical spacing is equal to or less than $0.4 \mathrm{~m}$, all the calculated reliability indices were higher than the highest target reliability index $\left(\beta_{\mathrm{T}}=3.5\right)$.

Figure 7.33 shows the calculated reliability indices for $\mathrm{s}_{\mathrm{h}}=0.75 \mathrm{~m}$ and $\mathrm{s}_{\mathrm{v}}=0.4,0.5$, $0.6,0.7$, and $0.8 \mathrm{~m}$. For given horizontal and vertical spacings of the reinforcement, the reliability index decreases with increasing steel-strip reinforcement depth. This is because the maximum tensile force $T_{\max }$ on the steel-strip reinforcement increases with increasing reinforcement depth, while the resistance does not change with respect to reinforcement depth; therefore, the probability of failure increases with increasing reinforcement depth. 


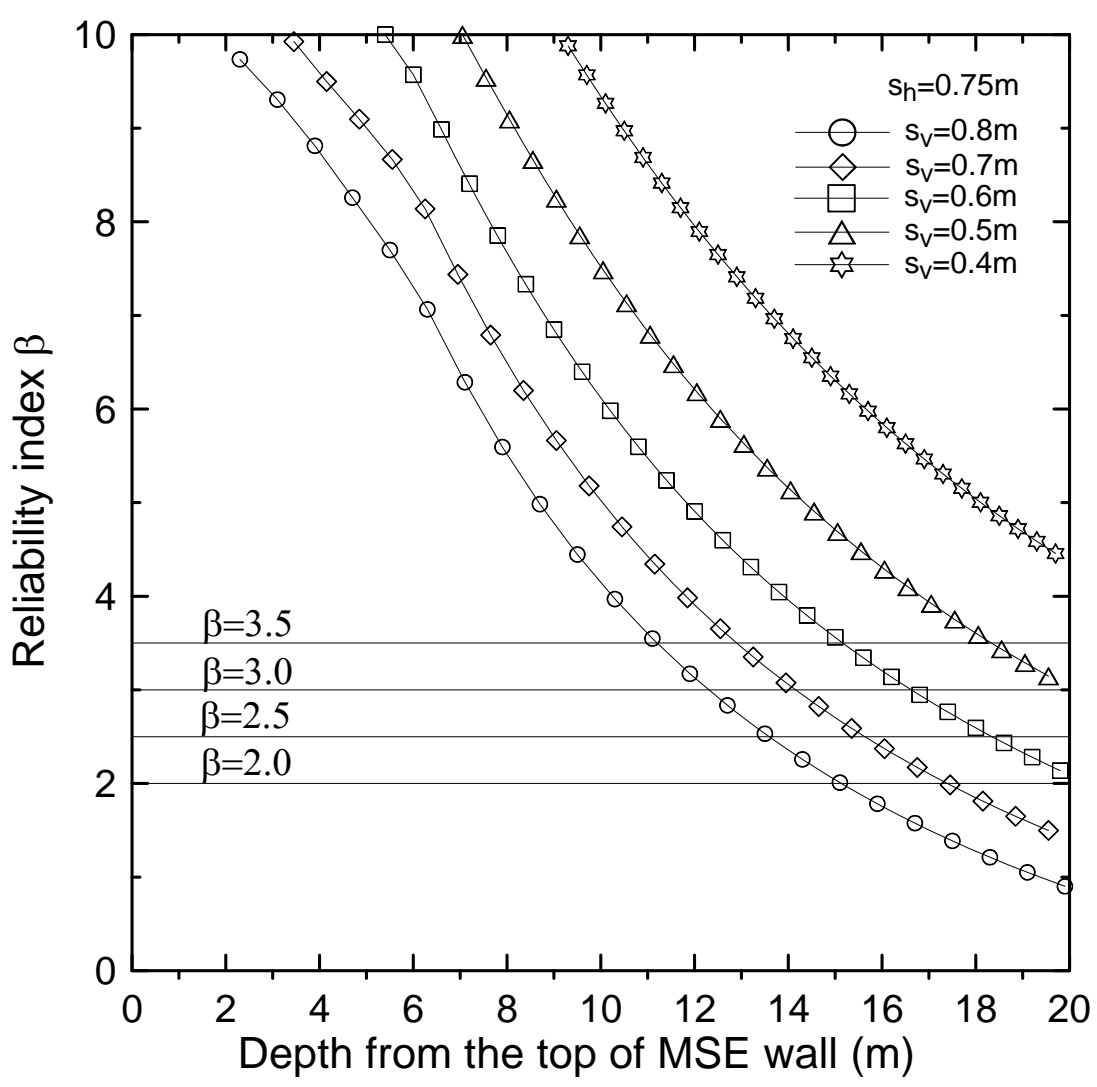

Figure 7.33 Reliability index $\beta$ for structural failure of steel-strip reinforcement versus reinforcement depth $\mathrm{z}$ (horizontal reinforcement spacing $\mathrm{s}_{\mathrm{h}}=0.75 \mathrm{~m}$ and vertical reinforcement spacing $\mathrm{s}_{\mathrm{v}}=0.4,0.5,0.6,0.7$, and $0.8 \mathrm{~m}$ )

In Figure 7.33 , when $\mathrm{s}_{\mathrm{v}}=0.8 \mathrm{~m}$ and $\mathrm{s}_{\mathrm{h}}=0.75 \mathrm{~m}$, the intersection between the line with circles $\left(\mathrm{s}_{\mathrm{v}}=0.8 \mathrm{~m}\right.$ and $\left.\mathrm{s}_{\mathrm{h}}=0.75 \mathrm{~m}\right)$ and the line of $\beta_{\mathrm{T}}=3.5$ exists at the reinforcement depth equal to $11.197 \mathrm{~m}$. Table 7.10 summarizes the calculation of reliability index for this case $\left(\mathrm{s}_{\mathrm{v}}=0.8 \mathrm{~m}, \mathrm{~s}_{\mathrm{h}}=0.75 \mathrm{~m}\right.$ and $\left.\beta_{\mathrm{T}}=3.5\right)$. 
Table 7.10 Result of reliability analysis for structural failure of steel-strip reinforcement $\left(\mathrm{s}_{\mathrm{v}}=0.8 \mathrm{~m}, \mathrm{~s}_{\mathrm{h}}=0.75 \mathrm{~m}\right.$ and $\left.\beta_{\mathrm{T}}=3.5\right)$

\begin{tabular}{|c|c|c|c|c|c|c|c|c|c|}
\hline & $\mathrm{m}$ & $\begin{array}{c}\text { equivalent } \\
\text { normal mean }\end{array}$ & $\mathrm{x}$ & $\mathrm{stdev}$ & $\begin{array}{c}\text { equivalent } \\
\text { normal stdev }\end{array}$ & \multicolumn{4}{|c|}{ Covariance matrix, $\mathrm{C}$} \\
\hline $\mathrm{K}_{\mathrm{r}}$ & 0.196 & 0.196 & 0.42 & 0.068 & 0.068 & 0.0046 & 0.0000 & 0.0000 & 0.0000 \\
\hline$\gamma_{\mathrm{rf}}$ & 20 & 20 & 20.06 & 0.24 & 0.240 & 0.0000 & 0.0576 & 0.0000 & 0.0000 \\
\hline $\mathrm{q}_{0, \mathrm{rf}}$ & 13.8 & 14.354 & 14.43 & 3.45 & 0.246 & 0.0000 & 0.0000 & 0.0605 & 0.0000 \\
\hline$\eta\left(\mathrm{f}_{\mathrm{y}}\right)$ & 1 & 1 & 0.95 & 0.05 & 0.050 & 0.0000 & 0.0000 & 0.0000 & 0.0025 \\
\hline
\end{tabular}

\begin{tabular}{|c|c|}
\hline $\mathrm{G}(\mathrm{x})$ & 0 \\
\hline$\beta$ & 3.500 \\
\hline $\mathrm{P}_{\mathrm{f}}$ & 0.0002 \\
\hline
\end{tabular}

Reinforcement depth $=11.197 \mathrm{~m}$

\begin{tabular}{|l|l|}
\hline$\lambda$ & 2.594 \\
\hline$\zeta$ & 0.246 \\
\hline
\end{tabular}

$(\mathrm{m}$ : mean value, stdev: standard deviation, $\mathrm{G}(\mathrm{x})$ : function of margin of safety, $\beta$ : reliability index, $\mathrm{P}_{\mathrm{f}}$ : target probability of failure, $\lambda$ and $\zeta$ are the parameters related to lognormal distribution, and $\eta\left(f_{\mathrm{y}}\right)$ denotes a parameter that accounts the bias factor and coefficient of variation of the yield strength of the steel-strip reinforcement)

The ULS values of $\mathrm{T}_{\max }$ values due to the dead and live loads, and the yield force of the steel-strip reinforcement are listed in Table 7.11. The total $\mathrm{T}_{\max }$ is equal the yield force of the reinforcement $(75.791 \mathrm{kN} / \mathrm{m}+4.870 \mathrm{kN} / \mathrm{m}=80.661 \mathrm{kN} / \mathrm{m})$.

Table 7.11 ULS values of loads and resistance for structural failure of steel-strip reinforcement

\begin{tabular}{lrl}
\hline$T_{\max }$ due to the dead load & 75.791 & $\mathrm{kN} / \mathrm{m}$ \\
\hline$T_{\max }$ due to the live surcharge & 4.870 & $\mathrm{kN} / \mathrm{m}$ \\
\hline Yield force of reinforcement & 80.661 & $\mathrm{kN} / \mathrm{m}$ \\
\hline
\end{tabular}

The nominal values of $\mathrm{T}_{\max }$ values due to the dead and live loads, and the yield force of the reinforcement are shown in Table 7.12. These nominal values were computed using the nominal values of the parameters. Factor of safety for this particular case is 2.28 . 
Table 7.12 Nominal values of loads and resistance and FS value for structural failure of steel-strip reinforcement

\begin{tabular}{lcc}
\hline$T_{\max }$ due to the dead load & 35.198 & $\mathrm{kN} / \mathrm{m}$ \\
\hline$T_{\max }$ due to the live surcharge & 2.169 & $\mathrm{kN} / \mathrm{m}$ \\
\hline Yield force of reinforcement & 85.272 & $\mathrm{kN} / \mathrm{m}$ \\
\hline $\mathrm{FS}=$ & 2.28 & \\
\hline
\end{tabular}

The optimum load and resistance factors are calculated using Eq. (2.5) and Eq. (2.6). In addition, the RF value for structural failure of steel-strip reinforcement is computed using Eq. (2.11) with these optimum factors and the AASHTO LFs $\left[(\mathrm{LF})_{\mathrm{DL}}=1.5\right.$ and $\left.(\mathrm{LF})_{\mathrm{LL}}=1.75\right]$.

Table 7.13 Calculation of optimum factors and RF using AASHTO LFs for structural failure of steel-strip reinforcement

\begin{tabular}{|c|c|c|c|c|c|}
\hline$(L F)_{D L}{ }^{*}=$ & 2.15 & $(L F)_{D L}=$ & 1.5 & $(\mathrm{LF})_{D L}{ }^{*} /(\mathrm{LF})_{\mathrm{DL}}=$ & 1.44 \\
\hline$(L F)_{L L}{ }^{*}=$ & 2.25 & $(\mathrm{LF})_{\mathrm{LL}}=$ & 1.75 & $(\mathrm{LF})_{\mathrm{LL}^{*}} /(\mathrm{LF})_{\mathrm{L}}$ & 1.28 \\
\hline $\mathrm{RF}^{*}=$ & 0.95 & & & $\mathrm{RF}=$ & 0.66 \\
\hline
\end{tabular}

$\left[(\mathrm{LF})_{\mathrm{DL}}{ }^{*}\right.$ and $(\mathrm{LF})_{\mathrm{LL}}{ }^{*}$ are the optimum load factors for dead and live load, $\mathrm{RF}^{*}$ is the optimum resistance factor, $(\mathrm{LF})_{\mathrm{DL}}$ and $(\mathrm{LF})_{\mathrm{LL}}$ are the AASHTO load factors, and RF is the resistance factor]

$\mathrm{RF}$ values and the corresponding reinforcement levels are listed in Table 7.14 for the intersection points (Figure 7.33) between the lines that consist of the calculated reliability indices and the lines corresponding to the target reliability indices $\left(\beta_{\mathrm{T}}=2.0\right.$, $2.5,3.0$, and 3.5). 
Table 7.14 RF and the corresponding reinforcement level for different target reliability indices $\left(\mathrm{s}_{\mathrm{h}}=0.75 \mathrm{~m}\right)$

\begin{tabular}{|c|c|c|c|c|c|}
\hline \multirow{2}{*}{$\begin{array}{c}\text { Vertical } \\
\text { spacing, } \\
(\mathrm{m})\end{array}$} & \multirow{2}{*}{$\begin{array}{c}\text { RF \& Reinf. } \\
\text { level }\end{array}$} & \multicolumn{4}{|c|}{ Target reliability index, $\beta_{\mathrm{T}}$} \\
\cline { 3 - 6 } & RF & 3.5 & 3 & 2.5 & 2 \\
\hline \multirow{2}{*}{0.8} & 0.66 & 0.72 & 0.79 & 0.87 \\
\cline { 2 - 6 } & Reinf. level (m) & 11.20 & 12.30 & 13.59 & 15.13 \\
\hline \multirow{2}{*}{0.7} & RF & 0.66 & 0.72 & 0.79 & 0.87 \\
\cline { 2 - 6 } & Reinf. level (m) & 12.90 & 14.15 & 15.63 & 17.39 \\
\hline \multirow{2}{*}{0.6} & RF & 0.66 & 0.72 & 0.79 & - \\
\cline { 2 - 6 } & Reinf. level (m) & 15.17 & 16.63 & 18.35 & - \\
\hline \multirow{2}{*}{0.5} & RF & 0.66 & - & - & - \\
\cline { 2 - 6 } & Reinf. level (m) & 18.34 & - & - & - \\
\hline
\end{tabular}

From inequality (2.2), if the factored resistance is not equal to or greater than the sum of the factored loads, designers should reduce either the horizontal or vertical spacing of the reinforcements until the inequality (2.2) is satisfied.

Table 7.15 shows the FS values for the different target reliability indices. The FS value for working stress design (WSD) is 1.8 (the inverse of 0.55). Because we are using different method to assess the maximum tensile force $\mathrm{T}_{\max }$ compared to the method given in the specifications (FHWA, 2001), the direct comparison between these FS values is not possible.

Table 7.15 FS for different target reliability indices $\left(\mathrm{s}_{\mathrm{h}}=0.75 \mathrm{~m}\right)$

\begin{tabular}{|c|c|c|c|c|}
\hline \multirow{2}{*}{$\begin{array}{c}\text { Vertical } \\
\text { spacing, } \\
(\mathrm{m})\end{array}$} & \multicolumn{4}{|c|}{ Target reliability index, $\beta_{\mathrm{T}}$} \\
\cline { 2 - 5 } & 3.5 & 3 & 2.5 & 2 \\
\hline 0.8 & 2.28 & 2.09 & 1.90 & 1.71 \\
\hline 0.7 & 2.28 & 2.09 & 1.90 & 1.71 \\
\hline 0.6 & 2.28 & 2.09 & 1.90 & - \\
\hline 0.5 & 2.28 & - & - & - \\
\hline
\end{tabular}




\section{CHAPTER 8. PARAMETRIC STUDY}

The goal of this chapter is to determine the RF values for each stability limit state (both external and internal) using the LF values provided in AASHTO (2007). Before determining the RF values, we will examine the effect on the RF of each parameter used in the analysis. To observe these effects, sets of parametric studies were performed.

The equations for loads and resistance calculations in our design method are different from those in the specifications (AASHTO, 2007 and FHWA, 2001). Therefore, to use the RF values proposed in this study, designers must use the equations for load and resistance that are proposed in this study. For example, we used the critical-state friction angle to estimate the active earth pressure coefficient $\mathrm{K}_{\mathrm{A}}$, while the method in the specifications uses the peak friction angle for $\mathrm{K}_{\mathrm{A}}$ estimation.

\subsection{Effect of the Change in the Critical-State Friction Angle of Retained Soil on RF}

The critical-state friction angle of the retained soil $\phi_{\mathrm{c}, \mathrm{rt}}$ affects only the RFs for sliding and overturning because $\phi_{c, r t}$ is not used in the internal stability ULS equations. To see the effect of $\phi_{c, r t}$ on RF, analyses were performed using two different values of $\phi_{c, r t}\left(30^{\circ}\right.$ and $33^{\circ}$ ) fixing the values of the other parameters.

\subsubsection{External stability - sliding}

The RF value for sliding was investigated for two different values of $\phi_{c, \text { rt }}\left(30^{\circ}\right.$ and $\left.33^{\circ}\right)$, as shown in Figure 8.1. The result shows that the RF values for $\phi_{c, r t}$ was $33^{\circ}$ are slightly 
higher than those for $\phi_{\mathrm{c}, \mathrm{rt}}=30^{\circ}$. However, the differences in the RF values for these two cases are very small.

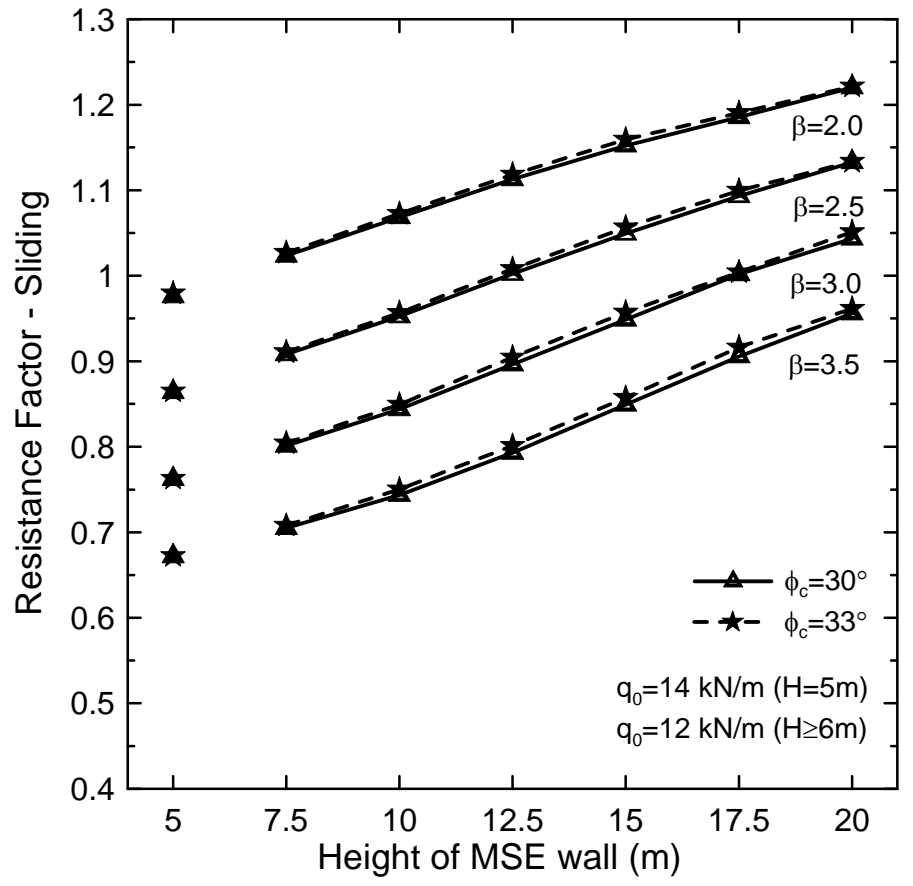

Figure 8.1 RF for sliding for different MSE wall heights when $\phi_{\mathrm{c}, \mathrm{rt}}$ is equal to $30^{\circ}$ and $33^{\circ}$ ( $\mathrm{q}_{0}$ is the live surcharge load)

\subsubsection{External stability - overturning}

Similarly to sliding, the RF values when $\phi_{\mathrm{c}, \mathrm{rt}}$ was $33^{\circ}$ were a little higher than for $\phi_{\mathrm{c}, \mathrm{rt}}=$ $30^{\circ}$. Also, the differences in the RF values for these two different $\phi_{c, r t}$ were very small. The RF values for the overturning are shown in Figure 8.2. 


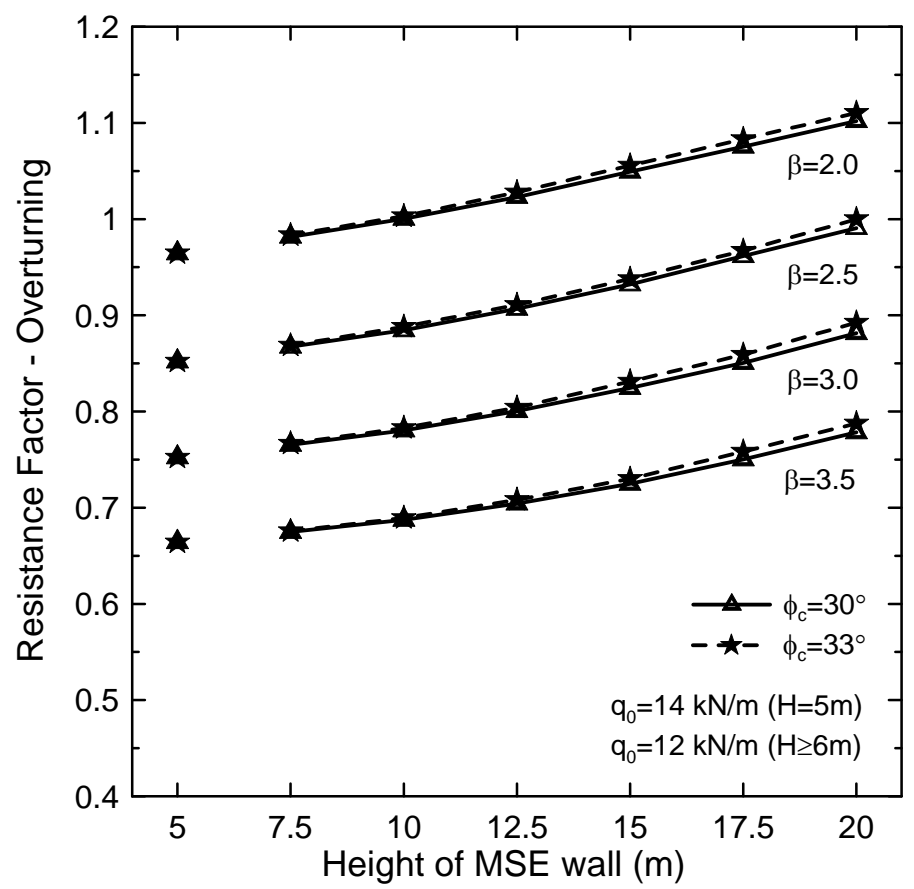

Figure 8.2 RF for overturning for different MSE wall heights when $\phi_{\mathrm{c}, \mathrm{rt}}$ is equal to $30^{\circ}$ and $33^{\circ}\left(\mathrm{q}_{0}\right.$ is the live surcharge load)

\subsection{Effect of the Change in Relative Density of Reinforced Soil on RF}

Three different values of relative density of reinforced soil $\mathrm{D}_{\mathrm{R}, \mathrm{rf}}(70,80$, and $100 \%)$ were considered to observe the effect of the change of $D_{R, r f}$ on $R F$ value. The parameter $D_{R, r f}$ was not used in the ULS equations of sliding and overturning; therefore, the examination was done only for the RF for steel-strip reinforcement pullout.

\subsubsection{Internal stability - pullout of steel-strip reinforcement}

As mentioned in chapter 7, the minimum RF value from those for all the reinforcement levels of an MSE wall is the one for the first reinforcement layer from the top of the wall. The change in the minimum RF value for the pullout of steel-strip reinforcement due to the change of $D_{R, \text { rf }}$ was so small that we can neglect it as shown in Figure 8.3 through 
Figure 8.5, which also show a tendency of the minimum RF to decrease as the $D_{R, r f}$ increases.

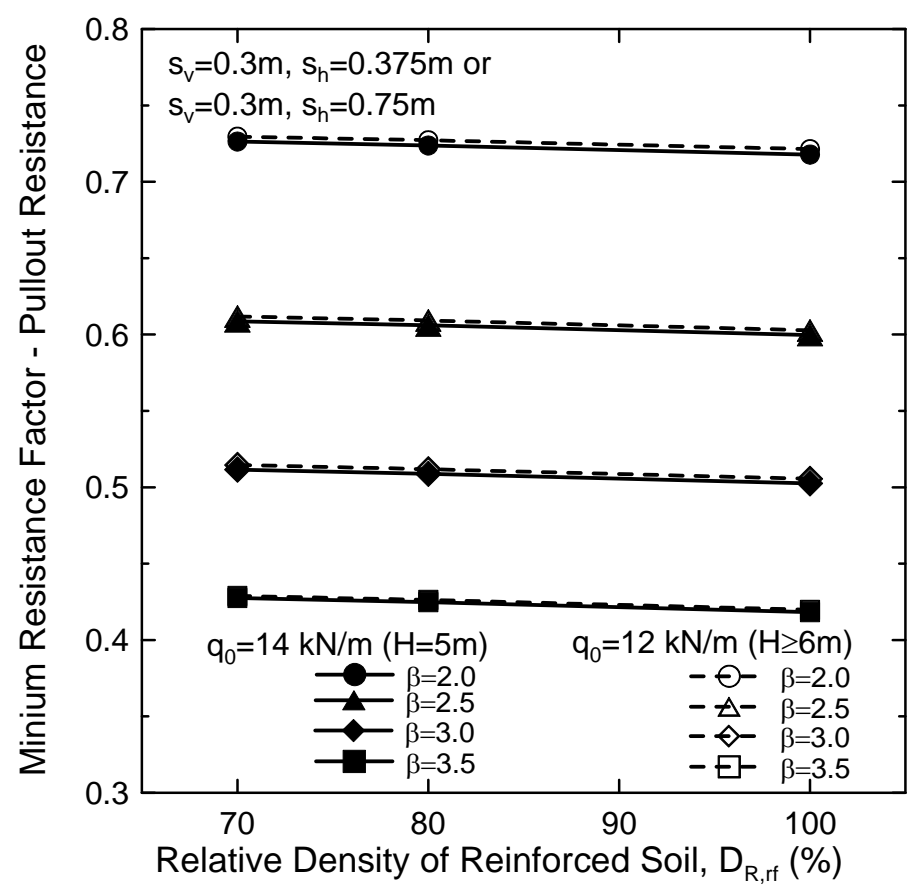

Figure 8.3 Minimum RF for pullout of steel-strip reinforcement for different values of $D_{R, r f}$ when $s_{v}=0.3 m\left(q_{0}\right.$ is the live surcharge load $)$ 


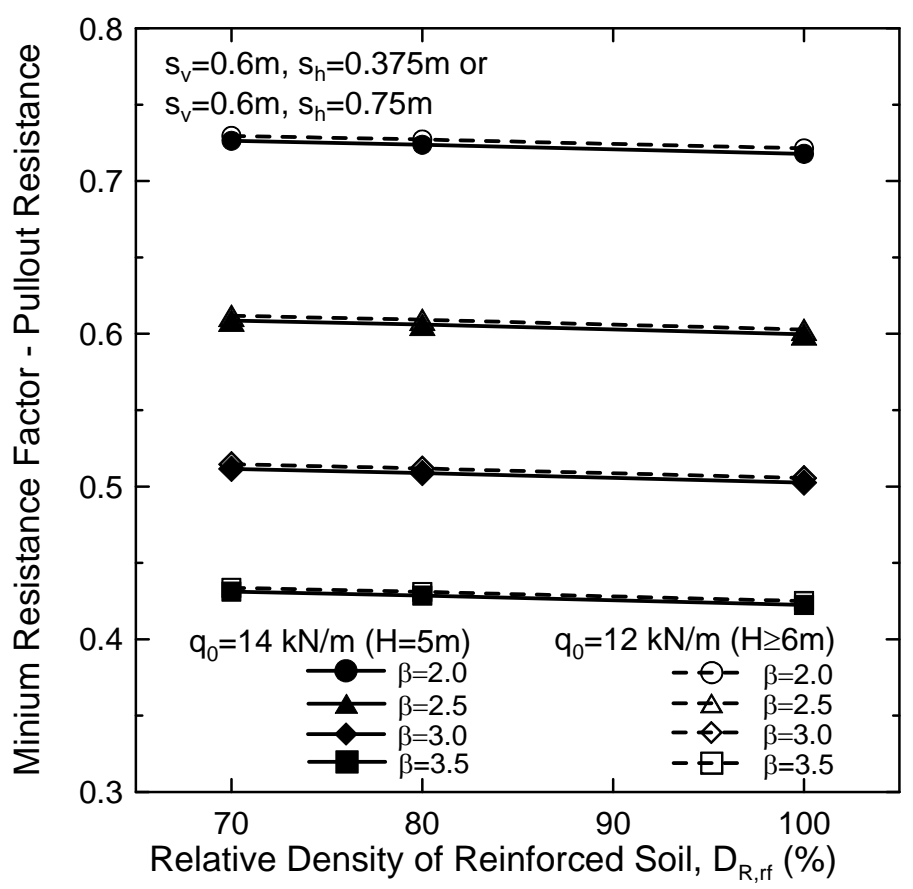

Figure 8.4 Minimum RF for pullout of steel-strip reinforcement for different values of $D_{R, r f}$ when $s_{V}=0.6 m\left(q_{0}\right.$ is the live surcharge load)

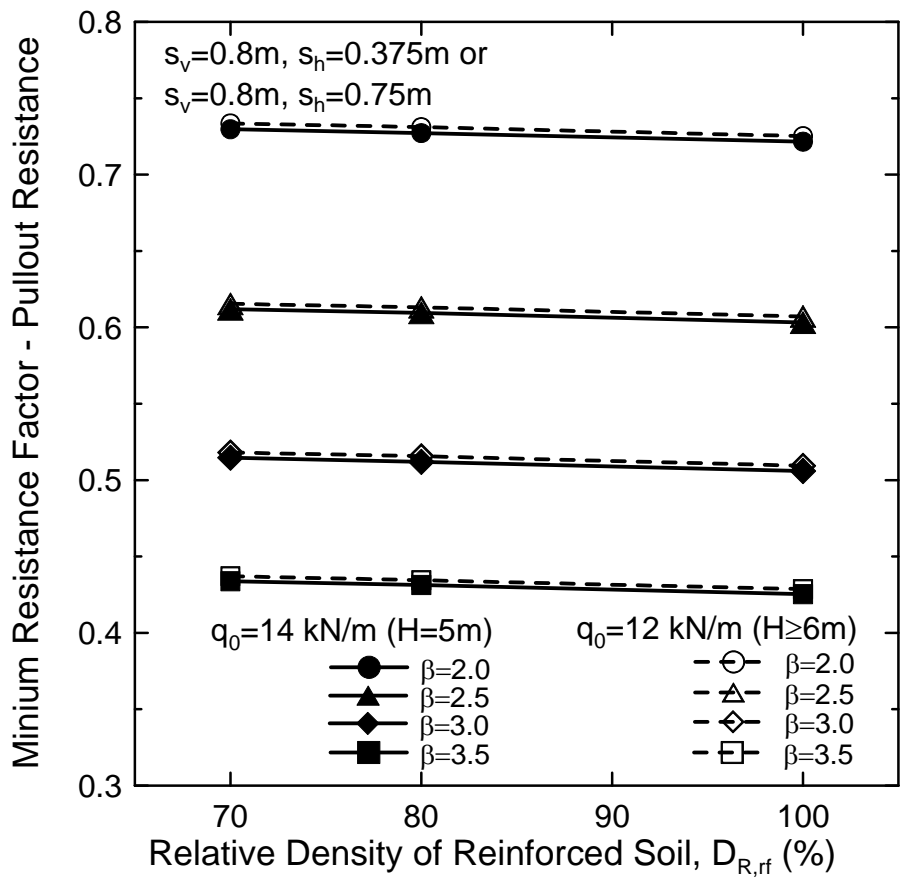

Figure 8.5 Minimum RF for pullout of steel-strip reinforcement for different values of $\mathrm{D}_{\mathrm{R}, \mathrm{rf}}$ when $\mathrm{s}_{\mathrm{v}}=0.8 \mathrm{~m}\left(\mathrm{q}_{0}\right.$ is the live surcharge load $)$ 


\subsection{Effect of the Change in the Critical-State Interface Friction Angle of the Steel-Strip}

\section{Reinforcement on RF}

The effect of the critical-state friction angle $\delta_{\mathrm{cv}}$ of the steel-strip reinforcement on the RF was assessed by performing the analyses for three different values of $\delta_{\mathrm{cv}}(25,28.5$, and $32^{\circ}$ ). The minimum RF values are obtained and shown in Figure 8.6 through Figure 8.8. For a given MSE wall, the minimum RF value from the values for all the steel-strip reinforcement levels of MSE walls is found at the first reinforcement level from the top of the MSE wall. This minimum RF value decreased with increasing $\delta_{\mathrm{cv}}$ and increased slightly as the first reinforcement depth $\mathrm{z}$ from the top of the MSE walls increased.

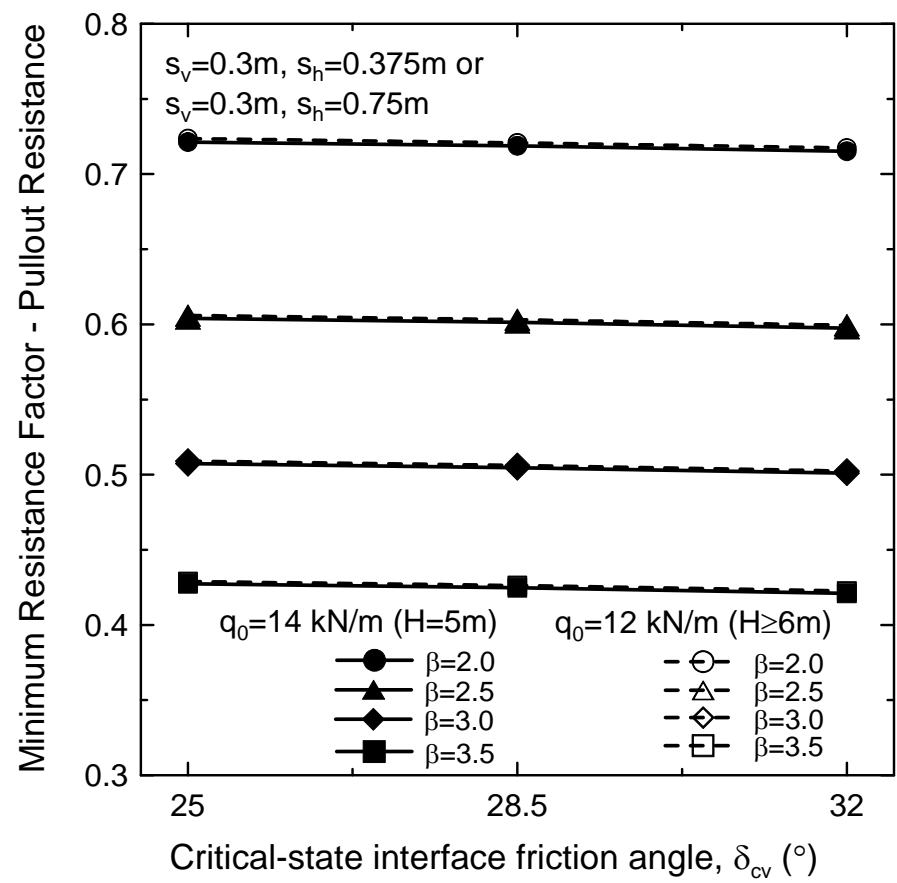

Figure 8.6 Minimum RF for pullout of steel-strip reinforcement for different values of $\delta_{\mathrm{cv}}$ when $\mathrm{s}_{\mathrm{v}}=0.3 \mathrm{~m}\left(\mathrm{q}_{0}\right.$ is the live surcharge load $)$ 


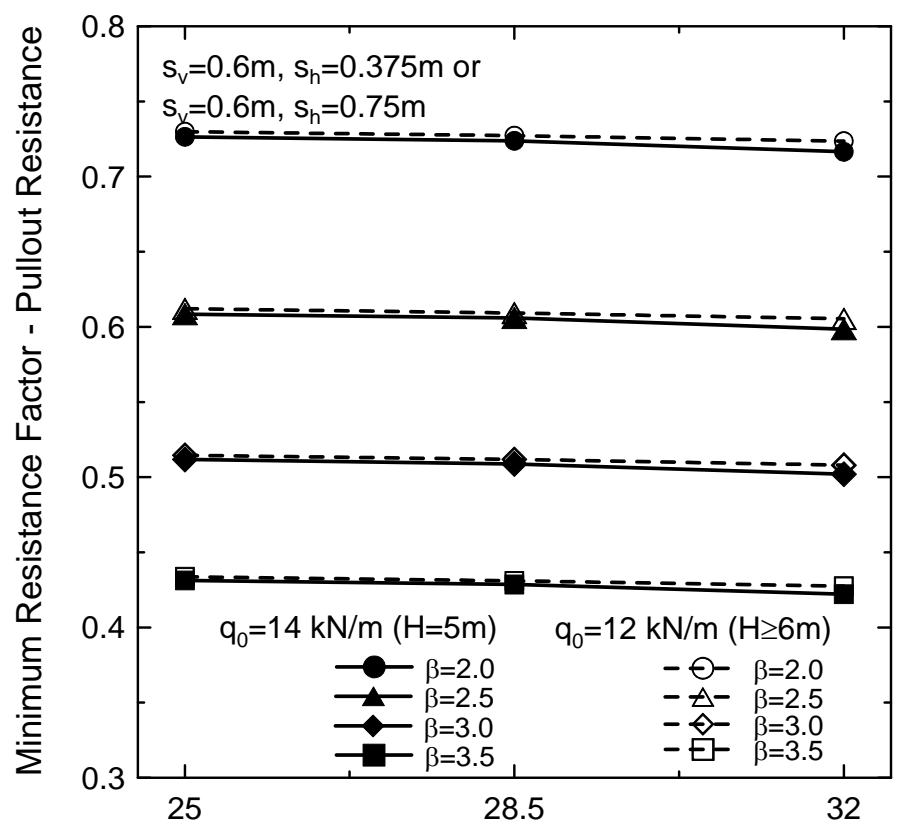

Critical-state interface friction angle, $\delta_{\mathrm{cv}}\left({ }^{\circ}\right)$

Figure 8.7 Minimum RF for pullout of steel-strip reinforcement for different values of $\delta_{\mathrm{cv}}$ when $\mathrm{s}_{\mathrm{v}}=0.6 \mathrm{~m}\left(\mathrm{q}_{0}\right.$ is the live surcharge load $)$

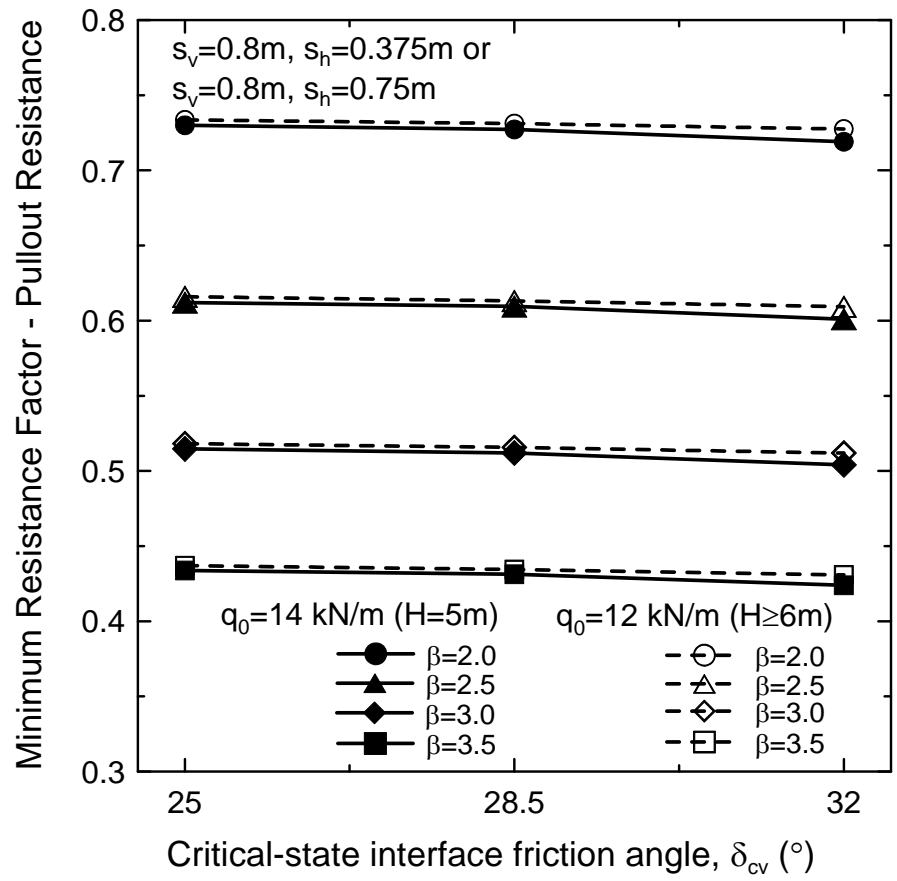

Figure 8.8 Minimum RF for pullout of steel-strip reinforcement for different values of $\delta_{\mathrm{cv}}$ when $\mathrm{s}_{\mathrm{v}}=0.8 \mathrm{~m}\left(\mathrm{q}_{0}\right.$ is the live surcharge load) 


\subsection{Effect of the Change in Unit Weight of Retained Soil on RF}

The effect of the change in the unit weight of the retained soil $\gamma_{\mathrm{rt}}$ on the RF value was investigated using two different $\gamma_{\mathrm{rt}}$ values $\left(18\right.$ and $\left.20 \mathrm{kN} / \mathrm{m}^{3}\right)$ and fixing the values of the other parameters. The unit weight of the retained soil $\gamma_{\mathrm{rt}}$ is used in the ULS equations for sliding and overturning but it is not used in the internal stability ULS equations.

\subsubsection{External stability - sliding}

The effect of the $\gamma_{\mathrm{rt}}$ on the RF value was investigated for sliding. Figure 8.9 shows that the RF values increased with increasing $\gamma_{\mathrm{rt}}$. The change in the RF values due to the difference on the $\gamma_{\mathrm{rt}}$ was noticeable. The increase in the RF value was more significant for higher MSE walls.

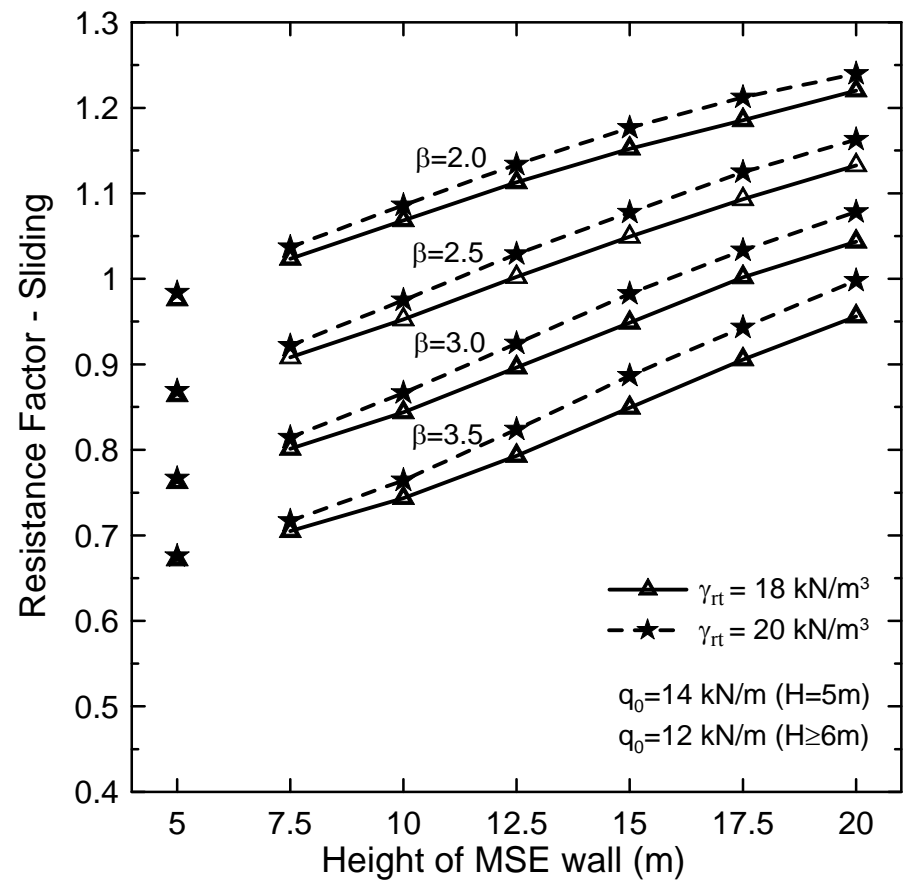

Figure 8.9 RF for sliding for different MSE wall heights when $\gamma_{\mathrm{rt}}=18$ and $20 \mathrm{kN} / \mathrm{m}^{3}\left(\mathrm{q}_{0}\right.$ is the live surcharge load) 


\subsubsection{External stability - overturning}

The calculation of the RF values was done for overturning under the same conditions that were used in the RF calculation for sliding. Similarly to the sliding case, the RF value increased with increasing $\gamma_{\mathrm{rt}}$. The change in the RF values due to changes in $\gamma_{\mathrm{rt}}$ was very small for lower MSE walls; the change in the RF value became more substantial as the height of the MSE wall increased, as shown in Figure 8.10.

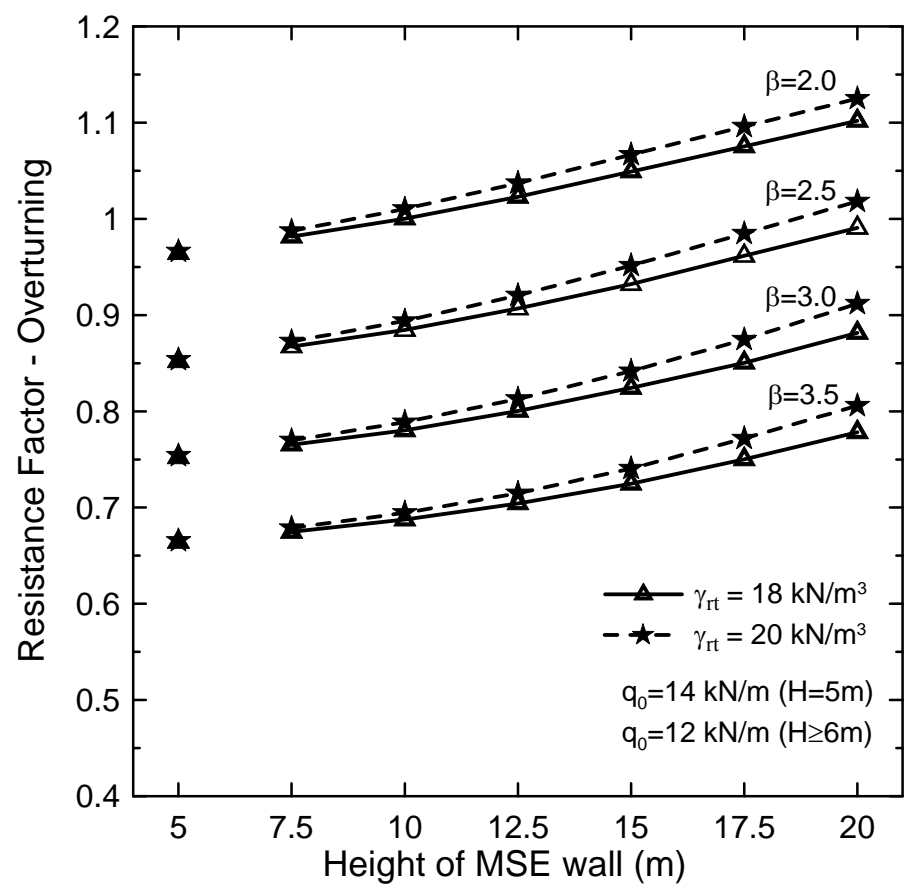

Figure 8.10 RF for overturning for different MSE wall heights when $\gamma_{\mathrm{rt}}=18$ and $20 \mathrm{kN} / \mathrm{m}^{3}$ ( $\mathrm{q}_{0}$ is the live surcharge load)

\subsection{Effect of the Change in the Unit Weight of the Reinforced Soil on RF}

The effect of the change in the unit weight $\gamma_{\mathrm{rf}}$ of the reinforced soil on the RF values for sliding, overturning, and pullout was examined by performing an analysis for two 
different values of $\gamma_{\mathrm{rf}}\left(20\right.$ and $\left.22 \mathrm{kN} / \mathrm{m}^{3}\right)$, fixing the values of the other parameters. The effect of the change in $\gamma_{\mathrm{rf}}$ on RF for each criterion was insignificant.

\subsubsection{External stability - sliding}

The effect of the change in $\gamma_{\mathrm{rf}}$ on the RF for sliding was negligible, as shown in Figure 8.11. The RF values for the higher $\gamma_{\mathrm{rf}}\left(22 \mathrm{kN} / \mathrm{m}^{3}\right)$ were slightly higher than those for the lower $\gamma_{\mathrm{rf}}\left(20 \mathrm{kN} / \mathrm{m}^{3}\right)$.

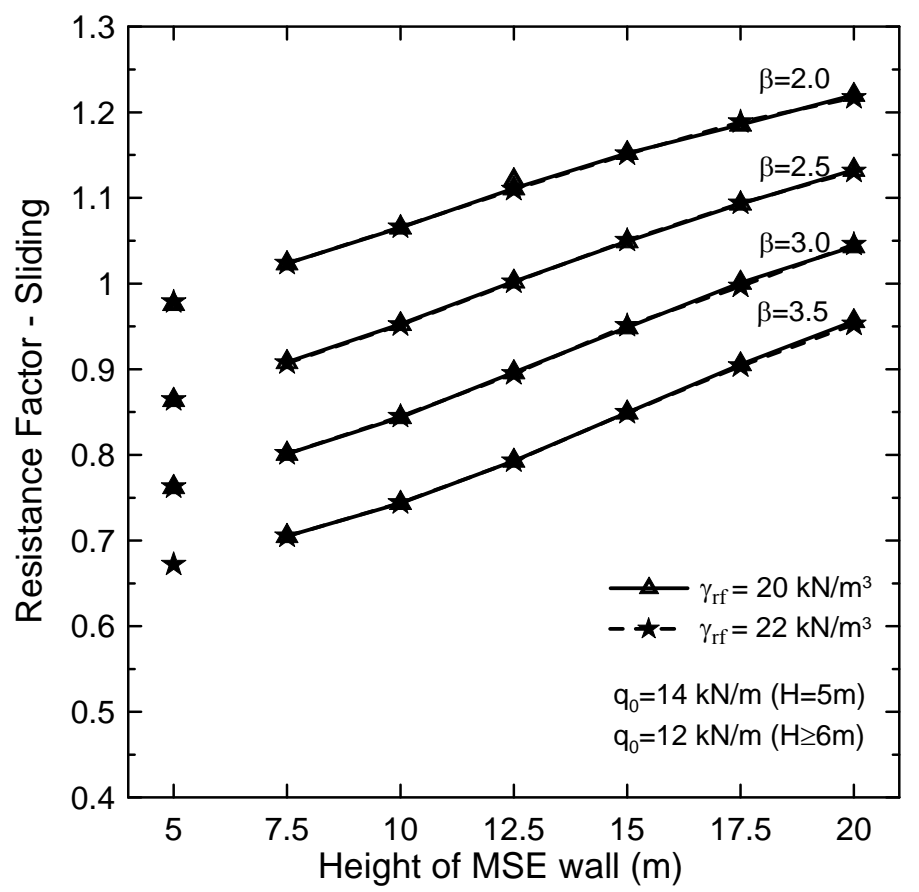

Figure 8.11 RF for sliding for different MSE wall heights when $\gamma_{\mathrm{rf}}=20$ and $22 \mathrm{kN} / \mathrm{m}^{3}\left(\mathrm{q}_{0}\right.$ is the live surcharge load)

8.5.2. External stability - overturning 
Similarly to sliding, the RF values did change significantly due to the change in $\gamma_{\mathrm{rf}}$, as shown in Figure 8.12. There was an insignificant increase in the RF value when the $\gamma_{\mathrm{rf}}$ changed from 20 to $22 \mathrm{kN} / \mathrm{m}^{3}$.

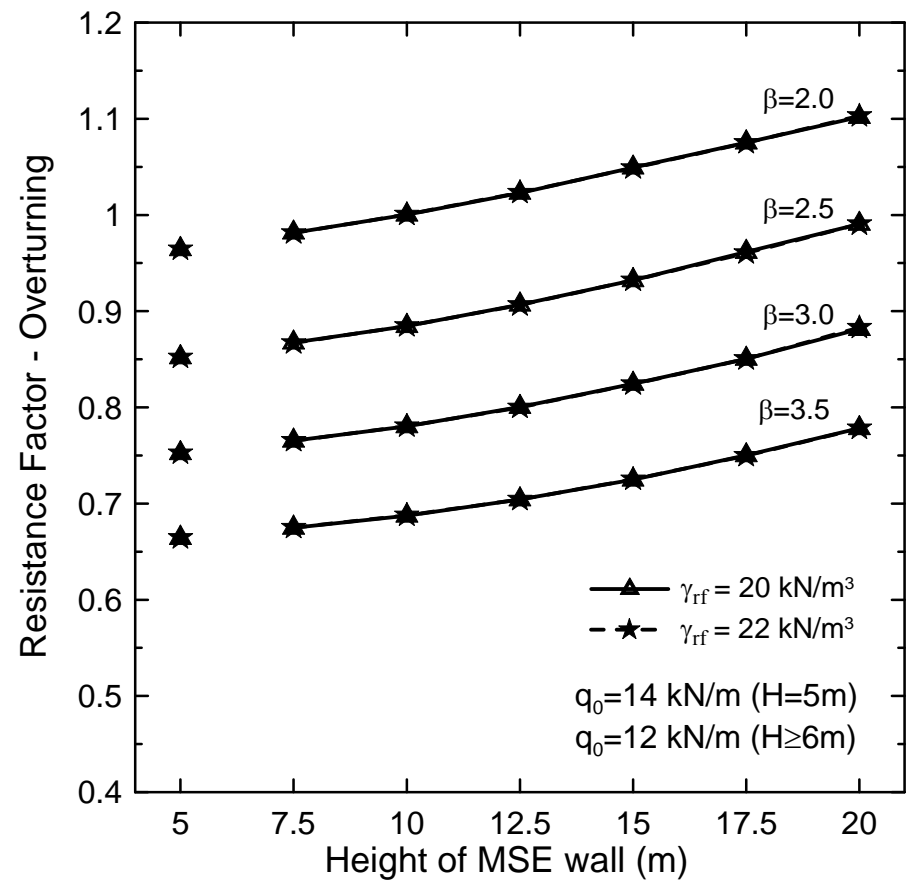

Figure 8.12 RF for overturning for different MSE wall heights when $\gamma_{\mathrm{rf}}=20$ and 22 $\mathrm{kN} / \mathrm{m}^{3}\left(\mathrm{q}_{0}\right.$ is the live surcharge load)

\subsubsection{Internal stability - steel-strip reinforcement pullout}

The effect of the unit weight $\gamma_{\mathrm{rf}}$ of the reinforced soil on the minimum RF value was also insignificant for pullout of the steel-strip reinforcement, as illustrated in Figure 8.13 and Figure 8.14. For a given reinforcement level, the RF value increased slightly with increasing $\gamma_{\mathrm{rf}}$. 


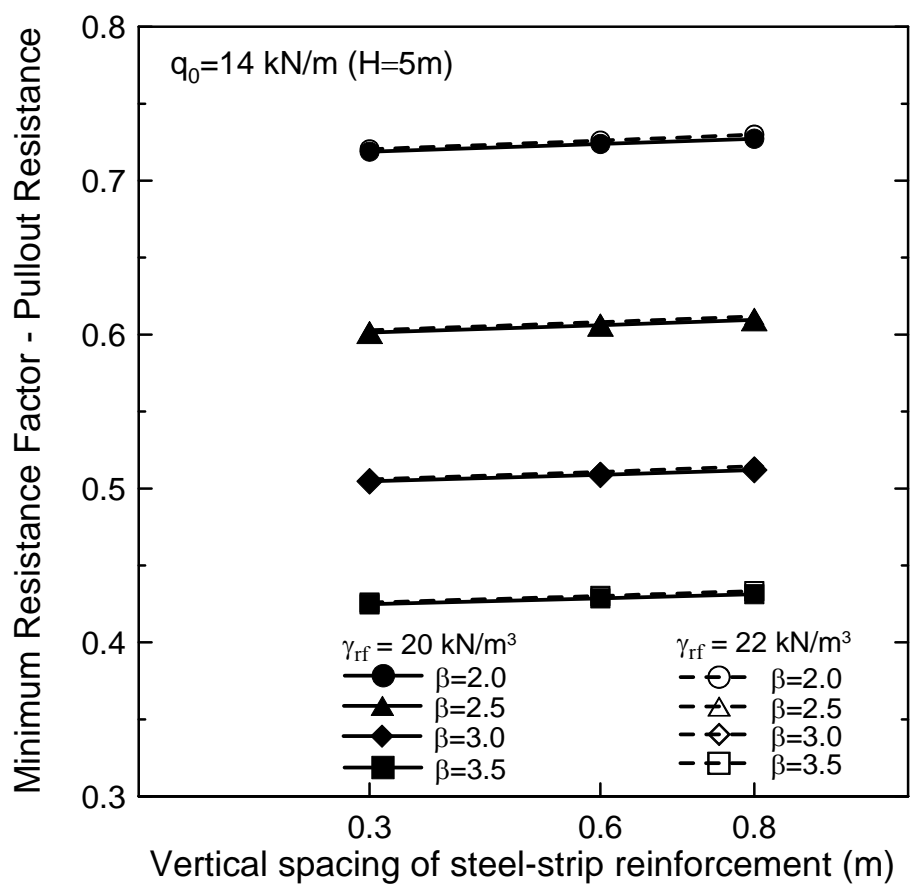

Figure 8.13 Minimum RF for pullout of steel-strip reinforcement for different vertical spacings of reinforcement for $\gamma_{\mathrm{rf}}=20$ and $22 \mathrm{kN} / \mathrm{m}^{3}(\mathrm{H}=5 \mathrm{~m})$

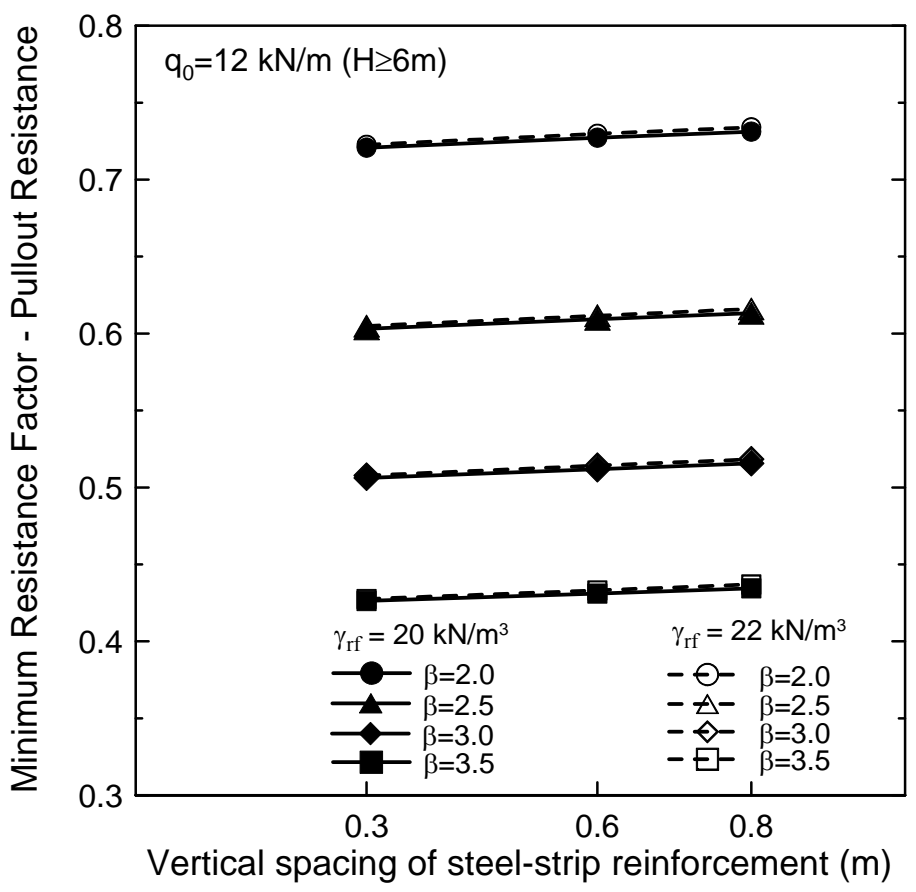

Figure 8.14 Minimum RF for pullout of steel-strip reinforcement for different vertical spacings of reinforcement for $\gamma_{\mathrm{rf}}=20$ and $22 \mathrm{kN} / \mathrm{m}^{3}(\mathrm{H} \geq 6 \mathrm{~m})$ 


\subsubsection{Internal stability - structural failure of steel-strip reinforcement}

The change of the unit weight $\gamma_{\mathrm{rf}}$ of the reinforced soil from 20 to $22 \mathrm{kN} / \mathrm{m}^{3}$ caused negligible change in RF value. The difference between RF values when $\gamma_{\mathrm{rf}}=20 \mathrm{kN} / \mathrm{m}^{3}$ and those when $\gamma_{\mathrm{rf}}=22 \mathrm{kN} / \mathrm{m}^{3}$ is less than $10^{-4}$. Therefore, the RF values given in Table 7.14 from the previous example (section 7.6.2) can be used as proposed RF values in design for structural failure of steel-strip reinforcement.

Table 8.1 RF value for structural failure of steel-strip reinforcement for $\gamma_{\mathrm{rf}}=20$ and 22 $\mathrm{kN} / \mathrm{m}^{3}$ (when live surcharge load $\mathrm{q}_{0}=12 \mathrm{kN} / \mathrm{m}$ )

\begin{tabular}{|c|c|c|c|c|}
\hline \multirow{2}{*}{} & \multicolumn{4}{|c|}{ Target reliability index, $\beta_{\mathrm{T}}$} \\
\cline { 2 - 5 } & 3.5 & 3 & 2.5 & 2 \\
\hline RF & 0.66 & 0.72 & 0.79 & 0.87 \\
\hline
\end{tabular}

\section{6. $\underline{\text { Results }}$}

In the earlier sections in this chapter, we examined the effects of the changes in the parameters $\phi_{\mathrm{c}, \mathrm{rt}}, \mathrm{D}_{\mathrm{R}, \mathrm{rf}}, \delta_{\mathrm{cv}}, \gamma_{\mathrm{d}, \mathrm{rt}}$, and $\gamma_{\mathrm{d}, \mathrm{rf}}$ on RF. For a given reinforcement depth $\mathrm{z}$, the RF value slightly increased with increasing $\phi_{\mathrm{c}, \mathrm{rt}}, \gamma_{\mathrm{d}, \mathrm{rt}}$, and $\gamma_{\mathrm{d}, \mathrm{rf}}$ and slightly decreased with increasing $D_{R, r f}$ and $\delta_{c v}$. For the recommendation of RF values for LRFD for MSE walls, we calculated the RF values for both external limit states (sliding and overturning) and internal limit state (pullout of steel-strip reinforcement) by changing the parameter values with its possible ranges $\left(\phi_{\mathrm{c}, \mathrm{rt}}=28-36^{\circ}, \mathrm{D}_{\mathrm{R}, \mathrm{rf}}=70-100 \%, \delta_{\mathrm{cv}}=28-32^{\circ}, \gamma_{\mathrm{d}, \mathrm{rt}}=17-20 \mathrm{kN} / \mathrm{m}^{3}\right.$, and $\gamma_{\mathrm{d}, \mathrm{rf}}=20-22 \mathrm{kN} / \mathrm{m}^{3}$ ). The worst case scenario for each limit state seems to develop when the parameters have the following values: (1) $D_{R, r f}=100 \%$; (2) $\gamma_{\mathrm{d}, \mathrm{ff}}=20 \mathrm{kN} / \mathrm{m}^{3}$; (3) $\gamma_{\mathrm{d}, \mathrm{rt}}=17 \mathrm{kN} / \mathrm{m}^{3} ;$ (4) $\phi_{\mathrm{c}, \mathrm{rt}}=28^{\circ}$; and (5) $\delta_{\mathrm{cv}}=32^{\circ}$. 
RF values of the worst case scenario for each limit state are compared with those values calculated in the examples in chapter 6 and chapter 7 . The RF values of the worst case scenario for each limit state could be proposed as the recommended RFs for LRFD for MSE walls when the design is done following all the proposed method in this report.

\subsubsection{External stability - sliding}

Both the RF values for sliding calculated in the example in chapter 6 and those of the worst case scenario increased with increasing MSE wall height and decreasing target reliability index. However, the difference in the RF value between these two cases increases with an increasing height of the MSE walls as shown in Figure 8.15.

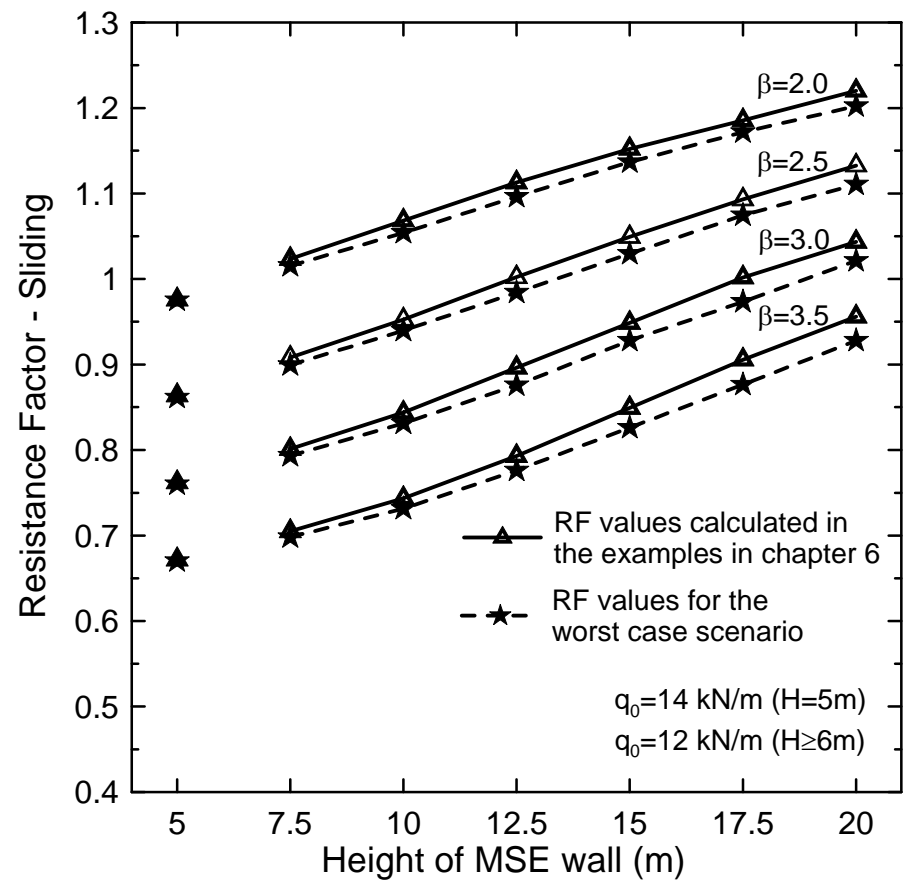

Figure 8.15 Comparison between the RF values of the worst case scenario (producing the lowest RF value) and those calculated in the examples in chapters 6 for sliding ( $\mathrm{q}_{0}$ is the live surcharge load) 


\subsubsection{External stability - overturning}

Similarly to sliding, the RF values for overturning for both the worst case scenario and those calculated in the example in chapter 6 increased with increasing MSE wall height. The difference between the RF values of these two cases increased with increasing MSE wall height, but the difference is less significant than for sliding.

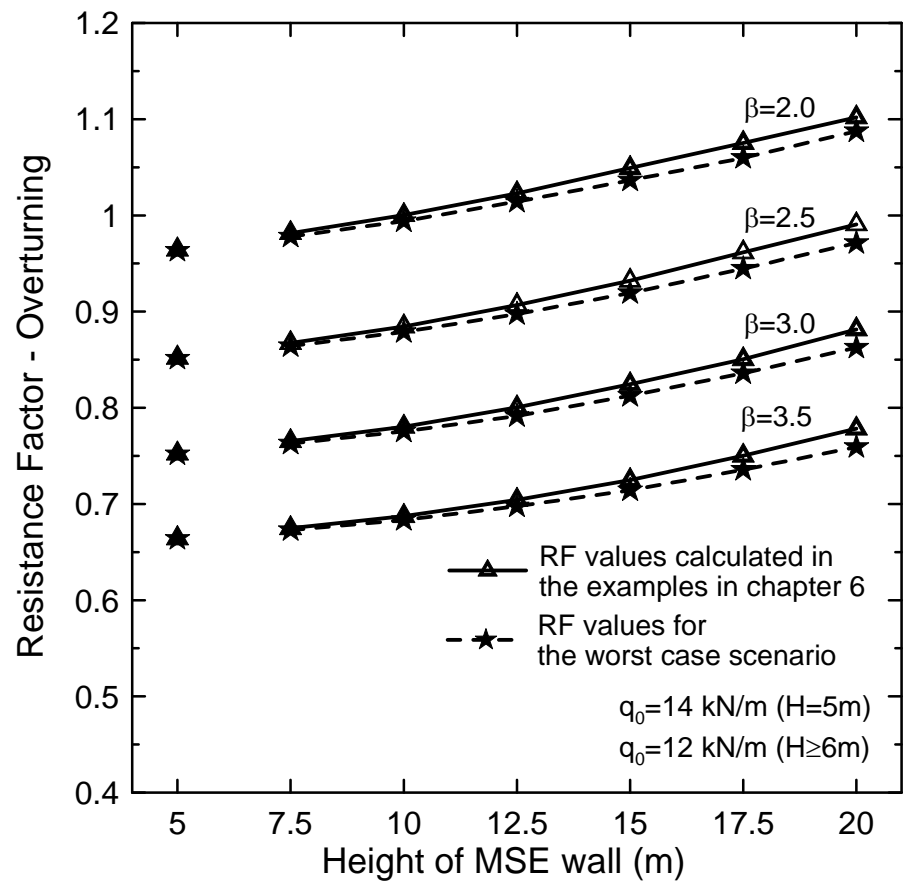

Figure 8.16 Comparison between the RF values of the worst-case scenario (producing the lowest RF value) and those calculated in the examples in chapters 6 for overturning ( $q_{0}$ is the live surcharge load)

\subsubsection{Internal stability - pullout of steel-strip reinforcement}

In the previous chapter (chapter 7), it was found that the RF value for pullout of the steelstrip reinforcement was independent of the horizontal spacing of the reinforcement. The comparison between the minimum RF values for pullout for the worst case scenario and those calculated in the example in chapter 7 is made and shown in Figure 8.17 and Figure 
8.18. Figure 8.17 represents the RF values for an MSE wall height equal to $5 \mathrm{~m}$, while Figure 8.18 shows the RF values for MSE wall heights equal to or greater than $6 \mathrm{~m}$. The $\mathrm{RF}$ for the worst case scenario was noticeably less than the RF values calculated in the example in chapter 7 .

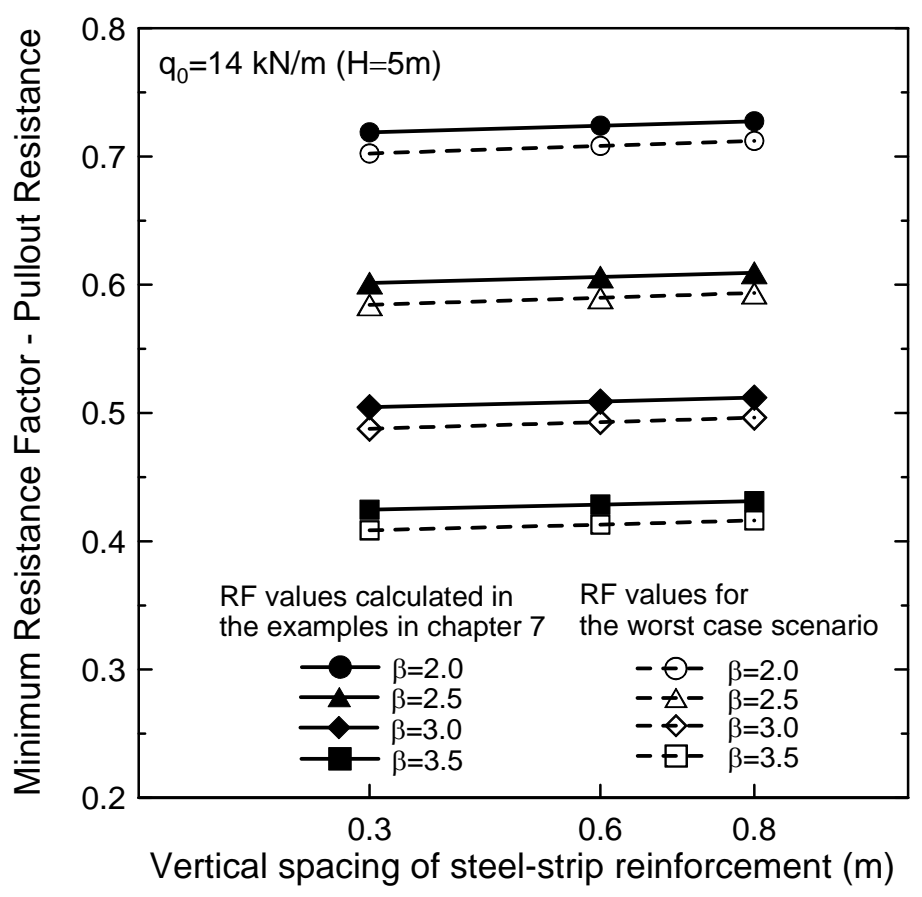

Figure 8.17 Comparison between the minimum RF values of the worst-case scenario (producing the lowest RF value) and those calculated in the examples in chapter 7 for reinforcement pullout $(\mathrm{H}=5 \mathrm{~m})\left(\mathrm{q}_{0}\right.$ is the live surcharge load) 


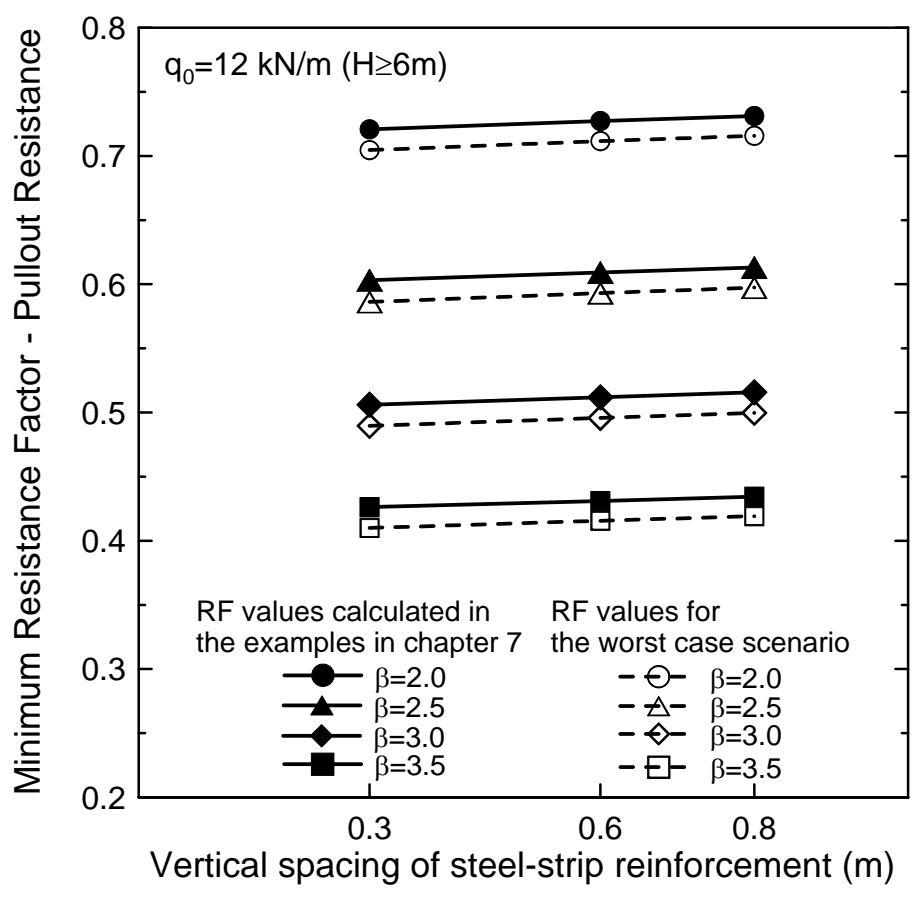

Figure 8.18 Comparison between the minimum RF values of the worst-case scenario (producing the lowest RF value) and those calculated in the examples in chapter 7 for reinforcement pullout $(\mathrm{H} \geq 6 \mathrm{~m})\left(\mathrm{q}_{0}\right.$ is the live surcharge load)

\subsection{Tentative RF Value Recommendations for Each Limit State}

The RF values for sliding and overturning are shown in Table 8.2 and Table 8.3, respectively. These RF values are rounded down after the second decimal place. Several values of RF in Table 8.2 and Table 8.3 are higher than one. This is because the load factors from AASHTO specifications (2007) are higher than the optimum load factors for these cases. However, the optimum resistance factors of these cases are less than one. 
Table 8.2 RF values for sliding criterion

\begin{tabular}{|c|c|c|c|c|}
\hline \multirow{2}{*}{$\begin{array}{c}\text { Height of MSE wall } \\
(\mathrm{m})\end{array}$} & \multicolumn{5}{|c|}{ Target reliability index $\beta_{\mathrm{T}}$} \\
\cline { 2 - 5 } & 2.0 & 2.5 & 3.0 & 3.5 \\
\hline 5 & 0.98 & 0.86 & 0.76 & 0.67 \\
\hline 7.5 & 1.02 & 0.90 & 0.79 & 0.69 \\
\hline 10 & 1.05 & 0.94 & 0.83 & 0.73 \\
\hline 12.5 & 1.10 & 0.98 & 0.88 & 0.77 \\
\hline 15 & 1.14 & 1.03 & 0.93 & 0.82 \\
\hline 17.5 & 1.17 & 1.07 & 0.97 & 0.87 \\
\hline 20 & 1.20 & 1.11 & 1.02 & 0.92 \\
\hline
\end{tabular}

Table 8.3 RF values for overturning criterion

\begin{tabular}{|c|c|c|c|c|}
\hline \multirow{2}{*}{$\begin{array}{c}\text { Height of MSE wall } \\
(\mathrm{m})\end{array}$} & \multicolumn{4}{|c|}{ Target reliability index $\beta_{\mathrm{T}}$} \\
\cline { 2 - 5 } & 2.0 & 2.5 & 3.0 & 3.5 \\
\hline 5 & 0.96 & 0.85 & 0.75 & 0.66 \\
\hline 7.5 & 0.98 & 0.86 & 0.76 & 0.67 \\
\hline 10 & 0.99 & 0.88 & 0.78 & 0.68 \\
\hline 12.5 & 1.01 & 0.90 & 0.79 & 0.69 \\
\hline 15 & 1.04 & 0.92 & 0.81 & 0.71 \\
\hline 17.5 & 1.06 & 0.94 & 0.84 & 0.73 \\
\hline 20 & 1.09 & 0.97 & 0.86 & 0.75 \\
\hline
\end{tabular}

The minimum pullout RF values from the values for all the steel-strip reinforcement levels are given in Table 8.4 and Table 8.5. The small difference of RF values between Table 8.4 and Table 8.5 results from different magnitudes of the live uniform surcharge load acting on the top of the reinforced soil $(14 \mathrm{kN} / \mathrm{m}$ for $5 \mathrm{~m}$-high MSE walls and $12 \mathrm{kN} / \mathrm{m}$ for MSE walls more than $6 \mathrm{~m}$ tall). Typically, the reinforcement length is controlled by the first reinforcement length, and the RF for pullout is proposed 
accordingly. In addition, the RF values for structural failure of steel-strip reinforcement are given in Table 8.6.

Table 8.4 Minimum RF value for pullout of steel-strip reinforcement for 5m-high MSE wall (with $\mathrm{q}_{0}=14 \mathrm{kN} / \mathrm{m}$ )

\begin{tabular}{|c|c|c|c|c|}
\hline \multirow{2}{*}{$\begin{array}{c}\text { The first reinforcement } \\
\text { depth (m) }\end{array}$} & \multicolumn{4}{|c|}{ Target reliability index $\beta_{\mathrm{T}}$} \\
\cline { 2 - 5 } & 2.0 & 2.5 & 3.0 & 3.5 \\
\hline 0.3 & 0.70 & 0.58 & 0.48 & 0.40 \\
\hline 0.6 & 0.70 & 0.58 & 0.49 & 0.41 \\
\hline 0.8 & 0.71 & 0.59 & 0.49 & 0.41 \\
\hline
\end{tabular}

Table 8.5 Minimum RF value for pullout of steel-strip reinforcement for MSE walls more than $6 \mathrm{~m}$-tall (with $\mathrm{q}_{0}=12 \mathrm{kN} / \mathrm{m}$ )

\begin{tabular}{|c|c|c|c|c|}
\hline \multirow{2}{*}{$\begin{array}{c}\text { The first reinforcement } \\
\text { depth (m) }\end{array}$} & \multicolumn{4}{|c|}{ Target reliability index $\beta_{\mathrm{T}}$} \\
\cline { 2 - 5 } & 2.0 & 2.5 & 3.0 & 3.5 \\
\hline 0.3 & 0.70 & 0.58 & 0.48 & 0.40 \\
\hline 0.6 & 0.71 & 0.59 & 0.49 & 0.41 \\
\hline 0.8 & 0.71 & 0.59 & 0.49 & 0.41 \\
\hline
\end{tabular}

Table 8.6 RF value for structural failure of steel-strip reinforcement

\begin{tabular}{|c|c|c|c|c|}
\hline \multirow{2}{*}{} & \multicolumn{4}{|c|}{ Target reliability index, $\beta_{\mathrm{T}}$} \\
\cline { 2 - 5 } & 3.5 & 3 & 2.5 & 2 \\
\hline RF & 0.66 & 0.72 & 0.79 & 0.87 \\
\hline
\end{tabular}




\section{CHAPTER 9. CONCLUSIONS AND RECOMMENDATIONS}

\subsection{Introduction}

The main objective of this project was to develop LRFD methods for slopes and MSE walls using ULS design concepts and probability theory. The study also suggests resistance factor $(\mathrm{RF})$ values that are compatible with the LFs of the AASHTO LRFD specifications (2007). The suggested optimum factors for LRFD of slopes and RF values for LRFD of MSE walls were obtained from the result of extensive reliability analyses on the basis of a rational assessment of uncertainties of the parameters that are used in the analysis.

To accomplish these goals for LRFD of slopes, (1) the algorithm for LRFD of slopes was developed, (2) the sources of uncertainty of each pertinent property were classified and examined, (3) the Gaussian random field concept was used for a more realistic representation of the soil parameters of slopes, (4) extensive Monte Carlo simulations were conducted to find the driving and resisting moments at the ULS for which the calculated probability of failure is equal to the target probability of failure, (5) optimum load and resistance factors were obtained using the ultimate limit state values and nominal values of driving and resisting moments.

For LRFD of MSE walls, (1) Limit states were identified, (2) a framework for LRFD of MSE walls was developed, (3) ULSs were mathematically defined in a way that is consistent with both the physics of the problems and the engineering requirements, (4) the uncertainties of parameters, transformations, and models used in the analysis were assessed, (5) reliability analysis for each limit state was done using FORM, and (6) the $\mathrm{RF}$ value for each limit state was suggested. 
At the end of this chapter, recommendations are presented for implementation in practice that could improve the accuracy and reliability of the RF values for LRFD of slopes and MSE walls.

\subsection{LRFD of Slopes}

We have successfully employed Gaussian random field theory for the representation of spatial (inherent) soil variability. The reliability analysis program developed for LRFD of slopes using Monte Carlo simulations in conjunction with the soil parameters represented by Gaussian random fields works well and provides reliable results.

Even for the given target probability of failure, geometry of slope, and mean values of parameters and their uncertainties, there is no uniqueness of the RF value for slopes. In other words, the RF value resulting from Monte Carlo simulations varies from case to case. This is because the Gaussian random fields and also the slip surface at the ULS for each random realization of a slope defined by the mean values of the strength parameters and unit weights of each layer and of the live load are different from simulation to simulation. We have proposed a way to deal with this nonuniqueness that provides an acceptable basis on which to make resistance factor recommendations.

\subsection{LRFD of MSE Walls}

For each limit state, the First-Order Reliability Method (FORM) was successfully used to compute the values of loads and resistance at the ULS for the given target reliability index and the corresponding optimal load and resistance factors.

A parametric study of the external stability (sliding and overturning) of MSE walls identified the unit weight of the retained soil as the parameter with the most impact on the RF value. This seems to be because the change of the unit weight of the retained soil results in a change of the composition of the uncertainty of the total lateral load acting on the reinforced soil. For example, if the unit weight of the retained soil increases, 
the ratio of the lateral load due to the live uniform surcharge load to the lateral load due to the self-weight of the retained soil decreases. Therefore, the uncertainty of the total load decreases because the lateral load due to the live uniform surcharge load has a much higher bias factor and COV compared to those of the lateral load due to the self-weight of the retained soil. Consequently, the RF values for sliding and overturning increase as the height of the MSE wall increases.

For pullout of the steel-strip reinforcement, the most important parameter on the $\mathrm{RF}$ value is the relative density of the reinforced soil because not only the relative density has the highest COV among all the parameters but also the mean value of the relative density has a significant influence on the pullout resistance factor. In addition, the level (or the vertical location) of the steel-strip reinforcement also has considerable impact on the RF value because the reinforcement level changes the uncertainty of total load significantly by changing the ratio of the load due to the self-weight of the reinforced soil to the load due to the live uniform surcharge load.

In this report, we found the worst cases, which have the lowest RF values, by varying the parameters within their possible ranges for different MSE wall heights and different target reliability indices. The "worst-case" RF values for sliding and overturning are given in the report (Table 8.2 and Table 8.3). The "worst-case" RF values for pullout, which occur at the first reinforcement level from the top of the MSE wall, are suggested as RF values to use in pullout failure checks (Table 8.4 and Table 8.5). The "worst-case" $\mathrm{RF}$ values for structural failure are recommended as RF values to use in structural failure checks (Table 8.6). Usually, the required reinforcement length $\mathrm{L}$ at the first reinforcement level from the top of an MSE wall is used for all the other reinforcement levels when the vertical and horizontal spacing of the reinforcements are the same. Therefore, in general, this required reinforcement length $\mathrm{L}$ can be calculated using the RF value for pullout at the first reinforcement depth $\mathrm{z}$. 


\subsection{Recommendations for Future Study}

RF values for LRFD of slopes and MSE walls in this report are calculated based on analyses done for a limited number of conditions. The RF values for slopes and MSE wall designs given in this report are valid only when designers use (i) the equations for load and resistance and (ii) the test methods for design parameters given in this report. The RF values are computed for two different target probabilities of failure $\left(\mathrm{P}_{\mathrm{f}}=0.001\right.$ and 0.01$)$ for slopes and four different target reliability indices $\left(\beta_{\mathrm{T}}=2.0,2.5,3.0\right.$, and 3.5) for MSE walls. The higher values of target probability of failure $(0.01)$ and the lower values of target reliability index (2.0 and 2.5) are provided for illustration purposes, as they would typically be excessively daring in most design problems. For slope stability, resistance factors for a probability of failure lower than 0.001 would require considerable time to calculate. In practice, the importance of the structure may vary; therefore, designers should select an appropriate target probability of failure (or target reliability index) that would produce an economical design without excessive risk to the stability of a structural and geotechnical system.

For development of complete and reliable sets of resistance factors for LRFD of slopes and MSE walls, we recommend the following:

(1) It is necessary to perform comprehensive research on the classification of the type of error associated with measurements, which is a process that requires extensive effort in testing and data collection. This effort would make it possible to assess the uncertainty of systematic error more accurately. As uncertainties in parameters reflect directly on RF values, improved assessment of these uncertainties would be very beneficial.

(2) The load factors provided in the current AASHTO LRFD specifications (2007) are equal to one regardless of the load type. This means that RF values $(0.75$ when the geotechnical parameters are well defined and the slope does not support or contain a structural element, and 0.65 when the geotechnical parameters are based on limited information or the slope contains or supports a structural 
element) proposed in the specifications are inverse values of the factors of safety (1.3 and 1.5) that were given in the old AASHTO specifications. Thus, LRFD of slopes as currently covered by the AASHTO specifications is in effect the same as Working Stress Design (WSD). Use of the algorithm provided in this report would produce appropriate load factors that reflect the uncertainty of the corresponding loadings and allow determination of suitable resistance factors. Then, the current load and resistance factor for LRFD of slopes in the AASHTO LRFD specifications could be updated to more closely reflect the principles of LRFD.

(3) More analyses are necessary for determining RF values for slope design. The following all should be explored: (i) different geometries; (ii) different external loading conditions (load type, location, and magnitude); (iii) different combinations of soil layers; (iv) different combinations of the values of soil property (considering wide ranges of soil property values); (v) wider ranges of probability of failure (and, in particular, lower probabilities of failure); (vi) repeatability checks to further validate the method proposed to handle the nonuniqueness of resistance and load factors resulting from different simulations.

(4) Similarly to slopes, more analyses varying MSE wall geometry, loading condition and soil properties will be helpful to expand LRFD for MSE wall design for different site conditions.

(5) The RF value for general loss of stability of MSE walls could be examined using the appropriate load factors determined from extensive Monte Carlo simulations for LRFD of slopes.

(6) For certain geotechnical structures, such as levees, dams or abutments of large and massive bridges, lower target probabilities of failure (or higher target 
reliability index) should be considered. A more careful study of acceptable values of probability of failure should be conducted. 


\section{LIST OF REFERENCES}

AASHTO, 2002, Standard Specifications for Highway Bridges, American Association of State Highway and Transportation Officials, $17^{\text {th }}$ Edition, Washington, D.C., USA

AASHTO, 2007, LRFD Bridge Design Specifications, American Association of State Highway and Transportation Officials, $4^{\text {th }}$ Edition, Washington, D.C., USA

AISC, 2005, Specification for Structural Steel Buildings, American Institute of Steel Construction, Inc, 3rd printing, Chicago, Illinois, USA

ASCE/SEI 7-05, 2006, Minimum Design Loads for Buildings and Other Structures, American Society of Civil Engineers

Al-Homoud, A.S. And Tanash, N. (2001). "Monitoring and analysis of settlement and stability of an embankment dam constructed in stages on soft ground." Bulletin of Engineering Geology and the Environment, 59(4), 259-284.

Allen, T., Christopher, B., Elias, V., and DeMaggio, J. (2001). Development of the Simplified Method for Internal Stability Design of Mechanically Stabilized Walls, WDOT, Report number WA-RD 513.1

Allen, T. and Bathurst, R. J. (2003). Prediction of Reinforcement Loads in Reinforced Soil Walls, WDOT, Report number WA-RD 522.2 
Asaoka, A. and A-Grivas, D. (1982). "Spatial Variability of the Undrained Strength of Clays.” Journal of Geotechnical Engineering Division, 108(GT5), 743-756.

Auvinet, G. and Gonzalez, J.L. (2000). “Three-Dimensional Reliability Analysis of Earth Slopes." Computers and Geotechnics, 26, 247-261.

Baecher, G.B. (1982). "Simplified Geotechnical Data Analysis." Proceedings of the NATO Advanced Study Institute on Reliability Theory and its Application in Structural and Soil Mechanics, Bornholm, Denmark, Martinus Nijhoff, 257-277.

Becker, D.E. (1996). "Eighteenth Canadian Geotechnical Colloquium: Limit States Design for Foundations. Part I. An Overview of the Foundation Design Process." Canadian Geotechnical Journal, 33, 956-983.

Becker, D.E. (1996). "Eighteenth Canadian Geotechnical Colloquium: Limit States Design for Foundations. Part II. Development for the National Building Code of Canada.” Canadian Geotechnical Journal, 33, 984-1007.

Bishop, A.W (1948). "Some factors Involved in the Design of a large Earth Dam in the Thames Valley," Proc. $2^{\text {nd }}$ International Conference on Soil Mechanics and Foundation Engineering, Rotterdam, Paper 4, 13-18.

Bishop, A.W. (1955). "The use of the slip circle in the stability analysis of slopes." Geotechnique, 5, 7-17.

Broms, B.B. and Ingleson, I. (1971). "'Earth Pressure against the Abutments of a Rigid Frame Bridge.', Geotechnique, 21(1), 15-28.

Carder, D.R., Pocock, R.G., and Murray, R.T. (1977). “'Experimental Retaining Wall Facility-Lateral Stress Measurements with Sand Backfill.’ Rep. 766, Transport and Road Research Laboratory, Crowthorne, Berkshire, England. 
Chaisson, P., Lafleur, J., Soulie, M. and Law, K.T. (1995). "Characterizing Spatial Variability of a Clay by Geostatistics”, Canadian Geotechnical Journal, No.32, 1-10.

Chen, Y. (1999). "Practical Analysis and Design of MSE Walls by LRFD Method.” J. Engineering Technology, Spring, 8-17.

Chen, Y. (2000). "Practical analysis and design of mechanically-stabilized earth walls - I. Design philosophies and procedures.” Engineering Structures, 22, 793-808.

Chen, Y. (2000). "Practical analysis and design of mechanically-stabilized earth walls II. Design comparisons and impact of LRFD method." Engineering Structures, 22, 809830.

Cherubini, C. (1997). "Data and Considerations on the Variability of Geotechnical Properties of Soils." Proceedings of the International Conference on Safety and Reliability, ESREL97, Lisbon. Vol. 2. 1583-1591.

Cherubini, C. (2000) Reliability evaluation of shallow foundation bearing capacity in c'$\phi^{\prime}$ soils. Canadian Geotechnical Journal. 37, 264-269.

Chowdhury, R.N. (1984). "Recent Developments in Landslide Studies: Probabilistic Methods.” Fourth International Symposium on Landslides, Toronto. 209-228.

Chowdhury, R. and Flentje, P.N. (2002). "Uncertainties in Rainfall-induced Landslide Hazard.” Quarterly Journal of Engineering Geology and Hydrogeology, 35, 61-70.

Christian, J.T., Ladd, C.C., and Baecher, G.B. (1994). "Reliability applied to slope stability analysis.” Journal of Geotechnical Engineering Division, 120(12), 2180-2207. 
Corte, J. (1977). "La Methode des Elements Finis Appliqué an Ouvrages en Terre Armee," Buill. de Liais, LCPC, 90, 37-47.

Das, B.M. (1995). Principles of Geotechnical Engineering, PWS Engineering, Boston.

DeGroot, D.J. and Baecher, G.B. (1993). "Estimating Autocovariances of In-Situ Soil Properties.” Journal of Geotechnical Engineering Division, 119(1), 147-166.

ECS (1994). Eurocode 7:Geotechnical Design-Part I: General Rules. European Committee for Standardization, Central Secretariat, Brussels.

Ellingwood, B., Galambos, T.V., MacGregor, J.G. and Cornell, C.A. (1980). Development of a probability based load criterion for American National Standard A58 Building Code Requirements for Minimum Design Loads in Buildings and other Structures. National Bureau of Standards, Washington, D.C..

Ellingwood, B.R. (1999). "Wind Load Statistics for Probability-Based Structural Design.” Journal of Structural Engineering, ASCE. 125(4), 453-463.

Fang, Y.S., Chen, J.M. and Chen, C.Y. (1997). "Earth pressures with sloping backfill," Journal of Geotechnical and Geoenvironmental Engineeeinrg, 123(3), 250-259.

Fenton, G.A. (1990). Simulation and Analysis of Random Fields, Ph.D. Thesis, Princeton University, Princeton, New Jersey.

Foye, K. (2004) Limit States Design of Foundatin, JTRP final report, FHWA/IN/JTRP2004/21, Purdue University. 
Foye, K. (2004). A Rational, Probabilistic Method for the Development of Geotechnical Load and Resistance Factor Design. Ph.D thesis, Purdue University, West Lafayette, Indiana.

Foye, K., Scott, B. and Salgado, R. (2006). "Assessment of Variable Uncertainties for Reliability-Based Design of Foundations." Journal of Geotechnical and Geoenvironmental Engineering, ASCE, 132(9), 1197-1207.

Foye, K., Scott, B. and Salgado, R. (2006). "Resistance Factors for Use in Shallow Foundation LRFD." Journal of Geotechnical and Geoenvironmental Engineering, ASCE, 132(9), 1208-1218.

Fredlund, D.G. and Dahlman, A.E. (1972). "Statistical Geotechnical Properties of Glacial Lake Edmonton Sediments." First International Conference on Applications of Statistics and Probability to Soil and Structural Engineering, Hong Kong, 203-228.

Goble, G. (1999). “Geotechnical Related Development and Implementation of Load and Resistance Factor Design (LRFD) Methods", NCHRP Synthesis 276, Transportation Research Board, National Research Council, p. 68.

Hammitt, G.M. (1966). "Statistical Analysis of Data from Comparative Laboratory Test Program Sponsored by ACIL." Vicksburg, MS, U.S. Army Waterways Experiment Station.

Harr, M.E. (1987), "Reliability based design in civil engineering," McGraw Hill, London, New York.

Hasofer, A.M. and Lind, N.C. (1974). "Exact and Invariant Second-Moment Code Format.” Journal of the Engineering Mechanics Division, ASCE. 100(1), 111- 121. 
Hendron (1963) A Typical relationship between the coefficient of earth pressure at rest and the initial void ratio, $\mathrm{Ph} . \mathrm{D}$ thesis.

Ingold, T.S. (1982). Reinforced Earth, Thomas Telford Ltd., London.

Jaksa, M.B., Kaggwa, W.S., and Brooker, P.I. (2000). "Experimental evaluation of the scale of fluctuation of a stiff clay," Application of statistics and probability: Civil Engineering reliability and risk analysis; Proceedings of the ICASP 8 Conference, Sydney, New Scout, Vol. 1, 415-422.

Jaky, J. (1944). "The Coefficient of Earth Pressure at Rest," Journal for Society of Hungarian Architects and Engineers, Budapest, Hungry, Oct. 355-358.

Juran, I. (1977). "Dimensionment Interne des Ouvrages en Terre Armee", Thesis for Doctorate of engineering, Laboratoire Central des Pons et Chaussees, Paris.

Juran, I. and Schlosser, F. (1978). "Theoretical Analysis of Failure in Reinforced Earth Structures," Proceedings of ASCE Symposium on Earth Reinforcement, Pittsburgh, 528555.

Kulhawy, F.H., Roth M.J.S. and Grioriu, M.D. (1991). "Some Statistical Evaluations of Geotechnical Properties." Proceedings 6th International Conference on Applied Statistics and Probability in Civil Engineering, (2), Mexico City, 705-712.

Kulhawy, F.H., Birgisson, B. and Grigoriu, M.D. (1992). "Reliability-Based Foundation Design for Transmission Line Structures: Transformation Models for In-Situ Tests", Report EL-5507(4), Electric Power Research Institute, Palo Alto, p113.

Lacasse, S.M., and Ladd, C.C. (1973). Behaviour of Embankments on New Liskeard Varved Clay. Report R73-44, Department of Civil Engineering, MIT, p270. 
Lacroix, Y. and Horn, H.M. (1973). "Direct Determination and Indirect Evaluation of Relative Density and Its Use on Earthwork Construction Projects," Evaluation of Relative Density and Its Role in Geotechnical Projects Involving Cohesionless Soils, A Symposium Presented at the Seventy-Fifth Annual Meeting, American Society for Testing and Materials, LA.

Loehr, J.E., Finley, C.A. and Huaco, D. (2005). Procedures for Design of Earth Slopes using LRFD, Report No. OR 06-010, University of Missouri-Columbia and Missouri Department of Transportation, p80.

Low, B.K. and Tang, W.H. (1997). "Reliability Analysis of Reinforced Embankments on Soft Ground,” Canadian Geotechnical Journal, 34(5), 672-685.

Luckman, P.G. (1987). Slope Stability Assessment under Uncertainty: A First-Order Stochastic Approach. Ph.D. thesis, UC. Berkeley.

Mitchell, J.K. and Villet, W.C.B. (1987). Reinforcement of Earth Slopes and Embankments, NCHRP Report 290, Transportation Research Board, Washington, DC., $323 \mathrm{pp}$.

Muszynski, M.R. (2006). "Determination of Maximum and Minimum Densities of Poorly Graded Sands Using a Simplified Method," Geotechnical Testing Journal, 29(3), 1-10.

Negussey, D, Wijewickreme, W.K.D. and Vaid, Y.P. (1987). "Constant-volume friction angle of granular materials,” Canadian Geotechnical Journal, 25, 50-55.

Nowak, A.S. (1994). "Load Model for Bridge Design Code." Canadian Journal of Civil Engineering. 21, 36-49. 
Okochi, Y. and Tatsuoka, F. (1984). "Some factors affecting $\mathrm{K}_{0}$-values of sand measured in triaxial cell," Soils and Foundations, 24(3), 52-68.

Orchant, C.J., Kulhawy, F.H., and Trautmann, C.H. (1988). Critical Evaluation of In-Situ Test Methods and their Variability. Report EL-5507, Vol. 2, Electric Power Research Institute, Palo Alto.

Paikowsky, Samuel G. (2004). Load and Resistance Factor Design for Deep Foundations. NCHRP Report 507. Washington, D.C.: Transportation Research Board.

Phoon, K.K. and Kulhawy, F.H. (1999). "Characterization of Geotechnical Variability.” Canadian Geotechnical Journal, 36(4), 612-624.

Poulos, S.J. and Hed, A. (1973). "Density Measurements in a Hydraulic Fill," Evaluation of Relative Density and Its Role in Geotechnical Projects Involving Cohesionless Soils, A Symposium Presented at the Seventy-Fifth Annual Meeting, American Society for Testing and Materials, LA.

Popescu, R., Prevost, J.H. and Deodatis, G. (2005), “3D effects in seismic liquefaction of stochastically variable soil deposits," Geotechnique, Vol. 55, No. 1, pp. 21-31.

Pradhan, T.B.S., Tatsuoka, F. and Horii, N. (1988). "Strength and Deformation Characteristics of Sand in Torsional Simple Shear," Soils and Foundations, 28(3), 131148.

Rackwitz, R. (2000). "Reviewing Probabilistic Soils Modelling." Computers and Geotechnics, 26, 199-223.

Salgado, R. (2008). The Engineering of Foundations. McGraw-Hill. 
Santamarina, J., Altschaeffl, A., and Chameau, J. (1992). Reliability of Slopes: Incorporating Qualitative Information. Transportation Research Record 1343, 1-5.

Schlosser, F. (1978). "La Terre Armee, Historique Development Actuel et Futur," Proc. Symp. Soil Reinforcing and Stabilising Techq., NSWIT/NSW Univ., 5-28.

Schlosser, F. and Elias, V. (1978). "Friction in Reinforced Earth," Proceedings ASCE Symposium on Earth Reinforcement, Pittsburgh, 735-762.

Schlosser, F. and Segrestin, P. (1979). "Local Stability Analysis Method of Design of Reinforced Earth Structures," Proceedings of International Conference on Soil Reinforcement, 1, 157-162.

Scott, B. (2002). Development of Load and Resistance Factor Design Method for Shallow Foundations. Ph.D. Thesis. Purdue University. West Lafayette, Indiana.

Sherif, M.A., Fang, Y.S., and Sherif, R.I. (1984). " $\mathrm{K}_{\mathrm{A}}$ and $\mathrm{K}_{0}$ behind Rotating and NonYielding walls.” Journal of Geotechnical Engineering Division, 110, 41-56.

Simpson, B. (1992). "Partial factors of safety for design of retaining walls." Geotechnique, 42, 131-136.

Soulie, M., Montes, P. and Silvestri, V. (1990). "Modelling Spatial Variability of Soil Parameters.” Canadian Geotechnical Journal, 27(5), 617-630.

Spry, M.J., Kulhawy, F.H., and Grigoriu, M.D. (1988). A Probability-Based Geotechnical Site Characterization Strategy for Transmission Line Structures. Report EL-5507, Vol. 1, Electric Power Research Institute, Palo Alto.

Suzuki, M. and Takada, T. (1998). Discussion on "Response of Pile Embedded in Stochastic Ground Media," Structural Safety, 20, 189-193. 
Tatsuoka, F. (1987). Discussion on "The Strength and Dilatancy of sands," Geotechnique, 37(2), 219-226.

Tippett, L.H.C. (1925). “On the Extreme Individuals and the Range of Samples Taken from a Normal Population.” Biometrika. 17(3/4), 364-387.

Vanmarcke, E.H. (1977), "Probabilistic modeling of soil profiles," Journal of Geotechnical Engineering Division, 103(GT11), 1227-1246.

Vanmarcke, E.H. (1977). "Reliability of Earth Slopes", Journal of Geotechnical Engineering Division, 103(GT11), 1247 - 1265.

Vanmarcke, E.H. (1983). Random Fields: Analysis \& Synthesis, MIT Press, Cambridge, p383.

Verdugo, R. and Ishihara, K. (1996). "The steady state of sandy soils," Soils and Foundations, 36(2), 81-91.

Yang, H., White, D.J., Schaefer, V.R. (2005). Innovative Solutions for Slope Stability Reinforcement and Characterization: Vol. II, Final report CTRE Project 03-127, Center for Transportation Research and Education Iowa State University.

White, D.J., Schaefer, V.R., Yang, H., and Thompson, M.J., (2005). Innovative Solutions for Slope Stability Reinforcement and Characterization: Vol. I, Final report CTRE Project 03-127. Center for Transportation Research and Education Iowa State University. 
Wolff, T.F.(1994). Evaluating the reliability of existing levees. Report of a research project entitled: Reliability of existing levees, prepared for U.S. Army Engineer Waterways Experiment Station Geotechnical Laboratory.

Wu, T.H. (1974). "Uncertainty, Safety, and Decision in Soil Engineering.” Journal of Geotechnical Engineering Division, 100(3), 329-348. 
Appendix A. Symbols of the Loads in Table 2.2

\author{
DD: downdrag \\ DC: dead load of structural components and nonstructural attachment \\ DW: dead load of wearing surfaces and utilities \\ EH: horizontal earth pressure load \\ EL: accumulated locked-in force effects resulting from the construction process, \\ including the secondary forces from post-tensioning \\ ES: earth surcharge load \\ EV: vertical pressure from dead load of earth fill \\ BR: vehicular braking force \\ CE: vehicular centrifugal force \\ CR: creep \\ CT: vehicular collision force \\ $\mathrm{CV}$ : vessel collision force \\ EQ: earthquake \\ FR: friction \\ IC: ice load \\ IM: vehicular dynamic load allowance \\ LL: vehicular live load \\ LS: live load surcharge \\ PL: pedestrian live load \\ SE: settlement \\ SH: shrinkage \\ TG: temperature gradient \\ TU: uniform temperature \\ WA: water load and stream pressure \\ WL: wind on live load \\ WS: wind load on structure
}


Appendix B. Theory of Probability, Basic Statistics, and Its Application using Monte Carlo Simulation and First-Order Reliability Method (FORM)

\section{B.1. Probability Density Function and Cumulative Distribution Function}

A Probability density function (PDF) represents a probability distribution of a particular random variable $\mathrm{x}$, such as a probability histogram. For the random variable $\mathrm{x}$, PDF $p_{x}(x)$ of $x$ is a nonnegative function and its integral from $-\infty$ to $+\infty$ is equal to one:

$$
\int_{-\infty}^{\infty} p_{x}(x) d x=1
$$

A Cumulative distribution function $(\mathrm{CDF})$ of $\mathrm{x}^{\prime}$, denoted as $\mathrm{P}_{\mathrm{x}}\left(\mathrm{x}^{\prime}\right)$, is an integral of $p_{x}(x)$ from $-\infty$ to $x^{\prime}$ :

$$
P_{x}\left(x^{\prime}\right)=\int_{-\infty}^{x^{\prime}} p_{x}(x) d x
$$

\section{$\underline{\text { B.2 Basic Statistics }}$}

B.2.1. Mean and standard deviation of a population

When a population $\left(\right.$ size $=n$ ) of a certain random variable $\mathrm{x}$ exists, the mean $\mu_{\mathrm{x}}$ and variance $V_{x}$ of the population of $x$ are:

$$
\mu_{x}=\frac{\sum_{i=1}^{n} x_{i}}{n}
$$




$$
\mathrm{V}_{\mathrm{x}}=\frac{\sum_{\mathrm{i}=1}^{\mathrm{n}}\left(\mathrm{x}_{\mathrm{i}}-\mu_{\mathrm{x}}\right)^{2}}{\mathrm{n}}
$$

The standard deviation $\sigma_{\mathrm{x}}$ of the population of $\mathrm{x}$ is the positive square root of its variance and is a measure of intensity of scatter about its mean $\mu_{\mathrm{x}}$.

$$
\sigma_{x}=\sqrt{V_{x}}=\sqrt{\frac{\sum_{i=1}^{n}\left(x_{i}-\mu_{x}\right)^{2}}{n}}
$$

B.2.2. Sample mean and standard deviation (Estimation of mean and standard deviation of population)

The estimation of mean and standard deviation of a population of a certain property $\mathrm{x}$ is possible from a sample that consists of " $\mathrm{n}$ " measurements $\left(\mathrm{x}_{1}, \mathrm{x}_{2}, \cdots, \mathrm{x}_{\mathrm{n}}\right)$ of $\mathrm{x}$. These estimated mean and standard deviation of the population are called the sample mean and sample standard deviation, and are denoted by $\bar{x}$ and $s_{x}$, respectively. The expressions for the sample mean and sample standard deviation are:

$$
\begin{gathered}
\bar{x}=\frac{\sum_{i=1}^{n} x_{i}}{n} \\
s_{x}=\sqrt{\frac{\sum_{i=1}^{n}\left(x_{i}-\bar{x}\right)^{2}}{(n-1)}}
\end{gathered}
$$

\section{B.2.3. Covariance}


Covariance of random variable $\mathrm{x}$ and $\mathrm{y}$ is a measure of the strength of correlation between $\mathrm{x}$ and $\mathrm{y}$. Covariance has the positive sign when $\mathrm{x}$ and $\mathrm{y}$ are positively correlated (vice versa). When $x$ and $y$ are highly correlated, the absolute value of the covariance is large. If $\mathrm{x}$ and $\mathrm{y}$ are independent of each other, covariance is equal to zero. And the covariance between two identical random variables is equal to the variance of the variable. The covariance of $\mathrm{x}$ and $\mathrm{y}$ is:

$$
\operatorname{Cov}(x, y)=E\left[\left(x-\mu_{x}\right)\left(y-\mu_{y}\right)\right]
$$

For discrete random variables $\mathrm{x}$ and $\mathrm{y}(\mathrm{i}=1,2, \cdots, \mathrm{n})$, the covariance can be expressed as:

$$
\operatorname{Cov}(x, y)=\frac{\sum_{i=1}^{n}\left(x_{i}-\mu_{x}\right)\left(y_{i}-\mu_{y}\right)}{n}
$$

\section{B.2.4. Correlation coefficient}

Correlation coefficient $\rho(\mathrm{x}, \mathrm{y})$ of random variable $\mathrm{x}$ and $\mathrm{y}$ is equal to covariance divided by the standard deviation of these two random variables:

$$
\rho(x, y)=\frac{\operatorname{Cov}(x, y)}{\sigma_{x} \sigma_{y}}
$$

By this normalization, the strength of correlation between $\mathrm{x}$ and $\mathrm{y}$ can be expressed as a dimensionless number that is independent of the units of $\mathrm{x}$ and $\mathrm{y}$. The correlation coefficient varies from -1 to 1 . Correlation coefficient value is equal to $1(-1)$, if $x$ and $y$ have perfect positive (negative) linear relationship.

\section{B.2.5. Mean and standard deviation of a linear combination}


If a certain variable $Y$ can be expressed as a sum of $n$ random variables $\left(X_{1}, X_{2}, \cdot\right.$, $\left.\mathrm{X}_{\mathrm{n}}\right)$ multiplied by $\mathrm{n}$ corresponding numerical constants $\left(\mathrm{a}_{1}, \mathrm{a}_{2}, \cdot \cdot, \mathrm{a}_{\mathrm{n}}\right), \mathrm{Y}$ is:

$$
\mathrm{Y}=\sum_{\mathrm{i}=1}^{\mathrm{n}} \mathrm{a}_{\mathrm{i}} \mathrm{X}_{\mathrm{i}}
$$

Mean of $\mathrm{Y}$ is

$$
\begin{aligned}
E[Y] & =E\left[\sum_{i=1}^{n} a_{i} X_{i}\right]=a_{1} E\left[X_{1}\right]+a_{2} E\left[X_{2}\right]+\cdots+a_{n} E\left[X_{n}\right] \\
& =a_{1} \mu_{1}+a_{2} \mu_{2}+\cdots+a_{n} \mu_{n}
\end{aligned}
$$

When $\mathrm{X}_{1}, \mathrm{X}_{2}, \cdots, \mathrm{X}_{\mathrm{n}}$ are independent, variance of $\mathrm{Y}$ is

$$
V[Y]=V\left[\sum_{i=1}^{n} a_{i} X_{i}\right]=a_{1}^{2} V\left[X_{1}\right]+a_{2}^{2} V\left[X_{2}\right]+\cdots+a_{n}^{2} V\left[X_{n}\right]
$$

Therefore, standard deviation of $Y\left(X_{1}, X_{2}, \cdots, X_{n}\right.$ are independent $)$ is

$$
\sigma_{\mathrm{Y}}=\sqrt{\mathrm{V}[\mathrm{Y}]}=\sqrt{\mathrm{a}_{1}^{2} \sigma_{\mathrm{X}_{1}}^{2}+\mathrm{a}_{2}^{2} \sigma_{\mathrm{X}_{2}}^{2}+\cdots+\mathrm{a}_{\mathrm{n}}^{2} \sigma_{\mathrm{X}_{\mathrm{n}}}^{2}}
$$

\section{B.3. Bias Factor}

The mean (or expected) value of a continuous random variable $\mathrm{x}$ whose probability distribution function is $\mathrm{p}_{\mathrm{x}}(\mathrm{x})$ can be expressed as: 


$$
\mu_{x}=E[x]=\int_{a}^{b} x p_{x}(x) d x
$$

where $a$ and $b$ are the lower and upper bound values of the PDF, respectively.

The mean of discrete values of $\mathrm{x}$ whose discrete probability distribution is $\mathrm{p}_{\mathrm{x}}\left(\mathrm{x}_{\mathrm{i}}\right)$ can be expressed as:

$$
\mu_{\mathrm{x}}=\mathrm{E}[\mathrm{x}]=\sum_{\mathrm{i}=1}^{\mathrm{n}} \mathrm{x}_{\mathrm{i}} \cdot \mathrm{p}_{\mathrm{x}}\left(\mathrm{x}_{\mathrm{i}}\right)
$$

where $\mathrm{n}$ is the number of $\mathrm{x}$ observations (or measurements).

As shown in Figure B.1, the nominal value may not be equal to the mean value. In other words, the nominal value could be either greater than or less than the mean value. The nominal value is considered as a deterministic value that does not have uncertainty. For example, in the analysis using working stress design (WSD), we calculate the nominal resistance of geotechnical structures using nominal values for each parameter. To account for the relationship between the nominal value and the mean value, the bias factor (the ratio of mean value to nominal value) is introduced:

$$
\text { bias factor }=\frac{\mu_{\mathrm{x}}}{\mathrm{x}_{\text {nominal }}}
$$

where $\mu_{\mathrm{x}}$ and $\mathrm{x}_{\text {nominal }}$ are the mean and nominal values of a variable $\mathrm{x}$, respectively.

Given that the bias factor of a variable $\mathrm{x}$ is a known value, the mean value of $\mathrm{x}$ can be directly calculated by multiplying the bias factor by the nominal value. 


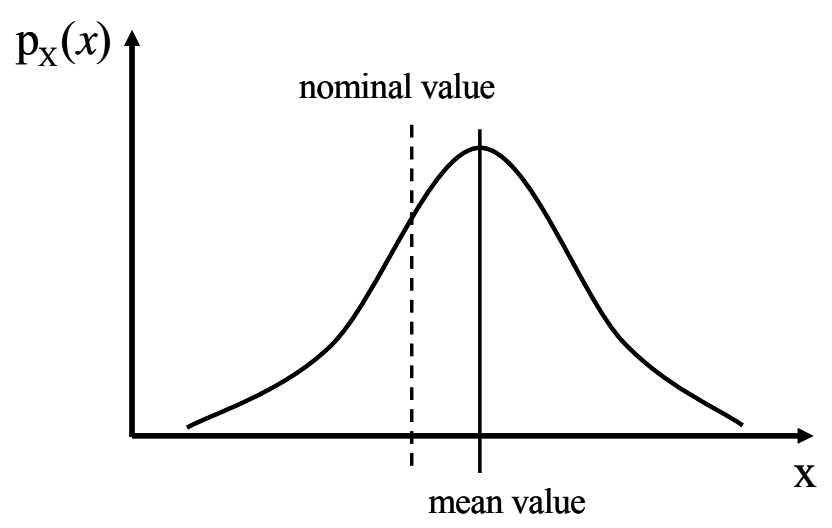

Figure B.1 Mean and nominal values of a certain parameter $\mathrm{x}$

\section{B.4. Uncertainty Calculations}

B.4.1. Uncertainty of a parameter

The coefficient of variation (COV) is defined as the ratio of the (estimated) standard deviation [Eq. (B.7)] to its (estimated) mean [Eq. (B.6)]:

$$
\operatorname{COV}=\frac{\mathrm{s}_{\mathrm{x}}}{\overline{\mathrm{x}}}
$$

The COV is a measure of how much data are scattered from the mean value and is a good reference for estimating the uncertainties of parameters. When we use a constant COV for different mean values in the analysis (which implies the COV is independent of the mean), we are imposing that the standard deviation of the sample is proportional to the mean. In reality, it is likely that data are more scattered about the mean as the mean increases. 


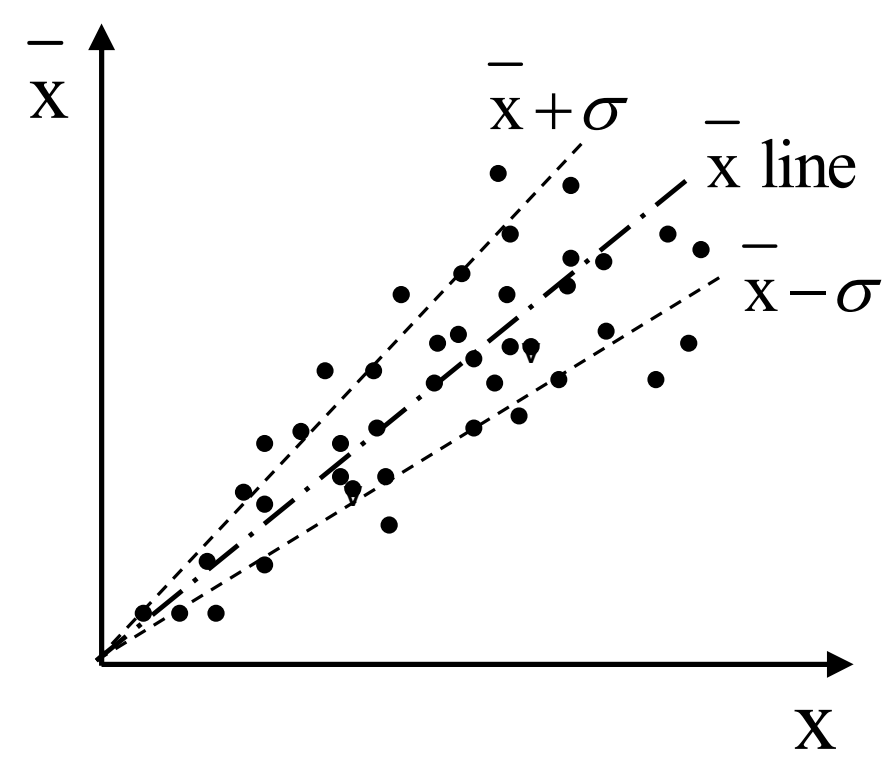

Figure B.2 Data scatter for a constant COV with respect to mean value

\section{B.4.2. Uncertainty of transformation}

Suppose that we have scattered paired data expressed as $\left(x_{i}, y_{i}\right)$, where $i=1,2, \cdots$, $\mathrm{n}$, and that $\mathrm{y}_{\mathrm{i}}$ and $\mathrm{x}_{\mathrm{i}}$ are related. When we perform a regression on the data set, we are able to obtain the best fitting function, $y=f(x)$. This regression function is determined by minimizing the summation of $\left[y_{i}-f\left(x_{i}\right)\right]^{2}$. All data of $\left(x_{i}, y_{i}\right)$ do not fit exactly to the function $y=f(x)$ so that there exists scatter along the function $f(x)$. Given the values of $y_{i}$ (observed data) and $\mathrm{f}\left(\mathrm{x}_{\mathrm{i}}\right)$ (predicted values), we can define an error for each datum as $\mathrm{w}_{\mathrm{i}}=$ $\mathrm{y}_{\mathrm{i}}-\mathrm{f}\left(\mathrm{x}_{\mathrm{i}}\right)$. Thus, the mean value and the standard deviation of errors can be obtained:

$$
\begin{gathered}
\overline{\mathrm{w}}=\frac{\sum_{\mathrm{i}=1}^{\mathrm{n}} \mathrm{w}_{\mathrm{i}}}{\mathrm{n}} \\
\mathrm{s}_{\mathrm{w}}=\sqrt{\frac{\sum_{\mathrm{i}=1}^{\mathrm{n}}\left(\mathrm{w}_{\mathrm{i}}-\overline{\mathrm{w}}\right)^{2}}{(\mathrm{n}-1)}}
\end{gathered}
$$


If error $\mathrm{w}_{\mathrm{i}}$ is normalized with respect to $\mathrm{f}\left(\mathrm{x}_{\mathrm{i}}\right)$ and named $\mathrm{w}_{\mathrm{i}}^{\prime}$,

$$
w_{i}^{\prime}=\frac{y_{i}-f\left(x_{i}\right)}{f\left(x_{i}\right)}
$$

The mean (or expected) value of $\mathrm{w}^{\prime}{ }_{\mathrm{i}}$ will be zero:

$$
\overline{\mathrm{w}}^{\prime}=\frac{\sum_{\mathrm{i}=1}^{\mathrm{n}} \mathrm{w}_{\mathrm{i}}^{\prime}}{\mathrm{n}}=0
$$

The equation for the standard deviation of $\mathrm{w}^{\prime}$ is

$$
\mathrm{S}_{\mathrm{w}^{\prime}}=\sqrt{\frac{\sum_{\mathrm{i}=1}^{\mathrm{n}}\left(\mathrm{w}_{\mathrm{i}}^{\prime}-\overline{\mathrm{w}}^{\prime}\right)^{2}}{(\mathrm{n}-1)}}=\sqrt{\frac{\sum_{\mathrm{i}=1}^{\mathrm{n}} \mathrm{w}_{\mathrm{i}}^{\prime 2}}{(\mathrm{n}-1)}}=\sqrt{\frac{\sum_{\mathrm{i}=1}^{\mathrm{n}}\left(\frac{\left.\mathrm{y}_{\mathrm{i}}-\mathrm{f}\left(\mathrm{x}_{\mathrm{i}}\right)\right)^{2}}{\mathrm{f}\left(\mathrm{x}_{\mathrm{i}}\right)}\right.}{(\mathrm{n}-1)}}
$$

Conditional probability distribution function $\mathrm{p}_{\mathrm{Y} \mid \mathrm{X}}(\mathrm{y} \mid \mathrm{x})$ is the PDF of $\mathrm{y}$ under the assumption that the event $\mathrm{x}$ has already occurred. For a fixed $\mathrm{x}_{\mathrm{i}}$, the expected value of $\mathrm{y}$ for the given $\mathrm{x}_{\mathrm{i}}$ is equal to $\mathrm{f}\left(\mathrm{x}_{\mathrm{i}}\right)$. This is expressed as:

$$
E\left(y \mid x_{i}\right)=f\left(x_{i}\right)
$$

The COV of the transformation $y=f(x)$ for the given $x$ is

$$
\operatorname{COV}_{y \mid x}=\frac{\sigma_{y \mid x}}{E(y \mid x)} \approx \frac{\sqrt{\frac{\sum_{i=1}^{n}\left(y_{i}-E\left(y \mid x_{i}\right)\right)^{2}}{(n-1)}}}{E(y \mid x)}=\sqrt{\frac{\sum_{i=1}^{n}\left(\frac{y_{i}-E\left(y \mid x_{i}\right)}{E\left(y \mid x_{i}\right)}\right)^{2}}{(n-1)}}
$$


By comparing Eq. (B.23) with Eq. (B.25), the COV of $\mathrm{y}$ for a given $\mathrm{x}$ is equal to the standard deviation of $\mathrm{w}^{\prime}\left(\mathrm{COV}_{\mathrm{y} \mid \mathrm{x}}=\mathrm{s}_{\mathrm{w}^{\prime}}\right)$. The $\mathrm{COV}_{\mathrm{y} \mid \mathrm{x}}$ of trended data that are calculated by this procedure is a good reference for estimating the uncertainty of a transformation.

\section{$\underline{\text { B.5. Monte Carlo Simulations }}$}

Monte Carlo simulation is the repetitive process of generating very large numbers of deterministic values that can reproduce the probability distributions of variables and models. The advantage of this method is its simplicity, but the method requires generation of very large numbers of random variable values.

To illustrate the process of a Monte Carlo simulation, the procedure of a simple example is introduced. We could obtain a distribution of $\mathrm{G}$ by conducting a large number of $\mathrm{G}$ computations using Monte Carlo simulation. Assume that $\mathrm{G}$ is a function of direct input parameters $\left(\mathrm{x}_{\mathrm{i}} ; \mathrm{i}=1, \cdots, \mathrm{n}\right)$ and derived input parameters $\left(\mathrm{y}_{\mathrm{j}} ; \mathrm{j}=1, \cdots, \mathrm{m}\right)$.

$$
\mathrm{G}=f\left(x_{1}, \cdots, x_{n} ; y_{1}, \cdots, y_{m}\right)
$$

For each direct input parameter $\mathrm{x}$, we can generate a random number following its own distribution. However, for the derived input parameters, we need to account for the uncertainties associated with transformations or models. For example, the derived input parameter $\mathrm{y}_{1}$ is a transformed value from $\mathrm{z}_{1}$ using a transformation $[\mathrm{y}=\mathrm{f}(\mathrm{z})]$. In this case, we generate $z_{1}$ values from the distribution of $z_{1}$ and plug this value into the transformation. Accounting for the uncertainty of the transformation, we calculate the final derived input parameter $\mathrm{y}_{1}$ by adding the effects of the bias factor and the COV for the transformation to the calculated $y\left[=\mathrm{f}\left(\mathrm{z}_{1}\right)\right]$. The final value $\mathrm{y}_{1}$ will be inputted in the function G. This process will be applied for the rest of derived input parameters. The schematic process of the simulation for $\mathrm{G}$ is shown as in Figure.B.3. 


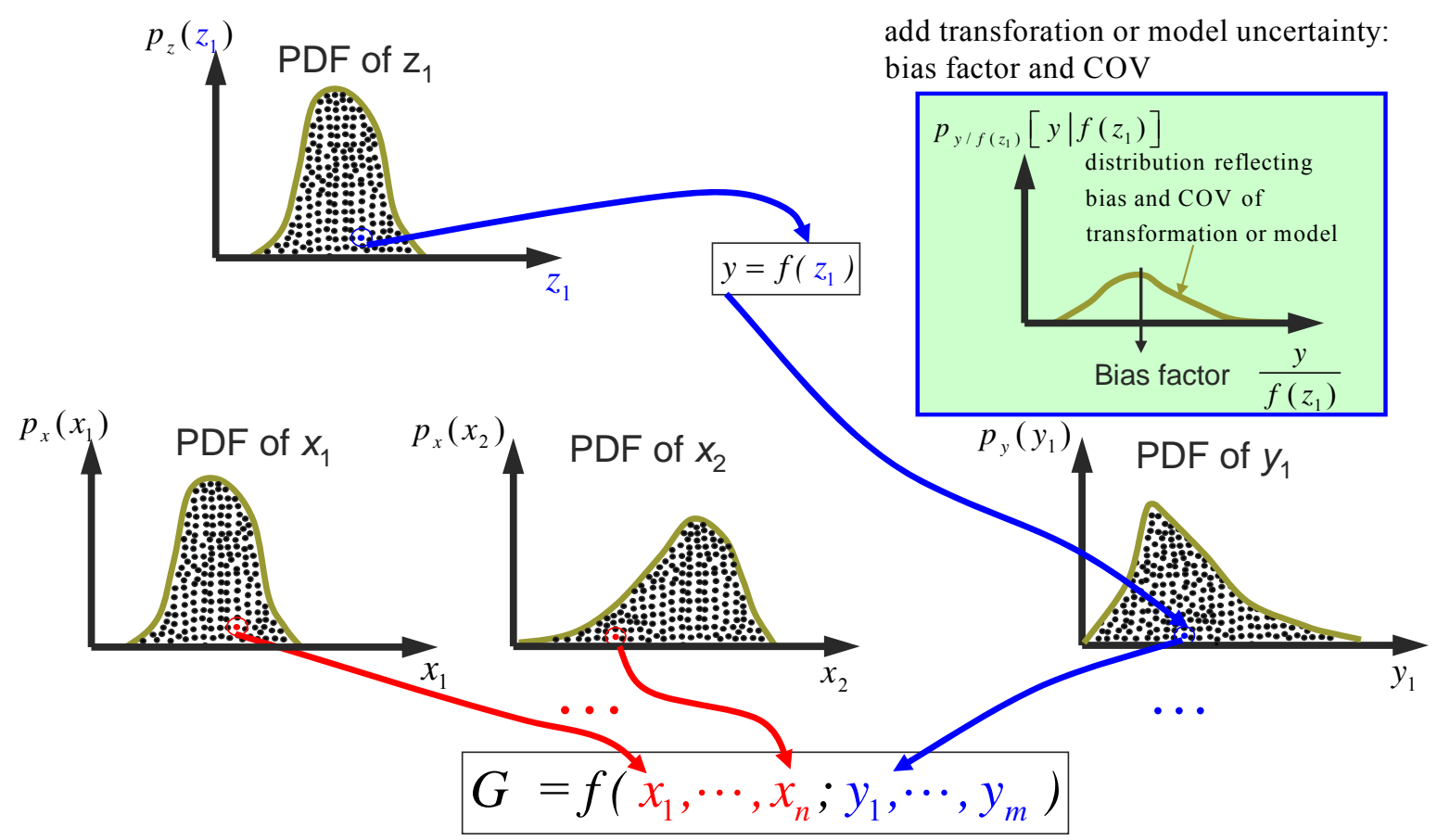

Figure B.3 Simple schematic procedure of Monte Carlo simulation

Suppose we have a random variable $\mathrm{x}$ and its PDF $\mathrm{p}_{\mathrm{x}}(\mathrm{x})$ and a transformation of $\mathrm{x}$ to $y$ is given by $y=f(x)$. Random values of $x$ can be generated based on Eq. (B.27).

$$
\int_{-\infty}^{x^{\prime}} p_{x}(x) d x=\xi
$$

where $\mathrm{x}^{\prime}$ is the generated random number reflecting $\mathrm{p}_{\mathrm{x}}(\mathrm{x}), \xi$ is a variable following a uniform distribution between 0 and 1 .

Because $\xi$ represents a Cumulative Distribution Function (CDF) of $x^{\prime}$, it ranges between 0 and 1. To generate a large number of $\mathrm{x}^{\prime}$ values, a large number of $\xi$ values are randomly generated from a uniform distribution between 0 and 1 and $\mathrm{x}^{\prime}$ values are backcalculated by inputting the generated $\xi$ s to Eq. (B.27). Then, the distribution of generated $\mathrm{x}^{\prime}$ values will follow the original PDF $\mathrm{p}_{\mathrm{x}}(\mathrm{x})$. 
For each value of $\mathrm{x}^{\prime}$ from the large set generated as described, the prediction for the corresponding $y$ value is made using the transformation $[\mathrm{y}=\mathrm{f}(\mathrm{x})]$, and the uncertainty of this transformation is added to the predicted y value. By repeating this process for all the generated $x^{\prime}$ values, we obtain the PDF of $y$, which is denoted by $p_{y}(y)$ in Figure B.3.

Compared to numerical integration, Monte Carlo simulation is much easier when there are many variables and transformations to be considered in the analysis.

\section{B.6. First-Order Reliability Method (FORM)}

The concept of the reliability index $\beta$ was introduced by Cornell (1969) and Hasofer and Lind (1974). To apply the reliability index concept to limit state analysis, we need to have a well defined limit state equation, a mean (or expected) value, a bias factor, and a standard deviation (or COV) for each random variable used in the analysis.

For the case in which we have $\mathrm{n}$ random variables in the ultimate limit state (ULS) equation, we can locate the failure surface from the ULS equation and the point whose coordinates are the mean values of the $n$ random variables in the $n$-dimension imaginary space. Geometrically, the reliability index $\beta$ is the ratio of the closest distance between the point defined by the mean values of the $n$ variables and the failure surface to the standard deviation of the multiple probability density function for the $\mathrm{n}$ variables.

For example, when we have two variables ( $x$ and $y$ ) in the ULS equation, we could draw both the point $\left(\mu_{\mathrm{x}}, \mu_{\mathrm{y}}\right)$ defined by two mean values of the variables and the failure surface defined by ULS equation (Figure B.4). It is possible to find the closest distance between $\left(\mu_{\mathrm{x}}, \mu_{\mathrm{y}}\right)$ and the failure surface from the figure and calculate the standard deviation of multiple probability density function by assessing the uncertainties associated with load and resistance. Then, the reliability index $\beta$ is the ratio of the closest distance to the standard deviation of the multiple probability density function. 


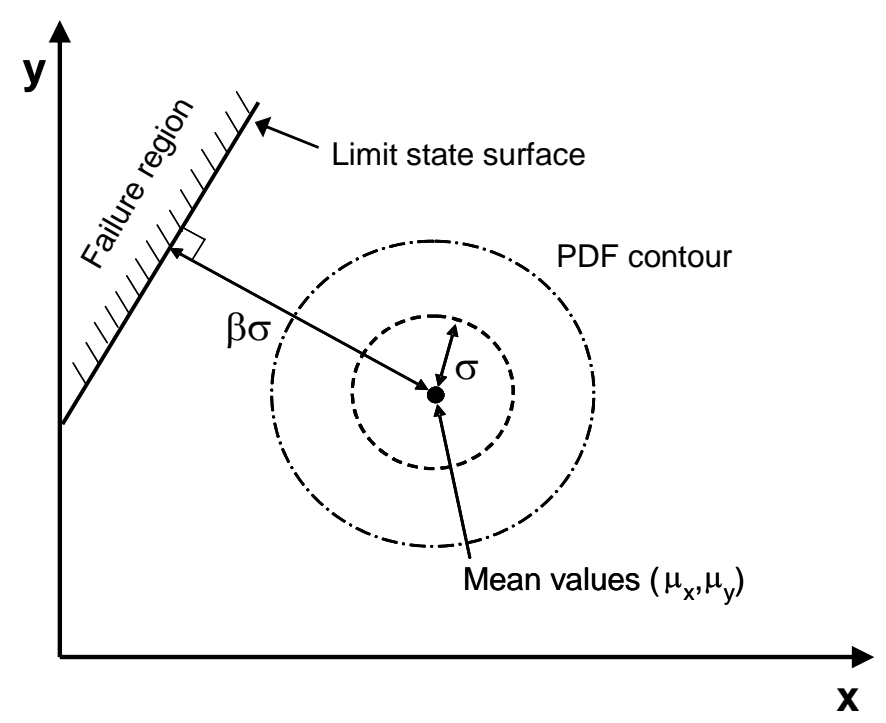

Figure B.4 Geometrical illustration of reliability index $\beta$ in two-dimensional space

Low and Tang (1997) suggested a useful technique for reliability index $\beta$ calculation by introducing Eq. (B.28). They also provided a method for calculating $\beta$ using the Microsoft Excel solver. For $n$ random variables $x_{i}(i=1,2, \cdots, n)$ and the corresponding ULS equation [ $\mathrm{M}\left(\mathrm{x}_{1}, \mathrm{x}_{2}, \cdots, \mathrm{x}_{\mathrm{n}}\right)=0$ ], the reliability index $\beta$ is calculated as the minimum distance between the point corresponding to the mean values of these $n$ variables and the ULS surface defined by the limit state equation $[\mathrm{M}(\mathrm{x})=0]$. The state where $\beta$ exist can also be interpreted as the situation that corresponds to the highest probability of failure.

$$
\beta=\min \sqrt{(\mathbf{x}-\mathbf{m})^{\mathbf{T}} \mathbf{C}^{-1}(\mathbf{x}-\mathbf{m})}
$$

where $\mathrm{m}$ is a vector consisting of mean values of $\mathrm{x}_{\mathrm{i}}, \mathrm{x}$ is a vector consisting of random variables that are arbitrarily generated and satisfy the limit state equation, and $\mathrm{C}$ is the covariance matrix.

The covariance matrix is expressed as: 


$$
\mathbf{C}=\left[\begin{array}{cccc}
\operatorname{Cov}\left(\mathrm{x}_{1}, \mathrm{x}_{1}\right) & \operatorname{Cov}\left(\mathrm{x}_{1}, \mathrm{x}_{2}\right) & \cdots & \operatorname{Cov}\left(\mathrm{x}_{1}, \mathrm{x}_{\mathrm{n}}\right) \\
\operatorname{Cov}\left(\mathrm{x}_{2}, \mathrm{x}_{1}\right) & \operatorname{Cov}\left(\mathrm{x}_{2}, \mathrm{x}_{2}\right) & \cdots & \operatorname{Cov}\left(\mathrm{x}_{2}, \mathrm{x}_{\mathrm{n}}\right) \\
\vdots & \vdots & \ddots & \vdots \\
\operatorname{Cov}\left(\mathrm{x}_{\mathrm{n}}, \mathrm{x}_{1}\right) & \operatorname{Cov}\left(\mathrm{x}_{\mathrm{n}}, \mathrm{x}_{2}\right) & \cdots & \operatorname{Cov}\left(\mathrm{x}_{\mathrm{n}}, \mathrm{x}_{\mathrm{n}}\right)
\end{array}\right]
$$

where $\operatorname{Cov}\left(x_{i}, x_{j}\right)$ is called the covariance between $x_{i}$ and $x_{j}$. 


\section{Appendix C. Two- Dimensional Fourier Transform}

The two-dimensional Fourier transform of the process $\mathrm{z}$ written in complex form is

$$
z(x, y)=\int_{0}^{\infty} \int_{0}^{\infty} z\left(\omega_{x}, \omega_{y}\right) \exp \left[i\left(\omega_{x} x+\omega_{y} y\right)\right] d \omega_{x} d \omega_{y}
$$

where $\mathrm{x}$ and $\mathrm{y}$ are two Cartesian directions, and $\omega_{\mathrm{x}}$ and $\omega_{\mathrm{y}}$ are the angular frequencies of the Fourier series in the $\mathrm{x}$ and $\mathrm{y}$ directions.

The inverse transform of Eq. (C.1) can be expressed as;

$$
\mathrm{Z}\left(\omega_{\mathrm{x}}, \omega_{\mathrm{y}}\right)=\int_{0}^{\mathrm{L}_{1}} \int_{0}^{\mathrm{L}_{2}} \mathrm{z}(\mathrm{x}, \mathrm{y}) \exp \left[-\mathrm{i}\left(\omega_{\mathrm{x}} \mathrm{x}+\omega_{\mathrm{y}} \mathrm{y}\right)\right] \mathrm{dxdy}
$$

Convenient variations of Eqs.(C.1) and (C.2) are;

$$
\begin{gathered}
z_{i j}=z\left(x_{i}, y_{j}\right)=z(i \Delta x, j \Delta y) \\
=\sum_{m=0}^{K_{1}-1} \sum_{n=0}^{K_{2}-1} z\left(\omega_{x, m}, \omega_{y, n}\right) \exp \left[-i\left(\frac{2 \pi i m}{K_{1}}+\frac{2 \pi j n}{K_{2}}\right)\right] \\
Z\left(\omega_{x, m}, \omega_{y, n}\right)=\frac{1}{K_{1} K_{2}} \sum_{i=0}^{K_{1}-1} \sum_{j=0}^{K_{2}-1} z_{i j} \exp \left[i\left(\frac{2 \pi i m}{K_{1}}+\frac{2 \pi j n}{K_{2}}\right)\right]
\end{gathered}
$$

where $\Delta \mathrm{x}$ and $\Delta \mathrm{y}$ are the discretization intervals in the $\mathrm{x}$ and $\mathrm{y}$ directions, $\mathrm{K}_{1}$ and $\mathrm{K}_{2}$ are the discretization elements in the $\mathrm{x}$ and $\mathrm{y}$ direction, $\mathrm{A}_{\mathrm{mn}}$ and $\mathrm{B}_{\mathrm{mn}}$ are the independent Fourier coefficients that follow a normal distribution with zero mean, $x_{i}$ and $y_{j}$ are the physical lengths from zero to the end of the $\mathrm{i}^{\text {th }}$ and $\mathrm{j}^{\text {th }}$ interval in the $\mathrm{x}$ and $\mathrm{y}$ directions, 
and $\omega_{\mathrm{x}, \mathrm{m}}\left(=2 \mathrm{~m} \pi / \mathrm{K}_{1} \Delta \mathrm{x}\right)$ and $\omega_{\mathrm{y}, \mathrm{n}}\left(=2 \mathrm{n} \pi / \mathrm{K}_{2} \Delta \mathrm{y}\right)$ are the angular frequencies of the Fourier series in the $\mathrm{x}$ and $\mathrm{y}$ directions.

The complex exponential function in Eq. (C.3) and Eq. (C.4) can be expressed in terms of sine and cosine by the Euler formula:

$$
\exp \left[\mathrm{i}\left(\frac{2 \pi \mathrm{im}}{\mathrm{K}_{1}}+\frac{2 \pi \mathrm{jn}}{\mathrm{K}_{2}}\right)\right]=\cos \left(\frac{2 \pi \mathrm{im}}{\mathrm{K}_{1}}+\frac{2 \pi \mathrm{jn}}{\mathrm{K}_{2}}\right)+\mathrm{i} \sin \left(\frac{2 \pi \mathrm{im}}{\mathrm{K}_{1}}+\frac{2 \pi \mathrm{jn}}{\mathrm{K}_{2}}\right)
$$

Assuming $Z\left(\omega_{x, m}, \omega_{y, n}\right)=A_{m n}+i B_{m n}$, then Eq. (C.3) and Eq. (C.4) can be written as;

$$
\begin{aligned}
& \mathrm{z}_{\mathrm{ij}}=\sum_{\mathrm{m}=0}^{\mathrm{K}_{1}-1} \sum_{\mathrm{n}=0}^{\mathrm{K}_{2}-1}\left(\mathrm{~A}_{\mathrm{mn}}+\mathrm{iB}_{\mathrm{mn}}\right)\left[\cos \left(\frac{2 \pi \mathrm{im}}{\mathrm{K}_{1}}+\frac{2 \pi \mathrm{jn}}{\mathrm{K}_{2}}\right)-\mathrm{i} \sin \left(\frac{2 \pi \mathrm{im}}{\mathrm{K}_{1}}+\frac{2 \pi \mathrm{jn}}{\mathrm{K}_{2}}\right)\right] \\
& \mathrm{Z}\left(\omega_{\mathrm{x}, \mathrm{m}}, \omega_{\mathrm{y}, \mathrm{n}}\right) \\
& =\mathrm{A}_{\mathrm{mn}}+\mathrm{iB}_{\mathrm{mn}}=\frac{1}{\mathrm{~K}_{1} \mathrm{~K}_{2}} \sum_{\mathrm{i}=0}^{\mathrm{K}_{1}-1} \sum_{\mathrm{j}=0}^{\mathrm{K}_{2}-1} \mathrm{z}_{\mathrm{ij}}\left[\cos \left(\frac{2 \pi \mathrm{im}}{\mathrm{K}_{1}}+\frac{2 \pi \mathrm{jn}}{\mathrm{K}_{2}}\right)+\mathrm{i} \sin \left(\frac{2 \pi \mathrm{im}}{\mathrm{K}_{1}}+\frac{2 \pi \mathrm{jn}}{\mathrm{K}_{2}}\right)\right]
\end{aligned}
$$

By comparing the real part and imaginary part of each side of Eq. (C.6), Fourier coefficients $\mathrm{A}_{\mathrm{mn}}$ and $\mathrm{B}_{\mathrm{mn}}$ are

$$
\begin{aligned}
& A_{m n}=\frac{1}{K_{1} K_{2}} \sum_{i=0}^{K_{1}-1} \sum_{j=0}^{K_{2}-1} z_{i j} \cos \left(\frac{2 \pi i m}{K_{1}}+\frac{2 \pi j n}{K_{2}}\right) \\
& B_{m n}=\frac{1}{K_{1} K_{2}} \sum_{i=0}^{K_{1}-1} \sum_{j=0}^{K_{2}-1} z_{i j} \sin \left(\frac{2 \pi i m}{K_{1}}+\frac{2 \pi j n}{K_{2}}\right)
\end{aligned}
$$


Because we are only considering the real part, $\mathrm{z}_{\mathrm{ij}}$ can be represented as

$$
\mathrm{z}_{\mathrm{ij}}=\sum_{\mathrm{m}=0}^{\mathrm{K}_{1}-1} \sum_{\mathrm{n}=0}^{\mathrm{K}_{2}-1}\left(\mathrm{~A}_{\mathrm{mn}} \cos \left(\frac{2 \pi \mathrm{im}}{\mathrm{K}_{1}}+\frac{2 \pi \mathrm{jn}}{\mathrm{K}_{2}}\right)+\mathrm{B}_{\mathrm{mn}} \sin \left(\frac{2 \pi \mathrm{im}}{\mathrm{K}_{1}}+\frac{2 \pi \mathrm{jn}}{\mathrm{K}_{2}}\right)\right)
$$




\section{Appendix D. Modified 6 $\sigma$ Method $\left(\mathrm{N}_{\sigma}\right.$ Method)}

Before introducing $N_{\sigma}$ method, $6 \sigma$ method is a technique that allows estimating the standard deviation of a large numbers of data which show a normal distribution. Suppose we have many data which have approximately a normally distribution. The assumption is that these large numbers of data lie within the range of six standard deviations. The range of data can be calculated by subtracting the minimum value of the data from the maximum of the date. The standard deviation can be evaluated as follow.

$$
\frac{\max (\text { data })-\min (\text { date })}{6}=\sigma
$$

where $\sigma$ is the standard deviation.

$\mathrm{N}_{\sigma}$ method, which is called modified $6 \sigma$ method, is devised by Tippett (1925). Instead of the number 6 in $6 \sigma$ method, he suggested the equivalent values of number $\mathrm{N}_{\sigma}$ that are applicable to the data which have a normal distribution. $\mathrm{N}_{\sigma}$ is dependent of number of data points. Therefore we do not have a sufficient number of data to apply $6 \sigma$ method, the estimation of standard deviation is possible by range [max(data)- $\min ($ data)] divided by $\mathrm{N}_{\sigma}$ values. $\mathrm{N}_{\sigma}$ values are listed in Table D.1.

$$
\sigma=\frac{\max (\text { data })-\min (\text { date })}{N_{\sigma}}
$$


Table D. $1 \mathrm{~N}_{\sigma}$ values for $\mathrm{n}$ data points

\begin{tabular}{cc|cc}
\hline $\mathrm{n}$ & $\mathrm{N}_{\sigma}$ & $\mathrm{n}$ & $\mathrm{N}_{\sigma}$ \\
\hline 2 & 1.1284 & 17 & 3.5879 \\
3 & 1.6926 & 18 & 3.6401 \\
4 & 2.0588 & 19 & 3.6890 \\
5 & 2.3260 & 20 & 3.7350 \\
6 & 2.5344 & 50 & 4.4982 \\
7 & 2.7044 & 100 & 5.0152 \\
8 & 2.8472 & 200 & 5.4921 \\
9 & 2.9700 & 300 & 5.7556 \\
10 & 3.0775 & 400 & 5.9364 \\
11 & 3.1729 & 500 & 6.0734 \\
12 & 3.2585 & 600 & 6.1835 \\
13 & 3.3360 & 700 & 6.2752 \\
14 & 3.4068 & 800 & 6.3536 \\
15 & 3.4718 & 900 & 6.4222 \\
16 & 3.5320 & 1000 & 6.4829 \\
\hline
\end{tabular}

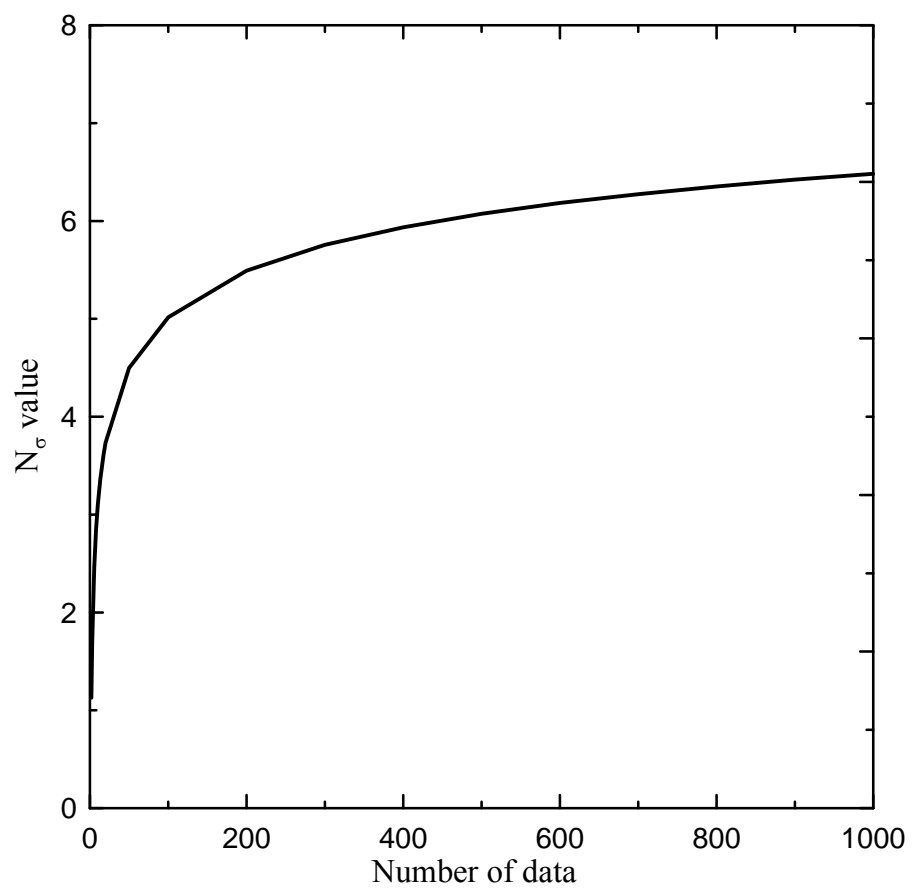

Figure D.1 Plot of $\mathrm{N}_{\sigma}$ value versus number of data 
Appendix E. Interface Friction Angle $\delta_{\mathrm{p}}$ between Backfill Soil and Steel-Strip Reinforcement

Lings and Dietz tested three different sands [virgin Leighton Buzzard coarse sand (VLB), medium Golden sand (MGS), and silver fine sand (SFS)] using special direct shear apparatus to find the average interface friction angle for sand-sand and sand-steel interfaces. For our analysis, SFS was not considered because fine sand is not a suitable backfill material of the reinforced soil. The soil properties of two sands are shown in Table E.1.

Table E.1 Soil properties of two sands

\begin{tabular}{|c|c|c|c|c|c|c|c|c|}
\hline Sand & $\mathrm{G}_{\mathrm{s}}$ & $\mathrm{e}_{\min }$ & $\mathrm{e}_{\max }$ & $\begin{array}{c}\mathrm{D}_{10} \\
(\mathrm{~mm})\end{array}$ & $\begin{array}{c}\mathrm{D}_{50} \\
(\mathrm{~mm})\end{array}$ & $\begin{array}{c}\mathrm{D}_{60} \\
(\mathrm{~mm})\end{array}$ & $\mathrm{U}_{\mathrm{c}}$ & Note \\
\hline VLB & 2.651 & 0.506 & 0.802 & 0.64 & 0.78 & 0.81 & 1.27 & rounded \\
\hline MGS & 2.567 & 0.494 & 0.806 & 0.34 & 0.44 & 0.45 & 1.32 & subrounded \\
\hline
\end{tabular}

From the result of tests (Table E.2), it was found that the interface friction angle is a function of relative (or normalized) roughness $R_{n}$, relative density $D_{R}$, vertical stress $\sigma^{\prime}{ }_{v}$ and critical-state friction angle $\delta_{\mathrm{cv}}$. The relative roughness $\mathrm{R}_{\mathrm{n}}$ is defined as an average of heights $\mathrm{R}_{\mathrm{a}}$ of peaks to $\mathrm{D}_{50}$ (diameter corresponding to weight-percent of soil finer than $50 \%)$ :

$$
R_{n}=\frac{R_{a}}{D_{50}}
$$


Table E. 2 Measurements and soil properties for interface friction angle $\delta_{\mathrm{p}}$

\begin{tabular}{|c|c|c|c|c|c|c|c|}
\hline $\begin{array}{c}\mathrm{D}_{50} \\
(\mathrm{~mm})\end{array}$ & $\begin{array}{c}\mathrm{R}_{\mathrm{a}} \\
(\mu \mathrm{m})\end{array}$ & $\mathrm{R}_{\mathrm{n}}$ & $\begin{array}{c}\mathrm{D}_{\mathrm{R}} \\
(\%)\end{array}$ & $\begin{array}{c}\sigma_{\mathrm{v}}^{\prime} \\
(\mathrm{kPa})\end{array}$ & $\begin{array}{c}\delta_{\mathrm{p}} \\
(\mathrm{deg})\end{array}$ & $\begin{array}{c}\delta_{\mathrm{cv}} \\
(\mathrm{deg})\end{array}$ & Sand type \\
\hline 0.78 & 300 & 0.385 & 97 & 25.4 & 48.2 & 31.90 & VLB \\
\hline 0.78 & 300 & 0.385 & 90 & 88 & 46.1 & 31.90 & $"$ \\
\hline 0.78 & 300 & 0.385 & 90 & 169.7 & 45.5 & 31.90 & $"$ \\
\hline 0.78 & 300 & 0.385 & 91 & 251.3 & 45.1 & 31.90 & $"$ \\
\hline 0.78 & 2.49 & 0.003 & 93.00 & 25.20 & 29.10 & 24.23 & $"$ \\
\hline 0.78 & 2.49 & 0.003 & 95.00 & 86.90 & 26.10 & 24.23 & $"$ \\
\hline 0.78 & 2.49 & 0.003 & 99.00 & 169.40 & 25.10 & 24.23 & $"$ \\
\hline 0.78 & 2.49 & 0.003 & 91.00 & 251.00 & 26.10 & 24.23 & $"$ \\
\hline 0.78 & 9.40 & 0.012 & 90.00 & 25.10 & 31.40 & 26.50 & $"$ \\
\hline 0.78 & 9.40 & 0.012 & 99.00 & 128.60 & 29.20 & 26.50 & $"$ \\
\hline 0.78 & 9.40 & 0.012 & 88.00 & 25.10 & 33.20 & 26.50 & $"$ \\
\hline 0.78 & 9.40 & 0.012 & 99.00 & 251.40 & 26.50 & 26.50 & $"$ \\
\hline 0.78 & 180.00 & 0.231 & 70.00 & 25.00 & 49.00 & 31.38 & $"$ \\
\hline 0.78 & 180.00 & 0.231 & 70.00 & 86.90 & 45.60 & 31.38 & $"$ \\
\hline 0.78 & 180.00 & 0.231 & 74.00 & 169.60 & 45.40 & 31.38 & $"$ \\
\hline 0.78 & 180.00 & 0.231 & 86.00 & 25.20 & 48.10 & 31.38 & $"$ \\
\hline 0.78 & 180.00 & 0.231 & 74.00 & 251.60 & 44.70 & 31.38 & $"$ \\
\hline 0.78 & 0.36 & 0.000 & 94.00 & 25.20 & 16.70 & 15.64 & $"$ \\
\hline 0.78 & 33.70 & 0.043 & 83.00 & 25.20 & 39.90 & 29.25 & $"$ \\
\hline 0.78 & 114.00 & 0.146 & 89.00 & 25.20 & 47.50 & 30.96 & $"$ \\
\hline 0.44 & 300 & 0.682 & 73 & 25.3 & 43.6 & 31.0 & MGS \\
\hline 0.44 & 300 & 0.682 & 64 & 25.4 & 40.9 & 31.0 & $"$ \\
\hline 0.44 & 300 & 0.682 & 20 & 25.5 & 31.9 & 31.0 & $"$ \\
\hline
\end{tabular}




\begin{tabular}{|c|c|c|c|c|c|c|c|}
\hline 0.44 & 0.356 & 0.001 & 93 & 25.3 & 15.3 & 11.3 & MGS \\
\hline 0.44 & 0.356 & 0.001 & 78 & 25.1 & 13.3 & 11.3 & $"$ \\
\hline 0.44 & 0.356 & 0.001 & 69 & 25.2 & 11.5 & 11.3 & $"$ \\
\hline 0.44 & 0.356 & 0.001 & 23 & 25.1 & 10.8 & 11.3 & $"$ \\
\hline 0.44 & 2.49 & 0.006 & 94 & 25.1 & 27.7 & 24.2 & $"$ \\
\hline 0.44 & 2.49 & 0.006 & 79 & 25.3 & 25.1 & 24.2 & $"$ \\
\hline 0.44 & 2.49 & 0.006 & 69 & 25.3 & 25.10 & 24.2 & $"$ \\
\hline 0.44 & 2.49 & 0.006 & 24 & 25.3 & 22.60 & 24.2 & $"$ \\
\hline 0.44 & 9.40 & 0.021 & 93 & 25.2 & 39.00 & 27.5 & $"$ \\
\hline 0.44 & 9.40 & 0.021 & 75 & 25.3 & 35.80 & 27.5 & $"$ \\
\hline 0.44 & 9.40 & 0.021 & 68 & 25.4 & 33.40 & 27.5 & $"$ \\
\hline 0.44 & 9.40 & 0.021 & 22 & 25.1 & 29.10 & 27.5 & $"$ \\
\hline 0.44 & 33.7 & 0.077 & 92 & 25.3 & 47.10 & 31.0 & $"$ \\
\hline 0.44 & 33.7 & 0.077 & 70 & 25.2 & 42.80 & 31.0 & $"$ \\
\hline 0.44 & 33.7 & 0.077 & 26 & 25.3 & 33.70 & 31.0 & $"$ \\
\hline 0.44 & 114.00 & 0.259 & 93 & 25.3 & 49.00 & 31.8 & $"$ \\
\hline 0.44 & 114.00 & 0.259 & 78 & 25.3 & 43.40 & 31.8 & $"$ \\
\hline 0.44 & 114.00 & 0.259 & 62 & 25.4 & 40.60 & 31.8 & $"$ \\
\hline 0.44 & 114.00 & 0.259 & 27 & 25.2 & 33.90 & 31.8 & $"$ \\
\hline
\end{tabular}

(VLS and MGS are two different soils explained in Table E.1, $\mathrm{D}_{50}$ is the diameter corresponding to weight-percent of soil finer than $50 \%$, Ra is the average of heights of peaks, $R_{n}$ is the relative roughness, $D_{R}$ is the relative density, $\sigma_{v}^{\prime}$ is the vertical effective stress, $\delta_{\mathrm{p}}$ is the interface friction angle, and $\delta_{\mathrm{cv}}$ is the critical-state interface friction angle)

By performing multiple-variable regression (interface friction angle $\delta_{\mathrm{p}}$ versus relative roughness $R_{n}$, relative density $D_{R}$, vertical effective stress $\sigma_{v}^{\prime}$, and critical-state interface friction angle $\delta_{\mathrm{cv}}$ ) using the data provided in Lings and Dietz (2005), the equation for interface friction angle $\delta_{\mathrm{p}}$ can be expressed as: 


$$
\delta_{p}=\min \left[0.201 \log \left(\mathrm{R}_{\mathrm{n}}\right)+1.201,1\right]\left\{\left[\frac{D_{R}}{100}\left(13.1-1.59 \ln \left(\frac{\sigma_{v}^{\prime}}{P_{A}}\right)\right)+1.15\right]+\delta_{c v}\right\}
$$

where $\mathrm{p}_{\mathrm{A}}$ is the reference pressure, which is $100 \mathrm{kPa}$.

From Eq. (E.2), if the relative roughness between sand and steel is higher than 0.1 (steel surface is relatively rough compared to sand), Eq. (E.2) can be modified as:

$$
\delta_{p}=\left\{\left[\frac{D_{R}}{100}\left(13.1-1.59 \ln \left(\frac{\sigma_{v}^{\prime}}{P_{A}}\right)\right)+1.15\right]+\delta_{c v}\right\}
$$

The steel-strip reinforcement can be considered as rough because it is ribbed to have more resistance against pullout. Therefore, Eq. (E.3) is used for prediction of interface friction angle between the steel-strip reinforcement and the backfill material for the reinforced soil zone. The bias factor and COV of Eq. (E.3) are 1.00 and 0.07, respectively. 